\title{
The Future of
}

Scholarly put is ine

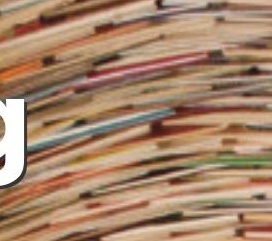

Open Access and the Economics of Digitisation EDITED BY PETER WEINGART \& NIELS TAUBERT' 


\section{The Future of Scholarly Publishing}

Open Access and the Economics of Digitisation

Edited by

Peter Weingart \& Niels Taubert 
First published in 2016 by De Gruyter Akademie Forschung under the title Wissenschaftliches Publizieren: Zwischen Digitalisierung, Leistungsmessung, Ökonomisierung und medialer Beobachtung.

This English language edition published in 2017 by African Minds 4 Eccleston Place, Somerset West 7130, Cape Town, South Africa info@africanminds.org.za

www.africanminds.org.za

(c) 2017 African Minds

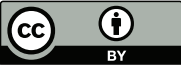

This work is licensed under a Creative Commons Attribution 4.0 International Licence.

() 2016 Berlin-Brandenburgische Akademie der Wissenschaften

Chapter 8: Copyright and Changing Systems of Scientific Communication translated from the German by Charles Heard. All other text translated by Marc Weingart, with the exception of Chapter 7: Open Access and Chapter 10: A Vision of Scientific Communication that were originally published in English.

ISBN: 978-1-928331-53-7

eBook edition: 978-1-928331-54-4

ePub edition: 978-1-928331-55-1

\section{ORDERS:}

African Minds

4 Eccleston Place, Somerset West 7130, Cape Town, South Africa

info@africanminds.org.za

www.africanminds.org.za

For orders from outside Africa:

African Books Collective

PO Box 721, Oxford OXl 9EN, UK

orders@africanbookscollective.com 


\section{CONTENTS}

List of Abbreviations iv

Foreword to the English Edition $v$

\section{INTRODUCTION}

1 Changes in Scientific Publishing: A Heuristic for Analysis

Niels Taubert $\theta$ Peter Weingart

PART ONE: THE CHANGING SCHOLARLY PUBLISHING SYSTEM

2 Different from Discipline to Discipline: Diversity in the Scholarly Publication System Konstanze Rosenbaum

3 Recent Processes of Change from the Perspective of Academic Publishers Niels Taubert

4 On the Situation and Development of Academic Libraries Peter Weingart

5 A Participatory Experiment in Science Policy:

Results and Evaluation of the 'Publication System' Online Consultation

Niels Taubert $\theta$ Kevin Schön

\section{PART TWO: FRAMING CONDITIONS}

6 Recommendations, Statements, Declarations and Activities of Science Policy Actors on Shaping the Scholarly Communication System

Ulrich Herb

7 Open Access: Effects on Publishing Behaviour of Scientists, Peer Review and Interrelations with Performance Measures David Ball

8 Copyright and Changing Systems of Scientific Communication Alexander Peukert $\theta$ Marcus Sonnenberg

PART THREE: VISIONS

Visions Concerning the Future of Publishing in Science

9 Electronic Publishing, Open Access, Open Science and Other Dreams Martin Grötschel

10 A Vision of Scientific Communication Reinhold Kliegl

11 Methodological Optimism Regarding the Digital Future: Critical Remarks on the Recommendations on the Future of the Scholarly Communication System Volker Gerhardt

12 Trust, Quality Assurance and Open Access: Predatory Journals and the Future of the Scholarly Publication System

Peter Weingart

13 Publishing in German Sociology in the Year 2030

Niels Taubert 


\section{LIST OF ABBREVIATIONS}

\begin{tabular}{|c|c|c|c|}
\hline $\mathrm{AHCI}$ & Arts and Humanities Citation Index & JCR & Journal Citation Report \\
\hline BBAW & $\begin{array}{l}\text { Berlin-Brandenburg Academy of } \\
\text { Sciences and Humanities }\end{array}$ & JISC & $\begin{array}{l}\text { Joint Information Systems } \\
\text { Committee }\end{array}$ \\
\hline BMBF & $\begin{array}{l}\text { Federal Ministry of Education and } \\
\text { Research }\end{array}$ & $\begin{array}{l}\mathrm{KE} \\
\mathrm{KII}\end{array}$ & $\begin{array}{l}\text { Knowledge Exchange } \\
\text { Commission on the Future of }\end{array}$ \\
\hline BOAI & Budapest Open Access Initiative & & Information Infrastructure \\
\hline $\mathrm{CC}$ & Creative Commons & MPDL & Max Planck Digital Library \\
\hline CODATA & $\begin{array}{l}\text { Committee on Data for Science } \\
\text { and Technology }\end{array}$ & $\begin{array}{l}\text { MPG } \\
\text { NPM }\end{array}$ & $\begin{array}{l}\text { Max Planck Society } \\
\text { new public management }\end{array}$ \\
\hline DFG & $\begin{array}{l}\text { Deutsche Forschungsgemeinschaft } \\
\text { (German Research Council) }\end{array}$ & $\begin{array}{l}\text { OA } \\
\text { OJS }\end{array}$ & $\begin{array}{l}\text { open access } \\
\text { Open Journal Systems }\end{array}$ \\
\hline DINI & $\begin{array}{l}\text { German Initiative for Network } \\
\text { Information }\end{array}$ & $\begin{array}{l}\text { OSF } \\
\text { PR }\end{array}$ & $\begin{array}{l}\text { Open Science Foundation } \\
\text { public relations }\end{array}$ \\
\hline $\begin{array}{l}\text { DOAJ } \\
\text { DOI }\end{array}$ & $\begin{array}{l}\text { Directory of Open Access Journals } \\
\text { digital object identifier }\end{array}$ & RfII & $\begin{array}{l}\text { Council for Information } \\
\text { Infrastructure }\end{array}$ \\
\hline DRM & digital rights management & RIN & Research Information Network \\
\hline EC & European Commission & \multicolumn{2}{|c|}{ ROARMAP Registry of Open Access } \\
\hline ERC & European Research Council & & Repository Mandates and Policies \\
\hline FhG & $\begin{array}{l}\text { Fraunhofer-Gesellschaft } \\
\text { (Fraunhofer Society) }\end{array}$ & $\begin{array}{l}\mathrm{RSC} \\
\mathrm{SCI}\end{array}$ & $\begin{array}{l}\text { Royal Society of Chemistry } \\
\text { Science Citation Index }\end{array}$ \\
\hline GDCh & Gesellschaft Deutscher Chemiker & SOAP & Study of Open Access Publishing \\
\hline GWK & $\begin{array}{l}\text { Gemeinsame } \\
\text { Wissenschaftskonferenz des } \\
\text { Bundes und der Länder (General } \\
\text { Science Conference of the Federal } \\
\text { Government and the States) }\end{array}$ & $\begin{array}{l}\text { SPARC } \\
\text { SSCI } \\
\text { STM } \\
\text { TA }\end{array}$ & $\begin{array}{l}\text { Scholarly Publishing Initiative } \\
\text { Social Science Citation Index } \\
\text { science, technology and medicine } \\
\text { toll access }\end{array}$ \\
\hline HEFCE & $\begin{array}{l}\text { Higher Education Funding Council } \\
\text { for England }\end{array}$ & TELOTA & $\begin{array}{l}\text { The Electronic Life Of The } \\
\text { Academy }\end{array}$ \\
\hline HEI & higher education institution & TWAS & The World Academy of Sciences \\
\hline HGF & $\begin{array}{l}\text { Helmholtz-Gemeinschaft Deutscher } \\
\text { Forschungszentren (Helmholtz } \\
\text { Association of German Research } \\
\text { Centres) }\end{array}$ & $\begin{array}{l}\text { UrhG } \\
\text { VAT } \\
\text { WGL }\end{array}$ & $\begin{array}{l}\text { German Copyright Act } \\
\text { value added tax } \\
\text { Wissenschaftsgemeinschaft } \\
\text { Gottfried Wilhelm Leibniz }\end{array}$ \\
\hline $\begin{array}{l}\text { HRK } \\
\text { IAP }\end{array}$ & $\begin{array}{l}\text { German Rectors Conference } \\
\text { InterAcademy Partnership }\end{array}$ & & $\begin{array}{l}\text { (Gottfried Wilhelm Leibniz Science } \\
\text { Association) }\end{array}$ \\
\hline $\begin{array}{l}\text { ICSU } \\
\text { IP } \\
\text { IR }\end{array}$ & $\begin{array}{l}\text { International Council for Science } \\
\text { intellectual property }\end{array}$ & ZPID & $\begin{array}{l}\text { Leibniz-Zentrum für Psychologische } \\
\text { Information und Dokumentation } \\
\text { (Leibniz Institute for Psychology) }\end{array}$ \\
\hline ISSC & $\begin{array}{l}\text { International Social Science } \\
\text { Council }\end{array}$ & & \\
\hline WG & interdisciplinary working group & & \\
\hline
\end{tabular}




\section{Foreword to the English Edition}

The formal scientific communication system is currently undergoing significant change. This is due to four intertwined developments: the digitisation of formal science communication; the increasing relevance of profit-making on the part of many academic publishers and other providers of information (in short: 'economisation'); an increase in the self-observation of science by means of publication, citation and utility-based indicators; and an intensified observation of science by the mass media ('medialisation'). Previously, these developments have only been dealt with individually in the literature and by science-policy actors. In fact, they not only affect the scientific communication system in the form of simple, individual causal chains but also in the form of long feedback loops and partly intertwined processes.

This book documents the materials and results of an interdisciplinary working group (IWG) commissioned by the Berlin-Brandenburg Academy of Sciences and Humanities (BBAW) to analyse the future of scholarly publishing and to develop recommendations on how to respond to the challenges posed by these developments. The IWG served a three-fold purpose: first, the connections between the abovementioned developments were described; second, further relevant research on understanding recent developments was undertaken; and third, recommendations on the design of a future scholarly publication system were formulated.

Aside from the analysis of these interactions, the IWG also set out to take diverse framework conditions, standards and perspectives from different scientific fields into consideration, the goal being to formulate recommendations in the name of science as a whole and for science as a whole. Thus, in addition to the factors of influence, the heterogeneity of the publication cultures in different disciplines and fields of research was to be taken into account. In order to become familiar with these conditions and to be able to develop this mass of information into a concise format, interviews with members of the BBAW were conducted. These provided valuable information on the communication habits of different disciplines and fields of research, and revealed significant differences in these habits. Given the limitations of this approach and of the 
information gained in this process, an online dialogue was conducted which invited all German-speaking scientists and academics to participate in the development of the recommendations. Almost 700 participants responded with great interest and provided the IWG with important information about current problems and challenges in the formal communication system. Moreover, this procedure helped in identifying a normative consensus on what constitutes a good communication system. In addition to the views of the scientists, perspectives of experts from publishing companies and libraries were surveyed in order to gain a multi-layered and more complete picture of the publication landscape. Finally, three expert reports on central issues were commissioned.

By means of a multi-level evaluation and decision-making process, the Academy adopts recommendations of working groups so that - in cases of approval - they are published in its name. In spite of efforts to involve scientists early on in the development of recommendations in order to learn about their perspectives, standards and interests, protests emerged during the final process of acceptance. Several Academy members from the humanities called the recommendations unbalanced insofar as the role of digital publication was overly emphasised while that of printed publications was neglected. These arguments were taken into consideration in a revised version. In our opinion, the debates during the course of acceptance indicate one thing in particular: there is a need for further extensive discussion about how to deal with the current challenges in the scientific communication system. This issue will continue to occupy science within and outside the Academy.

As per the IWG's intention, the focus was mainly on the sciences and humanities in Germany. However, in the course of the work it became clear that the issues discussed by the group are also relevant for academic publishing in other countries. This was corroborated by the fact that when presenting some of the findings at a conference at Stellenbosch University in September 2016, interest was expressed by the director of Centre for Research on Evaluation, Science and Technology (CREST), Professor Johann Mouton, to publish an English translation. This interest is based on two grounds: first, the academic publishing system is at the base of CREST's core activity, especially bibliometric studies of world-wide scholarly publishing, and second, Professor Mouton's role at the South African Academy of Science in reporting on the state of scholarly publishing in South Africa.

The anthology provides contributions that, at first sight, may be regarded as case-specific for Germany. For example, one contribution deals with the possibility for mandatory open access publishing in the context of German copyright law; another chapter reports results from a participatory experiment involving only German-speaking scientists. Yet, these topics notwithstanding, 
this book can contribute to the transfer of ideas and perspectives, and allow for mutual learning about the state of scientific publishing in different settings.

Other parts of the book clearly go beyond the German context and are pertinent to the current discussion at the international level. This applies to the contribution by Niels Taubert and Peter Weingart which provides a systematic introduction to the topic. The analytical focus is on current challenges which result in interactions between processes of digitisation, economisation, medialisation as well as the observation of the communication system via quantitative indicators. This applies equally for the four chapters in which the perspectives of scientists, libraries and representatives of publishing companies are analysed. Interviews with representatives from different types of academic publishing companies illustrate which 'market imperfections' can be found among the providers of academic publications, which actors play the role of protagonists of innovation and push development towards digital publication, and what the effects of digitisation have been on academic publishing companies. Likewise, another chapter deals with the situation of academic libraries. The focus here is on the financial situation of the libraries, their role as service provider in open access publishing as well as their future role in providing academic information. Although the chapter is based on the experience of libraries in Germany, the issue will resonate with libraries elsewhere. David Ball provides an overview on the development of and current state of discussions on open access, in particular in the United Kingdom. His chapter shows the different conceptions and initiatives regarding the implementation of open access as well as its effect on publication behaviour, problems of quality assurance (peer review) and performance measures.

Two chapters exhibit the plurality and diversity of views among scientists and different disciplines. The chapter by Niels Taubert and Kevin Schön provides a critical reflection on the results of an online consultation on the publication system of science and its influence on the 'recommendations on the future of the scholarly publication'. It documents how the wording of the recommendations changed following the input of 697 scientists, and describes the challenges of making use of such a participatory approach in decision-making processes as well as the deficits in this case. Moreover, it suggests possible future fields of application within science. Ulrich Herb's chapter covers the diverse explanations and connected activities of German science-policy actors related to the scholarly communication system. This provides the necessary background to put the BBAW recommendations into perspective. The expert report by Alexander Peukert and Marcus Sonnenberg focuses on copyright in connection with the transformation of the science communication system. Copyright plays a key role in the implementation of 
open access and in the development of the relationship between science and publishing companies.

The third part of this book attempts to deal constructively with those controversies that emerged during the process of acceptance. In the 'Visions' section, five representatives from the fields of mathematics, philosophy, psychology and sociology describe what, from their perspective, a desirable future of publishing in their respective disciplines could look like. The diversity of voices in this part once again underscores the different conditions and standards existing in the many areas of science, as well as the different perspectives regarding opportunities and risks of digitisation for scientific publishing. This leads to the conclusion that good framework conditions for the exchange of research results have to be designed individually for each of the disciplines.

A large number of people have supported the IWG with their expertise and contributed to the results. On behalf of the IWG, the editors wish to thank David Ball, David Ball Consulting; Horst Bredekamp, History of Art, Humboldt University Berlin; Ralf Birkelbach, Springer Science+Business Media; Rainer Brintzinger, University Library, Ludwig Maximilian University of Munich; Christoph Bruch, Alfred Wegener Institute for Polar and Marine Research in the Helmholtz Centre; Katja Fitschen, Fa. Zebralog; Peter Gölitz, editor of the journal Angewandte Chemie; Alexander Grossmann, publishing management and project management in media enterprises, Leipzig University of Applied Sciences (formerly at Verlag Walter de Gruyter); Silke Hartmann, Copernicus Publications; Petra Hätscher, University of Konstanz Library; Ulrich Herb, Fa. scinoptica; Wilhelm Heitmeyer, former editor of the International Journal of Conflict and Violence; Stefan Hornbostel, Institute for Research Information and Quality Assurance, Berlin; Wolfram Horstmann, Staats- und Universitätsbibliothek Göttingen (formerly at the Bodleian Library, Oxford University); Najko Jahn, University Library Bielefeld; Anne Lipp, Gruppe Wissenschaftliche Literaturversorgungs- und Informationssysteme, Deutsche Forschungsgemeinschaft (DFG); Wulf D. v. Lucius, Verlag Lucius \& Lucius; Oliver Märker, Fa. Zebralog; Frank Sander, Max Planck Digital Library; Peter Schirmbacher, Computer and Media Service, Humboldt University Berlin; Christoph Schirmer, Verlag Walter de Gruyter; Frank Scholze, KIT Library, Karlsruhe; Eric Merkel-Sobotta, Springer Science+Business Media; Matthias Trènel, Fa. Zebralog.

Thanks also go to the scientists who provided invaluable input for the development of the recommendations, and to the organisations and people who have helped in disseminating and making the invitations to the online dialogue public. 
The editors would also like to thank the members of the IWG for their engagement and dedication in developing the recommendations: Mitchell Ash, University of Vienna; Martin Carrier, University of Bielefeld; Olaf Dössel, Karlsruhe Institute of Technology; Ute Frevert, Max Planck Institute for Human Development; Siegfried Großmann, University of Marburg; Martin Grötschel, Berlin-Brandenburg Academy of Sciences and Humanities; Reinhold Kliegl, University of Potsdam; Alexander Peukert, Goethe University Frankfurt; Hans-Jörg Rheinberger, Max Planck Institute for the History of Science; Uwe Schimank, University of Bremen; Eberhard Schmidt-Aßmann, Ruprecht Karls University Heidelberg; Volker Stollorz, Cologne. Without the work of Kevin Schön, in particular in the preparation and evaluation of the online dialogue, the programme of the IWG would not have been possible. Finally, we would like to thank Ute Tintemann and Wolf-Hagen Krauth of the Academy for their wholehearted support, especially in administrative matters, and, last but not least, we are grateful to Professor Johann Mouton at CREST for making this translation possible, together with funding from the BBAW.

Peter Weingart

Niels Taubert 



\section{Changes in Scientific Publishing}

\section{A Heuristic for Analysis}

Niels Taubert \& Peter Weingart

\section{Introduction}

It is obvious: academic publishing is currently the topic of diverse discussions in science, science policy as well as among the general public. The main issues are the crisis of the 'library' as an institution, the repercussions of performance evaluation in connection with research evaluations on publications in general, and digital publication, which some consider a blessing while others view it as endangering the progress of science. There are controversial debates about open access, impact factors and peer review, about the increasing share of retracted articles as well as complaints with regard to the overly large influence of highly renowned journals such as Science, Nature, Cell and PLoS. These debates with their diverse topics, challenges and positions are complex. This leads to the question whether the discussions are mere coincidence, resulting from simultaneous developments, or whether there are diverse causes why the topic of academic publishing is being raised on many different occasions.

Two aspects of these debates are significant: first, public discussions, science policy control and research on the phenomenon merely focus on individual facets and aspects. In doing so, the breadth of the dynamics of change and the diversity and interconnections of different developments are neglected. Second, in large parts of the discussion, one motif is recurrent. In view of the dynamics of the development, the concern is that the process of change could affect publication in general so that processes internal to science - announcing and recognising research results - could be distorted by external factors. The 
main fear is that scientific/academic publishing could be in tension with the main objective of science, namely the production and testing of new truth claims.

This chapter focuses on the development of an analytical heuristic, which takes the dynamics of change and its complexity into account. This should not only serve to summarise individual aspects, but it should also be shown that different structural dynamics influence and change publication in general. An analysis relating to whether and how publishing in science is influenced by the abovementioned factors will be provided.

In a first step, the basic concepts are introduced. For the analysis of the current processes of change, it is helpful to redefine key terms. Aside from clarifying 'formal communication system', 'infrastructures of publication', and 'service organisations', the focus is on the communication system with regard to its functions for science. In a second step, the structural dynamics that cause concern and change within the formal scientific communication system are described. These are the digitisation of the system (see 3.1), the economisation of academic publishers (see 3.2), the increasing observation of publication activities by means of formal quantitative characteristics or bibliometric indicators (see 3.3), and the observation of the scientific communication system by the mass media (medialisation) (see 3.4).

In a third step, the effectiveness of the unfolded perspective is demonstrated. In view of the complexity of the process of change, it can, of course, not be the objective to analyse it entirely. Instead, by using different examples, it will be shown which effects the overlap of several of the mentioned structural dynamics has on the scientific communication system. Examples are the crisis of the libraries and the change towards freely accessible publishing (open access) (see 4.1), the diversity and growth of publications (see 4.2), as well as trust in published research results (see 4.3).

\section{Functions of the formal communication system of science}

Science is a collective endeavour, and the state of knowledge in a respective subject or field of research is the result of collective work. ${ }^{1}$ The standards for the exchange of research results stem from this basic fact. On the one hand, there is need for a free and easy circulation and order of research results. These are necessary in order to detect gaps in research, to identify innovative research questions, to test newly gained insights after successfully conducting research

1 On this, see also the norm 'communism' of the scientific ethos developed by Robert K. Merton (Merton 1942: 121-124). 
and to present them to the respective scientific community. The process of communication that achieves this - in the following referred to as 'communication system' - consists of two parts. One part is the informal communication which serves to develop research designs, to organise processes of research, to take interpretations of research results into consideration and to reject them as well as to develop truth claims. The other part is formal. In this part, truth claims are evaluated by colleagues (peer review), which are then occasionally circulated within the community in the form of publications. ${ }^{2}$ On the basis of publications, the internal scientific communication differentiates between 'old' and 'new' knowledge (Luhmann 1990: 220; Stichweh 1979: 96).

Truth claims and research results are not only evaluated in a professional and timely manner; they are also considered in the social dimension as an achievement of the respective researcher, which, in turn, adds to his/ her reputation. The attribution of reputation takes place in the informal communication system, where it can be found in face-to-face situations in the form of appreciation towards renowned colleagues, as well as in the formal communication system in the form of citations. In particular this institutionalised form of recognition is the foundation for the emergence of a social structure in scientific communities, namely a reputational hierarchy. ${ }^{3}$ Reputation as well as the respective hierarchisation has the function to steer attention $^{4}$ in the sense that it guides members of a discipline towards relevant topics as well as towards the most competent colleagues in that discipline. It acts as a 'symptom for truth' and pre-determines the flow of information insofar as it increases the chances of being noticed and thus being recognised by members of the discipline (Luhmann 1970: 237). Trust in the reliability of the internal scientific evaluation and the recognition of the reputational hierarchy depend on and strengthen each other.

The reputational hierarchy is also essential for the presentation of scientific knowledge to society as it provides the non-scientific audience with orientation. If politics, the economy or media want to make use of science, then they also orient themselves towards science. The world of science, with its highly

2 In the literature, a distinction is made between informal communication within science, which includes private exchange among scientists, internal discussions in research groups and similar forms of exchange, and formal communication, which is understood as the public presentation of research results in scientific communities. For an overview of different forms of scientific communication, see the handbook Forschungsfeld Wissenschaftskommunikation (Bonfadelli et al. 2016). The distinction between the two kinds of communication is not sharp. For example, talks held at conferences represent borderline cases (see, for example, Garvey \& Griffith 1967: 1013). On the transformation processes of research results on their way from the laboratory into formal communication, see Knorr-Cetina (1984: 175-209).

3 This differentiation between an informal and formal level already plays a role in Hagstrom, who distinguishes between institutionalised recognition in the form of citation and the personal or elementary recognition in face-to-face situations (Hagstrom 1965: 23 f.).

4 Aside from steering attention, reputation also plays a role as a means of motivation (Luhmann 1970: 239). This dimension is of lesser interest here. 
specialised languages, is otherwise not accessible to outsiders who have not undergone the same processes of training and socialisation. In a sense, the reputational hierarchy communicates the internal scientific interpretations to laypersons and makes the social structure, at least in part, comprehensible to the outside. Reputation can thus be used to disseminate the material resources that are necessary for the system of science to operate efficiently.

The two-fold role of circulation and order of truth claims and the attribution of reputation requires that the formal communication system comprises four sub-functions (Andermann \& Degkwitz 2004: 8; Hagenhof et al. 2007: 8; Kircz \& Roosendaal 1996: 107-108):

- Registration means that the time of submission and publication of a contribution can be verified. It is decisive for reconstructing the progress of knowledge in a field as well as for attributing the priority of truth claims to one or more persons.

- Certification refers to the recognition of a contribution as part of a collective state of knowledge, usually by means of evaluation. Only then is a contribution considered accepted by the scientific community, included in the stock of knowledge and worthy of reputation.

- Dissemination means the availability of information within a scientific (communication) community. Insufficient dissemination means the exclusion (without reason) from circulation of information within science, and can thus lead to hindrance of further research processes as well as distorting the recognition of research performance.

- Archiving describes the ongoing stabilisation of a knowledge inventory, so that further research activities can follow it in the near or far future. Moreover, archiving is the precondition for the cumulative research achievements of a unit of the system of science (for example, a scientist, a research institution or a research programme) to be evaluated.

Each of the four sub-functions is a prerequisite for the formal communication system to be able to fulfil its dual role of circulating and disseminating information and attributing reputation.

The formal communication system with its basic units - publications - is an important part of the system of science and connects central functions. It is therefore not surprising that science studies focus solely on internal scientific components when dealing with communication processes within science. This has proved to be very productive in the past, and is appropriate for a large number of questions. This perspective, however, does not take into consideration those preconditions on the level of media technology and organisations that enable registration, certification, dissemination and archiving in the first place. In 
particular, when focusing on processes of change in connection with digital publishing, it becomes obvious that the ways in which the functions of the scientific communication system are put into practice technologically and organisationally have consequences for the system. Such issues go beyond the traditional focus and cannot be described or analysed in this framework - the traditional perspective is too narrow. For that reason, two components are added here that lie outside of science and that are prerequisites for the fulfilment of the abovementioned functions: publication infrastructure and service organisations. ${ }^{5}$

\subsection{Publication infrastructure}

The term 'publication infrastructure' ${ }^{6}$ describes all those technological components and rules regarding their use, which make the formal scientific communication system possible. The components of the publication infrastructure therefore show a direct connection to at least one of the four functions. Looking at the different kinds of components, the publication media are striking at first. Traditionally, these are printed journals, monographs, anthologies, conference proceedings and review literature. Recently, other media have emerged. These include repositories, ${ }^{7}$ newspaper banks and repositories for research data, as well as social network platforms, such as ResearchGate and Academia.edu, which, aside from the exchange of research results, contribute to a network of scientific communities via their Web 2.0 functionality. Other technological components of the publication infrastructure serve the utilisation of publication media. These include classifications embodied in catalogues, abstract and subject databases, search engines, registries and citation databases, which make it possible to find and select as well as access publications. These components of the publication infrastructure first of all serve scientists as a means of orientation. They can, however, also be used to observe the scientific communication system by means of formal characteristics. The information provided by the databases can be used in more or less highly aggregated form in order to gain access to the elements of the system of science or to the formal communication system in general. ${ }^{8}$

5 On this extension, see Taubert (2016).

6 A competing term is 'publication system'. In the literature, the term is used similar to our use of 'publication infrastructure' since it refers to rather technological aspects of publication, its production and reception. This goes for science-political (for example, Hochschulrektorenkonferenz 2002) as well as science-reflexive literature (for example, Hanekop \& Wittke 2006: 202). We prefer the term 'publication infrastructure' as it is more comprehensive and emphasises the integration of individual components into a functioning whole by means of the word 'infrastructure'.

7 An overview of repositories can be found in the Directory of Open Access Repositories (http://www. opendoar.org/), which lists 195 repositories for Germany.

8 The effects on the scientific communication system will be described extensively in section 3.3 . 
Two characteristics of the publication infrastructure should be pointed out. On the one hand, it becomes obvious, especially during phases of media change, that the components of the publication infrastructure vary historically and depend on the development of media technology. Currently, this is visible in the rapid development of digital technology. On the other hand, the design of the publication infrastructure is always influenced by factors and developments within science. Thus, there is currently a change in perception as to what is considered research worthy of publication, and some fields of research consequently include data. In parallel, an infrastructure is emerging that allows the publication of research data and which thus takes the changing standards into account. ${ }^{9}$

\subsection{Service organisations}

With regard to the development and maintenance of their usability, the publication infrastructure as well as the individual technological components are dependent on the services provided by organisations. Organisations maintain the publication infrastructure, provide resources for its operation and ensure that the infrastructure is able to fulfil the respective tasks for the formal scientific communication system. The term 'service organisations' summarises different types.

Publishing companies, in cooperation with specialised scientific communities as well as independently, produce publications. They frequently hold the rights to publication media, operate technological components, such as content delivery platforms, ${ }^{10}$ and provide systems for organising review processes (online editorial management systems). In their operation, they have to take into consideration standards of communication in science as well as economic aspects. ${ }^{11}$

Libraries traditionally provide access to research literature by acquiring, collecting, systematising and indexing publications. They are the most important units on the demand side with respect to academic publications, and they acquire them through public funding. Libraries thus ensure continuous funding of the publishing companies and are a central element in the financing of the publication infrastructure. Since very recently, however, libraries also act as operators of publication media. This is done, first of all, via repositories in which copies of publications (that otherwise have limited accessibility) can be

9 See 'Future of the information infrastructure' (Kommission Zukunft der Informationsinfrastruktur 2011).

10 The platforms SpringerLink, ScienceDirect (Elsevier) and Wiley Online Library are well known examples.

11 Decision-making in publishing companies thus takes place in the power relations between scientific and economic rationality (Volkmann et al. 2014), whereas different constellations of the two rationalities can be observed (Schimank \& Volkmann 2012: 177 f.). 
deposited in order to ensure free access. In addition, libraries also host digital open access journals on platforms like Open Journal Systems (OJS).

Other significant organisations are the editorial offices of publication media, especially of journals that are responsible for deciding on the worthiness of the publication of submitted manuscripts. As will be shown later on, the kind of service organisation and its financing have a strong influence on the characteristics of the publication media they operate.

The considerations on extending the focus of study can be summarised as follows. In contrast to the classic perspective of science studies, the one taken here is not limited to internal scientific processes of communication. The focus is broader and takes on a tripartite structure consisting of components that are only at first glance heterogeneous: a specific form of communication - the formal science communication, a technological infrastructure as well as service organisations. To understand the object of study as a structure is thus not only appropriate because of the similarity of the components and the fact that they would fall into the same area of the social system - quite the contrary.

The image of a tripartite structure is used here because the three components are connected through a relationship of making something possible. As noted above, the service organisations ensure the development and maintenance of the publication infrastructure, while the latter is a prerequisite for the formal communication system with its four functions. In spite of their differences, all three components are social phenomena, which can be subjected to sociological analysis: the service organisations with their organisational logic and typical decision-making processes, the publication infrastructure with its institutionalised patterns of action, and the formal communication system of science with its institutionalised rules. The processes of change that are of interest here refer to all three components. While the cause of change can be attributed primarily to one of these components, the consequences and sideeffects can frequently be observed in another component.

\section{Four structural dynamics as sources of change}

In this section, the focus will be on the causes for the abovementioned dynamics of change.

In the following, four structural dynamics will be presented. The examination of these four factors is necessary to be able to show how a complex interaction between them leads to specific structural problems within the scientific communication system. 


\subsection{Digitisation}

The term 'digitisation' describes developments on the level of the publication infrastructure. These developments are based on innovations in the field of information and communication technologies. Digitisation began in the early 1980s at the latest and led to significant changes. One characteristic of digitisation is that it is not completed. It does not begin with a starting point which - analogous to a revolution - reaches an endpoint after a phase of dramatic change. Rather, one digital wave of innovation is followed by another, and leads to extensive and continuous change.

If the focus is limited to digitisation in the formal scientific communication system, it can be said that it changes the production process of texts, the resulting publications as well as pathways of dissemination and forms of reception. Already the availability of a personal computer at the workplace has led to the fact that research results and texts can be digitised immediately. 'Digital' is increasingly a native characteristic of texts, not one that is added later on. More transformations follow via the Internet. With regard to the production of publications, the introduction of online editorial management systems changed the working relationship between researcher and publisher (Taubert 2012). Whereas not long ago, researchers were invited via letter and later email to review a manuscript, online editorial management systems connect all people involved in the production process - the researchers involved in reviewing and deciding on the worthiness of publication of a manuscript as well as the employees of the publisher. This forms the basis for a reorganisation of working processes. With regard to the collaboration between researchers and publishers, it leads to a disadvantage in workload on behalf of the former, while within the publishing company, these systems are the prerequisite for an internationalisation of the division of labour.

Digitisation, however, also transforms the result of the production process, that is, the publications and publication media. New and not so new electronic publication media accompany the traditional printed formats, and - in part - even replace them. In this context, pre- and post-print servers and journal databases with retro-digitised publications have a supplementary character. Replacements and substitutions can especially be observed in the transformation from printed journals to electronic formats. Digitisation also leads to changes in the pathways of production and dissemination. In the case of electronic publication, the provision of a publication no longer occurs via a local library but via databases and dissemination platforms that have global reach through the Internet. Thus, from a technological viewpoint, it appears to be possible that every researcher at every place in the world at any time can have access to electronic publications via an Internet connection. The function of providing 
access to publications at least in part seems to shift away from libraries and towards the publishers. In the course of this process, however, local conditions do not lose relevance. As digitisation progresses, how extensive the collection of literature at a given place is becomes less important. More important is the extent of licences that grant access to journal or publication databases from a given place. The entailing stringency of technically available possibilities of dissemination leads researchers to digitise their publications themselves. Circulation of pre-, post- and offprint versions via mail is replaced by electronic publications sent via email or depositing of a copy in a repository or on Web 2.0 platforms.

Finally, the reception of publications, including the search, access and reading (Hanekop 2014: 5; Hanekop \& Wittke 2007: 215), is transformed in the course of digitisation as well. Libraries also lose their importance because publications are more and more searched via engines such as Google or Google Scholar, or the search is conducted by means of specialised repositories. Publication no longer only takes place via printed form but also through tablets, e-book readers and computers. In addition, publications are evaluated through text and data mining procedures. It is an open and interesting question what influence these new forms of reception have on the creativity of research and the development of knowledge in the different disciplines and fields of research.

\subsection{Economisation of publishers}

The second structural dynamic - economisation - refers to developments at the level of the service organisations. Economisation becomes possible through certain properties of publications. If they are viewed from an economic perspective as goods that are sold by the publisher to libraries after a process of commodification, ${ }^{12}$ one thing becomes obvious. Due to the standards of the major journals to publish original research exclusively (and not research that has already been published somewhere else), publications and journals are individual and unique goods and cannot be substituted. If a publication medium is not accessible, researchers can make use of other publications but the results published in the inaccessible publications remain closed to the researcher. This characteristic of publications is the basis for libraries to claim a fully comprehensive provision of information according to the needs of researchers in the respective institutions. The practical consequence is an inelastic demand. If prices increase, libraries are not able to shift to cheaper

12 On commodification and de-commodification in the chain of information provision, see the model by Hanekop and Wittke (2006: 203-204; 2013: 151). 
goods but have to hold on to the publication media until their financial resources are spent in order to fulfil their task of providing information.

Another attribute of economisation is a process of concentration, which has led to the formation of large publishing companies that are steered by financial investors. As a result, these publishing companies are strongly oriented towards economic criteria, such as shareholder value and an increase of the company's market value, so that the investors are able to sell the company at a profit. In turn, this results in the growth in size of the publishing companies and in changing ownership. One example is Elsevier whose pathway to a globally operating publishing company began in the mid-1980s. After the acquisition of Pergamon Press (in 1991), which led to a strong increase in the number of scientific journals, Elsevier merged with the British media enterprise Reed International and became Reed Elsevier Group plc in 1993. In 1999, Cell Press was bought, followed by the academic publisher Harcourt in 2001. By 2011, the company held more than 1250 journals in science, technology and health science. In 2009, Elsevier made a profit of USD 1.1 billion, a profit margin of $36 \%$, in 2011, a turnover of GBP 2.058 billion, $^{13}$ and in 2013, a profit margin of $39 \% .{ }^{14}$ The concentration processes in the case of Wiley and Springer are similar. ${ }^{15}$ Concentration in the area of scientific journals has de facto led to the emergence of an oligopoly in the market for scientific publications on the side of the providers. ${ }^{16}$ This is especially true with regard to the publishers in the area of science, technology and medicine (STM). The departments for journals in the humanities and social sciences are smaller. However, here, too, transformation processes towards enlargement of the publishing companies are apparent. ${ }^{17}$

13 See Arnold and Cohn (2012).

14 See http://poeticeconomics.blogspot.de/2014/03/elsevier-stm-publishing-profits-rise-to.html and http:// www.reedelsevier.com/investorcentre/reports\%202007/Documents/2013/reed_elsevier_ar_2013.pdf

15 See the contribution by Niels Taubert in this volume.

16 The overall number of scientific journals is currently estimated at around 28100 . A proportion of $40.5 \%$ of the journals belong to merely six publishing houses (Ware \& Mabe 2015: 45). One gets an even higher number if focusing only on the most important journals indexed in the Web of Science. Of these, 10900 journals, $50.1 \%$ are owned by one of the five largest publishing houses (Morris 2007: 307). These ownership proportions have led some to speak of an oligopoly.

17 See, for example, the result of the acquisition of Walter de Gruyter (http://www.degruyter.com/ staticfiles/pdfs/1410_Fact_Sheet_Imprints_de.pdf) and the acquisition of the Campus Verlag by the Beltz Rübelmann Holding (Handelsblatt, 6 February 2015. See http://www.handelsblatt.com/unternehmen/ it-medien/buecherbranche-beltz-schluckt-campus-verlag/11338350.html). 


\subsection{Observation of the communication system by means of formal characteristics}

A third source of the dynamics of change is institutions and instruments that allow an observation of the scientific communication system via formal characteristics (such as the number of publications and citations). This first became possible with citation databases such as the Science Citation Index (SCI), the Social Science Citation Index (SSCI) and the Arts and Humanities Citation Index (AHCI). Thus, they became possible as a result of the digitisation of publications in general. At first, they were supposed to serve researchers as a helpful tool for orientation in the communication system. The possibility to use these data for the analysis of research networks, their historical development as well as the early identification of 'hot' fields of research and for the evaluation of research was noticed early on. The performance of different units of the science system, such as nations, organisations, research groups or persons, can be observed and evaluated. With the introduction of publication databases and research information systems as well as the accessibility of automatic evaluation instruments, on the one hand, and regular evaluations, rankings and ratings, on the other, the frequency of utilisation of such instruments has increased. Meanwhile, aside from science policy and science administration, other actors, such as publishers and libraries, also make use of these opportunities.

A second development led to repercussions on the scientific communication system. Since the beginning of the 1990s, the governance of universities and research institutions in all European countries and the United States has shifted to new public management (NPM). As a result, rankings and evaluations were introduced in which bibliometric indicators are used. The apparently inevitable introduction of this new method of management is the result of a crisis of trust in the self-regulating mechanisms of science that started at the latest at the end of the 1980s. Some authors view this crisis more generally as a crisis of trust towards all societal institutions that has led society to become an 'audit society' (Power 1997) in which all institutions are subject to reporting, transparency, efficiency, and market orientation. The methods of NPM have also become the mantra of higher education policy. NPM reacts towards the specific political expectations of legitimation with respect to science: it is to serve the democratic control on behalf of the public through being transparent regarding internal practices, and to ensure efficiency through management, that is, the economic use of public funds (Weingart 2013).

Since the specific performances of science are frequently inaccessible from the outside, it is appropriate to focus on those processes that are responsible for the internal dissemination of reputation and that are simultaneously 
quantifiable. ${ }^{18}$ The usage of citation databases makes the implicit processes of the internal scientific attribution of reputation visible and comprehensive from the outside. The creation of transparency through the introduction of performance indicators is therefore viewed positively.

The instruments with which the scientific communication system is observed by means of formal characteristics are further developed and refined, and their application has recently intensified. The reception of publications is no longer measured by citations only, but also in form of activities at a lower scale. The term 'usage-based metrics' summarises activities such as clicks, downloads and bookmarking. These characteristics, too, are supposed to determine the impact or the significance of a publication. ${ }^{19}$ The mentioned indicators are no longer used in the context of research evaluation only, but also in decision-making processes regarding the allocation of funds in research organisations, the hiring of personnel (in particular professorships) and in decisions about third-party grant proposals. An additional dynamic results from the fact that the same large publishing companies that develop these data into bibliometric indicators and disseminate them, also control and organise their further production. Moreover, the publishers use metrics to advertise their products and scientists to represent their services. Since these data are suitable to conduct such self-marketing, they are widely accepted in spite of their fungibility for control purposes.

\subsection{Observation of the system of science by the mass media}

The external observation by the mass media, the fourth factor, also primarily affects the scientific communication system. Increasingly, scientific events as well as developments (and failed developments) in the system of science are the topic of mass media communication. In contrast to the influences described in 3.3, it is not an observation of the communication system by means of formal characteristics, but an observation of content and interpretation of its relevance for society and politics. As a topic of mass media reporting, science has experienced a boom in Germany since the 1990s. There were several science magazines, and the mass media extended their departments of science journalism. Even though this development has meanwhile been reversed due to the economic crisis of the print media, reports on important progress in research, on results in rankings or the Excellence Initiative continue to have

18 Aside from observing publication in general, the acquired funds as well as invitations to keynote speeches or the number of doctoral students are commonly used as such measures.

19 See Bollen and Van de Sompel (2008), Brody et al. (2006) and Shephard (2007). Another newer development that is noteworthy involves the services of companies like PlumX and Altmetric, which visualise and evaluate activities that refer to publications like downloads, reads, shares and mentioning of articles by using data from social networks, blogs, Facebook and Twitter as well as academic networks (Mendeley and CiteULike). 
news value (Schäfer 2011). This corresponds to the expectation on behalf of politics that science as a whole, but also universities, research institutions and scientists, are open to the public and report about themselves. In part, even specific instruments have been introduced that promote and reward communication with the public. ${ }^{20}$ The implication of this science policy expectation with respect to the scientific communication system is extensive. If the audience of the 'internal' communication of science is the respective disciplinary community, the general public now, too, is one of the addressees. This development has the potential to evoke conflicts between the new standards and scientific norms such as 'organised scepticism' (Merton 1942: 126) or the order of humility (Merton 1963: 250). The orientation of science towards the general public can be driven by two motives. First, it can be done by informing the public in an enlightening way. This is achieved by traditional science journalism in the role of 'translator', or earlier as 'populariser'. This form of science journalism, although not entirely vanished, has been replaced by a more investigative and critical reporting (Blattmann et al. 2014). In principle, it includes reports about science policy, even though this still rarely takes place. On the other hand, and at the same time, science itself conducts in part enlightening, in part persuasive, science communication. Publications such as Public Understanding of Science (PUS) or Public Engagement with Science and Technology (PEST) attempt to evoke the public's interest in science. The assumption underlying this form of communication (meanwhile disproved) is that a higher level of information among the public entails a higher level of support. ${ }^{21}$

Second, the competition for attention is motivated by expectations of advantages in the struggle for public funds. In practice, neither of the two motives are clearly separated, they overlap in part, strengthen each other and thus form a special constellation. The accountability and publicity called for in the democratic discourse supports the competition for attention mandated by science policy without the latter being critically distinguished from enlightening communication. Consequently, the boundaries between the respective formats of communication, between public relations, marketing and journalistic informing of the public become blurry. The number of employed science journalists is decreasing while that of professional communicators specialised in persuasive communication (PR) goes up. In the past years, a significant number of trained science journalists have moved to the field of science PR, on whose reports the media depend. Editorially controlled

20 For example, the programme Agora of the Swiss National Fund (SWF) or the Communicator Award of the German Research Council (DFG).

21 On the questionability of this assumption and on the development of this type of communication, see Bauer (2007), and on the effects on the attitudes of the public towards science, see Bauer et al. (2012). 
reporting is replaced by advertisement communication, which is increasingly less recognisable as such. ${ }^{22}$ Because of the described conjunction between the legitimating mandate of publicity and the attention management in the context of the competition for funds, science becomes 'medialised'. This means that the orientation of researchers or that of scientific organisations towards the criteria of relevance of the mass media (i.e. news values) can come into conflict with the code of truth of science (Weingart 2001: Ch. 6). What effects medialisation has on science is disputed, not least because of the different interpretations of the concept (Peters et al. 2013). It is important to differentiate between repercussions on the presentation of science, as it is apparent in the described PR communication of universities, and repercussions on the actual development of science, that is, its research agendas and the communication behaviour of scientists (Weingart et al. 2012).

\section{Current structural problems of the scientific communication system}

The four structural dynamics described above do not affect the scientific communication system individually but cause changes as a complex network of partly parallel, partly contradictory effects. The development of an appropriate understanding of the current problems and challenges in the formal scientific communication system thus requires taking several of the previously described factors and their interaction into account. The analytical power of the perspective that is developed here shall be demonstrated by means of three structural problems. Examples include the crisis of the library, which, from the perspective of the operators, is seen as a financial problem, and from the perspective of science, as a problem of accessibility of literature (see 4.1), the growth in size of the formal communication system (see 4.2), and the impact of the structural dynamics on the trust in published research results (see 4.3).

\subsection{The crisis of the library and open access}

One structural problem seems at first glance to have been caused primarily by the economisation of the publishing landscape. The increasing significance of the orientation to economic profit among large academic publishing houses, as described above, in connection with the characteristic of 'publication' as

22 On the role of medial self-presentation of higher education institutions in Germany, see Marcinkowski et al. (2013). The number of professional 'communicators' conducting PR communication at German universities and research institutions, is estimated to be around 800 to 1000 . The German academies have pointed to the problems of this development in 2014, and have formulated recommendations (Nationale Akademie et al. 2014). 
not being a substitutable good, since the 1980s has led to an explosion of costs on the side of the libraries. For the period 1975-1995, the rise in the price of scientific journals is indicated as being between 200\% and 300\% (European Commission 2006: 16), for 1986-2006 an average increase in price of 5 to $8 \%$ per year was noted (Kirchgässner 2008). After that, they are similar, thus in 2008 prices increased by between $9 \%$ and $10 \%$ and in 2009 and 2010 by $7 \%$ to $9 \%$, respectively (Boni 2010). The budgets of the libraries, however, did not grow to a similar degree during the same period, so that the increase in price could not be absorbed. As a consequence, libraries were and are forced to restrict their activities in acquisition and collecting. ${ }^{23}$

The causes for the crisis of the libraries have not changed; only their form of appearance has evolved during the past three decades. In order to understand these changes, a second factor - digitisation - has to be taken into account. The most striking development is the transformation towards electronic publications that started in STM in the 1990s. One hope was that prices would go down as several phases of the work process, such as printing and distribution, were no longer necessary. Instead, publishers raised their prices by up to $15 \%$ per year, referring to the high costs of the development and provision of digital production and dissemination platforms. The change towards electronic publishing also affected the business model of the academic publishing companies. The trend was towards a diversification of the product. While in times of print, the research contributions collected in an anthology represented a 'natural' form of the good 'publication', in times of electronic publication, a commodification in diversified forms takes place. The sale or rental of accessibility to individual PDF files is smaller in size than the classic model of subscription. The access to larger or even entire collections of journals of a publisher via a respective platform is more encompassing.

Especially the latter form of commodification leads to changes in the market. For libraries, the advantage of buying access to the entire collection of the publisher lies in significant price reductions in contrast to buying access to individual journals. The disadvantage is reduced flexibility since cancellations are limited to a certain percentage. For large publishing companies, such a 'bundle deal' is attractive since they can take up large parts of the library budget. One effect of this business model is that the publishing companies, depending on the size of their portfolios, can protect themselves against cancellations to varying degrees. Cost savings hit small publishing houses with smaller collections of journals or a programme that is dominated by books and anthologies.

23 The restrictions not only affect journals but also monographs and anthologies (Kopp 2000). 
As a reaction to the library crisis, researchers, libraries and organisations promoting science demand free access to scientific publications in which results of publicly financed research has been published. In order to realise such an open access, digitisation is a prerequisite. This is already visible in the text of the Budapest Initiative of 2002, which shaped the meaning of the term 'open access' (OA). The introductory passage reads:

An old tradition and a new technology have converged to make possible an unprecedented public good. The old tradition is the willingness of scientists and scholars to publish the fruits of their research in scholarly journals without payment, for the sake of inquiry and knowledge. The new technology is the internet. The public good they make possible is the world-wide electronic distribution of the peer-reviewed journal literature and completely free and unrestricted access to it by all scientists, scholars, teachers, students, and other curious minds. ${ }^{24}$

To realise this objective, two strategies are suggested which have also been pursued since then. On the one hand, the provision of free access and use of hitherto restricted publications by means of an electronic copy in a repository - known as 'green open access' - and, on the other hand, free access at the original place of publication, the so-called 'gold open access'. Free access for the reader can, in a practical sense, only be realised if an infrastructure such as the Internet exists, which allows the creation of copies of a text and their global dissemination at negligible costs.

At first it seemed as if the call for open access stood in contrast to the interests of the renowned academic publishing companies. They did, however, quickly take it up and re-interpreted it in economic terms. The demand for open access is realised via two business models that are compatible with the publishers' expectations of making profits. One model includes charging publication fees for all contributions of a journal or so-called 'article processing charges' (APC) ${ }^{25}$ All contributions of a journal are then freely accessible via open access, and the journal is entirely financed by publication fees. APCs are due when an article is accepted for publication and are usually paid by the research organisation for which the author works. ${ }^{26}$ A second model is based on the notion to offer free accessibility as an option. Here, access to the contributions of a journal on the side of the reader generally costs money. An

24 See http://www.budapestopenaccessinitiative.org/read

25 For more detail on this model, see Björk and Solomon (2014).

26 This is done via so-called 'publication budgets'. See the working group Open Access 2014. An overview of the current flow of funds from publication budgets in German-speaking countries can be found in Pampel (2014). 
author can, however, decide to make an individual article freely accessible after paying an APC. This optional model is often criticised, the suspicion being that the publishing companies charge money for their services twice - once from the authors, and once from the readers. Therefore, it is often referred to as 'double-dipping'. While these models solve the problem regarding access to publications, the financial problems that are at the core of the crisis in the library in the form of inflated prices, are not necessarily solved.

The current situation is characterised as follows. The transformation towards a strong degree of open access has only been successful in individual areas through green open access. ${ }^{27}$ The proportion of freely accessible work at their original place of publication is thus around $9.0 \%$ to $16.9 \% .^{28}$ This means that the model of subscriptions is still the more important model in comparison to the financing of journals via publication fees. The repositories, through which green open access is realised, provide a new and second level of publication, which supports the circulation of research results within scientific communities (dissemination function). However, certification remains dependent on the evaluation of the contributions at the original place of publication. Moreover, the versions available in the repositories can only be used to a certain extent as pagination is sometimes missing and there is often uncertainty whether the version concerned corresponds to the one in a journal. This is especially true in disciplines in which the practice of citation requires the exact page numbers. Therefore, a dependency on the original journals, which often are only accessible via subscriptions, remains.

The ongoing crisis has led to a number of reactions on behalf of scientists and the libraries. One that received the most attention was the boycott against Elsevier (Lin 2012), which was initiated in 2012 by mathematicians under the heading 'The cost of knowledge', and supported by almost 15000 scientists. The protest was based on the claim that there was an imbalance with respect to the work of the scientists (provided to the publishers for free) in the form of submitted manuscripts as well as editorial work of the editors and reviewers, on the one hand, and the unusually high costs of journals and the resulting profits, on the other hand. The boycott was against Elsevier because it was viewed by the protesters as the 'worst offender' among the large publishing companies. Since then, several universities (among them also German universities such as the

27 The proportion of green OA publications varies between the disciplines. A study of publications in 2010 revealed that chemistry, with $9.3 \%$ of self-archived publications, is last. The largest number can be found in mathematics $(40.8 \%)$. Throughout all disciplines, the proportion of green open access is $21.9 \%$ (Gargouri et al. 2012: 8).

28 The study by Laakso and Björk on publications in 2011 revealed a proportion of $9 \%$ freely accessible publications in gold OA journals in the Web of Knowledge and $11 \%$ in the citation database Scopus. Taking into account articles that are freely accessible with delay (a so-called 'moving wall') and the proportion of freely accessible articles in the optional OA models, the overall proportion in the Web of Knowledge is $16.2 \%$ and for Scopus 16.9\% (Laakso \& Björk 2012: 6). 
Technical University Munich and Konstanz University) have reacted by ending their subscriptions of Elsevier products. In November 2014, the Dutch union of universities (VSNU) cancelled negotiations with the company regarding renewals of subscriptions for 2015 and the introduction of open access. Already in April 2012, Harvard University (2012) released a Faculty Advisory Council Memorandum on Journal Pricing, which states:

We write to communicate an untenable situation facing the Harvard Library. Many large journal publishers have made the scholarly communication environment fiscally unsustainable and academically restrictive. This situation is exacerbated by efforts of certain publishers (called 'providers') to acquire, bundle, and increase the pricing on journals.

The university called upon its members to save their respective articles on the university's repository (DASH), to publish articles in open access journals and to strengthen the reputation of those journals, to withdraw from editorial boards of journals that do not support open access. A first success of the boycott was that Elsevier did not support the 'Research Works Act', a judicial initiative in the US Congress, which was supposed to prohibit mandates on OA publication of government-funded research results. 'The bill was declared dead by its sponsors in Congress on the very same day' (Arnold \& Cohn 2012: 832). ${ }^{29}$

The analysis of the crisis of the libraries and its change over time can only be successful if both dynamics of economisation and digitisation, and their entanglements are taken into account. Only then does it become clear that the large publishing companies, increasingly characterised by economic imperatives, and scientists and libraries interpret and make use of the opportunities and potential of digitisation for their own good. So far, it seems as if the publishers have the upper hand in this process, even though - as shown by the 'The cost of knowledge' boycott - digitisation leads to new opportunities for networking and organisation regarding the articulation of interests within scientific communities.

\subsection{Growth in size}

The second example, which should serve to demonstrate the potential of our analytic perspective, is the growth in size of the scientific communication system. From the beginning, complaints about such a growth - and especially

29 The development continues. At the beginning of November 2015, the six editors of the journal Lingua as well as the entire editorial board withdrew and announced the founding of a new OA journal (Ingram 2015). 
the problems that result from it - on the side of the recipients are side-effects of modern science. The growth of science in general, and of the communication system in particular, leads to a narrowing of the scope of absorbed literature since researchers' attention and time for reading are limited and cannot be extended arbitrarily. Growth is thus a driving factor for the specialisation of science, at first in disciplines, then in specialties with a tendency towards focusing on ever-smaller objects and research areas. This exponential growth of science, already described by Derek de Solla Price in 1963, that is, the simultaneous growth of research funds, institutions and number of scientists, is additionally accelerated by other factors within the communication system. They have different, partly interacting causes and concern different dimensions of the communication system. These developments lead to a structural problem, namely that the system becomes overly complex due to its growth.

One of the external factors that contribute to this growth is the observation of the communication system by means of formal characteristics. Studies on unintended consequences have shown that research evaluations could influence the publication behaviour of scientists under certain conditions (Espeland \& Sauder 2007). If the number of publications (or that of a certain type of publication) plays a role in the measuring and evaluation of performances in research and is directly connected to incentives in the form of an indicator - as, for example, via the allocation of third-party funds scientists react by adapting their publication strategies. They publish research results in as many individual publications as possible ('least publishable units') in order to influence the performance measures to their benefit. This strategic 'salami slicing' leads to an inflationary growth (Bornmann \& Daniel 2007; Geuna \& Martin 2003: 283) in the number of publications without creating a larger amount of research results. Linda Butler (2003) analysed this kind of reaction in the introduction of the Australian Research Evaluation System and found an increase in the number of publications, albeit only in a segment of journals of average quality. Scientists thus turned to less prestigious journals in order to increase their number of publications (Butler 2003: 41). This effect can be observed in all systems that have introduced purely quantitative measurements. Butler (2010: 137) concludes:

Increased publication output appears to be a common impact of PRFS, ${ }^{30}$ irrespective of the model used, and this has generated a great deal of attention. Much of the discussion is anecdotal, but it is the one impact on which there is considerable bibliometric analysis, accompanied by a belief that it is possible to demonstrate the causal effect of the assessment systems.

30 Performance-based research funding systems. 
The United Kingdom, Australia, Spain and Norway have been the focus of detailed studies.

According to more recent estimates, the volume of scientific publications increases annually by approximately $9 \%$, which means a doubling every nine years (Bornmann \& Mutz 2014). Based on the present findings, it cannot be said how large the proportion is that results from research evaluations.

Economisation also leads to effects that are relevant to growth. As a result of their journals' increasing relevance, academic publishing companies in the fields of science, technology and medicine (STM) respond by enlarging the respective journal and increasing the frequency of its appearance. The economisation to which the large publishers are subject, however, also leads to an expansion of the communication system to include less innovative, less relevant contributions of lesser quality. Two developments in particular should be noted: cascading peer review and predatory open access journals. The former ${ }^{31}$ refers to the transferring of rejected articles (including their reviews) from one journal to another. This procedure, which has been practised for a number of years now, is based on the view that in many areas of science, a hierarchy of reputation exists among journals, and that authors follow this hierarchy in the submission behaviour. If an article is rejected, it is often submitted to a journal that is ranked much lower in the hierarchy. The manuscripts are then reviewed once again. The professed goals of cascading are, on the one hand, to use the capacity of reviewers more efficiently by passing on their reviews (Hames 2014: 10), and, on the other hand, to accelerate publication of a manuscript. With regard to the form of organisation of cascading peer review, there are large differences. The procedure can be organised within a publishing company as well as between journals of different publishers. ${ }^{32}$ Other differences concern how far the transfer of manuscripts occurs automatically or via the author or editor. Cascading peer review can, under certain circumstances, accelerate growth in size since it is not only of use for science but also for the large publishing companies (Barroga 2013: 91). The transfer of manuscripts to journals of the same publisher is an appropriate means of binding a large amount of submissions to the company, and in case of negative reviews, to be able to publish them still. For this purpose, the cascade of journals consists of less renowned journals, and the author of a rejected article is given the opportunity to publish the article in one of those. ${ }^{33}$ In particular, with regard

31 The reference is not clearly defined. Occasionally, not the review but the manuscript is in the focus and it is referred to as 'automated manuscript transfer'.

32 See the example of the International Neuroinformatics Coordinating Facility (INCF) in De Schutter (2007).

33 This is visible regarding the criteria for accepting a manuscript. Such mega journals require consistency in methodological and formal standards, but criteria such as novelty or relevance do not play a role. 
to the financing of cascading journals, there are incentives to lower the criteria for accepting a manuscript. 'However, publishers may be tempted to condone low-quality research that is unworthy of scientific investigation in return for an article that can be published in their cascade journals' (Barroga 2013: 91). It is obvious that the growth of the communication system depends on how far the criteria for accepting an article for publication in the framework of such cascading systems are lowered.

The opportunities for publication at the lower spectrum of noteworthy research contributions are also increased by the founding of so-called predatory open access journals, a development that has been accelerated since 2012 (Butler 2013: 434). Predatory publishers aim at exploiting the publication fees in the framework of the gold OA model (Beall 2010: 15). They are financed by APCs, claim that they have a rigid review process, but often publish articles without evaluation and seldom guarantee listing or long-term accessibility. ${ }^{34}$ The authors are most likely not always victims of the business practices but might consider the journals as an opportunity to publish their research, which could not be published in other places. Estimations with regard to the size of this phenomenon differ. At the end of 2016, Beall's list comprised 1155 entries of 1000 'potential, possible or probable predatory scholarly' open access journal publishers. ${ }^{35}$ While Beall assumes that 5\% to $10 \%$ of all OA articles are published in such journals and endanger the reputation of the gold OA model in general, the managing director of the Directory of Open Access Journals (DOAJ), Lars Bjørnshauge, assumes that less than $1 \%$ of all articles financed by APCs appear in a predatory OA journal (Butler 2013: 435). The effect this development has on the scientific communication system is described by Beall (2010: 16) as follows:

Finally, one of the negative impacts of these predatory Open-Access publishers will be the avalanche of journal articles they are creating. This abundance will make it harder for scholars to keep up with research in their fields, and it will cause online searches to be filled up with links to low-quality research.

See, for example, a guideline for authors for the journal SpringerPlus: http://www.springerplus.com/ sites/10283/download/A00834_SpringerPlus_authors.pdf.

34 See the experiment by Bohannon (2013). He submitted rigged and erroneous manuscripts to OA journals that are financed via publication fees. Of 225 journals, 157 accepted the articles for publication; 106 journals $(70 \%)$ did not have the articles reviewed and accepted them right away. The immediate acceptance as well as publication after review suggests deficits in the journals' decision-making process. The selection of the journals was based on the Directory of Open Access Journals (Bohannon 2013: 64), supposed to have a 'quality control system to guarantee the content' (see doaj.org/about).

35 Beall's list of predatory open access journals was removed from the Internet in January 2017 due to threats of a lawsuit against Beall. An archived copy of the list is still available. See https:// clinicallibrarian.wordpress.com/2017/01/23/bealls-list-of-predatory-publishers/. 
In the humanities and social sciences, such a recycling of publications of lower quality takes on a different form. The pressure on scientists, caused by evaluations and performance measures, to publish as much as possible, and the opportunistic attitudes of publishing companies to make profits from additional funds for printing costs, has led to a boom in anthologies (Hagner 2015: 176). ${ }^{36}$ By skipping the review process and selection driven equally by competition and affirmation based on the do ut des principle, it is risky for the editors to tell those authors who the editors themselves have chosen that their texts do not meet the expected quality requirements. Renowned authors are usually asked to contribute to anthologies so that their names attract a large readership. In view of the frequency with which opportunities for publication are advertised, it is hardly surprising that many contributions are merely a recycled version of previously published work. As a result, quality and coherence of an anthology suffer, as does the reputation of this type of medium in general. ${ }^{37}$ The handbook, which is experiencing a boom, especially in the social sciences, has similar problems. ${ }^{38}$

The possibility to deposit articles in repositories, a result of digitisation, also leads to growth of the communication system. Here, two effects can be observed. Whereas operators of repositories emphasise that self-archiving is primarily about creating accessibility to high-quality, reviewed publications, many repositories are used as original place of publication in order to publish grey literature or research reports. Moreover, publication in a repository results in the dissemination of two or more digital versions of the same publication. The causes for multiple digital availability can be diverse. It is possible that authors archive their publications not only in repositories but also in social networks, such as ResearchGate or Academia.edu, or that co-authors deposit the same work in another repository, or that operators of repositories search the web for freely available content and aggregate their findings. Here, too, this form of growth can only be described but not quantified.

This growth in the volume of publications, which is not matched by a respective growth of research results, is caused by the concurrence of the observation of the communication system by means of quantitative

36 On the dilemmas of quality assurance of anthologies, see Kemp (2009: 1019-1020).

37 General statements on quality of the medium 'anthology' are not always appropriate as there is, of course, still the carefully conceptualised anthology, whose contributions are reviewed by external reviewers and commented on by the editors.

38 For example, Springer lists 229 books in the social sciences that contain 'handbook' in the title or subtitle (searched 30.10.2015). While 'handbook' suggests that the book summarises the state of knowledge of a larger field, the following titles indicate an advanced and small differentiation of the focus: Handbuch Kulturpublikum, Handbuch Kriegstheorien, Handbuch Spitzenpolitikerinnen, Handbuch NGO-Kommunikation, Handbuch militärische Berufsethik (in two volumes) and Handbuch standardisierte Erhebungsverfahren in der Kommunikationswissenschaft. The Handbuch nicht standardisierter Methoden in der Kommunikationswissenschaft is noteworthy as well. 
performance measures as well as economisation and digitisation. Looking at the consequences for science while ignoring questions of the financing of the system via public funds, it becomes clear that the growth in size has a inhibiting effect on the functionality of the system, especially on the side of the readers. In the search for literature by means of search engines, the problem is not to find contributions that fit thematically. Rather, the inflation of the communication system makes it difficult to decide whether a selected publication is worth looking at. This difficulty with regard to selection and evaluation is likely to be especially apparent in fields that do not have a wellordered communication system, with a clearly visible core of publication media in which relevant research results can be found. On the other hand, the phenomenon of different versions of a text leads to the question whether other versions than that of the original place of publication can be received or whether these deviate significantly from each other. This can easily be the case when a pre-print version is deposited in a repository. Here, the recipient needs to make sure that he or she cites the version of the original place of publication. In addition, several of the mentioned forms of growth in size can hinder or distort the internal scientific mechanisms of attributing reputation.

\subsection{Trust in published research results}

Our final example of how the interaction of several of the structural dynamics described above leads to structural problems pertains to trust in published research results. By trust, we do not mean a naïve belief in science that research is always conducted with care and according to the standards of a discipline, that scientists never make mistakes, that research results are always presented in a professional manner, and results are never interpreted subjectively. Rather, trust here is considered as the result of an operation that is in principle based on mistrust. This paradox becomes understandable when we take a closer look at the responsible mechanism - the review process. The scientific norm of scepticism (Merton 1942: 126) does not accompany claims of truth from their emergence in research processes to publication and reception but has its primary location in the peer-review process. In the course of this process, reviewers who are mostly selected by an editor check the plausibility of research results and the adherence to methodological and argumentative standards. Naturally, such an evaluation can never be complete and extensive, and even the most dedicated reviewer needs to end his or her work at some point due to practical reasons. ${ }^{39}$ In the end, it is not so much the substantive reasons and arguments raised in the review process that create trust - not 
least because in the traditional blind review, reviewers remain unknown to the reader. Rather, trust emerges from the fact that such an evaluation procedure has taken place at all and the article has passed through it successfully. ${ }^{40}$

The trust provided by the procedure is only ever provisional. In the course of reception and further research, doubts on the accuracy of a certain claim could emerge, which then leads to additional evaluations. The shift from trust to mistrust is the typical consequence of inconsistencies. In spite of its tentativeness, the preference of trust has consequences in social respect. It is one of the conditions of far-reaching division of labour within science and a prerequisite for increasing the capacity of the overall system since scientists no longer have to deal with the evaluation of all prerequisites of their research.

All of the structural dynamics mentioned in section 3 of this chapter influence the constitution of trust, whereby trust-eroding as well as trustsupportive effects can be observed. If these are viewed with regard to their connections, indications can be found for the thesis that the basis of trust is currently changing.

A number of trust-eroding phenomena are brought into connection with the immediate implementation into incentives during the observation of the communication system by means of formal characteristics. There are indications that the use of publication-based indicators in the framework of research evaluation, the performance-oriented allocation of funds, the grant proposals for third-party funds as well as hiring procedures lead to pressure in publishing and reactions among scientists that put strain on trust in research results in general.

One relevant phenomenon here is publication bias, which is apparent especially in quantitative experimental research in medicine and psychology (Scargle 2000). The strong orientation in these fields towards the journal impact factor and the observation that experiments providing evidence for a connection between two variables are more often cited than those indicating no connection, causing editors of journals to tend to publish positive results. Negative results, which also have the value of insight, are not published to a similar extent. These systematically higher chances of publication of positive results give rise to a distorted picture of the state of knowledge in the literature and thus put strain on the trust in published research results.

Not surprisingly, other scientists often cannot reproduce published findings, which undermines trust in research and wastes huge amounts of time and money. These practices also create a shaky knowledge base for science, preventing scholars from effectively building on prior research (Nyhan 2014).

40 Loosely alluding to Luhmann, one can speak, with reference to peer review, of the creation of a provisional 'trust by procedure' (Vertrauen durch Verfahren) (Luhmann 1969: 37). 
While publication bias represents an erosion of scientific standards, the pressure to publish (resulting from the role of bibliometric indicators) leads to questionable, undesired or illegitimate behaviour. Thus, agencies offer academic authors support in successfully manoeuvring their articles through the peer-review process. This service is not restricted to language editing of a manuscript before submission. Some agencies also try to manipulate review processes by suggesting reviewers that do not exist and provide editors with reviews. A study by BioMedCentral identified and retracted 43 articles where manipulation in the review process was proven. ${ }^{41}$ It remains unclear, however, whether the agencies acted alone or whether they acted with knowledge or even on behalf of the authors.

Furthermore, there are clear cases of fraud and softer forms of scientific malpractice that can be traced to the pressure to publish and eroding trust. These include not only manipulation of data, fabrication of results as well as more sophisticated or banal forms of plagiarism, but also practices such as selective choice of cases, adding 'fitting' measurement data or choosing 'convenient' model specifications (Plümper 2014: 4). Advantages in the competition for reputation and thus jobs gained by fraud promise material profit (Franzen et al. 2007) and increase chances in the acquisition of third-party funding. It is not clear whether the number of fraudulent cases has increased with the number of publications. It is certain, however, that the problem has received attention within science as well as the public and that trust in the functioning of scientific control mechanisms therefore has been damaged.

Another source of erosion of trust is the increasing medialisation of science. As mentioned above, medialisation has a legitimating function as well as one related to management of attention. One consequence is the communication of research results via mass media, circumventing regular peer-review processes or delaying them. Perhaps the most spectacular case was the television news about the discovery of so-called 'cold fusion' (Weingart 2001: 254-261). Only after several weeks was the scientific community able to disprove the results of these experiments as the original set up remained unknown. There is a structural problem. Editorial decision-making programmes of high-ranking multidisciplinary journals, which are oriented towards scientific quality as well as societal relevance (keyword: breakthroughs), create conflicting expectations on the side of the authors, who then tend to exaggerate their results. These conflicts seem to increase with the extent to which visibility in the media has become a performance criterion of scientific research. It is striking that the increase of ex-post public scrutiny of research results leads

41 See the blog by Elizabeth Moylan 'Inappropriate manipulation of peer review' from 26 March 2015 at http://blogs.biomedcentral.com/bmcblog/2015/03/26/manipulation-peer-review/ 
journals more often than hitherto to correct editorial decisions in the form of retractions of manuscripts. ${ }^{42}$ The increase of such retractions is a consequence of the orientation of science towards attention by the mass media, and this can be damaging to the image of the journals involved, the research institutions involved or even entire fields of research.

The image of eroding trust painted here is bleak and characterised by pathologies. Without taking into account the developments that strengthen trust and which are especially connected to digitisation, however, this image remains incomplete and one-sided. Effects that strengthen trust can originate in changes in the review process or in the characteristics of a publication. It has already been mentioned that the digital format of submitted manuscripts and of documents that have emerged during the review process together with connecting all those involved, provides the opportunity to organise the review process anew. This and a higher degree of openness and comprehensiveness of the process seem to be the answer to the challenges of eroding trust. The currently tested innovations of the procedure point in three directions:

- A first innovation refers to publication bias and is oriented towards the traditional procedure of scientific control. The innovation lies in a review process, which remains anonymous but is divided into two stages. In a first step, the research is registered and the experimental design is evaluated, as it is practised, for example, by the American Economic Association with its RCT (randomised control trials) Registry. ${ }^{43}$ In a second step, only the practical conduction of the study is evaluated; not the type of results. This is supposed to exclude bias on the side of the editors or the scientists (Nyhan 2014).

- A second innovation lies in the efforts to archive data underlying a publication and to make these transparent. Here, archiving is not only about making datasets re-usable in the context of subsequent research questions but - with regard to the review process and further reception - an improvement in the understanding of published research results (Wissenschaftsrat 2012: 14). The connection with research data could also be considered an extension of the traditional procedure of quality assurance and is thus closely oriented towards the classic model.

- A third innovation relates to alternative procedures that replace the traditional review process. Examples are open peer review, public peer review, post-publication peer review and open discussion, which,

\footnotetext{
42 See the increase of retraction rates that correlate with the journal impact factor. http://www.nature. com/news/why-high-profile-journals-have-more-retractions-1.15951; http://retractionwatch.com/ category/by-journal/nature-retractions/.

43 The registry can be found at https://www.socialscienceregistry.org/.
} 
although they have been established in some journals, are not yet standard procedures (Ware 2008: 18). The journals British Medical Journal (BMJ) and Atmospheric Chemistry and Physics as well as the publication platforms Faculty of 1000 (F1000) and ScienceOpen are pioneers in this context.

Presenting individual procedures and honouring their potential goes beyond the scope of this chapter, however. Instead, the focus here should be on the fact that new mechanisms of evaluation are being realised.

First, some procedures are characterised by extending the number of those involved in the review process. The persons involved are no longer selected by the editor but participate in the process via self-selection. Second, editorial confidentiality is in part, sometimes even entirely, given up so that the arguments emerging in the course of the review process can be tested. In addition, it is made transparent who was involved in the decision-making process. Third, the certification of quality is not provided before publication but after reception according to the principle 'publish then filter' (Hunter 2012: 2). Not all of these approaches are suitable for every journal and every research field. These innovations are interesting nonetheless because they entail a high degree of transparency and comprehensiveness of the assessment of quality. Returning to the abovementioned classic form of peer review, these innovations can be interpreted as an attempt to change the foundations of trust. The mechanism of creating trust via procedure is replaced by trust through transparency. In other words, the innovations are based on a tendency towards stronger reconnection of trust to facts.

\section{Conclusion}

The formal scientific communication system is currently undergoing farreaching change, which is far from over. The aim of this contribution was to provide a heuristic which supports the analysis of this change. Four factors (digitisation, economisation, medialisation and the increased use of quantitative, bibliometric indicators) have been identified, whose effects are rarely taken into account in their combined interactions. They influence the formal communication system of science, the technological infrastructures and service organisations and lead to changes and, in part, structural problems. The complexity of the analysis of current processes of change is due to two things. The first challenge is to penetrate the abovementioned, very heterogeneous factors analytically in their interaction. We have attempted to do this to a certain extent in this contribution. The second challenge is the heterogeneity 
of the subject. On a high level of abstraction, unified structures can be observed for science as a whole. For example, the formal communication system is characterised by its orientation towards the medium of truth and the medium of reputation (Luhmann 1990: 244-251; Schimank 2012: 234), and the four functions of the communication system described above are universal. One level below, however, there is a high degree of diversity in all three dimensions. The structure of the formal communication system, the publication infrastructure and service organisations differ strongly among different disciplines and fields of research; consequently, similar pathways of development can only be observed partially. Even in areas where there are similar developments, they occur at a different pace. With respect to the analysis, the heterogeneity of the subject should lead to caution in terms of generalisation of findings on scientific publishing. Regarding the design of the formal communication system of science, it can be expected that developments that have proved to be appropriate in certain disciplines or fields can only to a certain extent be useful in other fields. They can fail to achieve the goal under other circumstances, or even cause unintended and undesired effects. In view of the heterogeneity of scientific publishing, universal recipes do not promise much success.

For the analysis reflecting on science, the dynamic development of the subject is ambivalent. On the one hand, it continuously nourishes the fields of research involved in the reflection with new and relevant issues. On the other hand, reflection is aimed at a fast-moving goal. In view of the high pace of development and the fact that reflection takes time, studying recent processes of change always entails the danger of falling behind the developments. In guiding reflection, the heuristic offered here cannot solve this problem of time but might at least soften it. There are good reasons to assume that the factors focused on here will continue to influence the evolution of the publication system in the future.

\section{References}

Andermann, H. \& Degkwitz, A. 2004. Neue Ansätze in der wissenschaftlichen Informationsversorgung. Ein Überblick über Initiativen und Unternehmungen auf dem Gebiet des elektronischen Publizierens. Historical Social Research, 29(1):6-55.

Arbeitsgruppe Open Access der Schwerpunktinitiative Digitale Information der Allianz der deutschen Wissenschaftsorganisationen. 2014. Open-AccessPublikationsfonds. Eine Handreichung. doi:10.2312/allianzoa.006

Archambault, É. \& Larivière, V. 2009. History of the journal impact factor: Contingencies and consequences. Scientometrics, 79(3):635-649. 
Arnold, D.N. \& Cohn, H. 2013. Mathematicians take a stand. Notices of the AMS, $59(6): 28-33$.

Barroga, E.F. 2013. Cascading peer review for open-access publishing. European Science Editing, 39(4):90-91.

Bauer, M., Shukla, R. \& Allum, N. (eds). 2012. The Culture of Science: How the public relates to science across the globe. New York, NY: Routledge.

Bauer, M.W. 2007. What can we learn from 25 years of PUS survey research? Liberating and expanding the agenda. Public Understanding of Science, 16(1):79-95.

Beall, J. 2010. Predatory open-access scholarly publishers. The Charleston Advisor, April: 10-17.

Beall, J. 2015. Criteria for determining predatory open access publishers. Third edition. Retrieved from https://scholarlyoa.files.wordpress.com/2015/01/ criteria-2015.pdf [Accessed 30 October 2015].

Björk, B.-C. \& Solomon, D.J. 2012. Open access versus subscription journals: A comparison of scientific impact. BMC Medicine, 10:73.

Björk, B.-C. \& Solomon, D.J. 2014. Developing an effective market for open access article processing charges. In Final Report to a Consortium of Research Funders Comprising Jisc, Research Libraries UK, Research, Councils UK, the Wellcome Trust, the Austrian Science Fund, the Luxembourg National Research Fund and the Max Planck Institute for Gravitational Physics.

Blattmann, H., Jarren, O., Schnabel, U., Weingart, P. \& Wormer, H. 2014. Kontrolle durch Öffentlichkeit. Zum Verhältnis Medien - Wissenschaft in der Demokratie. In P. Weingart \& P. Schulz (eds). Wissen, Nachricht, Sensation. Zur Kommunikation zwischen Wissenschaft, Öffentlichkeit und Medien. Weilerswist: Velbrück Wissenschaft, 391-412.

Bohannon, J. 2013. Who's afraid of peer review? Science, 342(6154):53-60.

Bollen, J. \& Van de Sompel, H. 2008. Usage impact factors: The effects of sample characteristics on usage-based impact metrics. Journal of the American Society for Information Science and Technology, 59(1):136-149.

Bonfadelli, H., Fähnrich, B., Lüthje, C., Milde, J., Rhomberg, M. \& Schäfer, M. (eds). 2016. Forschungsfeld Wissenschaftskommunikation. Wiesbaden: VS Verlag.

Boni, M. 2010. Analoges Geld für digitale Zeilen: der Publikationsmarkt der Wissenschaft. Leviathan, 38(3):293-312.

Bornmann, L. \& Daniel, H.D. 2007. Multiple publications on a single research study: Does it pay? The influence of number of research articles on total citation counts in biomedicine. Journal of the American Society for Information Science and Technology, 58(8):1100-1107.

Bornmann, L. \& Mutz, R. 2014. Growth rates of modern science: A bibliometric analysis based on the number of publications and cited references. arXiv, 1402(4578). 
Brody, T., Harnad, S. \& Carr, L. 2006. Earlier web usage statistics as predictors of later citation impact. Journal of the American Society for Information Science and Technology, 57(8):1060-1072.

Butler, D. 2013. The dark side of publishing. Nature, 495, March:433-435.

Butler, L. 2003. Modifying publication practices in response to funding formulas. Research Evaluation, 12(1):39-46.

Butler, L. 2010. Impacts of performance-based research funding systems: A review of the concerns and the evidence. In OECD (ed.). Performance-based funding for public research in tertiary education institutions. OECD

De Schutter, E. 2007. Neuroscience leading the way: Reviews cascade by the INCF. Neuroinform, 5:205-206.

De Solla Price, D. 1963. Little Science, Big Science. New York, NY: Columbia University Press.

Espeland, W. \& Sauder, M. 2007. Rankings and reactivity: How public measures recreate social worlds. American Journal of Sociology, 113(1):1-40.

EC (European Commission). 2006. Study on the Economic and Technical Evolution of the Scientific Publication Markets in Europe. Final report January 2006. Retrieved from http://ec.europa.eu/research/science-society/pdf/scientific-publication-study_ en.pdf [Accessed 30 October 2015].

Franzen, M., Rödder, S. \& Weingart, P. 2007. Fraud: Causes and culprits as perceived by science and the media. EMBO Reports, 8(1):3-7.

Gargouri, Y., Larivière, V., Gingras, Y., Carr, L. \& Harnad, S. 2012. Green and gold open access percentages and growth, by discipline. arXiv, 1206(3664).

Garvey, W.D. \& Griffith, V.C. 1967. Scientific communication as a social system. Science, 157(3792):1011-1016.

Geuna, A. \& Martin, B.R. 2003. University research evaluation and funding: An international comparison. Minerva, 41 (4):277-304.

Gläser, J. 2006. Wissenschaftliche Produktionsgemeinschaften. Die soziale Ordnung der Forschung. Frankfurt am Main: Campus.

Hagenhoff, S., Seidenfaden, L., Ortelbach, B. \& Schumann, M. 2007. Neue Formen der Wissenschaftskommunikation. Eine Fallstudienuntersuchung. In Göttinger Schriften zur Internetforschung, 4. Göttingen: Göttinger Universitätsverlag, 201-233. Hagner, M. 2015. Zur Sache des Buchs. Göttingen: Wallstein.

Hagstrom, W.O. 1965. The Scientific Community. New York, NY: Basic Books. Hames, I. 2014. The changing face of peer review. Science Editing, 1(1):9-12. Hanekop, H. 2014. Wandel des wissenschaftlichen Publikationssystems durch das WWW? Die Wirkung wissenschaftlicher Suchportale und Suchmaschine. kommunikation@gesellschaft, 15(5):1-38.

Hanekop, H. \& Wittke, V. 2006. Das wissenschaftliche Journal und seine möglichen Alternativen: Veränderungen der Wissenschaftskommunikation durch das 
Internet. In S. Hagenhoff (ed.). Internetökonomie der Medienbranche. Göttinger Schriften zur Internetforschung. Göttingen: Universitätsverlag Göttingen, 201-233. Hanekop, H. \& Wittke, V. 2007. Der Einfluss des Internet auf die Re-Konfiguration des Systems wissenschaftlichen Publizierens. In U. Dolata \& R. Werle (eds). Gesellschaft und die Macht der Technik. Sozioökonomischer und institutioneller Wandel durch Technisierung. Frankfurt: Campus, 201-220.

Hanekop, H. \& Wittke, V. 2013. Der Wandel des wissenschaftlichen Publikationssystems durch das Internet. Sektorale Transformation im Kontext institutioneller Re-konfiguration. In U. Dolata \& J.-F. Schrape (eds). Internet, Mobile Devices und die Transformation der Medien. Radikaler Wandel als schrittweise Rekonfiguration. Berlin: Edition Sigma, 147-172.

Harvard University. 2012. Faculty Advisory Council memorandum on journal pricing. Retrieved from http://isites.harvard.edu/icb/icb.do?keyword=k77982\&tabgroupi d=icb.tabgroup 143448 [Accessed 30 October 2015].

Hirschauer, S. 2004. Peer Review Verfahren auf dem Prüfstand. Zum Soziologiedefizit der Wissenschaftsevaluation. Zeitschrift für Soziologie, 33(1):62-83.

Hochschulrektorenkonferenz. 2002. Zur Neuausrichtung des Informations- und Publikationssystems. Empfehlung des 198. Plenums vom 5. November 2002.

Hunter, J. 2012. Post-publication peer review: Opening up scientific conversation. Frontiers in Computational Neuroscience, 6(63):1-2.

Ingram, M. 2015. Elsevier mutiny: Cracks are widening in the fortress of academic publishing. Fortune, 2 November. Retrieved from http://fortune. com/2015/11/02/elsevier-mutiny/ [Accessed 7 November 2015].

Kemp, W. 2009. Gruppentexte. Ein kritischer Blick auf Sammelband und Forschergruppe. Merkur, 63(11):1013-1022.

Kirchgässner, A. 2008. Zeitschriftenkonsortien. Angebotsausweitung auf Kosten der Flexibilität. In E. Pipp (ed.). Informationskonzepte für die Zukunft. ODOK '07 (Schriften der Vereinigung Österreichischer Bibliothekarinnen und Bibliothekare 5). Graz-Feldkirch: Wolfgang Neugebauer, 137-146.

Kircz, J.G. \& Roosendaal, H.E. 1996. Understanding and shaping scientific information transfer. In D. Shaw \& H. Moore (eds). Electronic Publishing in Science: Proceedings of the Joint ISCU Press/UNESCO Expert Conference, 19-23 February, Paris, 106-116.

Knorr-Cetina, K. 1984. Die Fabrikation von Erkenntnis. Zur Anthropologie der Naturwissenschaft. Frankfurt: Suhrkamp.

Kommission Zukunft der Informationsinfrastruktur. 2011. Gesamtkonzept für die Informationsinfrastruktur in Deutschland. n.p.

Kopp, H. 2000. Die Zeitschriftenkrise als Krise der Monographienbeschaffung. Bibliotheksdienst, 34(11):1822-1827.

Laakso, M. \& Björk, B.-C. 2012. Anatomy of open access publishing: A study of longitudinal development and internal structure. BMC Medicine, 10:124. 
Lin, T. 2012. Mathematicians organize boycott of a publisher. The New York Times, 13 February.

Martin, B.R. \& Whitley, R. 2010. The UK research assessment exercise: A case of regulatory capture? In R. Whitley, J. Gläser \& J. Engwall (eds). Reconfiguring Knowledge Production: Changing authority relationships in the sciences and their consequences for intellectual innovation. Oxford: Oxford University Press, 51-80.

Merton, R.K. 1942. A note on science and democracy. Journal of Legal and Political Sociology, 1(1/2):115-126.

Merton, R.K. 1963. Resistance to the systematic study of multiple discoveries in science. European Journal of Sociology, 4(2):237-282.

Morris, S. 2007. Mapping the journal publishing landscape: How much do we know? Learned Publishing, 20(4):299-310.

Nationale Akademie der Wissenschaften Leopoldina, Deutsche Akademie der Technikwissenschaften - acatech, Union der deutschen Akademien der Wissenschaften. 2014. Zur Gestaltung der Kommunikation zwischen Wissenschaft, Öffentlichkeit und den Medien. Empfehlungen vor dem Hintergrund aktueller Entwicklungen.

Nyhan, B. 2014. To get more out of science, show the rejected research. The New York Times, 18 September.

Pampel, H. 2014. Offenlegung von Open-Access-Publikationsgebühren in Deutschland. wisspub.net. Retrieved from http://wisspub.net/2014/11/07/ offenlegung-von-open-access-publikationsgebuhren-in-deutschland/ [Accessed 30 October 2015].

Peters, H.-P., Allgaier, J., Dunwoody, S., Lo, Y.-Y., Brossard, D. \& Jung, A. 2013. Medialisierung der Neurowissenschaften. Bedeutung journalistischer Medien für die Wissenschafts-Governance. In E. Grande, D. Jansen, O. Jarren, A. Rip, U. Schimank \& P. Weingart (eds). Neue Governance der Wissenschaft. Reorganisation externe Anforderungen - Medialisierung. Bielefeld: Transcript, 311-335.

Plümper, T. 2014. Vertrauen ist gut, Kontrolle ist besser. FAZ, 20 August: 4.

Power, M. 1997. The audit society: Rituals of verification. Oxford: Oxford University Press. Scargl, J.D. 2000. Publication bias: The 'file-drawer' problem in scientific inference. Journal of Scientific Exploration, 14(1):91-106.

Schäfer, M.S. 2011 . Sources, characteristics and effects of mass media communication on science: A review of the literature, current trends and areas for future research. Sociology Compass, 5(6):399-412.

Schimank, U. 2010. Reputation statt Wahrheit: Verdrängt der Nebencode den Code? Soziale Systeme, 16(2):233-242.

Schimank, U. \& Volkmann, U. 2012. Die Ware Wissenschaft: Die fremdreferentiell finalisierte wirtschaftliche Rationalität der Wissenschaftsverlage. In A. Engels \& L. Knoll (eds). Wirtschaftliche Rationalität. Soziologische Perspektiven. Wiesbaden: Springer, 165-183. 
Shepherd, P.T. 2007. The feasibility of developing and implementing journal usage factors: A research project sponsored by UKSG. Serials: The Journal for the Serials Community, 20(2):117-123.

Stichweh, R. 1979. Differenzierung der Wissenschaft. Zeitschrift für Soziologie, $8(1): 82-101$.

Taubert, N. 2012. Online Editorial Management-Systeme und die Produktion wissenschaftlicher Fachzeitschriften. Leviathan - Berliner Zeitschrift für Sozialwissenschaften, 40(2):297-319.

Taubert, N. 2016. Formale wissenschaftliche Kommunikation. In H. Bonfadelli, B. Fähnrich, C. Lüthje, J. Milde, M. Rhomberg \& M. Schäfer (eds). Forschungsfeld Wissenschaftskommunikation. Wiesbaden: Springer.

Taubert, N. \& Schön, K. 2014. Online-Konsultation 'Publikationssystem'. Dokumentation und Auswertung. Retrieved from http://edoc.bbaw.de/volltexte/2014/2629/pdf/ BBAW_Publikationssystem_Taubert.pdf [Accessed 30 October 2015].

Volkmann, U., Schimank, U. \& Rost, M. 2014. Two worlds of academic publishing: Chemistry and German sociology in comparison. Minerva, 52(2):187-212.

Ware, M. 2008. Peer review in scholarly journals: Perspectives of the scholarly communication - an international study. Retrieved from http://www. publishingresearch.net/documents/PeerReviewFullPRCReport-final.pdf [Accessed 30 October 2015].

Ware, M. \& Mabe, M. 2015. The STM Report: An overview of scientific and scholarly journal publishing. Fourth edition. Retrieved from http://www.stm-assoc. org/2015_02_20_STM_Report_2015.pdf [Accessed 30 October 2015].

Weingart, P. 2001. Die Stunde der Wahrheit? Weilerswist: Velbrück Wissenschaft.

Weingart, P. 2013. The loss of trust and how to regain it: Performance measures and entrepreneurial universities. In L. Engwall \& P. Scott (eds). Trust in universities. Wenner-Gren International Series, Vol. 86. London: Portland Press, 83-95.

Weingart, P., Rödder, S. \& Franzen, M. 2012. Dimensions of medialization: Concluding remarks. In S. Rödder, M. Franzen \& P. Weingart (eds). Sociology of the Sciences Yearbook 28. The Sciences' media connection - public communication and its repercussions. Dordrecht: Springer, 363-373.

Wissenschaftsrat. 2012. Empfehlungen zur Weiterentwicklung der wissenschaftlichen Informationsinfrastrukturen in Deutschland bis 2020. Köln. 



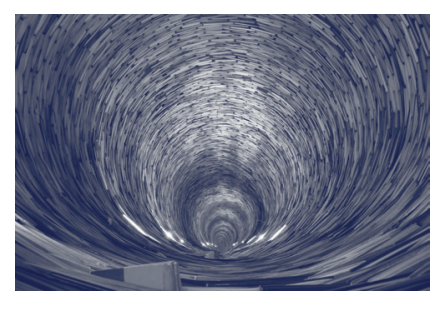

PART 1

The changing scholarly publishing system 



\section{Different from Discipline to Discipline Diversity in the Scholarly Publication System}

Konstanze Rosenbaum

In academia, publishing is of the utmost importance, and this in at least three ways. First, the publication is vital for the communication of new knowledge. Research results have to be published in order to be considered scientific (or scholarly) knowledge (Weingart 2003: 32). Second, the formal publication is a central part of the reward system of science, and serves as the foundation for attributing reputation. Third, mechanisms of external assessment of performance are also largely based on publications insofar as the measurement of performance is conducted via counting publications and citations. In the way science functions, publishing is an essential ingredient - in all disciplines. At the same time, however, there are significant differences within the various disciplines with regard to their cultures of publishing.

In the formal scientific communication system, homogeneity exists only in an abstract manner and refers to the functions of registration, certification, dissemination and archiving of new research. ${ }^{1}$ The present case study reconstructed the central differences of the publication system in seven disciplines on the basis of expert interviews.

The analysis is structured along four comparative dimensions. The first section compares the relationship of printed and digital publications in the individual disciplines, and shows influential factors for the respective states of digitisation in the scholarly publication system (section 2). In the course of digitisation, not only do the media of publication that are used change,

1 The present contribution is based on the conceptual understanding of the Academy's 'Future of the Scholarly Publication System' interdisciplinary working group. See the contribution by Taubert and Weingart in this volume for details on the concepts publication system, publication infrastructure, responsible organisations. 
but also the accessibility. The realisation of free accessibility and the extensive usability of publications are the most important developments within the system. The analysis of the differences is discussed in detail with respect to a certain model - free access to the original place of publication (gold open access) (section 3). Differences are found at the economic level and with regard to reputation. Subsequently, processes of self-monitoring of quality and of quantitative measurement of scientific performance were analysed. In section 4, the peer-review processes of the different disciplines will be compared and analysed with regard to their function of selecting contributions before publication. After that, the focus will be on the significance and perception of bibliometric measurement of performance (section 5). In a first step, the influence of bibliometric measures on the publication behaviour of researchers will be presented by using the example of the journal impact factor. Here, complementary to the mechanisms of the peer-review process, the selective function of impact factors in the context of publication activity, on the one hand, and the distributive decisions, on the other hand, will be worked out. The analysis is preceded by a brief description of the empirical material and methods of evaluation.

\section{Materials and method}

The main focus of this contribution is on the perspectives of scientists towards the communication system in their respective disciplines. In the framework of eight interviews, the members of the 'Future of the Scholarly Publication System' interdisciplinary working group and an invited contributor have gathered information on the characteristics and practices of the communication system in each discipline. The natural and engineering sciences are represented by experts from mathematics, physics and medical engineering. In the humanities and social sciences, two historians of science, one sociologist and one legal scholar were interviewed.

The interviews were conducted on the basis of a loosely structured guideline with which structural aspects of the formal communication system, on the one hand, and of the publication system as well as its responsible organisations, on the other hand, were revealed. Moreover, procedures of professional evaluation, performance measurement and accessibility to scientific information were taken into account. The transparent design of the interviews was chosen to provide experts with the opportunity to set different priorities and to explain the different facets of the scholarly communication system by means of the respective practical experiences (cf. Bogner et al. 2014: 12-15). Correspondingly, the evaluation was aimed at reconstructing 
the internal perspectives of different disciplines on the communication system and to elaborate the specific disciplinary differences by means of comparative dimensions. It is not claimed that the results are complete or that they can be generalised, however.

All interviews were transcribed, and all excerpts presented here were translated into English. The resulting amount of text formed the data material of the analysis. The computer-based qualitative content analysis was chosen as method of evaluation. The development of the system of categories was deductive as well as inductive. Analytical dimensions and main categories were derived from the interview guidelines. In comparison with the empirical material, further main categories could be added and sub-categories could be differentiated. Methodologically, techniques of thematic as well as summarising coding could be applied (cf. Kuckartz 2007: 83-96; Schreier 2012: 58-106).

\section{The relationship between printed and digital publications}

An initial and important comparative dimension is the relationship between printed and digital publication. As a result of the development and utilisation of digital information and communication technology, the scholarly communication system is subject to large dynamics of change. Mailing lists, email traffic and scientific Internet forums structure the social organisation of the exchange of information between scientists, and are used in the scientific communities to different degrees (cf. DFG 2005; Fry \& Talja 2007). Along with the spreading of digital infrastructures, the format of the digital publication has been established, albeit to a very different degree. As a comparatively young form of publishing, the establishment and utilisation of digital formats in the scholarly publication system are inconsistent. The heterogeneity of digitisation within the communication system becomes clear in the interviews. Digital publication has a high status in disciplines that are characterised by a strong international orientation or by high technological standards of graphical description. In the natural and engineering sciences as well as history of art, scientists make use of technological opportunities of digitisation more strongly in order to design or disseminate their publications. In the humanities and social sciences, digital publications play a less important role. Indications for the reasons why digital publications are of varying importance in the different disciplines come to the fore in the interviews.

The indication of an interdependency between the importance of electronic publications and the type of medium of publication originates in the history of science. There, printed monographs and anthologies are of central importance. These 'books of the normal scholarly production' (H.-J. Rheinberger) are still 
primarily received in paper format, and e-books are uncommon. Review journals such as sehepunkte and the Berlin mailing list $\mathrm{H}$-Soz-Kult are, however, published in digital form. These are important places of publication within the discipline, which are freely accessible in purely electronic form. ${ }^{2}$ In the journal sector, an electronic version appears in addition to the printed one. These publications are disseminated electronically by the publishers as a print version and via publication servers.

The state of digitisation in the publication system is, aside from the media of publication, also dependent on the performance abilities of the responsible organisations, in particular the publishing companies. In German-speaking sociology, the publisher Springer VS is a powerhouse. As a large publishing company with a central location in an otherwise fragmented landscape of publishers, Springer Verlag was easily able to take over platforms from science, technology, and medicine (STM) in order to provide digital products also within sociology. Smaller publishers frequently lack the resources to fulfil even minimum standards of their readership in terms of digital publications. Such developments have benefitted the creation of oligopolistic structures within the landscape of publishing companies.

Aside from publishing companies' technological ability for innovation, the attitude of the respective discipline towards digital publication also plays a role. In the field of law, the landscape of publishers is characterised by decentralisation. Here Beck Verlag is the leader in the market. In contrast to mid-sized publishers, like Mohr Siebeck and De Gruyter, Beck's status allows the company distribution of all digital products for money. E-books, however, have only been added to the portfolio of Beck-Online in recent years (cf. also Roxin 2009: 64). This hesitation in adding e-books correlates with the negative attitude of the scientific community towards digitisation as such.

In the history of art, there is a complementary relationship between printed and digital forms of publication. In this discipline, digitisation programmes and purely electronic publications were already developed and conceptualised at the beginning of the 1980s. ${ }^{3}$ At the same time, the form of the printed book remains indispensable for monographs or exhibition catalogues. The latter is a form of publication that not only addresses a broad public but also serves the exchange of research results within the discipline. ${ }^{4}$ Art history is a pictorial discipline (cf. also Boehm 2009: 62), whose publications are characterised by a

2 See http://www.sehepunkte.de/ and http://www.hsozkult.de/.

3 Example of the Census of the Antique Works of Art and Architecture Known in the Renaissance, freely accessible at http://www.census.de/.

4 Exhibition catalogues document an increasing connection between universities and the world of museums. Exhibitions produce new states of research and, as '[a]cademies for a time' (H. Bredekamp), influence the steering of content of research (cf. Boehm 2009: 63). 
special bonding between image and text. In most scientific disciplines, images additionally serve to illustrate connections between arguments that stem from theoretical or empirical work (for example, texts or in the laboratory). The history of art reverses this conventional relationship between image and text: 'images come first, the texts need to try to illustrate them' (H. Bredekamp). Aside from the quality of the image, factors such as choice of paper, density and complexity of the digital samples influence the outcome of a publication. In the printing process, authors are therefore strongly dependent on the printing and layout quality of the publisher and the competency of its designers. 'It's about providing the images with text without the reader having to turn the page [...]. If you have to turn back pages in a description, the description is gradually lost' (H. Bredekamp). Epistemic reasons and resulting high technological standards regarding presentation thus explain a 'unique standard in the art of book printing, which nowadays can be achieved through high-performance digital processes, but which cannot be well shown in digital form. Analogue highperformance books are produced by digital means' (H. Bredekamp).

Digital publications can supplement or even replace printed formats. The latter is the case in the natural and engineering sciences. Here, the electronic journal article as a typical medium of publication is predominant and has almost entirely replaced the printed journals (cf. DFG 2005: 22-25). From the perspective of the researchers interviewed, digital publications are of significant advantage regarding reception, dissemination and archiving of research regardless of spatial boundaries.

The interviewee from medical engineering, for example, emphasised the efficiency of access to digital publications. Here, digital journals play an essential role. The university libraries acquire their licences in the form of bundle deals and provide researchers access via the internal university network:

It's paradise and we sit at our desk ... and we read a publication and there's something in the reference list and I click on that and it's there. [...] So that's of course nice because it is important for research. It's very important that someone does not first have to be sent somewhere ... - and you wait three days until you have it. If you have it right away, then that's fantastic for scientific work. (O. Dössel)

In mathematics, the access to articles is mainly via the electronic way; the utilisation of printed journals is rare. Only journals of scientific societies provide their members - in some cases also the editors and the editorial board - with printed copies.

Physicists prefer a communication culture of direct and informal exchange. Prior information can be passed on verbally at conferences or symposia. Their 
daily work is almost exclusively organised in working groups through which even young researchers are integrated into the community (cf. also Haug 2009: 97-98). Over the last approximately 20 years, this face-to-face communication has been supplemented through e-mail traffic and the electronic dissemination of preprints among peers. Against this background, digitisation in physics has led to another opportunity of circulating information, which is complementary between the informal verbal exchange and formal publication. Especially the easy saving of contributions in PDF format and their archiving on socalled 'pre-print servers' accelerate the pace with which research results can be disseminated (cf. also Fry \& Talja 2007: 127). Moreover, manuscripts are nowadays much easier to produce or to revise while at the same time, the quality of colour figures has increased.

The results from the interviews illustrate that the state and characterisation of digitisation of the communication system are influenced by different factors. Epistemic factors - such as standards regarding graphical depiction and the relationship between image and text, such as described for the history of art, or the pace of scientific progress and the degree of competition about priority as in physics - play a role, as does the kind of media used for publication. This is clearly visible in the humanities, especially by the still high status of the monograph. Another influential factor is the responsible organisations of the publication system that, as has been reported from sociology, could limit the extent of digitisation in a discipline due to their restricted opportunities for technological innovation. Finally, there are also internal scientific factors on the level of normative attributions. A high degree of acceptance towards digitisation as in mathematics or aversion as in law, is also responsible for the differing extent of usage of digital publications.

\section{Open access in the scholarly publication system}

As a consequence of digitisation, there are new pathways of access to scientific publications, which, under the key term 'open access', have changed the traditional system of libraries and publishing companies and fee-based dissemination of printed works (cf. Andermann \& Degkwitz 2004). Open access (OA) first of all means free accessibility to electronic scientific publications, but can also refer to primary and metadata, source texts or digital reproduction of images. ${ }^{5}$

5 On the definition of open access, see the contribution by Ball in this volume. Cf. also http://www. budapestopenaccessinitiative.org/read. Two other public declarations from 2003 have supplemented the development of fundamental principles and goals of OA: the Berlin Declaration (cf. http://openaccess. 
Two factors are essential for open access: the practical implementation requires adequate infrastructures of Internet technology in order to create universal opportunities for access on the side of the recipients. Scholarly publications furthermore underlie the copyright which assigns a contribution to an author. In order to realise open access, the recipient needs to be granted extensive usability rights (cf. Andermann \& Degkwitz 2004: 6-10). ${ }^{6}$

Open access can be realised in two fundamental ways: green OA refers to the creation of free accessibility to publications by depositing a version of the text in a repository or on a home page when it has already appeared in a different location with restricted access (cf. Lossau 2008). ${ }^{7}$

Gold OA, on the other hand, provides free accessibility at the original place of publication. ${ }^{8}$ The following description is limited to the ambitious model of gold OA, which aims to remove financial entry barriers to scientific knowledge in the traditional publishing world. In the interviews, gold OA is critically discussed from the perspective of researchers in their role as authors. Here, the focus is on financing models and reputation and its use.

\subsection{The economics of gold open access and the financing of digital publications}

Due to free accessibility, the incomes publishing companies usually get from sales of printed works or subscriptions disappear. As an alternative to subscription fees, therefore, costs of publication are transferred to the author or his or her institution through article processing charges (APCs). In some disciplines, ACPs are already institutionalised regardless of open access. Thus, in medical engineering or physics, publication fees for journal articles are the rule rather than the exception, regardless of whether an article is designated for OA journals or not. In the humanities and social sciences, publication fees for journals are not common but frequently occur for monographs or anthologies

mpg.de/Berlin-Declaration) and the Bethesda Statement in Open Access Publishing of 2003 (http:// legacy.earlham.edu/ peters/fos/bethesda_ger.htm).

6 Copyright and rights of usability are defined in specific licence agreements, for example, via Creative Commons or the Digital Peer Publishing Licenses (cf. Mantz 2006). See the contribution by Peukert and Sonnenberg in this volume.

7 In the English language publication system, the proportion of green OA has increased significantly. Swan (2007) found an increase of 26 percentage points between 2004 and 2005 and concludes that almost half of the scientists participate in the self-archiving of their contributions (cf. Swan 2007: 200). Pioneers are mathematics and physics, initiating a repository in 1991 with arXiv, which currently contains 1014771 e-prints from physics, mathematics and related disciplines (cf. http://arxiv.org/). Researchers from the humanities and social sciences are less active in self-archiving (cf. Antelmann 2006; Gargouri, Larivière, Gingras \& Harnad 2012).

8 The proportion of gold OA has increased in the past 10 years. The Directory of Open Access Journals currently lists 10254 journals whose articles are all freely accessible (cf. http://doaj.org/). In Germanspeaking countries, $20.1 \%$ and $17.6 \%$ of journal contributions in the natural and engineering sciences, respectively, were freely accessible at the original place of publication in 2005. In the humanities and social sciences, it is much lower at 5.9\%, for monographs only 2.7\% (cf. DFG 2005: 45). 
and are usually referred to as additional costs for printing. ${ }^{9}$ The financing of gold OA through APCs is viewed differently among the interviewees, ranging from pragmatic attitudes (medical engineering, physics) to rejection (mathematics) and even to outrage (history of science). ${ }^{10}$

Authors in OA publications in the humanities face financial hurdles. According to the objective of science policy, publication fees should be paid by the research institutions and third-party funders following a grant proposal by the researchers. For this purpose, German science organisations are creating funds (cf. Eppelin et al. 2012). According to an interviewee, the budgets of projects in the history of science are often too small to cover publication fees of gold OA. At the same time, third-party funders, such as the DFG or research institutions such as the Max Planck Society, increasingly demand that projects, which are financed by them, need to be published in OA journals. Such financial difficulties of the golden model are aggravated by the size of the publication fees. From the perspective of the interviewees, the demands on behalf of the publishing companies are unjustified, and are interpreted as a strategy to have the system of science subsidise the transfer to open access indirectly. Many researchers in the humanities are not able to pay this money and thus have not become active in gold OA. Instead, they try to 'publish their work the way they can afford it, and that is in the best case green OA, text only in any case' (M. Ash).

Moreover, there is scepticism regarding the value-added chain of scientific information that is organised via the successive efforts of authors, publishers and libraries (cf. Andermann \& Degkwitz 2004: 7-10). While open access changes the function of publishers (dissemination) and libraries (archiving), the author as intellectual source of scientific information remains equally indispensable. In fields where publication fees are uncommon, such a model creates tension on the side of the authors. A historian of science states:

Whereas you ask yourself what this has to do with open access, that you should buy your own product, ... that you should pay Springer [€] 2000 for publication in a Springer-owned journal to put the piece online, yes, it ends there for me, I just don't publish in these journals anymore. (H.-J. Rheinberger)

9 According to the study of the DFG cited above, $21.1 \%$ of engineers and $46 \%$ of natural scientists have had to pay for publication in a specialised journal. In the humanities and social sciences, the proportion is much lower at 7.2\% (cf. DFG 2005: 21).

10 Specific cost problems in history of art are discussed at the end of this section. There are no data in the interviews on sociology and law that would enable a judgement on the attitudes in these disciplines. 
In physics and medical engineering, publication fees for open access are more often accepted. In these fields, APCs for journal articles are part of the normal conditions of scientific publishing. The collective organisation of the work processes enables physicists to divide the costs for publication: 'Since we mostly work and publish in groups, there is always some group or someone who can raise the publication fees' (S. Großmann). According to the interviewee, medical engineers prefer a pragmatic use of publication fees and orient their number of submissions to the third-party funds available per year. 'I use the money I have. If I still have money in the DFG project that was designated for this, then I use it, I don't want to let it expire' (O. Dössel).

The interviews with representatives from medical engineering and mathematics illustrate that acceptance or rejection of financing models on the side of the authors also results from the normative structures of the disciplinary communities. The interviewee from medical engineering described a close bonding of his field to industrial practice, in which the professional careers of almost half of the professors began. In principle, they show a positive attitude towards entrepreneurial profit orientation and adapt the generation of economic profit as a guideline for their scientific activity. While the specific code 'truth' guides scientific communication, in medical engineering, processes of organisation and the continuity of research are also oriented towards the economic differentiation of payment or non-payment (cf. Luhmann 1984: 312-314):

Many colleagues of mine also view their store as one where profits are made, which in turn are of course invested in research. But that you don't sell a research service at real costs, we don't play such a zero-sum game, there's no sense for us, then we only push money around in circles. (O. Dössel)

Setting the objective to gain 'profit' serves the stabilisation of solvency for future research.

From such an entrepreneurial perspective, the shifting of financing to the authors also seems rational. Summarising the interviewees' attitude, one could say that professional services have their price, and service providers want to re-earn their production costs plus profit. That is a matter of fact in a marketeconomy. ${ }^{11}$ 'Open access is not somehow cheaper because it is not printed' (O. Dössel). The important difference between closed and open access is in

11 At the non-profit organisation PLoS (Public Library of Science, http://www.plos.org/), the price is currently USD 1350 to 2900 per article (cf. http://www.plos.org/publications/publication-fees/). Depending on the journal, Springer Verlag demands between USD 665 or $€ 500$ and USD 1996 or $€ 1575$ per article submission in the Moving Wall Model (cf. http://www.springeropen.com/about/ apcfaq/howmuch) and USD 3000 or $€ 2200$ in the Open Choice Model (cf. http://www.springer.com/ gp/open-access/springer-open-choice). 
the money flow through which the services of the publishers are financed. The established subscription models of the libraries are supplemented by the opportunity for the author to buy him- or herself into OA journals.

The mathematical community is diametrically opposed to any commercial capitalisation of its knowledge. In its self-description, mathematics is characterised by a strong cognitive and normative consistency, which is also characteristic of communication in the field (see also Gritzmann 2009). As normative foundation of the publication system, the interviewee pointed to two principles. 'No author pays, no reader pays' ( $M$. Grötschel). There is consensus among mathematicians that scholarly knowledge is a public good that should be accessible to everybody at any time. The objective is to have the entire publication system be open access without demanding publication fees from the authors. For this purpose, mathematicians have been working on the ambitious project to develop a mathematical world library, the World Digital Mathematics Library, 'which contains all mathematical articles of all time, electronically, classified, retrievable and searchable' (M. Grötschel). The technological realisation is not so much a problem - ' 10 terabytes or so would be enough to store mathematics of all times' (M. Grötschel). The difficulty rather lies in copyright issues and licencing conditions as well as funding. The aim is a far-reaching change of the system to a publication system that is free of charge open access. 'I want a publication system where someone who does research and has finished a paper can submit it without having to pay for it, and where I can read it without having to pay for that' (M. Grötschel).

This basic attitude does not only concern OA publications but refers to all forms of publication costs on the side of the authors. 'Mathematicians do not want publication fees ... and do not try to publish where these are required' (M. Grötschel). This is based on the view that there is enough money in the entire publication system that needs to be redistributed so that readers and authors do not face costs. Such a model of true open access has, however, not yet been achieved.

A specific financial problem that affects the establishment of open access concerns the history of art with its primacy of visual culture. Art historians face specific challenges regarding the copyright and adequate citation of their visual sources. Obtaining copyrights for images is difficult, costs a lot of money and has become even more difficult in recent years. 'It has been shown that digitisation of photographs has not promoted free accessibility, but created obstacles, so that you now need student assistants to have images added to books or articles' (H. Bredekamp). In the United States, 'exorbitant prices' (H. Bredekamp) have to be paid for the reproduction of images in discursive contexts. Should these be introduced in Europe as a result of globalisation or new economic trade agreements, 'you can pack up or you will need huge 
resources such as the Mellon Foundation that is tapped by everybody' $(\mathrm{H}$. Bredekamp). In view of the high expectations within the discipline regarding advantages of digitisation and open access, the results are disappointing so far. The fear is that it will get even worse.

In most interviews, the practical realisation of gold open access was noted in connection with APCs and other publication costs. Aspects relating to reputation in OA publishing and reception are elaborated and described in the next section.

\subsection{The reputation of open access media}

Electronic media increase the range of scientific information and opportunity on behalf of the authors to increase their visibility and thus gain reputation. Contributions in OA media should therefore, it can be assumed, accelerate and simplify the individual development of reputation. Reputation is not only nourished by advantages regarding citation but also by the reputation of the place of publication. This is precisely where OA journals are lagging behind (cf. Taubert 2010: 217). One mathematician traces this situation to the lowering of quality standards, which is partly the result of new and dubious publishers. These create gold OA journals, which they operate with minimal effort and without a sound review system. The publishers make profits via the APCs, which are mostly paid by the authors themselves, and publish articles that would not be accepted by journals with serious review systems. These socalled 'predatory journals' thus discredit the model of OA publishing (cf. the contribution by Peter Weingart on predatory journals in this volume).

The interviewees from sociology and physics pointed to different limitations of gaining reputation through OA publications. In sociology - a small discipline with a strongly fragmented landscape of specialised journals - OA journals are generally uncommon and even less viewed as places where one's reputation could be improved, so that 'as an author, you still shrug away from' (U. Schimank). A different situation is described for physics. Here, a number of OA journals have been established - such as the New Journal of Physics - which also have a promoting effect on reputation. The most important journals, such as Physical Review and Physical Review Letters are, however, still financed via subscriptions and thus licensed with costs to the readers. In order to counteract cost-induced barriers, peers within the community practice an informal kind of enabling access: 'We so to speak make a living by providing this thing for free, and when it is published and somebody needs it or asks about it, then he will receive the respective file from us' (S. Großmann).

In law, acceptance and utilisation of open access is different. Open access practically does not play a role, and digital infrastructures such as repositories 
or recognised OA publishers are not well established. ${ }^{12}$ Structural specificities of the publication practice of the discipline influence the dissemination of open access. The publication system is basically financed through judicial practice, and not through universities. The publishers respond to that with different subscription packages that are adapted to the needs of the practitioners but these entail high costs. ${ }^{13}$ The interviewee reported that accessibility to relevant data and literature is not considered problematic. This is also due to the monopoly of Beck Online (in Germany) and the law portal Juris. 'As long as you have access to these two large data banks and maybe three or four special journals that you need, you are basically satisfied' (A. Peukert). For the most important medium of publication, the judicial commentary, authors are paid. These media have a relatively high number of copies since they address colleagues and students as well as practitioners, that is, law firms and courts. Royalties run to four or five digits and provide a significant income. These remain with the individual authors and are not returned to the system of science. Scholars of law thus not only generate intellectual capital through their publication practices but also monetary capital that would be lacking in OA publications (cf. also Taubert \& Schön 2014: 79). OA publishing is also considered an irrational strategy due to another aspect. OA media cannot be cited and are ignored by peers, since 'if texts are simply on the net, they are treated as being non-existent' (A. Peukert).

Overall, it can be noted that, from the perspective of researchers, the openness towards OA initiatives differs in the disciplines studied. In physics and mathematics, open access has the most important role. Existing obstacles are dealt with by the peers in different ways. In physics and medical engineering, a pragmatic dealing with current conditions of gold OA publishing prevails. Mathematicians, on the other hand, point to a need for reform with respect to free accessibility and the establishment of reliable peer-review procedures.

The interview partners from the humanities had more reservations towards gold $\mathrm{OA}$, and justified these with respect to the publication fees. In medical engineering and history of science, there are indications that the funding for publication provided by the responsible organisations differs according to the fields and thus influences the publication practice. Art historians, too, fear financial constraints due to changing regulations regarding copyright in the implementation of open access. Scholars of law have a different perspective.

12 In the English-speaking sphere, open access infrastructures are more common (cf. also http://openaccess.net/de/oa_in_verschiedenen_faechern/rechtswissenschaft/).

13 Beck-Online is, according to A. Peukert, a well-functioning database. In addition, the law portal Juris offers different subscriptions, the most common one (juris professional) costs $€ 1200$ per year (cf. http://www.juris.de/jportal/nav/produkte/juris_produkte/jurisprofessionell/produktuebersicht_ professionell.jsp). These data banks 'are subscribed to by many law firms and companies. That is a very big business' (A. Peukert). 
They do not consider publication fees problematic but the potential loss of royalties. The judicial field therefore proves to be an obstacle for the shift towards open access.

The interviewees from law and sociology mentioned reservations towards open access with respect to reputational aspects. The disciplinary culture of law is characterised by an aversion towards processes of change initiated by digitisation. In sociology, with few exceptions, the performance capacity of publishing companies in digital infrastructures is low. In both disciplines, OA publications are considered harmful to one's own reputation.

\section{Peer review}

In the communication system, peer review is a key mechanism of steering science. In the review process, contributions or research projects - thus the ideal assumption - are subject to an independent evaluation which attests to the worthiness of the publication of a manuscript or the novelty of a planned research project. ${ }^{14}$ Peer review thus serves the selection of truth claims and the construction of progress of knowledge. Competent scientific experts decide about research proposals and contributions and therefore also about the allocation of chances of individual scientists, working groups or research institutions to obtain reputation and financial resources (cf. Luhmann 1974: 236-238; Neidhardt 2010: 281-282; Weingart 2005: 284-292).

The review process precedes the publication of a text or the approval of a project proposal. In this context, the extent of implementation and standardisation of mechanisms of evaluation differ between the disciplines. This finding was documented during the interviews and will be presented in the following sections for the natural and engineering sciences, on the one hand, and the humanities and social sciences, on the other.

\subsection{Peer review in the natural and engineering sciences}

In the natural and engineering sciences, institutionalised peer review is very common and refers especially to journals (cf. DFG 2005: 23-25). In medical engineering, parts of the conference proceedings are also subject to rigorous review, particularly in areas that are pertinent to information technology. In interviews with mathematicians, the assessment of reliability and capacity

14 Difficulties of philosophy of science to establish and stick to verifiable and measurable criteria have been discussed in the literature and shall not be repeated here (cf. for example, Neidhardt 2006; Weller 2004). The focus here is on practical experience and attitudes of the interviewees towards peer review in their respective disciplines. 
of the peer-review system is more positive than among physicists or medical engineers. For mathematics, two normative conditions that support the formal scientific communication system and influence the submission and accessibility of contributions on the level of the publication system have been mentioned. ${ }^{15}$ The normative structure can be completed by two additional principles: 'Highquality archiving, high-quality refereeing' (M. Grötschel). With respect to the further reception of research results, the latter is of fundamental importance. The reading of mathematical articles is arduous and time-consuming for peers as well. Selecting contributions in terms of their worthiness before publication saves potential recipients a significant amount of time.

Therefore, specialised review is of high importance to us, so that we are only confronted with articles that are of high quality and where a competent colleague has already evaluated that the content is okay and that you can rely on that. (M. Grötschel)

Thus, at $50-80 \%$, rejection rates are high. The time of the review process is also not to be underestimated, as sometimes two years can pass between submission and publication.

The high quality of review does not provide an absolute but rather a widely acknowledged trustworthiness in scientific quality of the mathematical contributions. However, it also sets high standards regarding the competence of the reviewers and the willingness of the peers to participate voluntarily in the complex review process. ${ }^{16}$ To ensure motivation and quality of evaluation, editors of a journal often compile a team of reviewers comprising an experienced colleague and a doctoral student who currently works in the respective fields, 'so that you have two perspectives, since the doctoral student is interested in reading the article because he might gain something from the content, and the one who has an overview can assess the contribution' (M. Grötschel).

Other problems regarding the implementation of peer review and maintenance of its reliability are mentioned for physics and medical engineering. The massive increase of submissions, the trend to divide research results into 'least publishable units' and shorter half-life periods of research claims lead to excessive demands on reviewers. ${ }^{17}$ First, it is increasingly difficult to find reviewers at all, and second, they cannot always deal with the number of

15 See 3.1.

16 This is also true regarding the establishment and maintenance of databases in which a representative amount of test data for different issues is collected. The interviewee in this context points to a basic consensus about the norms of 'high-quality archiving' (M. Grötschel) and a strong willingness among peers to provide voluntary services of quality assurance.

17 Hornbostelet al. (2009) estimate a half-life period of 5.2 to 6.9 years for different areas of physics (cf. Hornbostel et al. 2009: 28). According to a study by the DFG in 2005, publication rates in natural 
submitted contributions. In terms of time, the resources are not sufficient to read all contributions in detail, to test experimental claims or even to identify fraud. Administrative demands on young researchers, for example, a certain number of peer-reviewed publications among doctoral students, increase the overburdening of the review system. ${ }^{18}$ To ease the workload for editors as well as reviewers, new technologies - such as plagiarism software and online editorial management systems - are increasingly used. Digital networking and the establishment of databases make it easier for editors to search for appropriate and willing reviewers.

The interviewees also criticised the lack of incentives to do the review. A potentially negative balancing of cost-benefit calculation decreases the willingness to review and contributes to the fact that the 'review system is not able to fulfil what we expect of it' (S. Großmann). The operational capability of the system is based on the willingness of scientists to provide part of their work resources to test the intellectual property of others. This occurs against a structural connection, which one engineer described as follows:

We have a dramatically increasing number of submissions ... but the highquality contributions only increase marginally. And that is understandable since science and the quality of scientific research institutions in the world do not increase exponentially but slowly and linearly. (O. Dössel)

The reviewers now not only write reviews about the few notable contributions but have to report about all submissions, even 'if they are no good' (S. Großmann). In contrast to the practice in mathematics to create incentives to review through disciplinary interest as described above, in physics and medical engineering, there appears to be a correlation between an increasing volume of communication and increasing opportunity costs of the reviewers. As a result, reviewers are not selected because of their competence but because of their willingness. This also leads to the fact that journals

continue to go lower with the qualification of the reviewers, which is then a vicious cycle, since, if the reviewer is clueless and ... thinks it is all fine, then, of course, a lot of articles can be published that just have no relevance for science. (O. Dössel)

and engineering sciences are at 21.8 and 17.6 journal articles per author respectively (including coauthorship) for a period of five years (cf. DFG 2005: 22-25).

18 The DFG therefore recommends not demanding a minimum but a maximum number of publications in the framework of applications (cf. DFG 2013: 20-21). 
If the scientific quality of publications goes down, the value of the peer-review system will eventually be put into question.

In both disciplines, the peer-review system faces a discrepancy between its claim for quality assurance and its practical capacity. To keep the state of knowledge up to date, there are forms of communication beyond formal publication structures in both fields. In medical engineering, the conference as place of interaction is gaining importance for the exchange of information: 'It is considered to be faster since the classic publication system is a bit slower ... with the review process' (O. Dössel). In physics, aside from verbal exchange in the framework of conferences, private communications and informal dissemination of pre-print texts among peers are also common. ${ }^{19}$ The latter are usually sent out within the respective communities and critical feedback is received from peers before the reviewed printing. Research results are thus disseminated within the community before the work has been formally registered. Still, there are seldom conflicts about priority. The peers are in closed communities and know about each other and who works on which projects. Expectations regarding the honesty of the colleagues are ensured via informal mechanisms of sanctions and prove to be a functional equivalent for the performance of formalised peer review. 'If a fundamental new finding is indeed discovered, then all involved know where it occurred ... and if then someone says it differently then there is an ostracism in the community, so it is corrected' (S. Großmann). ${ }^{20}$

\subsection{Peer review in the humanities and social sciences}

In contrast to the natural and engineering sciences, empirical examples from the history of science and art, sociology and law show a broader variety of publication media overall, and peer review covers a smaller range.

History of science is characterised by both interview partners as a classical humanities discipline with a small community compared to the natural sciences. The linguistic dichotomy is a structural characteristic of the communication system. English and German (or the respective national language) are used in parallel and cover different spaces of publication and reception. These are also reflected by the relevance of the different publication media. In German history of science, the monograph is predominant, 'which you are responsible

19 In this connection, the technological opportunities of digitisation are essential.

20 Informal knowledge about colleagues - 'you just know what has already been done' (S. Großmann) - and consensual normative expectations make it possible to reduce the complexity of the scientific communication system by means of the mechanism of trust (cf. Luhmann 1968: 21-29). 
for and which you have written yourself' (H.-J. Rheinberger). ${ }^{21}$ The evaluation of monographs depends on the place of publication. Especially regarding theses - relevant for access to the system of science - this is determined by economic and time-bound factors.

The evaluation of contributions in history of science is time-consuming and takes up to two years, even regarding submissions to highly respected journals, especially 'if all editors read all texts, that takes time, as they are absolute experts and very busy' (M. Ash). Rejections are rare. Usually there is a request for revision before printing. The specialised market of publication is fragmented to a strong degree and provides access to different price segments and speed regarding publication. This kind of landscape of publishers guarantees authors the publication of their work - provided that the payment of publication fees is secured. The selection of manuscripts is done by the funders and publishers. Some publishers are known to decide about worthiness of publication, not according to content but according to economic factors:

If you come with funding, you'll be printed. Lit is a bit higher quality than Lang, ${ }^{[22]}$ but if you want to publish fast, you know where to go and that actually presents a small dilemma. Younger researchers who are impatient go there because they want to publish and they are warned by us elders that this may not be the right thing for their reputation, but they don't listen. (M. Ash)

In the United States, peer review is a prerequisite of quality assurance and is a standard used by publishers of journal articles and monographs. Meanwhile, there are also standardised peer-review processes in German journals. Both interview partners reported in this context about low rejection rates in the evaluation of journal articles. Rejections are mainly not due to lack of quality but due to the topic of the contribution, which does not always fit the scope of the journal. This development can be traced to differences in the respective publishing system:

What we have here in the German-speaking sphere ... is what I would like to call a printing house mentality, i.e. the publishing companies are printing factories. As they were in the $16^{\text {th }}$ century, they still are today with the help of state funds. Quality assurance does not play a role in such a situation, or at best a small role. Now it has to play a role because everybody talks about peer review. Thus, the publishers have begun to institutionalise this,

21 Its reach is limited to the German-speaking sphere; international reception requires additional publication in English.

22 Lit and Lang are German publishers mostly publishing dissertations. 
but it would have never happened by itself, while in the USA the leading university presses and also the small university presses have had peer review for decades. (M. Ash)

According to its self-description, German legal studies are characterised by strong internal controversy due to conflicting legal interpretations ${ }^{23}$ and the duality of academic science and judicial practice. Quality control in this discipline is done by a small number of people. Evaluation of contributions is hardly standardised and conducted in part by judicial practitioners and in part by scholars. The evaluation is frequently done by 'an editor, who is often a lawyer. Then it is often special journals where the lawyer has a relatively lot of expertise, he then makes a pre-selection, and then it goes back to the editors who make a decision' (A. Peukert). The compilation of contributions into conference volumes is done by the speakers who participate after invitation by the organisers of the conference. In legal studies, personal networks are more important for developing reputation than the formal submission of contributions in reaction to calls for papers.

Structural similarities can be found in German-speaking sociology. In addition to the model of the deciding editor who, without assigning external reviewers, has the role of gatekeeper, standardised peer-review processes are partly institutionalised in journals. However, only about a third of new contributions are published as journal articles, of which again one third passes through the peer-review process. The typical place of publication in this discipline is anthologies, which are not subject to review before publication (cf. Volkmann et al. 2014: 203; Wissenschaftsrat 2008: 20-23). ${ }^{24}$ Demands for broad and standardised peer review are a reaction to the 'flood of anthologies' (U. Schimank) but have paradoxical effects:

The people first try it in journals. The journals have, however, not increased in volume or in numbers, and that means the pressure to publish more, of course more quality, leads to increased rejection rates and that you have to publish your rejected material somewhere else, and that's the anthologies. This means, paradoxically, the pressure that was to move away from the anthologies, now moves into the anthologies. (U. Schimank) ${ }^{25}$

23 This pertains to the dogmatically oriented continental European jurisprudence. In the Anglo-Saxon world, a social science perspective of law prevails.

24 According to the interviewee, monographs and anthologies are only reviewed in German-speaking sociology and on special occasions.

25 A similar effect was described by the interviewee from medical engineering (see section 3.2). 
Sociology describes itself as a multi-paradigmatic discipline with a small community, which is fragmented into competing theoretical and methodological fields (cf. also Münch 2009). The affiliation with a specific sociological field influences the results of the peer review process and success in job interviews. This is especially true for sociological theory, 'the most disrupted field in sociology' (U. Schimank). In contrast to mathematics, basic paradigmatic controversies lead to a low cognitive integration of the discipline and can be destructive in the review process.

If you dare to submit such an article to a journal, then you can be sure that the two colleagues who should peer review it, belong to another camp and will tear it apart. Then you rather publish the things you consider original in anthologies where nobody gets in your business. (U. Schimank)

On the other hand, the discussion of knowledge claims may profit from scant peer-review coverage, above all if advancement of knowledge not only denotes accumulation of empirical findings but also includes innovative contributions that open up new pathways (cf. Weingart 2003: 25-26). Standardised review processes refer to pre-defined criteria (cf. DFG 2013), and are thus based on the existing state of knowledge of a discipline. As a result, peer review in sociology creates mainstreaming effects while media without formal evaluation provide 'free space for unorthodox things' (U. Schimank). In view of the diversity of paradigms, anthologies as media of publication show a functionality which 'refers to the process of gaining knowledge in these fought-about fields even though it is clear that you cannot differentiate between original idea and nonsense any longer. The reader has to do that on his own then' (U. Schimank).

The interviewee from the history of art also criticized standardisation and a lack of clarity as consequences of standardised peer review. At the time of the interview, his discipline operated in five languages. At the same time, the scientific community had a functioning global association whose communicative exchange made a broad peer-review process seem not only unnecessary but also as an 'artificial, strange form of evaluation' (H. Bredekamp). The community is unwilling to subject their publications to a standardised evaluation, '[p] eer reviewing is against quality if you take quality to be methodological avant-garde' (H. Bredekamp). Here, a specific normative expectation to progress in knowledge is expressed in the history of art, which puts originality and deviation from the mainstream of scientific work in the forefront.

In mathematics, physics, and medical engineering, a relatively strong degree of cognitive homogeneity can be assumed due to the inherent structure of natural science knowledge (cf. Gritzmann 2009; Weingart 2003: 25-26). 
The example of mathematics additionally shows normative consensus in the scientific community. The self-steering function of peer review is of high importance in this discipline in order to select research contributions according to the criterion of scientific quality before publication. Problems emerge as a result of the high standards of quality that potential reviewers need to fulfil as well as the time required for the evaluations. In medical engineering and physics, the difficulties are in maintaining the reviewer system, especially in the dimension of time. Scientists respond to the high pace of new knowledge and the competition for priority with a high frequency of publications of journal articles, which overwhelms the resources available for evaluation.

In contrast to the natural and engineering sciences, the humanities and social sciences show a stronger heterogeneity, which corresponds to a comparatively low degree of institutionalisation of evaluation processes. The example of legal studies reveals an influential factor in the dual structure of the communication community. Within the two contexts of academic science and judicial practice, the processes of quality assurance are organised differently. Both have the low prominence and normative significance of peer-review processes in common, and thus a low number of potentially available reviewers. In history of science and sociology, the extent of institutionalised peer review depends on the medium of publication. Another aspect can be found in the evaluation system of history of science and history of art at the level of responsible organisations. Aside from the regional, financial and disciplinary variations in the publishers' services, the relevance these organisations attribute to quality control is essential for the institutionalisation of peer review.

The interview partner from mathematics welcomed the selective function of the peer-review system, as the evaluation according to clearly defined criteria of quality ensures that irrelevant contributions do not appear in the formal publication system in the first place. The interviewees from sociology and history of art provided epistemic reasons against such a pre-selection of contributions. On the one hand, predefined criteria for evaluation do not differentiate enough between diverging paradigms, while on the other hand, they limit the freedom of research.

\section{Bibliometric measuring}

While contributions are evaluated by peer review with respect to qualitative criteria, bibliometric indicators formalise the process of receptive attention and depict effects of selection of scientific communication (cf. Marx 2009: 132133). Citation analysis and index numbers can be used to measure scientific productivity and performance. Two areas where performance indicators are 
applied were discussed controversially in the interviews: the orientation function of impact factors and their application in the framework of processes of allocation.

In the next section, the selective function of impact factors is evaluated from the perspective of scientists as producers of knowledge. Two points of reference have evolved as worth focusing on: the interview partners discussed performance indicators in general and the journal impact factor in particular in the contexts of individual reputation and quality of content. The discussion here again takes into consideration disciplinary as criteria of ordering to compare their heterogeneous positions. Unintended structural consequences at the level of the publication system are elaborated in this context as well.

\subsection{The formalisation of reputation through the journal impact factor}

Not only can reputation be attributed to individual scientists or working groups and scientific organisations, such as research institutions, but also to publishing companies and journals. A contribution in renowned media can then be considered an indicator of individual reputation. Highly reputed places of publication indicate the scientific recognition of those who have access to these places (cf. Luhmann 1974: 237-238 \& 1992: 245-251; Weingart 2003: 22-35). In the publication system, the journal impact factor (JIF) is a standardised, quantitative measurement tool which can formally depict the impact of journals on the basis of citation analysis. ${ }^{26}$ The relevance of the journal article within the respective publication culture is essential for the JIF's degree of institutionalisation. In the humanities and social sciences, impact factors are more often provided in international journals and are also weakly institutionalised (cf. International Mathematical Union 2008: 8; Nederhof 2006). Performance indicators are mainly used here in the framework of employment interviews.

In the natural sciences and technological disciplines, the JIF is common at the level of the publication system and bibliometrically depicts the hierarchy of publication media (cf. Marx 2009: 134). ${ }^{27}$ However, the adequacy of the impact factors is viewed differently in these disciplines. The interviewee from medical engineering viewed the JIF as significant in the strategic choice of place of publication. In this discipline, the JIF of renowned journals is between 1 and maximum 2, and 'that's the ambition of my doctoral students that they

26 The journal impact factor is calculated as the number of citations in the year of reference to all articles of the previous two years divided by the number of all articles in the previous two years (cf. Havemann 2009: 49; Hornbostel et al. 2009: 28-29).

27 The data on bibliometric analysis in the natural and technological sciences are primarily based on the science citation index (SCI) of Thomson Reuters (cf. http://wokinfo.com/citationconnection/). 
want to get in there' (O. Dössel). The number of these top-ranked journals is small (approximately 10); most journals have a JIF of $<1$ and 'that's where you go if it didn't work out somewhere else' (O. Dössel). In a positive as well as negative way, impact factors serve as points of reference of scientific quality of publication media. The consequence is that a journal with a JIF of 0.2 is also not taken seriously among colleagues' (O. Dössel).

The strong orientation function of impact factors also influences the development of digital infrastructures in the publication system. According to the interviewee, the potential use of reputation is clearly connected to the establishment of electronic search engines. A research result only enters the citation cycle 'if it was placed with some publisher' (O. Dössel). Informal places of publication, such as homepages, which are not listed in established search engines and citation databases are not used by peers. Bibliometric formalisation efforts, however, influence gold open access. Here, there is a correlative connection between the implementation of impact factors and the design of fees of OA publishers: while subscription fees of high-ranked journals, such as journals of the IEEE (Institute of Electrical and Electronics Engineers), have decreased, publication fees in the OA field increased with the respective JIF. For example, PLoS has gained a strong reputation. Its thematically specialised journals have high impact factors, but they also demand high APCs. ${ }^{28}$ From the perspective of the interviewee, APCs prove to be a good investment in the OA field, 'We do that more often now, the trend clearly being that open access journals also have an impact factor, are officially listed and measured at Thomson Reuters' (O. Dössel).

In physics, the impact factor also indicates reputation. One particularity here is the discrepancy between informal circulation of pre-print versions and formally completed works. Current contributions are usually discussed and used within the community in parallel with submission, so that the peerreviewed published versions lose their character of novelty. The peers thus face a fundamental question:

Why do we still publish ... if we have already disseminated it some other way. And my conclusion is that it is published mainly due to prestigious reasons and because of the proposals to third party funders. This may be a harsh accusation but I think it is like that because we already know everything when it appears, so why does it have to appear? (S. Großmann)

28 IEEE, the Institute of Electrical and Electronics Engineers (https://www.ieee.org/) publishes several journals on the basis of the subscription model. Members of the IEEE have cheap access to high-ranked journals. PloS is an established OA medium in the natural and technological sciences that is financed through publication fees. 
Formally registered publications no longer have a central function for the continuation of scientific knowledge production, but they can be cited. In physics, impact factors provide incentives for formally certified publishing. The standardised measures make comparisons of production outputs easier in a discipline in which 'prestige and counts in publication lists' (S. Großmann) have far-reaching influence on career and research opportunities.

In mathematics, the impact factors of journals also correlate with the hierarchy of the media of publication. According to the interviewee, peers do not, however, orient their publishing behaviour towards the results of scientometrics and are sceptical of the mechanical use of statistical measures (cf. International Mathematical Union 2008). The criticism thus is not aimed at the capability of bibliometric measures as such but at publication-based indicators as representative of scientific quality. Fundamental criticism is levelled at considering the database as objective. It is always distorted due to the citation behaviour of researchers. 'They measure something but what is really measured? And can you in fact prove that they measure that which you think is being measured?' (M. Grötschel). ${ }^{29}$ Complementary and negative citations as well as strategic citations create attention. Consequently, increased citation rates are not really a positive indication of scientific quality. Moreover, reward mechanisms such as prizes, which promise a nearly irreversible benefit for reputation (cf. Weingart \& Winterhager 1984: 144), are not bound to impact points. The highest award in mathematics, the Fields Medal, has been awarded to persons whose citation numbers were lower by a factor of 100 than those of their competitors. In mathematics, people are cautious of using publicationbased indicators outside of the contexts of calculation and application.

The interviewee from history of art also had epistemic doubts regarding the significance of performance indicators in general and the journal impact factor in particular. Bibliometric measurement procedures are based on a basic flaw in categories. Quality cannot be measured quantitatively, so performance indicators in general do not allow positive conclusions on quality. In addition, citation indicators can trace a diffuse picture of the effectiveness and visibility of research contributions, but their validity is methodologically tenuous due to irrelevant factors of influence in the social dimension. Thus, citation cartels and the informal obligation to cite gatekeepers have a distorting impact on the distribution of attention. Power cannot be entirely excluded from communication of research results in science.

In addition, citation rates are influenced by the assumed respectability of the place of publication. Impact factors may stabilise respective assumptions

29 The interviewee also mentioned the difficulties of calculating impact factors in a valid manner and to standardise them for comparison of disciplines. This issue is discussed extensively in the scientometric literature (cf. for example, Bourke \& Butler 1996; Chang 2013; Nederhof 2006). 
without necessarily connecting them to quality or progress of knowledge. On the contrary, normative expectations of the worthiness of citation of publication media can limit the freedom of scientific visions. Advancement of knowledge is promoted at a few places of publication on the Internet 'which nobody cites, where the wildest, the freest theses are formulated. Everybody writes what they are not allowed to write when impact is involved and that's where the show is' (H. Bredekamp). In history of art, parallel infrastructures beyond the institutionalised criteria of evaluation emerge 'which nobody is allowed to cite, but which can be more important than published arguments' (H. Bredekamp).

The question whether 'the informal is a sign of low quality' (A. Peukert) is also at issue in studies of law, a discipline which, according to the interviewee, is structured controversially on the inside and autarchically on the outside. There is, however, consensus regarding the use of publication-based indicators. Quantitative evaluation mechanisms cannot create qualitative judgements 'because you can't measure that from the outside' (A. Peukert). Within the community, the evaluation mechanisms and opportunities for participation are weakly formalised without having a negative impact on function. In printed media, the hierarchies are well known and are documented, especially in the choice of the type of publication. Addressing one's own contributions could lead to prominence on the one hand or reputation on the other (cf. Weingart 2003: 26-28). 'The closer you go to the daily practice in law, the lower, I would say, is the scholarly reputation of performance, and that's where journals are structured differently, which degree of abstraction they allow and wish for' (A. Peukert). The allocation of attention is determined by the place of publication: 'Everybody goes to Beck Online and if a paper is not in there, then it is effectively invisible' (A. Peukert). ${ }^{30}$

In contrast to the internationally received journals in the natural and engineering sciences, the journals in the German-speaking humanities and social sciences are listed to a much smaller degree in the Thomson Reuters citation databases (cf. Hornbostel et al. 2009: 19-27). The interviewee from sociology illustrated this finding by means of citation rates in the Social Science Citation Index (SSCI). The two most important US journals, American Journal of Sociology and American Sociological Review, have about 5000 citations per year. In contrast, the most important German journal, the Kölner Zeitschrift für Soziologie und Sozialpsychologie, only has about 250 citations per year. Such discrepancies indicate a dubious validity of the SSCI in the social sciences. The citation index of Google Scholar is a bit better but does not provide reliable

30 Visibility by publishing at Beck is restricted to the German-speaking sphere. In the English-speaking field, there are repositories, for example, the Social Science Research Network (cf. http://www.ssrn.com/). 
reference values due to a lack of transparency. 'We do not know what Google Scholar measures and how they do that; they don't tell us' (U. Schimank). ${ }^{31}$

Another methodological reservation results from discipline-specific publication habits. In the history of science, some journals have an impact factor whose validity is already limited due to the comparatively low rates of publications within the field. The peers are aware of the informally valid hierarchy of publishers and professional societies. For example, there is consensus among authors as well as editors that the journal ISIS is at the top of the renowned places of publication, 'regardless of whether one associates it with an impact factor or not' (H.-J. Rheinberger). ${ }^{32}$ Impact factors are therefore an addendum that neither provides the peers nor the responsible organisations with additional information. 'Everybody knows who they are' (M. Ash).

\subsection{The practical relevance of performance indicators for allocative decisions}

The evaluation of the interviews pointed to the different degrees of institutionalisation of impact factors in the individual disciplines. The interviewees differed in their opinions about the advantages and disadvantages for their respective fields. In all interviews there were, however, indications that, from the perspective of scientists, performance indicators represent a 'measurement from outside'. Thus, these are external evaluations that are adapted and implemented to different degrees in the scientific communities. The different degrees of practical relevance of performance indicators can be shown by means of evaluations of proposals and employment interviews.

Performance indicators suggest a simple handling of distributive decisions as they abstract from specialised knowledge and offer standardised evaluation criteria which are parallel to elaborate peer-review processes. Performance indicators thus increasingly serve as an instrument to make and legitimise allocative decisions (cf. Weingart \& Winterhager 1984: 18-23). The interviewees from the humanities and sociology rejected this instrumental function of external evaluation procedures. One argument focused on the disciplinespecific landscape of publication, which serves a variety of different types of publication and is insufficiently registered in citation indices.

As the interviewee from legal studies reported, journals in his field do not have an impact factor, so that research organisations have to depend on the

31 Google Scholar is currently limited to articles from 2009 to 2013. Moreover, the data pool of the source items is unclear. Google itself notes, 'Since Google Scholar indexes articles from a large number of websites, we can't always tell in which journal a particular article has been published' (cf. http://scholar. google.de/intl/de/scholar/metrics.html\#coverage).

32 ISIS was founded in 1912, and is the oldest and most disseminated English journal of history of science (cf. http://www.press.uchicago.edu/ucp/journals/journal/isis.html). 
inside knowledge of their reviewers and qualitative evaluation criteria. From the outside perspective of administration, which often evaluates research proposals from different disciplines or interdisciplinary working groups, this makes it more difficult to compare research output. Reviewers from other disciplines do not have insight into the informally organised hierarchy of places of publication. The opportunities to classify publication lists in legal studies adequately are generally not given due to the use of interdisciplinary reviewers. 'The legal scholars hope that there is at least one of them in this group who will explain, if necessary, to the others what these kinds of media are' (A. Peukert). Meanwhile, there is pressure from the side of the responsible organisations to 'introduce formalised procedures and achieve rankings and to signal that this is conducted seriously' (A. Peukert).

Interviewees from history of science, sociology and history of art also mentioned administrative efforts to quantify science and research. The historians of science revealed a coherent opinion and seemed unwilling to use any form of evaluation. 'I am also surprised but history still seems to reject this kind of thinking' (M. Ash). Impact factors are considered disruptive in recruitment interviews and as not having any relevance. The European Reference Index for the Humanities (ERIH), created in 2002 by the European Science Foundation as a citation index of European humanities and revised many times since, is 'simply not noticed' in the scientific community (M. Ash). ${ }^{33}$

The interview partner from sociology described the handling of impact factors in the framework of recruitment interviews in a more heterogeneous way. Young researchers ascribe a lot of importance to their accumulated impact points and list their publications according to formal evaluation mechanisms. 'First they list the contributions in international peer-reviewed journals, then national peer-reviewed journals, sometimes with impact factor, where you have them and then comes the rest, the crappy rest' (U. Schimank). The interviewee did not, however, ascribe a legitimising function to the impact factors. ${ }^{34}$ Instead, he made it clear that their use for distributive decisions suggests loss of reputation. 'There are even audacious colleagues who take this seriously, because in our field, you can't take that seriously' (U. Schimank). A similar effect, although not motivated epistemically, was stated by the interviewee from history of art. 'Those who start mentioning the impact factor hardly have a say' (H. Bredekamp). Under the primacy of methodological avant-garde performance, indicators can explicitly turn out to be a negative criterion of selection.

33 Cf. http://www.esf.org/media-centre/ext-single-news/article/european-science-foundation-releasesthe-2011-revised-lists-of-european-research-index-for-humanitie.html and http://www.esf.org/index. php?id=4813.

34 See section 5.1. 
The interviewee from mathematics emphasised the risks of using publication-based indicators insofar as these replace scientific truth and guide allocative decisions (cf. Luhmann 1974: 237). The accumulation of high impact numbers in publication lists is not a central recruitment criterion. Rather, the respective performances in publishing are evaluated individually and in their context. The interviewee feared that the institutionalisation of performance indicators could lead to a bureaucratic and meaningless administration of career opportunities. 'We just don't want to have an evaluation mechanism that calculates the h-index and other indicators and then automatically assigns scientists to a certain category of quality' (M. Grötschel). ${ }^{35}$ One criticism is aimed at the reference size of the journal impact factor which measures the overall impact of the journal but not that of the individual contributions (cf. Marx 2009). Authors with less-cited contributions could then falsely take the credit - due to the success of other authors. Similar to the principle of highquality reviewing before publication, the evaluation of individual scientists before recruitment is not possible without the expertise of competent peers or 'the individual assessment of the person and his or her performance' (M. Grötschel).

While the interviewees from mathematics, law and history of science strongly criticized the reduction to a quantitative performance measurement, it is precisely this that makes the journal impact factor attractive, according to a medical engineer: 'It is the only thing they can really count' (O. Dössel). In the context of recruitment procedures, performance indicators provide a standardised criterion of evaluation, which makes it easier to compare research output. Aside from other, soft factors, such as the evaluation of the topic, the median impact value of an applicant is 'one point among many, which can easily be measured and is therefore significant' (O. Dössel). Performance indicators, such as the impact factor, do not function as an exclusive criterion of selection, but are part of further decisions in evaluation. According to the interviewee from physics, cost-benefit calculations as well as a lack of alternatives also contribute to the use of performance indicators in recruitment procedures. 'Checking the publication lists in detail is no longer possible because of the sheer mass of publications in the lists, and that's why we almost always end up with this bibliometric indicator' (S. Großmann). Adaptations on behalf of the scientists - publishing new research results in small units and in rapid succession to gain impact points - influence the structure of the publication system. 'It's definitely that way that publishing in general has followed external measurability’ (S. Großmann).

35 The Hirsch Index (h-index) surveys the performance of individual persons on the basis of the number and citation of published works (cf. Hirsch 2005). 
From the perspective of scientists as producers of knowledge, the possibilities and limitations of bibliometric measuring are viewed differentially. Impact factors can - insofar as they are considered a metric reflection of the hierarchy of media of publication - make selection processes of suitable places of publication easier and reduce the overhead costs of science (cf. Luhmann 1992: 248-251). As the examples from medical engineering and physics show, in a rapidly growing publication system, the journal impact factor proves to be a functional equivalent of experiential knowledge about reputation. At the same time, high impact values, in connection with quality assumptions, indicate use for reputation and become established in the structure of motivation of science (for example, via the certification function of ranked journals). In both disciplines, the orientation towards performance indicators influences individual publication behaviour as well as choices of selection in recruitment procedures. The application of publication-based indicators enables a standardised measurement of research performances and comparison. In cases of high numbers of applicants, it is also a shortcut to evaluate publication lists. In contrast to such pragmatic advantages, in mathematics, there are more reservations regarding a widespread use of performance indicators. Methodological problems of calculation and the general loss of contextual information in quantitative indicators lead to a restricted use of performance indicators in mathematics.

In the humanities and social sciences, performance indicators are hardly or only weakly institutionalised due to the small and fragmented publication landscape in these fields. Methodological aspects, for example, the lower coverage of publication types or distorting effects due to citation behaviours, limit the validity of publication-based indicators. Moreover, epistemic reasons, such as the categorical distinction between quality and quantity, strengthen the mostly negative attitude of scientists towards the use of performance indicators.

\section{Conclusion}

The results of this case study illustrate that differences with respect to time frames, contents and social organisation in the various disciplines constitute specific publication behaviour. These have effects on the structure of the publication system as well as the development and interaction of responsible organisations. Taking into account current dynamics of change, such as digitisation, economisation and intensified observation of scientific productivity from outside, structural connections of the system of science in the respective disciplinary contexts can be seen. For example, there is a fundamental connection 
between the variety of publication types used and the requirements towards the presentation and reception of research results. Aside from epistemic factors, the latter determine the different relevance of digital and analogue forms of publication. Differences of the practical relevance of digitisation moreover have an effect on the dissemination of open access. Further influential factors lie in the financing models of gold open access and the attitudes of the scientific community towards publication fees, on the one hand, and expectations towards costs and benefits of OA publishing, on the other.

Aside from different mechanisms of scientific publishing that refer to one another, and which influence the development of digitisation and open access, the empirical material also provided insight into the steering function of peer review and bibliometric performance measurement. In the natural and engineering sciences, evaluation mechanisms - qualitative peer reviewing and quantitative performance measurement - are in general more strongly institutionalised than in the humanities and social sciences. Due to feedback effects, there are changes in the publication system of these disciplines. Such changes can be seen, for example, in the preferred types of publications or in the increasing frequency of publications in small units. The medium of reputation turned out to be a significant dimension that directly influences the publication behaviour of the peers. Changes that, as in the case of gold open access or bibliometric performance measurement, concern the publication infrastructure, in turn affect the incentive structures of scientific publishing. The analysis has shown that the scientific communication system appears to consist of diverse, mutually influencing factors.

\section{References}

Andermann, H. \& Degkwitz, A. 2004. Neue Ansätze in der wissenschaftlichen Informationsversorgung: Ein Überblick. Historical Social Research, 29(1):6-55. Retrieved from http://nbn-resolving.de/urn:nbn:de:0168-ssoar-50509 [Accessed 13 January 2015].

Antelmann, K. 2006. Self-archiving practice and the influence of publisher policies in the social sciences. Learned Publishing, 19(2):85-95. Retrieved from http://www.ingentaconnect.com/content/alpsp/lp/2006/00000019/00000002/ art00002 [Accessed 4 March 2015].

Boehm, G. 2009. Publikationsverhalten in der Kunstgeschichte/Kunstwissenschaft. In Alexander von Humboldt Stiftung (ed.). Publikationsverhalten in unterschiedlichen Disziplinen: Beiträge zur Beurteilung von Forschungsleistungen. Second edition. Diskussionspapiere der Alexander von Humboldt Stiftung, 12/2009. Bonn, 62-63. 
Bogner, A., Littig, B. \& Menz, W. 2014. Interviews mit Experten: Eine praxisorientierte Einführung. Wiesbaden: Springer.

Bourke, P. \& Butler, L. 1996. Publication types, citation rates and evaluation. Scientometrics, 37(3):473-494.

Chang, Y.-W. 2013. A comparison of citation contexts between natural sciences and social sciences and humanities. Scientometrics, 96:535-553.

DFG (Deutsche Forschungsgemeinschaft). 2005a. Publikationsstrategien im Wandel? Ergebnisse einer Umfrage zum Publikations- und Rezeptionsverhalten unter besonderer Berücksichtigung von Open Access. Tabellenband. Retrieved from http://www.dfg. de/download/pdf/dfg_im_profil/evaluation_statistik/programm_evaluation/ studie_publikationsstrategien_tabellenband.pdf [Accessed 2 January 2015].

DFG (Deutsche Forschungsgemeinschaft). 2013. Sicherung guter wissenschaftlicher Praxis. Denkschrift. Retrieved from http://www.dfg.de/download/pdf/dfg_im_ profil/reden_stellungnahmen/download/empfehlung_wiss_praxis_1310.pdf [Accessed 3 March 2015].

Eppelin, A., Pampel, H., Bandilla, W. \& Kacmirek, L. 2012. Umgang mit OpenAccess-Publikationsgebühren - die Situation in Deutschland 2010. GMS Medizin - Bibliothek - Information, 12(1/2):1-12. Retrieved from http://www.egms.de/ static/en/journals/mbi/2012-12/mbi000240.shtml [Accessed 25 February 2015].

Fry, J. \& Talja, S. 2007. The intellectual and social organization of academic fields and the shaping of digital resources. Journal of Information Science, 33(2):115-133.

Gargouri, Y., Larivière, V., Gingras, Y. \& Harnad, S. 2012. Green and gold open access percentages and growth, by discipline. arXiv. Retrieved from http://arxiv. org/abs/1206.3664 [Accessed 23 March 2015].

Gritzmann, P. 2009. Publikationsverhalten in der Mathematik. In Alexander von Humboldt Stiftung (ed.). Publikationsverhalten in unterschiedlichen Disziplinen: Beiträge zur Beurteilung von Forschungsleistungen. Second edition. Diskussionspapiere der Alexander von Humboldt Stiftung, 12/2009. Bonn, 82-83.

Haug, R.J. 2009. Publikationsverhalten in der Festkörperphysik. In Alexander von Humboldt Stiftung (ed.). Publikationsverhalten in unterschiedlichen Disziplinen: Beiträge zur Beurteilung von Forschungsleistungen. Second edition. Diskussionspapiere der Alexander von Humboldt Stiftung, 12/2009. Bonn, 95-98.

Havemann, F. 2009. Einführung in die Bibliometrie. Retrieved from http://www. wissenschaftsforschung.de/Havemann2009Bibliometrie.pdf [Accessed 17 March 2015].

Hirsch, J.E. 2005. An index to quantify an individual's scientific research output. In Proceedings of the National Academy of Sciences of the United States of America, 102(46):16569-16572.

Hornbostel, S., Klingsporn, B. \& Von Ins, M. 2009. Messung von Forschungsleistungen - eine Vermessenheit? In Alexander von Humboldt Stiftung (ed.). Publikationsverhalten in unterschiedlichen Disziplinen: Beiträge zur 
Beurteilung von Forschungsleistungen. Second edition. Diskussionspapiere der Alexander von Humboldt Stiftung, 12/2009. Bonn, 14-34.

IMU (International Mathematical Union). 2008. Citation statistics. Retrieved from http://www.mathunion.org/fileadmin/IMU/Report/CitationStatistics.pdf [Accessed 4 March 2015].

Kuckartz, U. 2007. Einführung in die computergestützte Analyse qualitativer Daten. Wiesbaden: VS Verlag für Sozialwissenschaften.

Lossau, N. 2008. Der Begriff 'Open Access'. In Der Deutschen UNESCOKommission (ed.). Open Access. Chancen und Herausforderungen. Ein Handbuch. Köln: Gebrüder Kopp, 18-22.

Luhmann, N. 1968. Vertrauen. Ein Mechanismus der Reduktion sozialer Komplexität. Stuttgart: Ferdinand Enke.

Luhmann, N. 1974. Selbststeuerung der Wissenschaft. In Soziologische Aufklärung. Aufsätze zur Theorie sozialer Systeme. (Ders.) Opladen: Westdeutscher, 232-252.

Luhmann, N. 1984. Die Wirtschaft der Gesellschaft als autopoietisches System. Zeitschrift für Soziologie, 13(4):308-327.

Luhmann, N. 1992. Die Wissenschaft der Gesellschaft. Frankfurt am Main: Suhrkamp.

Mantz, R. 2006. Open Access-Lizenzen und Rechtsübertragung bei Open AccessWerken. In G. Spindler (ed.). Rechtliche Rahmenbedingungen von Open AccessPublikationen. Göttingen: Universitätsverlag Göttingen, 55-103.

Marx, W. 2009. Forschungsbewertung auf der Basis von Zitierungen Aussagekraft und Grenzen der Methode. In Alexander von Humboldt Stiftung (ed.). Publikationsverhalten in unterschiedlichen Disziplinen: Beiträge zur Beurteilung von Forschungsleistungen. Second edition. Diskussionspapiere der Alexander von Humboldt Stiftung, 12/2009. Bonn, 132-155.

Münch, R. 2009. Publikationsverhalten in der Soziologie. In Alexander von Humboldt Stiftung (ed.). Publikationsverhalten in unterschiedlichen Disziplinen: Beiträge zur Beurteilung von Forschungsleistungen. Second edition. Diskussionspapiere der Alexander von Humboldt Stiftung, 12/2009. Bonn, 69-77.

Nederhof, A.J. 2006. Bibliometric monitoring of research performance in the social sciences and the humanities: A review. Scientometrics, 66(1):81-100.

Neidhardt, F. 2006. Fehlerquellen und Fehlerkontrollen in den Begutachtungssystemen der Wissenschaft. In S. Hornbostel \& D. Simon (eds). Wieviel (In-) Transparenz ist notwendig? Peer review revisited. iFQ working paper no. 1, 7-13.

Neidhardt, F. 2010. Selbststeuerung der Wissenschaft: Peer Review. In D. Simon, A. Knie \& S. Hornbostel (eds). Handbuch Wissenschaftspolitik. Wiesbaden: VS Verlag für Sozialwissenschaften, 280-292.

Roxin, C. 2009. Publikationsverhalten im Bereich der Jurisprudenz. In Alexander von Humboldt Stiftung (ed.). Publikationsverhalten in unterschiedlichen Disziplinen: Beiträge zur Beurteilung von Forschungsleistungen. Second edition. Diskussionspapiere der Alexander von Humboldt Stiftung, 12/2009. Bonn, 64-66. 
Schreier, M. 2012. Qualitative content analysis in practice. Thousand Oaks, CA: Sage. Swan, A. 2007. Open access and the progress of science. The American Scientist, 95:198-200.

Taubert, N. 2010. Open access. In D. Simon, A. Knie \& S. Hornbostel (eds). Handbuch Wissenschaftspolitik. Wiesbaden: VS Verlag für Sozialwissenschaften, 310-321.

Taubert, N. \& Schön, K. 2014. Online-Konsultation 'Publikationssystem'. Dokumentation und Auswertung. Retrieved from http://edoc.bbaw.de/volltexte/2014/2629/pdf/ BBAW_Publikationssystem_Taubert.pdf [Accessed 8 January 2015].

Volkmann, U., Schimank, U. \& Rost, M. 2014. Two worlds of academic publishing: Chemistry and German sociology in comparison. Minerva, 52:187-212.

Weingart, P. 2003. Wissenschaftssoziologie. Bielefeld: Transcript.

Weingart, P. 2005. Die Stunde der Wahrheit? Zum Verhältnis der Wissenschaft zu Politik, Wirtschaft und Medien in der Wissensgesellschaft. Weilerswist: Velbrück Wissenschaft.

Weingart, P. \& Winterhager, M. 1984. Die Vermessung der Forschung. Theorie und Praxis der Wissenschaftsindikatoren. Frankfurt: Campus.

Weller, C. 2004. Beobachtungen wissenschaftlicher Selbstkontrolle. Qualität, Schwächen und die Zukunft des Peer Review-Verfahrens. Zeitschrift für Internationale Beziehungen, 11(2):365-394.

Wissenschaftsrat. 2008. Pilotstudie Forschungsrating Soziologie. Abschlussbericht der Bewertungsgruppe. Retrieved from http://www.wissenschaftsrat.de/download/ Forschungsrating/Dokumente/Grundlegende\%20Dokumente\%20zum\%20 Forschungsrating/8422-08.pdf [Accessed 2 March 2015]. 


\section{Recent Processes of Change from the Perspective of Academic Publishers}

Niels Taubert

Like science itself, the academic publishing companies are characterised by a high degree of heterogeneity. They vary strongly with regard to their size, their products, their willingness and capability to innovate - there is obviously a relationship of correspondence between the publishers and their characteristics, on the one hand, and the different areas of science and their forms of announcing research results, on the other. ${ }^{1}$ The 'Future of the Scholarly Communication System' interdisciplinary working group (IWG) invited representatives of three academic publishing companies as well as one editorial staffer to present this diversity and to ask which effects digitisation, economisation, an increased use of performance indicators, as well as medialisation have for the publication landscape. The objective of the discussions and interviews was to obtain a multi-layered picture of the publication landscape, which would reveal significant similarities and differences regarding the business models and positions towards the demands in science policy (for example, open access).

The evaluation of the conversations is organised as follows. In a first step, the four publishing companies - represented by the interviewees and their current position on the market - are introduced. Then, the effects the publishers have on the structure of the market is questioned. Here, the focus is on how the publishers position themselves with respect to central developments and which role they play with respect to the digitisation of the publication infrastructure. The spectrum of roles ranges from the protagonist, who actively participates in

1 Schimank \& Volkmann (2012: 170). 
the design of the process, to the defensive market participant who, for various reasons, cannot play an active role and is rather a victim of the development. In a third step, the attitudes of the publishers regarding demands in science policy for open access to publications are contrasted. In addition to the basic position towards this development, the attitude towards green and gold open access (OA) models is also of interest. A second important demand in science policy is the creation of transparency. Since especially public funds are used to finance the scholarly communication system, there are calls for transparency of the cash flow. The positions of the publishers on this issue are fleshed out in the fourth step. The evaluation concludes with a summary of the findings.

\section{Introduction of the publishing companies}

Interviews with representatives from the following companies were conducted:

- $\quad$ Springer Science+Business Media

- Angewandte Chemie/Wiley-VCH

- Walter de Gruyter

- $\quad$ Lucius \& Lucius

\subsection{Springer Science+Business Media}

The publishing group Springer Science+Business Media is a large publisher, and was represented by interviewees I-1 and I-2. According to the 2011 business report, the turnover was $€ 875.1$ million (Springer 2011: 5). The group publishes more than 2900 academic journals. The Web of Knowledge calculates a Journal Citation Report for 1293 of these journals. ${ }^{2}$ The majority belongs to the publishing company, and a large number of the journals are considered to be central in the respective discipline or field of research. Moreover, the group also publishes books and book series. The current digitisation project, Springer Book Archives, aims to make all titles that have been published since 1840 electronically available. It is assumed that after the project has been completed, a digital library will have been created that will include more than 100000 titles. Finally, a number of databases are also part of the portfolio of the group.

The size and structure of the company are the result of a decades-long strategy of growth. Particularly the past 15 years deserve special attention since

2 This and information on the other publishers were found in the 2011 Journal Citation Report. For this purpose, all journals of the group represented in the Science Citation Index (SCI), Social Science Citation Index (SSCI) and Arts and Humanities Citation Index (A \& HCI) were counted (see the Springer website under 'Imprints and Publishers', http://www.springer.com/?SGWID=1-102-0-0-0) 
the acquisition activities have developed dynamically in this period. In 1999, the Bertelsmann Group bought Springer Verlag and included the publishers Gabler, Teubner and Heinrich Vogel in the group BertelsmannSpringer. Four years later, in 2003, the financial investor Cinven and Candover purchased the publisher Kluwer Academics and BertelsmannSpringer and merged these publishing companies into the group Springer Science+Business Media. ${ }^{3}$ With the acquisition of VS Verlag and its integration into the group as Springer VS, the aggregation stopped for the time being. In the recent past, ownership once again changed. After the investment trusts EQT and GIC had acquired a 90\% share of the group in 2009 for $€ 2.3$ billion, it was announced in mid-July 2013 that the publisher had been sold for $€ 3.25$ billion to BC Partners. ${ }^{4}$

According to the company, Springer is a publisher that successfully operates in a global market and practises an international division of labour. Moreover, it views itself as a technological pioneer that advances and creates new developments in the context of digital publication. This became apparent in several passages of the interviews with the company's representatives. For example:

We are, of course, an international publishing company with GermanDutch roots since the merger with Kluwer Academic. Not everybody likes to hear this. We also meanwhile have more own employees in India than in Germany, and we are rapidly expanding in Asia, South America, and Africa. [...] What is really interesting, especially about Springer, which was not considered the most modern publisher, is that we were the first to provide an Internet platform for contents. Springer Link went live in 1996 - that is hard to imagine today. So, if people say Springer is a traditional publisher, oldfashioned and so on, then that is totally wrong. The revolution, especially in publishing, is behind us, that was the Internet. (I-1)

Due to its broad portfolio, the company has a significant position and is basically able to shape the market for academic publications together with other large publishing houses. The abovementioned strategy of acquisition has at the same time led to a reduction in the number of independent academic publishing companies and an increase in the number of journals belonging to Springer. In addition, the relationship to the customers of scientific publications - the

3 A short summary of the company's history can be found at http://www.springer.com/about+springer/ company+information/history?SGWID=1-175807-0-0-0.

4 See http://www.bloomberg.com/news/2013-06-19/bc-partners-to-buy-springer-science-for-4-4-billion. html. The short periods in which ownership changed indicate that there are no long-term active portfolio strategies that aim at making a stable profit, but that rather these are businesses, which pursue maximising the difference between wholesale and retail sale prices of the object 'publisher'. 
academic libraries - is of interest here. For a long time, the business model was to sell subscriptions for printed journals.

Already during the 1980s, prices increased in this model, which wasn't only due to the growth of the journals and their overall number or to cancellations of subscriptions by financially troubled libraries. ${ }^{5}$ There is evidence that journal prices in the subscription model do not primarily follow the costs of production but the price that can maximally be achieved, which has its limitation in the budget of the libraries. The discrepancy of production costs and market price is the result of several specificities of the market for academic publications. First, on the side of providers of publications - especially in the area of science, technology and medicine (STM) - there is a strong tendency of concentration, which has led some observers to describe the landscape as an oligopoly (see European Commission 2006: 50). Second, scientific journals are individual, non-replaceable goods. Since they have the objective to publish original research contributions exclusively, they differ from each other with respect to the published contributions and the research results that they present. Particularly those journals that are ranked high in the pyramid of reputation are 'must-have' journals and the demand is correspondingly inelastic. ${ }^{6}$ Third, there is also a speciality on the side of the customers, which makes it easier for the publishers to enforce price hikes. Publications are usually not demanded by scientists themselves but by libraries or library consortia. The demand for a publication and budget responsibility thus lies with two different actors (Brinzinger 2010: 334; Parks 2002: 324). For individual scientists, it is rational to signal strong demand to the libraries while remaining ignorant with regard to costs.

In the second half of the $1990 \mathrm{~s}^{7}{ }^{7}$ the 'journal' product was supplemented by coarse and fine-grained units through which publications are commodified (Hanekop \& Wittke 2006: 203-204; 2013: 151). In the age of digitisation, the commodity 'publication' comes in various forms. A smaller unit is the sale of or temporary access to individual articles; ${ }^{8}$ the larger unit is the sale of socalled 'journal bundles' (bundle deals or big deals). Following the discussion in the literature, big deals seem to be of large significance for the journal market.

5 The increase in prices is documented in the literature. See Kopp (2000: 1824), Panitch and Michalak (2005), European Commission (2006: 16), Kirchgässner (2008: 138) and Boni (2010: 294).

6 See Odlyzko (1997) and Wyly (1998). The latter compares the profit of the four largest academic publishers by means of different measurement numbers and takes the resulting rates of profit as indicator for the lack of competition on the market and the presence of structural problems, which make absorption of monopoly profits possible.

7 The exact time is hard to tell. In the literature, bundle or big deals are mentioned since at least 2001 (Frazier 2001), the pay-per-view model, at least since 1995 (Harnad 1995).

8 A rental can entail a transfer of different usage rights. Of significance are digital rights management systems, which make it possible to restrict usage to a certain period or to allow only certain ways of usage (for example, the creation of a printout). 
Their role was also addressed in the interview between the IWG and the Springer representatives:

What we have today is that the academic publishers sell a lot of their journals in packages to universities, which corresponds to the legalities of the digital age, where those systems have an advantage that has a lot to offer. (I-2)

So where are the mentioned benefits of this model for the publisher? In big deals, journals are no longer disseminated individually. Instead, there is digital access to a group of journals compiled by the publisher. Both partners enter a binding contract for a certain period, which entails that the publisher caps prices for the package while the libraries are obliged not to exceed a certain percentage when cancelling their journal subscriptions. The advantage for libraries is that they gain access to journals at a relatively low price, while the advantage for the publisher is that they can bind part of the library budget in the medium term. As indicated in the interviews, this business model favours publishers who have a large portfolio of journals. A second aspect of bundle deals, which also strengthens large publishers as providers of non-replaceable products, is the confidentiality clause. The libraries are obligated to keep the conditions of the bundle contracts confidential. This prevents the market providing information to third parties.

\subsection{Wiley-VCH}

Interviewee I3 was not a representative from the management of a publishing company but a member of the editorial staff of the journal Angewandte Chemie. The journal is owned by a scientific society, the Gesellschaft Deutscher Chemiker (GDCh), and I3 was employed by the publisher Wiley-VCH at the time of the interview. This constellation already indicated the close connection between the society and the publisher. Wiley-VCH is also part of a larger group, namely Wiley-Blackwell. The name indicates that the group has emerged from a process that can indeed be compared to that of Springer Science+Business Media. The aggregation included a 90\% partnership with VCH (1996), the acquisition of Van Nostrand Reinhold (1997), the acquisition of the publishers Hungry Minds (2001), Whatsonwhen (2006) and finally Blackwell Publishing (2007). ${ }^{9}$ The group can thus also be considered a large internationally operating publishing company and, according to its website, it had revenues of USD 1.743 billion in 2011 . It publishes 1500 specialised journals, 1227 of which are indexed in

9 The history of the group is documented on its website. See http://eu.wiley.com/WileyCDA/Section/id301697.html. 
the Journal Citation Report (JCR) of the Web of Knowledge, and the company considers itself the largest publisher associated with scientific societies. Similar to Springer Science+Business Media, the company also publishes 10500 books, anthologies, conference proceedings and databases. Wiley aims to cover all areas of science but also generates profits through publications that address a broader readership. ${ }^{10}$

With about 30000 members, the GDCh is the largest German scientific society in the field of chemistry. Until 1996, the society published its contributions, which are aimed at scientific and professional publics, through its own Verlag Chemie. With the advent of digital publication, it sought a partner who was able to handle the changing standards, and found Wiley. The journal Angewandte Chemie is, so to speak, the flagship of the society. Contrary to what one would expect from the title, the journal is published in English, and is one of the most successful journals in the field: the JCR of 2012 shows a journal impact factor (JIF) of 13.455. The number of publications (citable items) is, according to the JCR, a remarkable 2 002. While there are six journals in the subject category 'multidisciplinary chemistry' that have higher impact factors of up to 40, these are significantly smaller and more selective in the choice of articles. Noteworthy here is the journal Advanced Material, which has an impact factor of 13.877 and 789 citable items, a notable number of publications. In the subject category, only Chemical Communication is larger with 3408 publications and the Journal of the American Chemical Society with 3176 publications. Their JIFs of 6.169 and 9.907 are, however, below that of Angewandte Chemie.

Due to this construction, the model of cooperation between the society and the publisher is the focus here. ${ }^{11}$ There is a contract between Wiley and the society, according to which the journal is owned by the GDCh; the publisher is responsible for publication and pays a sort of lease. This model is also used by other scientific societies that are not able to publish their journals on their own and thus transfer this task to a professional publishing company. The publisher generates a turnover in this model by selling printed and electronic versions of the journal either individually or as part of a bundle to libraries. Part of this profit is given to the society and serves to cover their costs - for example, for editorial work and organisation of the peer review. In addition, the money is also used for activities that are outside the area of scientific publishing, such as the organisation of conferences, the endowment of awards or the promotion of young researchers. Such a lucrative lease model is, however, not possible with every journal but is subject to certain conditions. In order to generate notable

10 An example is the series 'For Dummies', which aims to provide knowledge in an easy to comprehend way. See http://www.dummies.com/.

11 The cooperation model goes beyond Angewandte Chemie, as of the 21 journals of the society, 20 are published by Wiley-VCH. Angewandte Chemie is, however, the most significant journal. 
profits, the journal has to be outstanding and visible and of special value for the publisher. ${ }^{12}$ This became obvious in the conversation with the interviewees from Springer who compared different types of cooperation between publisher and specialised societies.

And the societies come to us; there is, of course, a hierarchy. There are very good, powerful societies for which we would like to work, and there are smaller ones where we say, okay, that will not have much of an impact for us prestige-wise, but yes, we can also do that. With the larger powerful societies, it is mostly about how much money we pay them for the privilege to edit or publish their journals. These are tough negotiations. The societies hire advisors who really work out the best deal for them. And the publishers compete for the societies [...] But eventually it depends on how much prestige this journal has, that we can include it in our package, that librarians want to have it and, how much income the societies can expect from the publisher. (I-1)

According to this interviewee, for the publisher, the primary value of the journal of a specialised society is its significance as a potential flagship for a journal package. Renowned journals are of strategic importance in the bundle model as they enhance the attractiveness of the respective packages and lead to higher prices and better sales.

\subsection{Walter de Gruyter}

Walter de Gruyter was represented by I-4, a member of management. The publishing house is located in Berlin, publishes in several languages, and aims to provide communication channels for all areas of science. The extent of coverage varies, however. While the company is in a leading position in certain sections of linguistics, it lags behind others in the major areas of science. The portfolio is, however, broad and includes some interesting titles, such as the standard reference work in medicine, Psychrembel. Of the 120 journals, 45 are indexed in the Web of Knowledge. Among them are journals with some visibility in the respective disciplines. The majority, however, is ranked average or low with respect to their subject categories or JIF. The history of the company dates back to 1749 when the oldest of the five founding publishers (bought by Walter de Gruyter) started its business. According to its website, in 2011, its

12 The strategic value of the cooperation with the specialised society is emphasised by Wiley (1998), 'the acquisition of the VCH Group further strengthened Wiley's leadership in these markets'. See http:// eu.wiley.com/WileyCDA/Section/id-301697.html. 
turnover was $€ 42$ million. The company profile and its self-conception are expressed in the following quote:

De Gruyter is, in a sense, a small publisher in many languages. We do, however, have the entire scope of an academic publisher ranging from archaeology to zoology. In some areas, we are the leading publisher. In linguistics, maybe internationally, but those are almost the exceptions. The challenge is how you cover this broad scope - science is not only STM but all areas from A to Z - to develop something technical, develop an offer that covers as much as possible? The communities think differently, the scientific discourse, scientific publishing is not the same everywhere. (I-4)

Similar to the two large publishers described above, De Gruyter has acquired smaller publishers up to the present: the acquisition of Max Niemeyer and K.G. Saur Verlag as well as Oldenbourg Verlag and the Akademie Verlag in 2013 should be noted. ${ }^{13}$ These purchases, however, were smaller in size and the aggregation is limited. Thus, the company is visible on the market but its position is much weaker compared to large publishing companies - it could be purchased by a larger player in the market. De Gruyter also uses bundle strategies for the dissemination of journal packages. ${ }^{14}$ In view of the smaller number of journals and the smaller number of highly reputed journals it can be assumed that De Gruyter is not able to bind parts of the library budget the way the larger publishers do.

\subsection{Lucius \& Lucius}

The publisher Lucius $\&$ Lucius is a small publishing house led by its owner (represented by I-5). Its programme is limited in two ways. On the one hand, the focus is on certain disciplines, namely economics and sociology; the company also publishes a series on the history of agriculture. ${ }^{15}$ On the other hand, the language is mainly German. ${ }^{16}$ The company publishes 19 journals, of which three are indexed in the JCR of the Social Science Citation Index (SSCI). It has to be noted, however, that the two disciplines are covered only to a limited extent by the SSCI. Furthermore, the company publishes anthologies

13 See the fact sheet of the company at https://www.degruyter.com/staticfiles/pdfs/1410_Fact_Sheet_ Imprints_de.pdf.

14 Information about the journals as well as their prices can be found at http://www.degruyter.com/page/849.

15 The series is the Quellen und Forschungen zur Agrargeschichte. See http://www.luciusverlag.com/reihen/qfa.htm.

16 Among the 19 journals, one is in English (Review of Economics) and there are individual monographs in English. 
and monographs. It ended its production of educational books a few years ago. In the interview, the profile of the company was characterised as follows:

If I start with journals, that's an area which, with few exceptions, does not need subventions and despite a decrease in sales numbers still works. On the other hand, people complain about the increasing subscription costs. I have journals with 150 subscribers and I think it's quite an achievement that almost all publishers can publish these journals [...]. Without direct funding. [...] The only area in my company in which I will continue to sell monographs is a good series on the history of agriculture. (I-5)

The limited number of journals is an essential part of the company's portfolio even though sales are declining. The number of subscriptions is low, and varies between 150 and 700. In contrast to many of the journals owned by Springer (and also Angewandte Chemie), these are not 'must-have' journals, and cancellation on the side of the libraries would not necessarily raise a lot of attention. This explains why the maximum sales price is achieved early on and - from the perspective of the publisher - higher prices for additional services, such as a digital version, can hardly be set. For a turnover that remains the same, the costs of the digital version lead to lower profits.

Economically, monographs are not of significant interest to the publisher, as is expressed in the following statement:

The second area are the monographs. They are mostly financed, I would say they are productions on assignment. I don't look for this type of monograph. Rather, scientists, institutions, organisers of some symposia come and say, we want to print this. And we do that if it is economically possible. [...] The sales numbers have decreased dramatically meanwhile. We produce monographs of which we don't even sell 100 copies, it's pretty tough. (I-5)

In the area of monographs, the publisher does not actively seek to acquire manuscripts but is rather passive. This is due to the low expectations of profit. The publication of a monograph or anthology is usually only possible and economically feasible if it is funded. This can be the case if a certain number of copies are guaranteed to be sold or if there are additional funds for printing.

This publisher's position in the market is precarious. Due to their smaller size, the journals cannot be disseminated in the form of bundle deals but only individually. The sales of monographs suffer from the fact that large parts of the library budget are bound to bundle contracts with larger publishers (Kopp 2000). The owner has meanwhile retired, was not able to find a successor, and the publishing house was sold to De Gruyter as a consequence. Therefore, 
Lucius $\&$ Lucius can be regarded as an example that illustrates the dynamics of a market that works against smaller publishers.

\section{Effects of digitisation}

The introduction of the publishing companies and the description of their positioning indicate that the market for scientific publications rewards size. Big players are able to make big profits and have a significant effect on the market. Through their activities in acquisition, they have an influence on the constellation of the providers, and through the development of products and their changes in price, they also influence the kind of demand. In this second step of the analysis, the focus is on the influence digitisation has on the strategic position of the different types of publishers. The presentation will be oriented towards the respective effects, which - if appropriate - will be described in more detail.

\subsection{Investments in digital infrastructures}

One major effect of digitisation results from the extensive financial investments which are needed for the development, maintenance and monitoring of an information and communication infrastructure. Here, two things need to be taken into account. First, the establishment of such an infrastructure is more complex than simply providing PDF files on a server that is connected to the Internet. The platform has to provide metadata and search functions, should be listed in library catalogues and search engines, and needs a rights management system which limits accessibility to persons who are in the possession of the necessary licences. For certain business models, ${ }^{17}$ it is necessary to connect the platform to electronic payment systems. Not only the dissemination of publications is based on a digital infrastructure: production processes, too, use electronic systems to a large extent. Online editorial management systems ${ }^{18}$ support the peer-review process and organise a workflow that ranges from submission to occasional linguistic editing to typesetting. Second, the development of a digital infrastructure does not end but is a process that constantly brings forth new challenges and waves of innovation. Current examples here are the connection of publications to research data in the

17 For example, the individual dissemination of articles.

18 Examples of such platforms are Editorial Manager (http://www.editorialmanager.de/) and Open Journal Systems (https://pkp.sfu.ca/ojs). 
sense of enhanced publications, the goal being to replace PDF as the common format, ${ }^{19}$ or the connection to user-based data (usage-based metrics) ${ }^{20}$

The development of digital infrastructures entails high investments, which are especially visible in the case of Springer. Interviewee I-1 describes these platforms as 'very, very expensive' and makes it clear that a large part of the company's profit is invested in infrastructure.

The profit is not as large as with some competitors but it is a good business and in the past years, the profit was $24 \%$. Of these $24 \%$, about half were reinvested into the company, among others for the new Springer Link platform. One quarter was invested in other internal systems, and a quarter was dividend payouts to the owners. (I-1)

These investments represent one factor that leads to a differentiation of publishing companies' positions. While large publishers, like Springer, are able to shoulder these costs and to develop a digital infrastructure actively on a broader scale, this is not the case for smaller companies. Their reactions differ. One possibility is to cooperate with a large publisher. As described in the case of a scientific society and by I-3, this can take place in the form of a lease model. In addition, two or more companies could cooperate, for example, by using the same online platforms or pathways of dissemination. ${ }^{21}$ Especially small companies are under pressure because of digitisation and particularly because of their limited financial resources.

It's totally clear, we cannot even do the programming ourselves, we have to buy all the stuff from specialists or have something made in cooperation with our colleagues. A smaller publisher cannot even work in this area autonomously anymore, that's a big problem for us. It's becoming more expensive because this hybrid function is indispensable nowadays, and we have little say in the design, we have to work with kits that are offered somewhere on the market. (I-5)

With regard to digitisation, size is essential since it is a prerequisite to be able to shoulder the financial expenses necessary for the development of platforms. The creation of in-house expert units, as in the case of Springer, or at least the assignment of developmental tasks, are framework conditions under which opportunities for deciding on and designing an individual digital strategy

\footnotetext{
19 A much-discussed alternative is XML format.

20 For example, Altmetric (Aldie \& Roe 2013).

21 For example, the partnerships of De Gruyter: https://www.degruyter.com/staticfiles/pdfs/1410_Fact_ Sheet_Imprints_de.pdf.
} 
emerge. Size is also essential with respect to the efficiency of the investment the developmental costs for an infrastructure decrease with the broadness of its use.

\subsection{Development of new products}

Digitisation provides new opportunities regarding the product. In times of print, the product was, so to speak, what fitted between front and back covers, and there were only variations with regard to the number of such units that were subject to a transaction. ${ }^{22}$ Today, there is a diversification and the front-back cover unit has lost significance. Digitisation makes it possible to commodify publications in different formats and to develop a variety of business models. The bundle deals and individual dissemination of articles have already been mentioned. But there are also other types of products. One example is retrodigitisation of old and rare literature. Here, large and small publishers have different perspectives on the marketability of such a product.

We have continuously expanded archiving. One of the first things we did was the retro-digitisation back to volume 1 , issue 1 . Back to the $19^{\text {th }}$ century. Of course, we did not offer that for free, not because we are good people and archivers, but because we saw a product that libraries wanted to have. We do the same now with all books. It goes back almost to the $18^{\text {th }}$ century. [...] But once we are done, we have 100000 titles in our archive that go back to the 1840s. (I-1)

This statement reveals that the goal is to make all of Springer's publications permanently available and that digital backlists of journals and rare monographs are seen as a product in which libraries are interested. In this context, it is not primarily about the sale of access to individual works but to larger parts or even the entire inventory of a digital library. Interviewee I-5 took a different position when asked about retro-digitisation:

I have thought about this question a lot. Today, I could put all my old books on a platform and then print them out in an on-demand system [...] I would then have about 20000 titles. But you don't need [...] complex calculations to figure out what digitisation would cost and what the download probability of old data would be. So the treasure, that's my opinion, is totally fictitious. I don't earn money with things that are older than ten years. (I-5)

22 Thus, in the case journal publications, the distribution of journals in the framework of subscriptions or the distribution of single journal issues. 
The diametric perspectives of marketability of retro-digitised publications lead to the question why this is so. Why does one publisher invest heavily in retrodigitisation while another one does not see any opportunity to gain money through this strategy? There are supposedly several factors that may affect the position of the publishers. Aside from the time span of the reception of a publication, a factor mentioned in the second interview passage, the average quality of rare works may have an influence on the marketability of retrodigitised inventories. A third factor is probably the language in which the works are published, as the sales market of English publications is larger than that of German ones. Moreover, the volume of retro-digitised publications may have an influence. The number of journals edited by Springer is well over 100 times more than that of Lucius $\&$ Lucius and the number of monographs already five times higher. Therefore, the interest of libraries for packages of retro-digitised publications may increase if the inventories are perceived as collections of certain significance with respect to their size and coverage of fields.

De Gruyter has developed an innovative model of retro-digitisation of outof-print publications. It aims to transfer printed works into a digital product without having to shoulder heavy investments upfront.

De Gruyter has produced more than 40000 book publications in 260 years, and it was quite clear from an economic perspective that we cannot and don't want to digitise all of them, regardless of rights. I mean there are also a lot of works where the author has been dead for 70 years, if you go back to 260 years. ${ }^{23}$ There we just said, we let the user decide what he wants. That's the model we introduced with this edition three years ago. We only offer metadata of the 40000 articles and then we let the users, libraries or researchers decide if they want a copy of this book printed, digitised or newly bound or an electronic version like a modern e-book, which is then made available as an e-book by chapters. (I-4)

In general, this strategy aims at a smaller product in which not a large part or even the entire inventory is combined into one product, but individual works are digitised and disseminated according to demand. This limits the financial investment at the beginning, but also the potential sales volume.

Another advantage of size is apparent with regard to the risks that the introduction of new products entails. Large academic publishers offer individual sales for the dissemination of individual journal articles, and a publisher such

23 According to German copyright law, copyrights expire after a period of 70 years post mortem auctoris and publications can be copied and distributed without any restrictions. 
as De Gruyter also follows this strategic model. An exception, however, is Lucius \& Lucius.

That's a very special question, whether you want to sell individual articles. At the moment, I am ambivalent and cautious about that because I am worried that [...] it would kill the subscriptions. It could also be the other way around, that there are demands from people who would never have subscribed to the journal; then it would be an additional sale. The question is very complicated, and I have to say, the individual sale of journal articles is, at the moment, not one of my goals. (I-5)

The business model of individual dissemination, which became possible as a result of electronic publication, is not implemented here because the effects are unclear. It could lead to new income; however, it could also harm subscription models that are important for the publisher. The reason why the publisher in this situation pursues a risk-averse strategy needs to be seen in terms of its size. First, the financial resources for executing such an experiment are scarce. Second, in contrast to a large publisher, a small publisher does not have the opportunity to experiment with new business models in a separate area, which is large enough to gain experiences for the entire programme of the company, but small enough to keep the financial loss in case of failure at a minimum.

\subsection{Making international division of labour possible}

It has been mentioned above that digitisation not only concerns dissemination but also provides potential to reorganise the production process. Examples are editorial management systems, which allow a restructuring of all processes of scientific review and decision about publication of a manuscript up to the production of accepted articles on the basis of a digital platform. The implementation of such systems is complex, and it is a significant challenge, especially for smaller publishers. ${ }^{24}$ Since the product (the publication) with all its previous versions and all related documents (such as reviews and correspondence between all involved persons) are digitally available, the systems could be used to outsource individual working steps and to have them completed at different locations. Such outsourcing took place in predigital times, after the founding of the first journals on behalf of the academic

24 Here, Lucius \& Lucius, whose journals do not use such a system, should be mentioned again. The publisher offered it to the editorial staff of its journals, who rejected it due to the small number of articles published each year. In view of the complexity and financial investments, the publisher was relieved by this decision, although he speaks of a 'grace period' until they do want to implement such a system after all. 
editorial offices by introducing peer review. Here, scientists outside of the editorial staff were assigned to evaluate the worthiness of publication of articles on paper. This took place quite early in the history of journals and followed the criterion of competence. Online editorial management systems moreover allow outsourcing that follows the criterion of economic efficiency, namely outsourcing of individual working phases in production. ${ }^{25}$ The employees of Springer in India are responsible for the technological production of the articles, i.e. the hardcopy printing and the compilation of issues. This shows that the systems are able to establish an international division of labour, which follows the principle of cost-minimisation. This potential of digitisation can, however, only be fully exploited by larger publishers, since such an outsourcing entails significant investments that will only be profitable with a large number of journals.

Overall, it can be stated that digitisation 'rewards' the size of the publishing companies in many respects:

- It is much easier for large publishers to produce the necessary investments for the establishment of digital infrastructures.

- Due to their financial power, large companies can co-determine the design of such infrastructures.

- With regard to the products, it can be said that size not only enables certain forms of dissemination - bundle deals - but special products are also marketable only if they have a certain size. This concerns, for example, the retro-digitisation of out-of-print inventories.

- Experimenting with new products and abandoning old and reliable business models could turn out risky for small publishers quite fast while larger publishers can control such risks. ${ }^{26}$

\section{Attitude towards open access}

After analysing the effects of digitisation with regard to the size of academic publishers, the focus is now on the companies' perspective towards open

25 See Taubert (2012).

26 Two more factors that reward size should be mentioned. On the one hand, there are so-called 'cascading strategies', in which a publisher has a hierarchy of journals and transfers articles that were rejected by one journal to another journal ranked lower in this hierarchy. This strategy aims at binding submissions to the publisher. On the other hand, there are services and other products that are connected to journal databases. Examples are the database Scopus, which gets its citation data from the Elsevier journal database, Science Direct, and the electronic evaluation tool, Sci Val. See http://www.elsevier.com/ electronic-products/scival. 
access. Aside from the general attitude, the attitude towards the two variations of green and gold open access will be illustrated.

\subsection{Springer Science+Business Media}

Springer describes itself as being open-minded and progressive with regard to OA publishing.

First, on open access: It's true, we are a bit more open or progressive or more willing to experiment than other publishers. [...] We said, good, if scientists want to have that, if the scientific community wants to have open access, who are we to say no? We are the publisher, and if they say, no, we would rather have it organised like this, we either have to try it or the options are to say no. Other publishers have done that. (I-1)

According to this statement, Springer considers itself - in contrast to other publishers - an actor who is oriented towards the needs and wishes of science. Looking at the activities of the company, it should be noted that this is not merely rhetoric, but that the demand for open access is, at least in part, being fulfilled. Thus, the self-archiving of articles published in Springer journals is allowed if it is the author version of the relevant contribution. At the time of the interview, this right referred to the self-archiving on homepages and in repositories. In reaction to the Finch Report (Finch Group 2012) and the recommendations of the Research Council UK, Springer tightened its green open access policy. ${ }^{27}$ Now, the immediate self-archiving on a home page and archiving in a repository are allowed after an embargo period of 12 months. If, however, a file has been deposited in a repository before publication in a Springer journal, it can remain there. ${ }^{28}$ The interview made it clear that there are reservations towards green open access:

The somewhat perverse thing about green open access is that the article will be put on a repository after an embargo period, and that the green open access model relies on a well-functioning subscription model. It could, however, lead in some disciplines, which are not centrally financed [meaning through

27 The policy is documented at http://www.springer.com/gp/open-access/authors-rights/self-archivingpolicy/2124 and on the Sherpa/Romeo-List at http://www.sherpa.ac.uk/romeo/search.php?id=74EfIDn $\mathrm{um}=\mid \delta$ mode=simple\&la=en\&format=full. It is, however, disputed whether there can be a differentiation between self-archiving on homepages and an institutional repository. For example, a link on a repository could lead to a version on a home page. This makes it possible to use the functionality of the repository to find a document.

28 Changes in the green open access policy refer to a basic problem. These rights that publishers grant the authors could be revoked in the future. This can go so far that a publisher no longer allows selfarchiving at all. 
bundle deals], to the death of smaller publishers and smaller journals because they are no longer able to deal with it financially. I can guarantee you that no matter what will be decided on the EU or Federal level [...] Springer [...] will find models to advance. (I-1)

The attitude towards gold open access is quite different. This form of freely accessible publication is viewed as compatible with the interests of the publisher:

In the last two years, we agreed on a position, internally: gold model open access. We will do what is sustainable. We are neutral here. Neutral is the word that we use. The problem with open access, at least the golden version, is that it is ideal for disciplines that move rapidly, in biomedicine, for example, in genetics. Because these disciplines are mostly supported financially in a central manner. The social sciences, the humanities are another thing. Gold open access, where are the resources? It's about the resources. (I-1)

This emphasised neutrality of Springer refers to two business models of journals. The publisher offers a model on the side of the authors (gold open access) as well as one on the side of the recipient (subscription model), none of which is treated as priority. This indicates that Springer sees gold open access as an opportunity to maintain its position on the market and to make similar profits as in the subscription model. Economic sustainability is achieved through the following prices: in the case of gold OA journals - i.e. the Springer journals that are financed via article processing charges (APCs) - the fees range from $€ 500$ to $€ 1500 .{ }^{29}$ Fees are higher in the case of optional open access/hybrid open access (Springer Open Choice), where open access to an individual article is paid for in an otherwise restricted journal. The APCs range from $€ 2200$ to $€ 3000 .{ }^{30}$ In this model, too, one aspect is viewed critically: while the model is compatible with Springer's economic interests, it currently only works in some areas of science due to lacking financial resources. ${ }^{31}$

29 See an overview of the Springer Open Programme at http://www.springeropen.com/.

30 http://www.springeropen.com/get-published/article-processing-charges/how-much-is-springeropencharging.

31 Ways of financing are presently being created, among others, through partially DFG-supported publication funds. Its 'Guidelines for Open Access Publishing' state the following funding conditions: 'The articles to be published appear in journals that make all articles available over the internet to users free of charge as soon as they appear (pure, gold open access journals) and that they apply recognised and strict quality assurance procedures' (DFG 2013: 9). The APCs should amount to no more than $€ 2$ 000. Support for optional open access is ruled out, so as to avoid 'double dipping', i.e. dual payment for the same publication. Nor can publications that do not appear in journals be paid from these funds. 


\subsection{Angewandte Chemie/Wiley-VCH}

The editorial staff member of Angewandte Chemie took a critical stance towards any form of open access. Freely accessible publishing is rejected in its entirety even though the interview did not reveal any clear position towards open access. Regarding self-archiving, the author is not allowed to deposit his or her article in a repository or on a home page. According to I-3, it is, however, acceptable for an author to link their publication list on their home page with the article published in Angewandte Chemie. Thus, the author's rights in terms of the journal are very limited. The informal exchange of PDFs is accepted, and the use of the Internet as a public place to deposit an article is understood as publication and therefore rejected. ${ }^{32}$ This rejection refers to the scientific idea that every research result should be published only once and that Angewandte Chemie provides appropriate accessibility. ${ }^{33}$ Redundant publication is criticised. This is continued in gold open access. Angewandte Chemie offers optional open access. ${ }^{34}$ But with 20 to 30 contributions per year and $0.4 \%$ of the number of articles published each year, the relevance of this model can be discounted. The publisher does not consider its interest in profits compatible with the interest of the scientific society in remuneration from an APC-financed model of gold open access.

Two kinds of connections are possible. In the case of the subscription model, the price of a journal or the profit that goes to a specialised society, as well as the quality are positively connected. High quality of a journal is a precondition for achieving high prices. In this model, the economic goal of maximum profit is equally oriented to the scientific goal of a stricter control of quality. In the case of the funding of a journal via APCs, the type of connection changes, according to the perspective of I-3. The profits of a journal are first dependent on the number of articles that are published and less dependent on their quality. The interviewee stated, however, that the conflict between gaining profits and controlling quality could be detrimental to the latter. The general view regarding the financing of gold OA journals via APCs is thus critical.

32 See the Copyright Transfer Agreement of Angewandte Chemie. Sending an article to individual persons is allowed; systematic dissemination, such as posting the article on a website or a mailing list is prohibited. See http://media.wiley.com/assets/1540/98/ctavchglobal.pdf.

33 This argument only holds if one takes a repository to be a place of publication, and the deposited version as a publication. The argument is countered, however, by the fact that not all functions of registration, certification, dissemination and permanent accessibility are guaranteed by a repository (Andermann $\delta$ Degkwitz 2004: 36).

34 This is in the framework of Wiley's general model, OnlineOpen. The APCs are $€ 3$ 500. See http:// onlinelibrary.wiley.com/journal/10.1002/\%28ISSN\%291521-3773/homepage/2002_onlineopen.html. 


\subsection{De Gruyter}

The publisher De Gruyter is strongly engaged in the promotion of unrestricted access to scientific publications. It has a broad OA programme and seeks cooperation with libraries ${ }^{35}$ and research organisations. ${ }^{36}$ It has a green OA policy ${ }^{37}$ that allows self-archiving of contributions in anthologies and journals 12 months after publication - in the publisher's version. ${ }^{38}$ There are, however, restrictions concerning the place of self-archiving, which is only allowed in institutional repositories and one's own website. ${ }^{39}$ Commercial archives are explicitly prohibited. This is understandable insofar as this could enhance the product of a competitor. The interviewee was against limitations in selfarchiving, and thus had a more permissive position than the publisher.

And also the limitation that you cannot put your own contributions in some form or another on some server, I think has to be reconsidered because that limits visibility. (I-4)

With regard to gold OA, De Gruyter is open-minded as well. It offers an optional or hybrid OA option for all of its products including monographs, anthologies and articles in journals. Especially the acquisition of the OA publisher Versita in $2012^{40}$ strengthened De Gruyter's position on the market for gold OA journals. The fees for an article in an OA journal or anthology are currently $€ 1$ 750. In the following statement, however, I-4 made it clear that he did not view the financing of gold OA publications based on APCs for every individual article as seminal:

But that's not the future, if you pay USD 3000 so that your article is freely accessible. [...] I think there is a different way. The model that institutions [...] per se pay a kind of flat fee or support an entire journal as sponsor is a third way in the realm of open access which is more successful I think. I can imagine, just as an example, if Max Planck would say, hey, we want to negotiate a flat fee with this publisher for all Max Planck institutes, at least

35 Libraries are offered an institutional membership with reduced fees for OA publications. See http:// www.degruyter.com/page/1089.

36 See the contract with the Max Planck Society on the publication of OA books at http://www.degruyter. $\mathrm{com} / \mathrm{dg} /$ newsitem/56/die-maxplanckgesellschaft-und-de-gruyter-schlieen-rahmenvertrag-zurpublikation-von-open-accessbchern.

37 http://www.degruyter.com/dg/page/576/repository-policy.

38 This version includes layout and page numbers, so that the article can be cited.

39 This leads to confusion, as a repository, such as arXiv.org, is not considered commercial but also not institutional.

40 See http://www.degruyter.com/applib/newsitem/9/de-gruyter-erwirbt-versita-und-wird-zum-drittgrteninternationalen-open-accessverlag. 
for the contributions by Max Planck authors, that would be a much larger step towards gold OA than thus far. (I-4)

It should be noted that this criticism is not aimed at gold OA in general but only at a certain form of it. It is the starting point for further elaborations regarding financing of gold open access, and such steps have already been taken in the framework of a flat rate model, which allows research institutions certain volumes in journals or an entire inventory at reduced prices.

\subsection{Lucius \& Lucius}

Lucius \& Lucius also advocates open access to publications. There is no explicit policy on its website regarding green open access, so it must be assumed that self-archiving is prohibited. ${ }^{41}$ With respect to copyright issues and embargo periods pertaining to the secondary publication right, the attitude depends on the time span.

And then comes green road, and that practically means secondary publication rights, and that is of course a hot topic, which will probably decide the future of many journals and publishers, how this is solved. And if I think about the six months that are demanded by many radicals, I am certain that this would be the death of most journals and many publishers. [...] 18 to 24 months, that would be possible. Because you always have to think if the current subscription will be open so soon that the user says, oh God, tax policy in Ulm in the $14^{\text {th }}$ century, I can wait till September until I read that, I don't have to have the subscription. But those are then works that we have. If you say, we want to have journals, then you have to develop differentiated, realistic rules for the embargo period that are in line with the market. (I-5)

The significance of the periods mentioned lies in the fact that the interviewee considered the period between primary publication and the deposit in a repository as the time in which the publisher makes money. The example of late medieval tax policy indicates that the deadlines should be adapted to the specific conditions of the respective disciplines, which are especially characterised by the progress in knowledge and pace of reception. In the case of Lucius $\&$ Lucius, it is not about maximisation of profits but about maintenance of the economic basis of the company.

41 The Sherpa/Romeo List also suggests this conclusion and states that self-archiving is not supported ('not formally supported'). See http://www.sherpa.ac.uk/romeo/search.php. 
Regarding gold $\mathrm{OA}$, the interviewee narrowed his perspective on the funding of such journals via APCs and did not take other models into account. Answering the question of functionality of the model depends on the context in which it is applied.

Yes, well, gold route is, as has clearly been said for a long time, an opportunity for the publishers, a business model that can work or not. It works badly in the German system so far, and especially in the humanities even worse because the funds are lacking. [...] The gold route shoud be viewed carefully. I just don't see a chance to carry it out in economics or social sciences in Germany at the moment. (I-5)

I-5 here used an argument that was already apparent in the interviews with representatives of Springer Science+Business Media, namely whether the model works depends on the available resources in funding. As Lucius $\delta$ Lucius is oriented towards the German market, it is especially dependent on local research institutions and organisations.

\section{Demand for transparency}

A second demand from science policy concerns the increase of transparency with respect to financing of scientific literature. This is due to the fact that libraries and research institutions mostly use public money to create accessibility to scientific publications. The interviews revealed reasons for the lack of transparency:

- Bundle deals: While the individual and institutional subscription prices for journals are published on the websites of the companies, this is often not the case when it comes to bundle deals. Negotiations with libraries or library consortia are usually confidential and the contracts contain a clause that ensures this (Edlin 2004: 151 f. 90). Due to this confidentiality, prices and conditions of bundle contracts function only to a limited degree as an orientation for negotiations between other actors.

- Discount for publication quotas: In the case of gold OA financed by APCs, there is a possibility that there will be a similar lack of transparency as in the subscription model. While the APCs can be well compared for individual publications on the basis of publicised fees, it is already clear that the financing of individual publications will not be the only form of 
APC-based financing. The possibility of deductions of contingents was mentioned several times:

There is always this discussion, yes, APCs, and if you now look at Springer, what does an article in your access programme in the hybrid model cost, that's $€ 2$ 000, that's crazy, because if you add it up, all articles, then they would make even more money. [...] I can tell you, it's the same with a new car, nobody will pay the list price. They make volume discounts, they negotiate with universities or societies that come to us and say, we publish about this much per year, how can we make a deal. (I-1)

Here, it can be assumed that negotiations between publishers and research institutions or libraries are confidential and not made public to third parties. Should it come to that, the information function of prices would also be lost in this kind of financial model.

- Lease fee for journals or specialised societies: The cooperation model between publisher and scientific societies (e.g. Angewandte Chemie) impedes an understanding of the money flows. Due to bundle deals, it is difficult to say which profits of the company can be attributed to an individual journal. And, due to confidentiality clauses, not even the prices for the bundles are known. In the lease model, it moreover remains unclear how the profits are divided between the publisher and the society and how high the overall profit of the society is from journals in general and Angewandte Chemie in particular. ${ }^{42}$

Thus, the business models of the large publishing companies are responsible for the lack of transparency in the first place. As a result, the question for more transparency was aimed at them. The interviewees from Springer were rather reserved:

I can tell you, if there will be a committee that should determine what an acceptable profit is, then no. [...] As you know, we are happy to be part of all initiatives if there is a discussion, but I would have to know the details, and what exactly is being asked. We are on the stock market, there are certain things we do not make public. (I-1)

These reservations indicate that Springer's willingness to contribute to more transparency was limited. The member of the editorial staff of Angewandte

42 The interviewee did not mention concrete numbers but only described the basic characteristics of the lease model. The publicly available report of the Gesellschaft Deutscher Chemiker (GDCh) details the immaterial area, asset management, tax-purpose companies and economic operations. The income from the publication business is not displayed separately (GDCh 2011: 34). 
Chemie provided a different answer. The demand for more transparency of pricing was raised in the interview three times, but the interviewee did not take a position regarding the issue. Here, too, it can be assumed that the willingness to participate was rather low.

\section{Summary}

The evaluation of the interviews with four academic publishing companies revealed important characteristics of a market that has strong tendencies towards concentration and is subject to the influences of a dynamic digital change. The most important aspects for the science policy design of publishing in general are summarised here.

- Market imperfections: The concentration of a significant number of journals in the portfolio of only a few publishers is one characteristic of the market. This structure, together with the specificity of the 'journal' product (non-substitutability) and a special form of commodification (bundle deals) is a precondition for the high profits in the STM field.

- Structural dynamics of the market: The structural powers of the market and the effects of digitisation work against the smaller publishing companies (rewarding size). It can be assumed that the process of aggregation is not yet over and that acquisitions of publishers or the economic death of smaller companies will continue to be observed in the future.

- Innovative actors: The role of promoting innovations in the area of digital infrastructures depends on the size of the companies and available resources. Herein lies some ambivalence. From the perspective of science, it is desirable that innovative publishers make a contribution to the advancement of digital publication and digital infrastructures. On the other hand, it is problematic if publishers orient their innovative decisions more strongly towards securing their position on the market and their business model than towards the needs of science.

- Transparency: Since the prices of journals are not shaped by the mechanisms of competition but by negotiations, a high degree of transparency is desirable in order to strengthen the position of publicly financed libraries in negotiations. In the transfer to an APC-financed gold OA model, it may well be that deductions of contingents lead to a similar lack of transparency in prices and price development.

- Gold open access: The four publishers showed different degrees of willingness to adopt gold OA models and the reasons for this varied. Aside from the unclear financial issues (money flow and available 
resources), technological preconditions cannot always be fulfilled by the smaller publishers. On the other hand, the adoption of gold open access can also be counterproductive for the current business model.

\section{References}

Adie, E. \& Roe, W. 2013. Altmetric: Enriching scholarly content with article-level discussion and metrics. Learned Publishing, 26(1):11-17.

Andermann, H. \& Degkwitz, A. 2004. Neue Ansätze in der wissenschaftlichen Informationsversorgung. Ein Überblick über Initiativen und Unternehmungen auf dem Gebiet des elektronischen Publizierens. Historical Social Research, 29(1):6-55.

Boni, M. 2010. Analoges Geld für digitale Zeilen: der Publikationsmarkt der Wissenschaft. Leviathan, 38(3):293-312.

Brinzinger, K.-R. 2010. Piraterie oder Allmende der Wissenschaften? Zum Streit um Open Access und der Rolle von Wissenschaft, Bibliotheken und Markt bei der Verbreitung von Forschungsergebnissen. Leviathan, 38(3):331-346.

DFG (Deutsche Forschungsgemeinschaft). 2013. Merkblatt Open Access Publizieren. DFG-Vordruck 12.20. 03/13. Retrieved from http://www.dfg.de/ formulare/12_20/12_20_de.pdf [Accessed 23 March 2016].

Edlin, A. 2004. Exclusion or efficient pricing: The 'big deal' bundling of academic journals. Antitrust Law Journal, 72(1):128-159.

EC (European Commission). 2006. Study on the economic and technical evolution of the scientific publication markets in Europe. Final report January 2006. Retrieved from https://www.ulb.ac.be/unica/docs/librarians_2006_scientific_pub_study.pdf [Accessed 23 March 2016].

Finch Group. 2012. Accessibility, sustainability, excellence: How to expand access to research publications. Report of the Working Group on Expanding Access to Published Research Findings. Retrieved from http://www.researchinfonet.org/wp-content/ uploads/2012/06/Finch-Group-report-FINAL-VERSION.pdf [Accessed 23 March 2016].

Frazier, K. 2001. The librarians' dilemma: Contemplating the cost of the 'big deal'. D-Lib Magazine, 7(1):n.p.

GDCh. 2011. GDCh Jahresbericht 2011. Retrieved from https://www.gdch.de/serviceinformation/downloads.html [Accessed 23 March 2016].

Hanekop, H. \& Wittke, V. 2007. Der Einfluss des Internet auf die Re-Konfiguration des Systems wissenschaftlichen Publizierens. In U. Dolata \& R. Werle (eds). Gesellschaft und die Macht der Technik. Sozioökonomischer und institutioneller Wandel durch Technisierung. Frankfurt: Campus, 201-220. 
Hanekop, H. \& Wittke, V. 2013. Der Wandel des wissenschaftlichen Publikationssystems durch das Internet. Sektoriale Transformation im Kontext institutioneller Rekonfiguration. In U. Dolata \& J.-F. Schrape (eds). Internet, Mobile Devices und die Transformation der Medien. Radikaler Wandel als schrittweise Rekonfiguration. Berlin: Edition Sigma, 147-172.

Harnad, S. 1995. The Postgutenberg Galaxy: How to get there from here. The Information Society: An International Journal, $11(4): 285-291$.

Kirchgässner, A. 2008. Zeitschriftenkonsortien. Angebotsausweitung auf Kosten der Flexibilität. In E. Pipp (ed.). Informationskonzepte für die Zukunft. ODOK '07 (Schriften der Vereinigung Österreichischer Bibliothekarinnen und Bibliothekare). GrazFeldkirch: Wolfgang Neugebauer, 137-146.

Kopp, H. 2000. Die Zeitschriftenkrise als Krise der Monographienbeschaffung. Bibliotheksdienst, 34(11):1822-1827.

Odlyzko, A. 1997. The economics of electronic journals. First Monday, 2(8):n.p. Retrieved from http://firstmonday.org/htbin/cgiwrap/bin/ojs/index.php/fm/ article/view/542/463 [Accessed 23 March 2016].

Panitch, J.M. \& Michalak, S. 2005. The serials crisis: A White Paper for the UNCChapel Hill Scholarly Communications Convocation. Retrieved from www.unc.edu/ scholcomdig/whitepapers/panitch-michalak.doc [Accessed 23 March 2016].

Parks, R. 2002. The Faustian grip of academic publishing. Journal of Economic Methodology, 9(3):317-335.

Schimank, U. \& Volkmann, U. 2012. Die Ware Wissenschaft: Die fremdreferentiell finalisierte wirtschaftliche Rationalität der Wissenschaftsverlage. In A. Engels \& L. Knoll (eds). Wirtschaftliche Rationalität. Soziologische Perspektiven. Wiesbaden: Springer, 165-183.

Springer Science+Business Media. 2011. General overview and financial performance 2011 . Retrieved from http://www.springer.com/cda/ content/document/cda_downloaddocument/Overview+2011. pdf?SGWID=0-0-45-1175537-0 [Accessed 23 March 2016].

Taubert, N. 2012. Online Editorial Management Systeme und die Produktion wissenschaftlicher Fachzeitschriften. Leviathan, 40(2):297-319.

Volkmann, U., Schimank, U. \& Rost, M. 2014. Two worlds of academic publishing: Chemistry and German sociology in comparison. Minerva, 52(2):187-212.

Wyly, B. 1998. Competition in scholarly publishing? What publisher profiles reveal. ARL Bimonthly Newsletter: n.p.

Zuckerman, H. \& Merton, R.K. 1971. Patterns of evaluation in science: Institutionalisation. Minerva, 9(1):66-100. 



\title{
On the Situation and Development of Academic Libraries
}

\author{
Peter Weingart
}

Together with publishers, academic libraries are the main institutional actors in the scholarly publication system; therefore it is relevant to provide a description of how libraries perceive the current situation. Here, it can be assumed that there are differences in this perception according to size and financial resources among the different libraries. For this reason, it was attempted to gain a broad spectrum of opinions by inviting representatives of several libraries, from universities, research institutions as well as the renowned Bodleian Library. ${ }^{1}$

The following text summarises the statements made by these representatives. With few exceptions, we have refrained from attributing individual positions to persons or their institutions. Only at certain points is additional information provided in footnotes. We therefore do not want to be understood as representing a position of our own but merely as editing the transcript.

The discussion focuses on four areas:

1. the financial situation;

2. digital strategies;

3. future functions; and

4. outlook.

1 The interview with representatives of libraries took place on 15 April 2013 in the Berlin-Brandenburg Academy of Sciences and Humanities. Participants included Norbert Lossau (Niedersächsische Staatsund Universitätsbibliothek Göttingen; part member of the interdisciplinary working group); KlausRainer Brintzinger (UB LMU München); Christoph Bruch (Helmholtz Open Access Koordinationsbüro); Petra Hätscher (UB Konstanz); Wolfram Horstmann (Bodleian Library, University of Oxford); Anne Lipp (DFG and leader of the Scientific Literature and Information Systems group); Frank Sander (Max Planck Digital Library); Peter Schirmbacher (Director, Computer and Media Service, Humboldt University). 


\section{The financial situation of libraries}

First of all, the central question whether the imbalance between the size of the libraries' budgets and the prices demanded by publishers is the result of insufficient financial resources made available to libraries or of excessive prices on the side of the publishers, cannot be answered fully. Indeed, large publishing companies have pursued an aggressive policy regarding prices which has provided them with high profits. The financial means of the libraries, however, have not increased accordingly. As a result, the current (financial) situation of libraries is thus considered critical. Some libraries have resisted especially Elsevier's pricing policy by cancelling all contracts (as the University of Konstanz did). The University of Göttingen also cancelled contracts with Elsevier a few years ago after the publisher wanted to increase prices by twodigit percentage points due to a new business model (Web Editions). Together with the Committee for Development and Financial Planning of the Senate, it was agreed that in such cases of price increase, an automatic cancellation would be implemented. Other institutions of the university were free to decide whether to keep subscriptions and pay for them themselves, which was ultimately done by the Department of Medicine.

Financial restrictions can have dramatic consequences for so-called 'singlelayered libraries' (such as at the universities of Konstanz and Bielefeld, where there are no separate libraries for institutes or departments, but only one central library). If cancelled journals or books are no longer available, there are no other opportunities for scientists. As a consequence, countermeasures have to be taken early on, for example, in the form of initiatives in the delivery of documents and 'just-in-time' provision of literature via individual sales of articles in the most convenient way. In the life sciences, the natural sciences and medicine, alternative ways of obtaining literature have emerged. Articles are deposited on working group servers, the existence of which nobody officially knows about, or colleagues who have access to them pass them on to the respective groups.

Financial limitations have led libraries to introduce stricter control, which, in turn, resulted in competition among the disciplines due to different costs and demands. The costs can be calculated per access due to lists indicating the costs of journal and accesses.

At the University of Göttingen, the representative of the library, a scholar of medicine, ordered that everything costing more than $€ 15$ per access is to be cancelled. The natural and life sciences pay far less than 50\%. Especially in medicine, funds are allocated according to performance-oriented funding. This policy, however, can only be pushed through to the detriment of the humanities and social sciences. 
The financial crisis of university libraries becomes obvious in view of the monetary appropriations. According to the Deutsche Bibliotheksstatistik, the overall expenses for acquisitions of academic libraries were around $€ 300$ million in $2011 .^{2}$ The proportion for the acquisition of digital media was $38 \%$. The budget for literature as part of the appropriation of the state of Lower Saxony (and thus the budget of the Göttingen library as such), for example, has not been increased for the last approximately seven years. At the University of Göttingen, the budget for literature was capped at around $€ 3.6$ million.

The Max Planck Digital Library (MPDL) receives part of its money from the research budget of the institute to spend on literature. As a result, it was able to negotiate with publishers and to make so-called 'big deals' at reduced costs, something smaller libraries are not able to do. Already in 1999, the budgets of all institutes were combined, so that the Max Planck Society (MPG) receives a large part of its digital access in a central manner through the MPDL. This is approximately $80 \%$ of what the Max Planck Society cites. About $10 \%$ of this is open access, while about $10 \%$ is acquired by the libraries of the institutes.

The financial crisis of libraries is determined by three major factors:

- the pricing policy of the (large) publishers, which have obtained an oligopoly status;

- the mechanisms of receiving and attributing reputation (branding) within science; and

- the resulting competition between scientists, universities and research institutions and between disciplines (prices of journals in different fields of research differ significantly).

The interaction of these factors leads to the helplessness of libraries with regard to the pricing policy of the publishers. This is discussed next.

One problem is the fragmentation of libraries as negotiating partner of the publishers as well as the latter's lack of transparency regarding contractual design. The overall volume of turnover of the three largest STM (science, technology and medicine) publishing companies in Germany, for example, is unknown. For Elsevier alone, it is estimated to be around $€ 30-50$ million. Companies like Elsevier negotiate contracts with confidentiality clauses. ${ }^{3}$ A large number of contracts are not made public. In part, universities ignore this confidentiality agreement by referring to the accountability obligation towards parliament and the respective ministry, ${ }^{4}$ which is then also not

\footnotetext{
2 See https://www.hbz-nrw.de/dokumentencenter/produkte/dbs/archiv/auswertungen/wb_gesamt_1l.pdf. See Pampel (2014) and Gutknecht (2014).

This obligation is de facto fulfilled towards the audit courts.
} 
contested by the publishers. German library statistics nonetheless provide the opportunity to record the costs for electronic media, at least for the large full universities, where most of the funds are spent on publications in the fields of medicine and life sciences. (The government of Baden-Württemberg has meanwhile developed an e-science strategy, which is supposed to make costs for subscription contracts transparent. $)^{5}$ There is consensus that such a publicity obligation should be implemented. ${ }^{6}$

The attribution of reputation and gaining of reputation within science are based on the practice of publishing, i.e. on the specialised journals and their functional equivalents (monographs and anthologies). As a result, scientists are inherently dependent on the publishing companies. This dependency has even increased due to the introduction of performance measures that are based on publications. In recent years, the significance of evaluation has increased dramatically. For example, the journal impact factor (JIF) frequently serves as a performance measure, i.e. articles are weighed according to the JIF of the journal in which they appear, and this is then attributed to the author. For scholars from the humanities and social sciences, the same holds true with regard to publishing companies. A publication is thus evaluated based on the reputation of the publisher. Both measures have become indicators of quality that are supposed to replace existing qualitative performance measurement from 'outside', i.e. without actual reading of the publications.

This connection between the reputation system internal to science, politically promoted performance measurement and the commercial publishing landscape needs to be seen as very problematic. Publishers are interested in the development and marketing of their 'brands', that is, the JIFs, are attributed to the individual journals. This assumption occurs primarily from commercial and not scientific points of view. A publisher is interested in how many journals it has with high JIFs, or in which disciplines it has a renowned brand. The more journals with high JIFs are concentrated in one company, the stronger the position of that company in negotiations with libraries. The creation of brands is, however, not the result of the concentration of publishing companies but derives from science itself since scientists (and politics) need an instrument of evaluation. It is thus not clear whether the dependence on the creation of brands, which characterises the area of the subscription model, will not be perpetuated in an open access (OA) world.

From the perspective of the libraries, it is assumed that scientists are interested in a continuation of the situation. (This may be due to the fact that

5 E-science: Wissenschaft unter neuen Rahmenbedingungen [Fachkonzept zur Weiterentwicklung der wissenschaftlichen Infrastruktur in Baden-Württemberg].

6 This demand is also included in the Amsterdam Call, see http://www.eu2016.nl/documenten/ rapporten/2016/04/04/amsterdam-call-for-action-on-open-science. 
they are pressured to publish at certain locations and therefore fear changes that would impair their opportunities in publishing in conformity with the system. A restructuring of the evaluation system would perhaps also lead to changes in this position.) Accordingly, the scientist pays for everything, they negotiate everything in their employment interviews, they know exactly what they cost and what their research costs. They just do not know what scientific publications cost and to what extent they are a burden. In contrast to librarians, to heads of universities and also to funding organisations, the scientist has an influence on these costs. ${ }^{7}$ The scientist submits their papers for publication but the costs do not reach them or their budget. (Exceptions are those disciplines - social sciences and humanities - where scientists earn money through the publication. In the natural sciences, however, only editors, not authors, earn money.) From the perspective of the scientists, only adequate framework conditions for research are necessary because these are decisive for obtaining reputation. The latter is the basis for competition among scientists. It is extremely dependent on time, and the introduction of performance measures has even increased this time pressure. This hardly leaves room for a long-term, strategically reflected and critical position towards the application of performance measures and alternative models of publication.

The same logic can be found for universities. They are in competition with each other, and the intensity of competition has increased with the growing number of evaluations. Rankings are the decisive measure. Ranks decide about the possibilities of hiring the best scientists and being able to choose students, etc. It is extremely difficult and thus unlikely to bundle the resulting interests, so that universities can confront the publishing companies, who almost have a monopoly, with a respective market power. Since it is about securing and stipulating the status quo, it is not possible to organise the system in such a way that all scientists and the public as well as the enterprises have information at their disposal from which they can benefit. This has significant disadvantages for science, the economy, the state of information of citizens and thus for democracy.

The current and future situation of the libraries also has to be seen against the background of the particularities of the publication market, i.e. the traditional subscription market and its recent changes.

In competition theory, the concept of the relevant market plays an important role. The relevant market is not the market for services in general. In scientific publishing, this category refers to individual publication. The respective

7 It remains unmentioned that libraries do not have to keep subscriptions but can cancel them. Funding agencies can enact guidelines for publishing of supported publications as the American National Institutes of Health (NIH) have done, and university administrations can back their libraries and issue OA policies like Harvard University, for example. 
publication is generally not substitutable, except for the literature it cites. The economy of publishing in general was, until 15 years ago, driven by the costs of publication, which were of a physical as well as organisational nature. Through digitisation, however, the dissemination of publications has become nearly free of costs. This is not true of the processing of publications though. It is economically interesting that in the case of an electronic publication, there is no rivalry with regard to consumption: the consumption by one individual does not exclude consumption by another individual. This is different in the case of a printed book or a printed newspaper, which can only be read by one person at a time. If the publications do not appear open access, they compete but individuals are still excluded from using them. Economists then speak of 'club goods'. These are usually inefficient from a welfare economy perspective since it would be possible that a large part of consumers use this good without there being any kind of wear or additional costs. ${ }^{8}$

Perhaps this explains the tendency of large publishers towards abandoning the traditional model of publication (this is, for example, indicated by the acquisition of the software programs PURE and Mendeley by Elsevier). For some years now, it can be observed that publishers directly negotiate with the heads of universities instead of libraries. They create new channels of communication to university leaderships and offer them tools for research evaluation in which they increasingly invest. In principle, all large publishers have already strategically placed their bets on these so-called 'value-added services' with which they want to involve scientists and research institutions more strongly. The establishment of publication management and research information systems at universities and research institutions once again increases scientists' dependency since it requires obtaining literature from the large publishers' platforms. The chief executive officers of Elsevier openly say that, at least in the STM disciplines, the subscription model will disappear and all publications will be open access. This will, however, only be the case in a basic format. The value-added services, i.e. the data generated with the publications, will remain under the control of the publishers and will stay part of their platforms in order to be sold at high prices. Elsevier's refusal to release the 'text mining' rights and rights to evaluate reference lists has far-reaching implications. On the one hand, the data are needed for the control of the network between the publications in order to understand how publications are connected. More specialised criteria of evaluation can be developed from this. The entire bibliometrics depends on these data. On the other hand, the

8 This argument depends on several factors. Open access provides a public good without the property of a commons. The digital publication, which is subscribed to by libraries, is a club good without competing consumption. The printed publication, which is bought by libraries, is a club good with competing consumption. 
development that the reading of texts will increasingly occur with the help of machines can be derived from this. This, too, will then be controlled by the publishers. In 10 years - at the most - the business model of Elsevier will be the dissemination of these data. Data from data banks like SCOPUS or Web of Science will be released in raw format. They can be used as tools in order to retrieve them but libraries are de facto forced to buy the licensed data back from them.

Libraries increasingly depend on systems like Alma, Exlibris or OCLC. Consequently, they later have to buy back their own catalogue data. Libraries licence the raw data themselves but the conditions under which they are licensed indicate that the relevant publishers are preparing to be in control of this strategic asset. What this means for future science and copyright is unclear.

One resulting imminent danger is in the feedback effect between the generation of data that are used as tools for research evaluation, and the commercial interests of the quasi monopolist Elsevier. ${ }^{9}$ It makes it possible in principle that data, such as the JIF, can be steered. Representatives of large universities point out that they depend on the cooperation with large publishing companies in the development of these systems because their data are the 'currency' without which they cannot do. Although they deem it necessary to react, they do not yet know what a reaction could look like. The interest in the JIF, which is shared by scientists, university leaderships and science policy, stabilises the current system due to a lack of alternatives.

\section{Digital strategies of libraries}

The digital strategy of libraries includes the creation of repositories for digital secondary publication (and connection with research data) as well as the different pathways of first publication.

\subsection{Repositories (green open access)}

Repositories are data storage platforms that serve to make publications (unpublished and published) as well as research data available via the Internet to all interested (the so-called green open access). Repositories are therefore mainly operated by universities and research institutions. The institutional repository has established itself entirely, albeit to different degrees. Almost every university meanwhile has one in one form or another. The success of

9 Note: A distinction needs to be made between citation and other bibliometric data that serve the construction of indicators for performance measurement and evaluation, and metadata which merely describe the publication. 
a repository depends on how deeply rooted it is in the respective institution, for example, to what extent the members of the institution deposit their contributions in it. For a long time, universities did not know how many publications emerged per year within their own walls. Repositories are used as tools, as hub, as statistical tool for their own publications and for sustainable value-added services, and they also serve one's own monitoring.

Disciplinary repositories need to be distinguished from institutional repositories but should not be seen as an exclusive alternative. There are disciplinary repositories (such as ArXiv in physics) that are indispensable. Gaps remain within these disciplinary repositories, however, and it is unclear who is responsible for closing these gaps.

The leadership of the respective institution needs to make sure that publications are deposited in the institutional repository. This is best achieved if all internal research proposals and the like are only processed via links on the respective database. Another location should serve to receive research data. First of all, it is about securing one's own output. This, however, does not yet ensure the provision of information to third parties. One legitimation of the institutional repository or comparable databases for research data thus lies in securing one's own output. This is followed by the question how science organises the exchange of information across individual institutions. Disciplinary repositories and repositories for research data could take on such a provisional role but this does not necessarily have to be so. In this connection, we speak of a global information provision. Thus, a certain amount of professionalism is needed, which, in turn, requires a certain amount of staff with regard to the individual database. A further issue lies in how it can be tested what is being made accessible to third parties and when. According to many representatives of libraries, accessibility to the outside is viewed by many as a problem.

Another problem from the perspective of libraries is seen in the contextualisation of the frequently discussed amount of data. This means that the central task of libraries is the organisation of the environment of research data, and the integration of the information received by libraries into the working environment of the scientists. This includes the integration of information flows that are acquired or made available through open access. This also goes for the information that is licensed and made available again. The task is to integrate this information into the self-designed working environment of the scientist so that it is permanent and complete, which is a complex challenge. In this context, the question also arises as to why there is no 'German academic cloud'. Scientists rely on online storage such as Dropbox, even though they are being warned by information technology experts and librarians that this is an extremely unreliable platform. The interest in these services shows, however, that there is a demand. 


\subsection{Digital first publications (gold open access)}

With regard to the digital strategy, special attention should be paid to making open access a reality. There is broad consensus within science on open access, albeit not to the same extent in every discipline. As soon as the debate concerns the implementation of the next steps, however, there is a broad heterogeneity of opinions among scientists, so that no consensus can develop to form an effective strategy. A positive example is the geosciences. Geoscientists were able to formulate a clear strategy within the society of their discipline, the European Geosciences Union, when defending their profile against their American counterparts. The Union agreed to create new OA journals with an innovative peer review model - a pre-print server where discussions are possible - which then provides clear pathways of publication, i.e. academic journals. This quickly led to high quality and anchoring within the community, partly because Nobel Prize laureates were willing to serve as members of the editorial board in order to concentrate reputation in these journals. In this case, it was confirmed that reputation eventually lies in science, not with the publishers. This way the large publishers were kept at bay, and with a very small publisher something was developed the way the society wanted it. The European Geosciences Union thus achieved a functioning countermodel in a very short time. It established top-quality journals with high impact factors, which have cost relations that are very different from those of commercial journals. The largest benefit of open access may lie in the fact that open access displays more transparency with regard to costs, something that is often criticised as lacking in subscription prices. The example of The Economic Journal, which switched from Elsevier to Wiley, shows that it is possible to change the publisher without losing reputation. The journal, which belongs to the Royal Economic Society, has become much cheaper, i.e. the cost-benefit relationship for science has improved.

Another side of the problem is to have a balance between quality and open access. A journal that appears open access should not be of lower quality or should be just as good a brand as one that is published by a large company and for which subscription fees are being paid. Many reservations towards open access are based on scepticism regarding the quality of OA journals. It is surprising that a mechanism such as the choice of renowned editors in the natural sciences tends to be forgotten. In the humanities, it is still present and may be one of the reasons why the JIF is not needed there. The editor offers his/her name as a 'brand', which guarantees that what is published within a volume has a certain quality. Nobel Prize laureates and/or an accordingly renowned editorial board fulfil this function. If these conditions are not stated, the JIF takes on the role of a surrogate indicator. 
Other specialised societies do not show such a development. They may agree that open access is desirable but there is no broad consensus on how it can be achieved. Thus, these societies remain in the subscription model and do not even take the step towards hybrid formats such as Springer open access. Libraries can help in this situation but they cannot provide strategic guidance. This has to be done by the society itself. The different options are the creation of archives, the model of the geosciences, or the classic open access journal. It is decisive that there is agreement on a format in which one is able to act for three to five years.

One decisive factor for the strategies of libraries is the expectations of the scientists. They want to have everything online first, but then it should also be made available in other forms (e.g. printed monographs or anthologies). For scientists, it is a huge step to abandon a certain expectation towards libraries. Especially in universities mainly oriented towards the humanities, for example, this results in costs that need to be covered. Attitude and expectations on behalf of the scientists can also be understood as differences between authors and recipients. Bringing these two roles, which every scientist plays, into alignment would be a significant step as the conflicts of interest would then have to be discussed internally, namely to have easy electronic access as early as possible (at least in disciplines in which writing plays a major role, thus in most humanities), but to have the printed book or article on the bookshelf, even though one is aware of the fact that most scientists would prefer to make use of these in electronic form. The societies of respective disciplines are called upon to discuss intensively how these attitudes and behaviours could be aligned.

Indeed, the proportion of OA publications in relation to the subscription business is increasing. For many years, the latter has been decreasing. Looking at the overall output of science, the increase of the publication cloud lies with OA publications. This means that the change is already under way. Still, there is consensus that the transition from a common subscription economy to the OA world is not without difficulty. However, different pathways are taken, which entail different costs. In Great Britain, for example, it was assumed that a push was needed and that costs of transformation would emerge, which would then be paid by politics. ${ }^{10}$ Some believe this is the right way to implement a temporary programme, which should serve to complete transition from subscription to the OA world. Other solutions also have their advantages. The solution of the German Research Council (DFG), for example, is to introduce a cap on the costs and to enable a strong institutional influence by establishing a grant proposal procedure. This is in contrast to Great Britain where the funds

10 Here it is about paying the article processing charges via public publication funds. 
are allocated according to a bibliometric indicator. The German approach is to reallocate funds from subscriptions to gold open access. ${ }^{11}$ One question then is how the budgets for article processing charges (APCs) should be administrated. Here, the state level is considered appropriate because competition, aside from efficiency, is considered important. The complaints concern the high costs. Ideally, costs should be lowered.

For example, in 2003, the MPG combined budgets with the advent of gold open access, so that it now has one budget from which subscriptions and APCs are paid. Moreover, the same budget also pays membership fees. This is done intentionally because it allows a deeper entry in contractual negotiations. It is then a judicial question whether a membership fee is paid per publication or per access. If the budget for the publication fund lies in the department or the faculty and the subscription budget is with the library, then a conflict that cannot be solved and which a commercial publisher will readily exploit to demand a constant growth for both budgets is apparent. Therefore, it seems important to combine them.

Pressure can be exerted on publishers via the publication fund, which, from the perspective of the publishers, is a new fund. If the publisher makes a new offer, the focus should not only be on what is offered directly with regard to gold publication, but OA fees should also be paid to publishers who have a reasonable green policy. This would be an important part of a digital strategy.

The funding of scholarly journals is in most disciplines done via the library budget. (This statement, however, disguises the proportion which often comes from other budgets in the form of page or colour charges. With that, information about how APCs should be financed in the future can be obscured.)

At large universities, these library budgets are large central funds. From the perspective of the individual actors, it is indeed rational to use them largely for oneself. Even where quotas have been introduced, these funds are not constructed to remain stable with regard to prices. If that were the case, then the life sciences would not have had money for funding for a long time. If no quotas are applied, regular ownership rights to these funds are missing. Economists then speak of common pool resources, which are goods that are basically in competition but where the principle of exclusivity is not realised.

The central question is what happens during the transition to the OA world. In a pure OA world, there are two possibilities. One is that there is a large university or even better a national budget to which everybody has access. The

11 This pre-empts the development insofar as it is being discussed but has not been decided. See Schimmer et al. (2015). CC-BY 4.0, http://creativecommons.org/licenses/by/4.0/ (31.05.2016). Evidently, there is a divergence of interests between local libraries and national actors (MPDL, DFG). The pooling of publication funds would concentrate negotiating power. On the other hand, this is a counter to the interests of local libraries that want to retain their budgetary sovereignty. 
second possibility is that an attempt be made to combine the responsibility for the reception of scientific publications and the responsibility for support, i.e. for resources that fell apart in the subscription world. This would mean that the individual scientist - or in most natural sciences the individual working group, the institute, the clinic - once again is responsible to finance the contribution to a publication from their own money.

In recent years, the APCs have increased significantly. ${ }^{12}$ In order to stop this trend, there needs to be a common effort instead of leaving the responsibility of gathering funds to the individual scientists. In view of the development of the APCs, it is feared that, after the establishment of large central budgets for OA financing, the same will happen as did previously in the subscription world, namely that the journal crisis is followed by an article crisis, and the explosion of journal prices is followed by an explosion of APCs. This will also be due to institutional reasons since large budgets will be created and the responsibility will be taken away from the scientists. OA funds can play a useful role as an incentive during a transitional period. This, however, is only the case if they entail a transformation strategy from the beginning, which cannot reside in the central budgets. Therefore, the DFG programme seems to be the right way.

The transition to a complete OA world implies three basic distribution effects.

- First, an international distribution effect, i.e. allocation from countries with low research output to countries with high research output. In the extreme case, this means relief for developing countries and a burden on industrial nations.

- Second, there is relief for applied research and a burden for basic research. This especially concerns applied research in chemistry, materials science and similar areas which have brought money into the system but which will bring less money to an OA world because they will conduct less research and take on a more recipient role.

- Third, and this is decisive, there are vertical effects between the research institutions and especially between universities. This needs to be emphasised because it will be very controversial. Relief will be on the side of less research-oriented institutions, and the burden on the side of top-quality research.

Regarding a nation such as Germany, this means that the different institutions need to distinguish themselves even more. Top-quality institutes would then

12 There are efforts to track the use of funds from publication funds. Cf. https://njahn82.github.io/ unibiAPC/. 
receive more money while those conducting less research (for example, up to the application-oriented institutions) will be relieved but will receive less money as well.

It can be said that management on the one hand lowers the costs significantly. On the other, if the same processes can be used systematically, the number of personnel can be reduced. Tools have yet to be found to process APCs more efficiently. There is consensus that an institutional publication management is needed. The institution needs to know what scientists have published, where the publications are eventually deposited - whether in a journal, a special or institutional repository - as well as their number. Multiple deposits should not be seen as a contradiction but as a complementary approach. A publication is primarily assigned to a discipline because it belongs to the communication of that discipline. Thus, the respective scientific community should decide about the procedure. For example, in physics, a pre-print version is deposited on ArXiv before the article is published in a journal. Each scientist, however, is assigned to an institution that is interested in conducting its own publication management. In this regard, open access is the best paradigm. If the publication, including the metadata, is free, it is also easier to support such processes via automated interfaces.

Questions remain:

- First, what does the plurality of journals, which develop in the realm of open access, but which are not yet established with respect to their reputation and editorial boards, mean in practice if, on the one hand, it should be avoided that they disappear again, but, on the other hand, misuse should be prevented?

- Second, what are the experiences with overheads, i.e. what size are the burdens for the overall financial system if the model of APCs based on individual article costs is successful in a broad sense?

- Third: A science policy question is why the DFG does not advocate a secondary publication in a green model. In the usage guidelines of the DFG, there is a passage which states that the DFG expects availability of results from DFG-funded projects in open access. This, however, is only an expectation, not an obligation, as in the National Institutes of Health. Making it an obligation is not possible due to the freedom of science (which includes the freedom of publication), as stipulated in the constitution. Thus, it is a special situation in Germany.

It is also a 'good old DFG tradition' that rules hold true for all disciplines. There seems to be a slow change in thought in this context. The 'one-size-fits-all' view is no longer appropriate. Therefore, a broader discussion needs to be 
initiated to achieve different speeds in the fulfilment of obligations according to disciplines, maybe also types of research, in other words empirical or heuristic disciplines.

\section{Future function of libraries}

The change in the function of libraries is manifested in the collaboration between libraries and data centres. At the library of the Humboldt University, for example, this collaboration started in 2003 with the founding of a working group, which has conducted a number of projects on the infrastructure of information since then. ${ }^{13}$ Information infrastructure is a kind of service just like the service publishers provide to science, and it should eventually be led and dominated by science. There is, however, an imbalance because publishers in the STM field define themselves as infrastructure to a certain degree. The division of labour, in which scientists can expect that publishers take care of publication, could change insofar that, for example, libraries or university publishing companies become involved in initial publication. ${ }^{14}$ DINI, the German Initiative for Network Information, has defined a number of points in the DINI certificate, ${ }^{15}$ such as the counselling of authors. This must be taken into account as a main task of service centres.

A common task of libraries and data centres is long-term archiving. Authors can hardly take responsibility for this, even though they first have to be convinced that 'Word for Windows is not suitable for this in spite of Microsoft's power'. Authors need to be taken on board, and this should be done in collaboration between libraries and data centres. Neither individual universities nor the German National Library can take care of the storage of long-term digital data. Political decisions for a decentralised system are long overdue. If they are not made, it can very well be that commercial players fill the gap and find a good field of activity. The experiences with the Mendeley program are a pertinent but also discouraging example of how a useful and appropriate service for science suddenly turns out to be part of the private sector. ${ }^{16}$ In a library system, such as the Bodleian Libraries in Oxford, which

13 See WR (2011a: 16; $2011 \mathrm{~b})$ and WR (2001).

14 This touches on the fundamental question whether libraries should be private, commercial or public organisations.

15 https://dini.de/dini-zertifikat/?optout=18no_cache=1.

16 Mendeley is a program for processing data on literature which was developed by a start-up and sold to Elsevier in April 2013. Users criticised the sale decision due to the fear that Elsevier could check the PDF libraries of Mendeley users with regard to copyright violations. 
consists of several sub-libraries and autonomous college libraries, tensions between the traditional functions and the new ones are particularly strong.

There are two kinds of services a library provides today: services for the author and services for the reader. This is new because there used to be only the service for the reader. But what does the library do for the author? The support in publication (insofar it exists) is new, for example, it produces publications, consults in issues of publication, i.e. in what form publications should appear, how to handle the formats, or according to which criteria providers or publishers are chosen. Furthermore, it assists in matters of open access, pointing out which providers offer open access with the desired services, etc. This also includes issues of archiving, the institutional repository, informing yearbooks, etc. These are all tasks that are new and that were not part of the library before.

On the side of the reader, which was always part of the library, things have changed as well. In general, this concerns the provision and assurance of accessibility to publications and, in particular, the legal complications that have resulted from the digitisation of licencing management. With the printed book, it was simple: if you had it in your hand, you had it in your hand. There was also the photocopy but the situation was clear.

With OA material, the classic function of libraries as place where literature can be found has changed. It is no longer sufficient to go to a library and look at the catalogue; the extensive OA material also has to be taken into account. The issue of access has also resulted from digitisation because an identification procedure to a publisher's server or other provider, such as JSTOR, has to be determined.

The new function of libraries together with data centres has also been characterised as the function of knowledge management, for publications, for research data and for any type of intellectual output. In the end, this means that every university and infrastructure is responsible for providing research, teaching and other output in a form that corresponds to certain standards, so that it can be accessed and used internationally in a network or system. A prerequisite is consensus regarding the standards. Network means a plea for a decentralised system and against a large super-institution. For this purpose, international or global communities need to be established.

In the digital sphere, libraries also maintain functions that require local knowledge, for example with regard to systems. This, for instance, goes for author identification or for information about individual departments or individual research projects. This knowledge needs to be administered in the digital system. The complete depersonalisation that resulted from digitisation needs to be turned around, and the respective knowledge needs to be returned to the library. This knowledge management has to be administered locally, 
which is easy in principle. Aside from the digital realm, there is the physical one. Spaces are being provided, as has already begun. Libraries thus serve as meeting points. The rooms that are no longer used for books are transformed into rooms for learning and research.

The future of libraries will also be characterised by the development of the communication media. PLOS ONE shows similarities to the established communication system. Looking at the volume of communication in PLOS ONE and extrapolating it, and assuming further that there will not be saturation, then within three to five years, 60 to $70 \%$ of STM publications will be published in PLOS ONE. Another aspect concerns the trend towards atomisation of publication forms in software codes, annotations, living reviews, a continuous form of publication. It is not yet certain whether this trend towards atomisation of publications and scientific communications will not lead to the commercial system being superfluous or whether the system will take on an entirely new form. Phenomena in the commercial field such as Figshare ${ }^{17}$ or a whole new series of enterprises that deal with publication of individual aspects of scientific results, all point towards even more decisive changes. In the not too distant future, there will be journals in which especially datasets and other failed experiments will be published. Those who want to know what failed know where to look. How can processes of differentiation be initiated, which then in turn allow the recipient to proceed in a selective manner?

Especially the hosting of research data is a task that is not administered by one organisation only. In order to assure professional data security, professional units are needed that have a certain size and need to be financed. Which services can be provided in-house and which outside, and which finance mechanisms are required, lead to the question about which tasks are better done by a commercial service provider and which by an internal infrastructure. In principle, academic publishers are interested in science organisations providing expensive hosting and adding metadata for research data. These infrastructures, however, are lacking or are only available in individual cases, and the financing remains unclear as well. The operators of repositories of research data do not have a clear model of long-term financing and ideas about their costs, nor do those that deposit data have an idea how much they actually have to pay. With regard to the future functions of libraries, it is an interesting question how the division of labour in publication management will develop between the libraries and the individual disciplines.

17 Figshare is a repository where users can make their research output accessible in a format that can be cited, shared and found (see http://figshare.com/about). 


\section{Outlook}

It is important that scientists, as actors, return to the arena in a stronger way. This also corresponds to the motto of SPARC, the Scholarly Publishing Initiative, a few years ago: 'Give scholarly communication back to scholars' or 'give scientific communication back to science'. What influence do scientists as producers of knowledge have on the publishing market? In the view of some representatives of libraries, open access is superior to the subscription model in terms of welfare economics because a more efficient allocation can be achieved if the budgets are used adequately. Therefore, the transformation should be pushed forward quickly.

Regarding the role of libraries, the interaction between scientists and librarians as well as all those involved in the development of research and information infrastructure becomes ever more important. The overarching goal is to make the global knowledge of science available in open access, in a format that makes it possible to gain new knowledge via scientific methods. And this is the big difference from what is currently being offered as open access by the publishing companies: only a basic format that does not allow text mining or algorithms. The term 'open science' was mentioned only once in the discussion. The entire process of research should be free, not only the publication. Research data are a part of this. The discussion about what all belongs to this process is still at the beginning. We do not know how to describe it, how to document it and how to prepare it for long-term archiving. It is, however, decisive in order to reach the next step after open access, which would then be the step towards open science, so that the entire process is laid open.

To realise this, it is necessary to truly perceive the market power of scientists and their institutions. In order to control the growing market power of publishers, there needs to be a closer collaboration between science and infrastructure institutions. The libraries are at the bottom of the chain; the scientists at the other end of it. Moreover, science policy needs to initiate this process and, if it takes place, scientists have to support it. Against this background, a decentralised model is favoured because it is a rapidly developing system. Experimenting with different solutions needs to be possible. Certain solutions also need to be able to fail, and this has to be accepted in the financing of different initiatives. A point where the system could derail is the question of what exactly is to be understood under 'open access'. The publisher side currently attempts to redefine this concept. A kind of position could be introduced which evaluates - according to legal rules - whether it is open access in the sense of the community. 
Another issue is that of references. Publishers position themselves as reference databases. The acquisition of Mendeley by Elsevier is probably also due to the fact that Mendeley is establishing a reference system.

\section{References}

Gutknecht, C. 2014. Intransparenz bei den Bibliotheksausgaben von Schweizer Hochschulen. Retrieved from http://wisspub.net/2014/10/13/ intransparenz-bei-den-bibliotheksausgaben-von-schweizer-hochschulen/ [Accessed 17 January 2015].

Pampel, H. 2014. Offenlegung von Open-Access-Publikationsgebühren in Deutschland. Retrieved from http://albertopen.telegrafenberg.de/?p=931 [Accessed 17 January 2015].

Schimmer, R., Geschuhn, K.K. \& Vogler, A. 2015. Disrupting the subscription journals' business model for the necessary large-scale transformation to open access. A Max Planck Digital Library Open Access Policy White Paper. doi:10.17617/1.3

WR (Wissenschaftsrat). 2001. Empfehlungen zur digitalen Informationsversorgung durch Hochschulbibliotheken. Greifswald: Drs. 4935/01.

WR (Wissenschaftsrat). 201 la. Empfehlungen zu Forschungsinfrastrukturen in den Geistes- und Sozialwissenschaften. Berlin: Drs. 10465-11.

WR (Wissenschaftsrat). 2011 b. Übergreifende Empfehlungen zu Informationsinfrastrukturen. Berlin: Drs. 10466-11. 


\section{A Participatory Experiment in Science Policy}

Results and Evaluation of the 'Publication System' Online Consultation

Niels Taubert \& Kevin Schön

\section{Introduction}

As part of developing its recommendations (BBAW 2015), the 'Future of the Scholarly Communication System' interdisciplinary working group (IWG) of the Berlin-Brandenburg Academy of Sciences (BBAW) conducted an online consultation. In this innovative online participatory approach, Germanspeaking scientists were invited to present their views on current problems and challenges in academic publishing and to formulate respective objectives. It was supposed to provide the IWG with input for developing recommendations. The goal of this chapter is to describe, reflect on and evaluate the experiences that were made with this participatory tool. This should provide insight into whether such an approach is in principle appropriate for gaining perspectives from within science, what the requirements are for such an approach and whether other areas of application and further development of the tool are conceivable.

The chapter is structured as follows. In the first section, the contexts in which the online consultation was set up will be described. The significant contexts are the working programme of the IWG, on the one hand, and the evaluation and decision-making procedures within the BBAW, on the other. In the second section, the goals and conceptual framework of the consultation 
will be described. This includes the relevant characteristics of the procedure, the description of the two areas of consultation and the mobilisation strategy. The subsequent quantitative analysis of extent and composition of participants will provide information on who made use of the participatory offer. In the fourth section, the results of one consultation area, in which scientists were able to state their position on the principles of a good publication system will be summarised. Here it will be documented in which form the contributions of the participants influenced the recommendations. In the second consultation area, scientists were asked to provide indications of the problems and challenges of publishing. The fifth section briefly summarises the results. The sixth section attempts to give an evaluation of the overall approach. The chapter concludes with an outlook on possible future use of participatory approaches within science.

\section{Setting up the 'Publication System' Online Consultation}

\subsection{Working programme of the IWG}

As stated above, the objective of the IWG was to develop recommendations on the future of the scholarly publication system. For this purpose, four large dynamics, which are usually only looked at separately, and which the communication system is currently subject to, were to be analysed with respect to their mutual interactions. These are the diverse influences of processes of digitisation, an increasing observation of publication activities by means of bibliometric and user-based indicators, the economic orientation of academic publishers especially in the field of science, technology and medicine (STM), as well as the repercussions that result from the observation of science by the mass media (medialisation).

The working programme of the IWG brought the perspectives of three groups of actors together. During three hearings with experts, the IWG made itself familiar with the perspectives of academic publishers and libraries. ${ }^{1}$ The perspectives of the most important group, the scientists, were revealed in interviews with representatives of different disciplines. ${ }^{2}$ In view of the significant differences in the communication cultures of the different disciplines, as well as those between generations of researchers and the framework conditions, the limitations of this approach quickly became apparent. In order to reflect this diversity adequately, interviews would have needed to be conducted

1 The results are documented in chapters 3 and 4 of this volume.

2 See the chapter 2 by Konstanze Rosenbaum in this volume. 
on a much broader scale than was possible in the context of the group. An alternative, however, was an online consultation. ${ }^{3}$

After hearing the three groups of actors and conducting the online consultation, the information gathered was summarised, evaluated and the recommendation text was formulated on this basis. In each session of the IWG, information on specific issues or challenges, such as access problems or unintended consequences of bibliometric indicators, were discussed and parts of the recommendation text were edited. After completing the recommendations, the aim was to publish them not as a group but in the name of the BBAW. For this purpose, the Academy has an evaluation and decision procedure (Nostrifizierung). ${ }^{4}$ The president of the BBAW is presented with the results and assigns a group of reviewers. After the review process and possible revisions, the text is discussed among members of the BBAW in classes. ${ }^{5}$ The board of the BBAW suggests to the council of the Academy whether to accept or reject the recommendations, which then decides.

\section{Concept of the online consultation}

\subsection{Objective}

In the online consultation, as many scientists as possible were addressed and given the opportunity to state their position on the issue. Participation served three purposes: ${ }^{6}$

Information: The most important objective by far was to mobilise the knowledge of scientists about the publication system of their discipline for the development of recommendations. This approach is in contrast to an expertoriented approach in which specialists are interviewed about relevant issues, such as digital publication, open access and long-term archiving, and whose expertise is subsequently evaluated. The main differences are not only the number of persons involved in the process, but also the type of knowledge that is mobilised. While experts provide a systematic and often theory-

3 Participatory online approaches have emerged in Germany especially in urban and regional planning. See Märker and Wehner (2008: 84-85), Albrecht et al. (2008: 35) and Märker (2010: 48-49).

4 The concept usually relates to the recognition of academic and occupational certificates of foreign countries. Here it refers to the recognition of the results of a working group of the academy as scientifically and/or socially relevant and based on scientific standards (BBAW 2013).

5 Members of BBAW are assigned to five classes: humanities, social sciences, mathematics-natural sciences, biosciences-medicine, engineering sciences.

6 See Nanz and Fritsche (2012: 31-35, 120-123). The term 'consultation' should emphasise the significance of the function of information. 
grounded knowledge, scientists have practical experiences in dealing with the communication system and the publication infrastructure of their discipline.

Legitimation: A second objective was to strengthen the perspective of science in handling the current challenges and shaping the scholarly communication system. ${ }^{7}$ Taking such a position as an advocate for science is particularly in need of legitimation. Thus, scientists - as authors and recipients - should be involved as the group for whom the functional context of the communication system is of central importance. ${ }^{8}$

Implementation: By involving a large group of researchers, the scientific community was supposed to be made aware of the topic of the IWG and of the current problems within the communication system of science. The approach itself, the continuous public documentation of the results and their use, as well as publication of the recommendations, aimed to put emphasis on the challenges and problems, and to strengthen respective initiatives and activities.

\subsection{Topic}

The topic of the online consultation was the scholarly communication system which, according to the understanding of the IWG, has three analytical dimensions. ${ }^{9}$ The first dimension includes all published communication by scientists, which addresses the scientific community and informs it about new discoveries and research results. In the literature, this is often called the formal communication system of science. ${ }^{10}$ Aside from dissemination, this first dimension also includes registration, certification and archiving of reported research results. ${ }^{11}$

The second dimension involves technological components, such as publication media (for example, journals, monographs, anthologies, conference proceedings and review literature) as well as institutions that serve the production and use of publications and publication media (for example, newspaper databases, repositories, specialised databases, search engines, citation databases, and online

7 This objective is in line with the intention of the academy to provide advice to politics and society and to promote science. Cf. http://www.bbaw.de/die-akademie/aufgaben-und-ziele/staatsvertrag-pdf and the constitution of the Berlin-Brandenburg Academy of Sciences and Humanities of 14 August 2012 (http:// www.bbaw.de/die-akademie/aufgaben-und-ziele/satzung-pdf).

8 Only in the section 'Principles of a good publication system' of the online consultation was it intended to achieve a consensus among the scientists. The idea was to achieve legitimacy by establishing a fair procedure in which all perspectives and interests could be articulated (Luhmann 1969).

9 A more detailed elaboration of this perspective on the formal communication of science is provided by Taubert (2016a; 2016b)

10 Gravey and Griffith (1967) and Whitley (1968).

11 For the functions of the formal scholarly communication system, see Kircz and Roosendaal (1996: 107-108), Andermann and Degkwitz (2004: 8), Hagenhoff et al. (2007: 8), Taubert (2016a) as well as Taubert and Weingart in this volume. 
editorial management systems). Since, taken together, these components have the character of an infrastructure, they are also called publication infrastructure. Organisations responsible for developing and maintaining these technological items (libraries, publishing companies, editorial offices of journals, as well as research institutions and specialised societies) constitute a third dimension that could be called service organisations.

\subsection{Characteristics of the participatory approach}

In the following, the most important characteristics of the approach are described. One significant characteristic is the openness towards setting new topics on behalf of the participants. It was not the aim to ask about predetermined dimensions of the formal communication system. Instead, the approach was supposed to be open and to enable the participants to come up with topics they regard as being relevant, and to articulate new and unanticipated perspectives. In addition, the intention was to depict controversial issues and perspectives. Therefore, the procedure was designed in a dialogic manner.

Together with a provider for participation services, ${ }^{12}$ an online platform was developed on which the consultation took place. ${ }^{13}$ The platform consisted of two areas, which allowed different kinds of participation. In the first area - in the following termed Principles for a Good Scholarly Communication System (or 'Principles' in short) - the focus was on finding out whether there was a general consensus within science of what a desirable communication system would look like. In order to achieve such a consensus, it was considered necessary to focus the discussion and to provide pre-formulated, brief texts for discussion. The participating scientists were able to comment in this area on the six principles as presented and to provide their evaluation via supporting or rejecting votes.

The second area was to survey the participants' perspectives towards current challenges and problems of the formal communication system of science. Such problems could refer to science as a whole, such as, for example, general conditions with respect to copyright, as well as to individual disciplines. In order to enable the participants to address unpredicted topics and issues, this part of the consultation was characterised by a weak structure and openness. The Problems and Challenges area can probably best be described as a space for communication in which the participants were invited to formulate their problems to which other participants could then react. The platform allowed the

12 Zebralog (see http://www.zebralog.de).

13 This platform was available under http://www.publikationssystem.de until one year after the procedure had been completed. 
participants to comment on the topics or, again, evaluate them via supporting or rejecting votes. In order to focus the contributions on the topic of the online consultation and to provide a starting point for the discussion, two things were done. On the one hand, example topics were indicated on a slider at the top of the website of the area. On the other hand, members of the IWG described problems and posted short descriptions at the beginning of the process in the consultation section. In order to create transparency, the authorship of the contributions was indicated. A search tool provided orientation in the collected contributions and topics and issues. During the online consultation, the collection seemed to become blurry. Therefore a tagging system was introduced, which helped the participants to navigate through the descriptions of problems and challenges.

A further characteristic of the procedure comprised low hurdles in terms of the accessibility and use of the platform. All participatory functions, with the exception of positive and negative votes, could be used anonymously without having to go through a registration process. The evaluation function was protected by a registration procedure to prevent individual participants from voting more than once and thus distorting the results. ${ }^{14}$ In the course of the registration, the participants were asked to answer six personal questions voluntarily. These concerned their discipline, position, academic qualification, age, gender and institution. This information was surveyed in order to interpret the results of the procedure. Registered participants moreover had the opportunity to subscribe to a newsletter to stay informed about the further development of the procedure and the recommendations. ${ }^{15}$ In addition, information on the procedure and its embedding in the process of developing recommendations was made available on the website where the rules (netiquette) of the online consultation were also described. The platform also had a 'Praise and Critique' forum in which participants were invited to give feedback on procedural aspects or were able to ask questions. Contributions that were posted on the platform were immediately visible to other participants. The moderation was restricted to keeping the rules of the procedure in place and to responding to emerging questions.

14 This made it more difficult for participants to vote more than once on each contribution but did not exclude this possibility entirely. Experience shows, however, that this protection was sufficient and there were no indications that there were multiple registrations of individual participants.

15 To avoid stressing the attention span of the participants, newsletters were sent out on two occasions during the online consultation. After the procedure had been completed, the subscribers of the newsletter were informed about the initial results, the publication of the evaluation report, and the publication of the recommendations. 


\subsection{Addressees, mobilisation strategy}

As participants in the online consultation, German-speaking scientists from universities, non-university as well as privately funded research institutions were invited. In order to reach this group of addressees and to get them involved in the consultation, an extensive mobilisation strategy was pursued. The most important step here was the dissemination of invitation emails via mailing lists of research institutions and specialised societies. All research institutions in Germany as well as all German-speaking learned societies received emails and 205 scientific societies and research institutions agreed to disseminate the invitations. ${ }^{16}$ In addition, an email mailing list with interested people was compiled, and Facebook and Twitter accounts were created where the process of the procedure was regularly documented. Furthermore, the online consultation was announced on websites and in print media that were related to science.

\section{Extent of participation ${ }^{17}$}

A total of 697 persons participated in the online consultation. A large majority of 651 persons registered while 46 persons chose the role of 'guests'. Of the registered participants, the majority ( 542 people $=83.3 \%$ of registered persons or $77.8 \%$ of all participants) were willing to provide information about themselves voluntarily. These data allowed a description of the composition of participants. A strong diversity was achieved in terms of age, highest qualification, position, and (to a limited extent) discipline. The opposite was the case for gender and type of research organisation.

- The age groups 30-39, 40-49 and 50-59 each represented one quarter of the participants. The age groups 20-29 and 60-69 were each represented by a little more than $9 \%$.

- Highest qualification: $21.7 \%$ of the participants held an academic degree, $46.2 \%$ a doctoral degree, and $32.2 \%$ a habilitation. ${ }^{18}$

- Position: $34.7 \%$ of the participants had a professorship, $40.4 \%$ worked as research assistants or lecturers, $6.9 \%$ were doctoral students and $17.9 \%$ had some other position.

\footnotetext{
16 For the list of organisations that supported the online consultation, see Taubert and Schön (2014: $124 \mathrm{ff}$.).

17 The results of the online consultation are also described in Taubert and Schön (2015).

18 The highest qualification level attainable through a process of a university examination in Germanspeaking countries.
} 
- The humanities and social sciences were represented by $43.1 \%$, the life sciences by $26.1 \%$ and the natural sciences by $21.5 \%$. Of the participants, $9.3 \%$ were from engineering sciences.

- Gender: $74.7 \%$ were men and $25.3 \%$ women.

- Research organisations: The majority was employed at universities $(66.9 \%)$. A significant part of the contributors also came from the Leibniz Society (9\%), Max Planck Institutes (4.3\%) and Helmholtz Research Centres $(3.1 \%)$.

In summary, it can be said that the desired diversity in the group of participants was achieved. In the interpretation of the results, it was taken into account that the humanities and social sciences were strongly represented and that the online consultation predominantly reflected the perspectives of male participants employed at universities. Overall, the participants contributed valuable input for the development of recommendations, with reports on problems and challenges, 527 comments and 2884 votes.

\section{Results from the 'Principles' area}

In this section, the results from the Principles for a Good Scholarly Communication System ('Principles') consultation area and their influence on the recommendations are described. The principles for a good scholarly communication system discussed here were taken into account in the formulation of the final recommendation and represent an important pillar of the argument (BBAW 2015: 22-27). On the one hand, these principles formed the normative basis for evaluating characteristics as well as structures and mechanisms of the publication system as problematic or ripe for change. On the other hand, the principles provided orientation for desirable directions of development. In the next section, we briefly contrast the original formulation of the principles, the feedback of those involved in the consultation and the final version of the recommendations. This will make the influence of the feedback from the online consultation on this part of the recommendations visible. It has to be taken into account that the brief principles are supplemented by explanatory texts in the final version, which also explains the relationship between the principles. Due to limitations of space, they were omitted here.

\section{Principle 1 Freedom of scientific exchange}

The scholarly publication system should be oriented along the principle that it supports the free exchange of research results and scientific knowledge in 
the best possible way. Access barriers should be as low as possible, so that every interested person can participate in the publication system.

Of the 245 votes cast on this principle, $96.7 \%$ agreed and only a small number of $3.3 \%$ rejected the principle. In the comments, there were only very few requests for change/adaptation. It was questioned whether participation here should refer to the role of the reader, the reviewer or the author. In addition, it was controversially discussed what is meant by 'access barriers as low as possible' and how this could be put into practice. The final version of the recommendations is in line with the original formulation, albeit much briefer. The requested clarification was taken into account in the explanatory passages. The scholarly publication system should support the free exchange of research results.

Principle 2 Self-regulation by science/Self-regulation of quality

The exchange of research results should be determined by the criteria of the respective disciplines. The quality of a contribution should be defined solely through science itself and not through the influence of other factors - such as the public perception or monetary factors.

A full $85.6 \%$ of the 229 votes were in favour of this principle. The relatively large number of negative votes $(14.4 \%)$, however, indicated that there was need for revision. This concerned the unit that steered the exchange, which was not always adequately termed 'discipline' or 'subject'. Second, it was discussed to which aspect 'self-regulation' referred. This is clear with regard to 'quality' but not with respect to 'relevance'. Third, participants were asked to explain which processes are precisely meant by 'self-regulation'. The final version took these reservations into account, the principle was limited to the self-regulation of quality and a broader formulation was chosen for the steering unit.

The quality of published research results should be defined by the criteria of the respective fields of knowledge and not by the influence of other factors such as a specific media public or monetary incentive.

\section{Principle 3 Choice (of medium)}

The choice to publish as well as the choice about the adequate medium of publication should solely lie with the scientists responsible for the research 
results. A precondition is a plurality of publication media and the absence of strong mandates to publish in a certain medium.

Of the 203 votes, $84.7 \%$ were in favour of this principle, and the comments indicated that the principle was formulated comprehensively. A large number of comments and $15.3 \%$ of negative votes, however, indicated that there was disagreement. The participants were split with respect to the question whether the principle of choice should have its limitations in an obligation to publish open access. Here, choice and free accessibility were viewed very differently. Moreover, it was pointed out that restrictions of the principle of choice must not influence the mechanisms of recognising achievements in research. In the final version, all of this was taken into account. The final recommendation does not refer to an obligation of publishing open access, and does not exclude a limitation in the freedom of choice by a respective regulation.

In principle, the choice to publish as well as the choice of the appropriate medium of publication should lie with the scientists responsible for the research results. A precondition is a plurality of publication media and the absence of strong mandates to publish in a specific medium.

\section{Principle 4 Sustainability/Permanent accessibility}

With regard to publications, the goal is first of all to have permanent access as open as possible. This requires a reliable archiving of publications. Concerning the media of publication, this also means that the operation is permanently secured and that there are possibilities for change.

'Sustainability' received $98.6 \%$ (of 214 votes) positive votes. The basic formulation, however, was criticised. The discussion focused on the implementation of this principle. In the final version, the principle was therefore changed to 'permanent accessibility':

Open and permanent accessibility of scientific publications should be ensured.

\section{Principle 5 Transparency of funding/Competitiveness}

The scholarly publication system is financed largely by public funds. The recipients of these funds, therefore, need to lay open their extent and form 
of use. This concerns all recipients and, aside from the researchers, includes libraries, publishing companies, scientific societies and research organisations.

Of 191 votes, $16.2 \%$ rejected this principle. Together with the critical comments, this indicated a need for revisions. In the discussion, participants were first asked to clarify what the demand for transparency precisely refers to. Second, the benefit of transparency should be considered in relation to the resulting effort in documentation. Third, the generality of the principle was criticised, and it was pointed out that in using public funds, the state had an obligation towards the taxpayer, but enterprises do not have an obligation towards the state. Therefore, the demand for transparency could not refer to the 'use' of funds by the recipients.

Due to the clear and plausible criticism of the principle, the working group considered the general direction of the principle and a change of focus. The aspect of transparency was no longer addressed. Rather, the focus was on competition on the market for privately produced and publicly financed services in connection with scientific publication.

Within the chain of production of publications, part of the services are done by private enterprises and financed by public trusts. In order to prevent inflated prices, securing a functioning, competitive market for such services is a public task.

\section{Principle 6 Efficiency of resources/Saving of time resources}

The scholarly publication system should use resources in an efficient manner. It should only use as many resources as it needs to be successful. Efficiency of resources refers to the monetary resources necessary for the operation as well as the voluntary resource of time provided by the researchers in the role of author, reader, editor and reviewer.

The largest rate of rejection (29.8\% of 171 votes) concerned the principle 'efficiency of resources'. The main criticism was that the principle was too vague, the definition too imprecise, as well as the aspect of efficiency. A large number of comments referring to superfluous work phases in the production process of publications indicated, however, agreement with part of the objective of the principle. In the recommendations, the principle was redefined as 'saving of time resources'. 
The framework conditions of the scholarly publication system should be designed in such a way that the working time of scientists is not unnecessarily increased.

\section{Results from the 'Problems and Challenges' area}

In this second area of the consultation that focused on participants' perspectives towards current challenges and problems of the formal communication system of science, the participants discussed 124 problems and challenges, which covered a broad thematic spectrum. A large number of the contributions can be assigned to one of the following eight fields.

1. Printed and digital publication: One topic was the basic technologies of the publication media, print and digital technologies. Among the participants there were advocates for both whereas the positions strongly corresponded to the areas of science in which they worked. In the natural and life sciences, there seemed to be a preference towards electronic publication. In the humanities, scientists seemed to like both. The discussion made clear that the preference did not only result from habits of accessing or receiving but also from different attitudes towards the problem of long-term archiving, different understandings of 'good accessibility' and diverging patterns of ascribing quality to media of publication.

2. Business models of the publishing companies: The business practices of particularly the large publishers in the fields of STM were another major focus in the online consultation. Criticism of the business models referred to the costs of journal subscriptions, the revenues generated in this area and the structural problems of the market for scientific publications. As a result of the high prices, access problems were reported, which were especially apparent at locations that were financially weaker. Moreover, other interested people, such as experts, the interested public and journalists, were partly excluded from having access to publications. The business models were problematic in the humanities and social sciences since the licensing fees in STM bind large parts of the library budget, thus having a negative effect on literature in terms of monographs and anthologies. Suggestions by the participants on how to solve this problem mainly aimed at a weakening of the publishers' position and asking for a structural change.

3. Open access: This area shows strong reference to the preceding one. The majority of contributions welcomed the free accessibility of publications on behalf of the recipients. Two types of arguments supported this 
position: research that is publicly funded should also be publicly available, and open access has the potential to increase the dynamics of science and to improve the transfer of knowledge into fields of practice. In addition, advantages and disadvantages of the different types of open access (green and gold) were evaluated. It is worth noting that especially the gold open access model, financed by publication fees, was criticised.

4. Indicator-based performance evaluation: The basic tendency of contributions in this field was critical or even disapproving. Criticism was aimed at the pressure to publish, which leads to splitting research results into as many publications as possible, a growth in the number of publications, and a decrease in substance and quality of publications. A broad spectrum of perspectives can be found regarding the question of the role publication-based performance indicators should play in the future. This ranges from a basic critique to a call for reform to a position that advocates further development of the indicators. The complexity of the discussion resulted from the fact that three fields of application were discussed simultaneously: the use of performance-oriented allocation of funds, the context of recruiting procedures, and the evaluation of project proposals.

5. Authorship: Here, the focus was on the question according to which rules authorship should be allocated. The perspectives can be summarised as four types of understanding authorship: writing (i.e. cooperating in writing the text), exclusive (i.e. cooperating in all phases of knowledge production), inclusive (i.e. cooperating in one phase of knowledge production), or documenting (i.e. documenting precisely the type of contribution). It is noteworthy that the discussion almost exclusively revolved around the question of a fair attribution of performance, disregarding other aspects entirely. This could be due to the publication-based measurement of performance and the resulting significance of (first) authorship.

6. Peer review: Here the focus was on two areas. First, there were the problems in review procedures of journals. Participants mentioned problems in quality which, in part, were attributed to the growth of the number of publications and to a lack of care on behalf of reviewers. Second, suggestions were made for the reorganisation of the procedure on the basis of digital technologies. The digital network of all those involved in the review process would provide the opportunity to experiment with the new forms of open peer review and open discussion. The objective then is to improve the old procedures (single-blind/double-blind peer review).

7. Publication bias: Research results that do not confirm a hypothesis are more likely not to get published than results which proved a connection or an effect. To solve this problem, different measures are considered, 
such as the introduction of a two-phase review procedure or the establishment of a second level of publication in addition to journals for the often-rejected null results.

8. Research data: In addition to the advantages of accessibility of research data - such as the improvement of comprehensibility and an increase of trust in publications - the focus here is on the outstanding tasks of developing a particular infrastructure. Aside from creating sustainably financed research data repositories, the development of routines in archiving and establishment of standards, the necessity of developmental processes within science is also emphasised. The willingness to publish research data often only exists if there are corresponding mechanisms of acknowledging publications of data.

In comparison to the Principles area, transferring the output of the Problems and Challenges area into the work of the IWG turned out be more difficult. It became obvious that it would be impossible to take all of the issues into account in the final recommendation text. Therefore, it was decided to concentrate on five issues that the IWG considered to be of significance as these were largely commented on in the online discussion as well. These were prices and costs, resulting access problems, the archiving of electronic publications, wrong incentives due to indicator-based performance measurement, and the growth of the number of publications. The description of these problems in the recommendation text (BBAW 2015: 28-34) is mainly based on the online consultation and the first four issues in the list above, as well as on other sources of information. The recommendations (BBAW 2015: 35-50) also dealt with many aspects and suggestions that were mentioned in the Problems and Challenges area. Still, although an effort was made to integrate as many aspects as possible and to take into account different perspectives, processing the input of this area was more indirect than the first one.

\section{Role model or failed experiment? Evaluating the online consultation}

In conclusion, some points on the evaluation of the procedure should be made. In order to prevent any misunderstanding, it has to be noted that this is not about results of a formal evaluation. Rather, strengths and weaknesses of the procedure should be discussed based on the experiences. It should not be concealed that the authors of this contribution were also advocates for the online consultation and they were also the ones who carried it out. An impartial observer may therefore come to a different conclusion. There is still no acknowledged set of evaluation criteria to assess success or failure of such an 
innovative, non-standardised (Nanz \& Fritsche 2012: 90) online participatory approach. Thus, it seems appropriate to assess the online consultation with respect to its own standard and objectives. ${ }^{19}$ These were, as described at the beginning, the functions of information, legitimation and implementation.

With regard to the information function, it should be asked whether the online consultation represented the practical experiences and diverse perspectives of scientists. Furthermore, to what extent was this knowledge successfully taken into account in the development and acceptance of the recommendations?

Regarding the execution of the procedure, the target group of researchers could be reached, and the mobilised knowledge was indeed mainly practical knowledge of people who used the publication infrastructure of their respective disciplines as authors and recipients. The objective to reach a plurality of perspectives was also achieved. A total of 124 descriptions of problems and challenges, 527 comments and 2884 votes provided a large variety of perspectives. Participation was thus sufficient to depict diverse aspects and different arguments, and was not too divergent to prevent consideration of the individual accounts. Moreover, the contributions were all thematically relevant and the tone was, except for a few cases, rational.

Comparing participation in the two areas, there is a striking difference. In Principles for a Good Scholarly Communication System, the predetermined statements provided by the IWG led to longer discussions that were also related to each other. In the Problems and Challenges area, intensive discussions only occurred on controversial issues. Together with the large thematic diversity, this made the evaluation of this area more difficult.

In general, it can be said that the contributions of the online consultation were compressed into longer texts that were the basis for the IWG sessions. Dealing with the results, however, varied. While criticism and suggestions could be taken into account for the Principles area, the diversity of issues discussed in the second consultation area made it necessary to set a certain focus. Thus, some interesting discussions could not be pursued. These experiences suggest that it would have been better to limit the themes discussed in the consultation.

With regard to the function of legitimation, the question is whether the online consultation has contributed to the perception of the recommendations as a contribution to the debate about the future of academic publishing, i.e. that it speaks for an important part of the scientific community. This question

19 The evaluation on the basis of the achievement of objectives has already occurred in another participation exercise (Taubert et al. 2012: 31-35). Such a goal-oriented evaluation is appropriate in the case of individual exercises and avoids the controversial discussions about general evaluation criteria. See Kersting (2008: 283) and Hebestreit (2013: 173-194). 
cannot be answered fully here. ${ }^{20}$ The experience in the course of adoption of the recommendations within the BBAW indicated that the legitimating effect of such a participatory approach should be viewed with caution. During this process, a small group of members from the humanities protested against the tone of the recommendation text as presented, which hinted at a preference for digital over printed publication. In the course of the discussion, it became obvious that neither the opportunity of participation nor the fact that the tenor of the recommendations reflected the opinions of the participants of the online consultation developed any legitimating effect.

The greatest weakness of the process was revealed by the fact that the changes of the recommendations were a result of micro-political negotiations rather than the online consultation. The participatory approach and the decision-making process within the Academy were not in line with each other. During the development of the recommendations by the IWG, the absence of formal rules could be compensated by the fact that the IWG stood behind the procedure and was willing to deal with the results. Such willingness could not be observed in the committees of the BBAW in which the online consultation was perceived from a distance.

The question to which extent the consultation was able to focus attention on challenges and questions on how to shape the formal communication system of science (implementation) can also not be answered fully. More than 8500 visitors $^{21}$ of the online platform, more than 550 visitors of a presentation with initial results of the procedure and overall 10 invited lectures at conferences of scientific societies and research in different fields of study institutions indicate a certain response. It should be noted, however, that the Publication System Online Consultation is part of a much larger discourse about the future of academic publishing that has been going on for quite a while and at various locations. The same goes for the recommendations that emerged from the procedure, at least in part. They are part of a series of recommendations and science policy papers on that topic that have been released at local, national, international and global level.

\section{Outlook}

The evaluation of the 'Publication System' Online Consultation arrived at a mixed result. The practicality of such an approach in science could be demonstrated.

20 An analysis of the perceptions of the recommendations on behalf of the addressees would be necessary.

21 See http://de.slideshare.net/ntaubert/onlinekonsultation-publikationssystem-zwischenstandauswertung. 
In particular, the initial assumption was corroborated that such a procedure would be appropriate for science since the addressees were reachable through scientific societies and research institutions and used to respond to complex issues and problems. On the other hand, the requirement to embed such a procedure in the process of developing and passing recommendations became obvious, and was not always met. Moreover, the online consultation would have benefitted from a stronger structure with respect to issues in the second consultation area. These deficits, however, do not represent basic problems that would speak against using such a procedure, but could contribute to developing further participatory approaches in future.

Therefore, the final question should be in which fields of science such a procedure could be applied. There are at least three.

1. Science policy: First, an online dialogue could be used to develop science policy recommendations, strategies, declarations and positioning papers, which take up feedback from scientists. As in the 'Publication System' Online Consultation, the function of information, which aims at surveying and focusing on the diversity of perspectives within science, would be at the core.

2. Research evaluation: A second potential field of application could be processes of research evaluation as long as they refer to larger units, such as entire disciplines or types of research organisations. Involving the evaluated scientists could, for example, contribute to the acceptance of the evaluation results. Here the function of legitimation would be at the core.

3. Research funding programmes: Online participatory approaches could contribute to assessing the need for larger research funding programmes like collaborative research centres or priority programmes. The participation of potential future applicants could help to coordinate the individual research interests and may contribute to the development of suitable programmes for the respective fields of study.

Especially in the latter two fields of application, a high willingness to participate is likely since these issues are of immediate relevance for researchers.

\section{References}

Albrecht, S., Kohlrausch, N., Kubicek, H., Lippa, B., Märker, O., Trénel, M., Vorwerk, V., Westholm, H. \& Wiedwald, C. 2008. E-Partizipation-Elektronische Beteiligung von Bevölkerung und Wirtschaft am E-Government. Studie im 
Auftrag des Bundesministeriums des Innern, Ref. IT 1. Bremen: Institut für Informationsmanagement Bremen GmbH.

Andermann, H. \& Degkwitz, A. 2004. Neue Ansätze in der wissenschaftlichen Informationsversorgung. Ein Überblick über Initiativen und Unternehmungen auf dem Gebiet des elektronischen Publizierens. Historical Social Research, 29(1):6-55.

BBAW (Berlin-Brandenburgischen Akademie der Wissenschaften). 2013. Geschäftsordnung der Berlin-Brandenburgischen Akademie der Wissenschaften. Retrieved from http://www.bbaw.de/die-akademie/aufgaben-und-ziele/ geschaeftsordnung-pdf [Accessed 2 April 2016].

BBAW (Berlin-Brandenburgischen Akademie der Wissenschaften). 2015. Empfehlungen zur Zukunft des wissenschaftlichen Publikationssystems. Berlin.

Gravey, W.D. \& Griffith, B.C. 1967. Scientific communication as a social system. Science, 157(3762):1011-1106.

Hagenhoff, S., Seidenfaden, L., Ortelbach, B. \& Schumann, M. 2007. Neue Formen der Wissenschaftskommunikation. Eine Fallstudienuntersuchung. In Göttinger Schriften zur Internetforschung, No. 4. Göttingen: Göttinger Universitätsverlag.

Hebestreit, R. 2013. Partizipation in der Wissensgesellschaft. Funktion und Bedeutung diskursiver Beteiligungsverfahren. Wiesbaden: Springer.

iFQ, FIT, WR. 2015. Kerndatensatz Forschung - Dokumentation der Ergebnisse. Retrieved from http://www.kerndatensatz-forschung.de/versionl / Ergebnisbericht_Projekt_KDSF.pdf [Accessed 14 April 2016].

Kersting, N. 2008. Evaluation dialogischer Beteiligungsinstrumente. In N. Kersting (ed.). Politische Beteiligung. Reihe Bürgergesellschaft und Demokratie, No. 28. Wiesbaden: Springer, 270-292.

Kircz, J.G. \& Roosendaal, H.E. 1996. Understanding and shaping scientific information transfer. In D. Shaw \& H. Moore (eds). Electronic publishing in Science. Proceedings of the Joint ISCU Press/UNESCO Expert Conference, 19-23 February, Paris, 106-116.

Luhmann, N. 1969. Legitimation durch Verfahren. Neuwied am Rhein: Luchterhand. Märker, O. 2009. Studie. E-Partizipation in Deutschland. E-Journal of E-Democracy $\vartheta$ Open Government, 1(1):45-54.

Märker, O. \& Wehner, J. 2008. E-Partizipation. Bürgerbeteiligung in der Stadt- und Regionalplanung. Standort - Zeitschrift für Angewandte Geographie, 32:84-89.

Nanz, P. \& Fritsche, M. 2012. Handbuch Bürgerbeteiligung. Berlin: bpb.

Taubert, N. 2016a. Digitale Publikations- und Forschungsinfrastrukturen. In D. Simon, A. Knie, S. Hornbostel \& K. Zimmermann (eds). Handbuch Wissenschaftspolitik. Second edition. Wiesbaden: Springer, 591-608.

Taubert, N. 2016b. Formale wissenschaftliche Kommunikation. In H. Bonfadelli, B. Fähnrich, C. Lüthje, J. Milde, M. Rhomberg \& M. Schäfer (eds). Forschungsfeld Wissenschaftskommunikation. Wiesbaden: Springer, 125-139. 
Taubert, N., Krohn, W. \& Knobloch, T. 2012. Evaluierung des Kölner Bürgerhaushalts. Kassel: Kassel University Press.

Taubert, N. \& Schön, K. 2014. Online-Konsultation 'Publikationssystem'. Dokumentation und Auswertung. Retrieved from http://edoc.bbaw.de/volltexte/2014/2629/pdf/ BBAW_Publikationssystem_Taubert.pdf [Accessed 30 October 2015].

Taubert, N. \& Schön, K. 2015. Online-consultation 'scholarly publication system': Documentation and main results. ScienceOpen. doi:10.14293/S2199-1006.1.SORSOCSCI.AE2GYG.v1.

Whitley, R.D. 1968. The formal communication of science: A study of the organization of British social science journals. The Sociological Review, 16(1):162-179. 



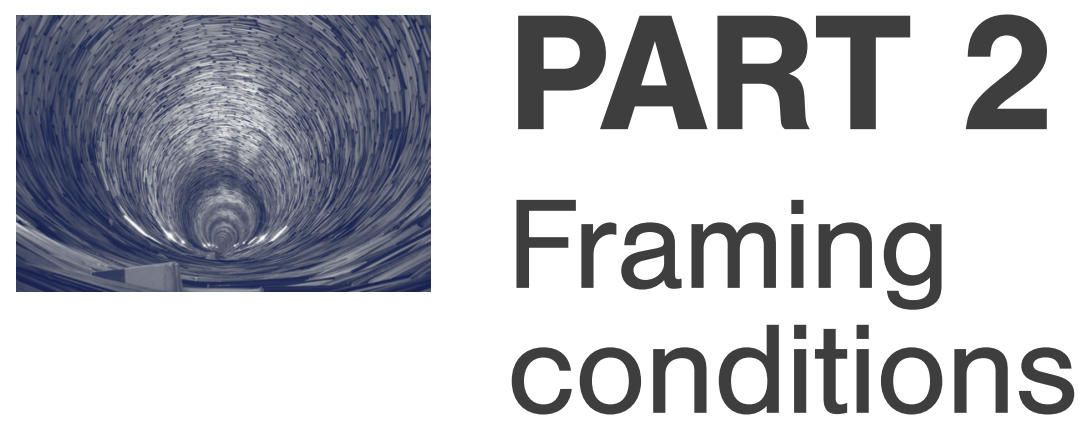





\section{Recommendations, Statements, Declarations and Activities of Science Policy Actors on Shaping the Scholarly Communication System}

Ulrich Herb

1 Introduction

\subsection{Assignment}

During the past ten years, different actors from the science policy sector have made different statements on the future design of the scholarly communication system. Moreover, they have been active in trying to change the design. The goal of this text is to give an overview of the different forms of those statements for Germany, the United States and Europe, and to summarise the content of the statements in the form of a synopsis in which the major similarities and differences can be fleshed out. In addition, experts have to determine the most important fields of activity and describe concrete measures and activities. The object of this chapter is to discuss the scholarly communication system through which research results are disseminated and exchanged within the scientific community.

\subsection{Scope}

The basis of the synopsis is a list of institutions from the context of science policy and science funding, supplemented by the research funding association Knowledge Exchange. The list was developed by the Future of the Scholarly 
Communication System working group. The institutions are mainly from Germany, with some from Europe and the United States:

- Allianz der Deutschen Wissenschaftsorganisationen (Alliance of German Research Organisations)

- Gemeinsame Wissenschaftskonferenz des Bundes und der Länder (General Science Conference of the Federal Government and the States)

- Commission on the Future of Information Infrastructure

- Deutsche Forschungsgemeinschaft (German Research Council)

- Max Planck Society/Max Planck Digital Library

- Alexander von Humboldt-Stiftung

- Fraunhofer-Gesellschaft

- Helmholtz-Gemeinschaft Deutscher Forschungszentren (Helmholtz Association of German Research Centres)

- $\quad$ Leibniz-Gemeinschaft - Wissenschaftsgemeinschaft Gottfried Wilhelm Leibniz (Leibniz Association - Science Association Gottfried Wilhelm Leibniz)

- Deutsche Akademie der Naturforscher Leopoldina (German Academy of Sciences Leopoldina)

- German Rectors Conference

- Wissenschaftsrat(Science Council)

- Deutscher Akademischer Austauschdienst (German Academic Exchange Service)

- Börsenverein des Deutschen Buchhandels (German Publishers and Booksellers Association)

- European Commission

- Soros Foundation/Open Society Foundations

- National Science Foundation

- National Institutes of Health

- Scholarly Publishing and Academic Resources Coalition

- Wellcome Trust

- Knowledge Exchange

Sources of information were primarily journalistic publications, reports, recommendations, comments, statements, websites, as well as funding lines of the listed organisations.

Relevant issues were identified through reading and analysis, the selected organisations made statements and are active in these issues. Joint projects/ collaborations that comprise especially coordinated or differentiated activities will be briefly described in the next section. 
1.3 Information on selected organisations and collaborations between organisations

\subsubsection{Allianz der Deutschen Wissenschaftsorganisationen (Alliance of German Research Organisations)}

The Alliance of German Research Organisations acts as an association of the following research organisations to coordinate their activities in the context of scientificinformation systems (Allianz der deutschen Wissenschaftsorganisationen 2008b: 1):

- Alexander von Humboldt-Stiftung

- Deutsche Akademie der Naturforscher Leopoldina (German Academy of Sciences Leopoldina)

- Deutsche Forschungsgemeinschaft (German Research Council)

- Deutscher Akademische Austauschdienst (German Academic Exchange Service)

- Fraunhofer-Gesellschaft (FhG)

- Helmholtz-Gemeinschaft Deutscher Forschungszentren (Helmholtz Association of German Research Centres)

- German Rectors' Conference

- Leibniz-Gemeinschaft - Wissenschaftsgemeinschaft Gottfried Wilhelm Leibniz (Leibniz Association - Science Association Gottfried Wilhelm Leibniz)

- Max Planck Society

- Wissenschaftsrat (Science Council)

The alliance mainly advocates the creation of an integrated information infrastructure within the Digital Information focus area (2008-2012). This infrastructure should be characterised by 'free accessibility to publications, primary data of research and virtual research and communication environments' (Allianz der deutschen Wissenschaftsorganisationen 2008b: 1). The goal is to 'create a sustainably integrated digital research environment in which every researcher has access from anywhere in Germany to the entire published knowledge and relevant research data' (Allianz der deutschen Wissenschaftsorganisationen 2008b: 1). In order to achieve these goals, the Alliance is active in the following areas, which are each coordinated in an individual working group:

- open access;

- research data;

- virtual research environment; 
- national licensing;

- National Hosting Strategy;

- legal framework conditions; and

- cross-cutting issues on the above.

The German Research Council (DFG) in part stimulates the realisation of the recommendations of the alliance via respective funding programmes.

\subsubsection{General Science Conference of the Federal Government and the States (GWK)} In 2009, the GWK assigned the Gottfried Wilhelm Leibniz Society to develop a concept on specialised information infrastructure. A working group developed a framework (Wissenschaftsgemeinschaft Gottfried Wilhelm Leibniz 2009) that was presented to the GWK in September 2009 and which suggested the establishment of an extensive concept of scientific information infrastructure for Germany. The overall concept was developed by the newly created commission Future of the Information Infrastructure (KII) (2011), which was coordinated by the Leibniz Society, and presented to the GWK in April 2011. The overall concept of the KII is basically a well-founded formulation of the WGL framework concept by expert groups.

\subsubsection{Commission on the Future of Information Infrastructure (KII)}

The work of the KII involved representatives from government, the states, research institutions, academic publishers, user groups from different academic disciplines as well as industrial research. Moreover, representatives from the GWK took part as permanent guests. The commission comprised approximately 135 people from about 60 institutions, which partly overlapped with the Alliance partner organisations, ${ }^{1}$ and the steering group consisted of 19 people.

The KII considers eight areas as essential for the information infrastructure, for each of which working groups were created:

1. licensing (corresponding to the Alliance agenda);

2. hosting/long-term archiving (corresponding to the Alliance agenda);

3. non-textual material;

4. retro-digitisation/cultural heritage;

5. virtual research environment (corresponding to the Alliance agenda);

6. open access/electronic publishing (corresponding to the Alliance agenda);

7. research data (corresponding to the Alliance agenda); and

8. information competence/training.

1 DFG, Fraunhofer-Gesellschaft, HRK, Leibniz Society as well as the Max Planck Society (represented by the Max Planck Digital Library) were represented in both groups. 
At local level, information infrastructures, such as, for example, individual research institutions or disciplinary infrastructures (KII 2011: 15) were excluded from the analysis of KII. Even though the topics of the Alliance and KII are mostly identical and personal overlaps exist in the working groups and steering committees, there are different objectives. While the Alliance initiative strives for the coordinated collaboration of the partner organisations in six defined fields of action and all working groups should name and implement concrete tasks, the KII wants to create an overall concept, which summarises the optimised landscape of the information infrastructure in Germany and describes the required framework conditions as well as synergies, concepts and options for collaboration (Lipp 2010).

\subsubsection{German Publishers and Booksellers Association}

The German Publishers and Booksellers Association criticised the overall concept of the KII harshly, stating that it lacks important participants, for example, scientific societies, higher education associations, academic publishers and providers of libraries'. Accordingly, the concept suffers from obvious 'deficits', which is why 'the implementation of central results of the KII paper would rather worsen Germany's chances in the international competition of knowledge societies than improve them' - this concerns especially the 'fields of licensing and Open Access' (Börsenverein des Deutschen Buchhandels 2011b: 1).

\subsubsection{German Research Council (DFG)}

The projects of the DFG in the context of science communication were previously bundled in the interdisciplinary initiative Digital Information, which described the major funding areas until 2015. The objectives of funding in the area of scientific literature and information systems were already formulated in 2006 in their position paper (DFG 2006). By the beginning of 2016, the following relevant funding programmes were developed:

- cross-regional licensing;

- infrastructure for electronic publications and digital science communication;

- OA publishing;

- virtual research environments; and

- information infrastructures for research data.

\subsubsection{Knowledge Exchange (KE)}

Knowledge Exchange is an active collaboration since 2005 between the funding organisations Danish Electronic Research Library (DEFF, DK), Joint Information Systems Committee (JISC, UK), SURF Foundation (SURF, NL) 
and the DFG, as well as, since 2013, the IT Center for Science (CSC, FIN). The goal is to make scientific content freely available on the web.

The KE home page lists as primary fields of activity the advancement of open access as well as accessibility of research data. ${ }^{2}$ Within these fields, the organisation of workshops, the commissioning of studies and the creation of reports are especially relevant.

\subsubsection{Max Planck Society (MPG)/Max Planck Digital Library (MPDL)}

In 2006, the Max Planck Society founded the Max Planck Digital Library, ${ }^{3}$ which guarantees the basic provision of information (with publications and databases) and supports the institutes in developing digital and Internet-based research environments as well as in processing scientific raw data. In the following section, the activities of the MPG as well as the MPDL will be mentioned.

\subsubsection{General information on other institutions}

Some organisations provide few statements on the design and future of the scholarly publication system and are therefore not mentioned in the synopsis. This mainly concerns the Alexander von Humboldt-Stiftung, the Academy of Sciences Leopoldina, the German Rectors' Conference and the German Academic Exchange Service. Since all of these institutions are represented in the Alliance of German Research Organisations, however, their positions are noted by the description of the Alliance activities. The case of the General Science Conference of the Federal Government and the States is similar, and its contribution can be seen mainly as the establishment of the framework concept for the KII and its assignment to develop an overall concept for information infrastructure in Germany.

\section{Access to scientific publications}

\subsection{Open access and electronic publishing}

The following institutions have signed the Berlin Declaration on Open Access to Knowledge in the Sciences and Humanities (2003) and support open access:

- German Research Council (DFG)

- Max Planck Society (MPG)/Max Planck Digital Library (MPDL)

- Fraunhofer-Gesellschaft (FhG)

2 See http://www.knowledge-exchange.info/projects.

3 See http://www.mpdl.mpg.de/. 
- Helmholtz-Gemeinschaft Deutscher Forschungszentren (HGF) (Helmholtz Association of German Research Centres)

- Leibniz Association - Science Association Gottfried Wilhelm Leibniz e. V. (Leibniz-Gemeinschaft - Wissenschaftsgemeinschaft Gottfried Wilhelm Leibniz) (WGL)

- Deutsche Akademie der Naturforscher Leopoldina (Academy of Sciences Leopoldina)

- German Rectors' Conference (HRK)

- $\quad$ Science Council (Wissenschaftsrat)

- Scholarly Publishing and Academic Resources Coalition (SPARC)

As a member of the G8 Academies of Science, the Academy of Sciences Leopoldina signed the joint G8+ Science Academies' Statement on education for a science-based global development, which emphasises the advantages of open access for networking and collaboration. It further demands the free accessibility to publications and databases, especially in view of the needs in academic education: 'Support international collaboration to set up quality e-learning facilities, accessible to all, including students worldwide, and promote open access to scientific literature and databases' (G8+ Science Academies 2011:2).

The DFG, MPG, HGF, HRK, FhG and WGL moreover support the information platform Open Access, ${ }^{4}$ which provides information on open access for authors, editors of journals, operators of repositories, university leadership, libraries, funding organisations and publishing companies.

The Alliance of German Research Organisations intends to 'politically advance and implement open access to texts, primary data and other digital objects' (Allianz der deutschen Wissenschaftsorganisationen 2008b: 4) - in the case of green open access by developing institutional and disciplinary repositories further and also by strengthening their networking (Allianz der deutschen Wissenschaftsorganisationen 2008b: 4). Of relevance - with respect to institutions - are standardisation, networking and quality assurance, and regarding scientists, the necessity to create incentives in order to publish documents in repositories. Regarding gold open access, the Alliance emphasises the development of business and funding models as well as the general financing of these models (Allianz der deutschen Wissenschaftsorganisationen 2008b: 4). For this purpose, it is suggested to redeploy subscription fees into publication fees (Allianz der deutschen Wissenschaftsorganisationen 2008a). These models should be tested taking into account specificities of different disciplines. The Alliance emphasises however that the funding of OA publications must not be

4 See http://open-access.net/. 
to the detriment of the research budget. The testing of new funding models is reflected in the participation in sponsoring by the Consortium for Open Access Publishing in Particle Physics (SCOAP ${ }^{3}$ ) of Helmholtz, MPG and DFG as well as by the establishment of publication funds for original OA publications (for example, in the FhG and HGF).

The KII considers the removal of barriers that hinder the promotion of open access as relevant. This concerns the establishment of funding models, questions of inter-operability and networking with disciplinary local services. From a legal point of view, the reusability of content in other contexts (virtual research environment) needs to be ensured in order to guarantee efficient scientific exchange. The KII calls for the establishment of a coordinating institution on the further development and adjustment of national and international collaboration (KII 2011: 41). It especially recommends the development of publication funds in the model of gold open access as well as (cf. the issue of licensing) innovative subscription contracts that allow OA options. Furthermore, the KII states the need for sufficient resources at technological and organisational level and demands the establishment of a sustainable repository infrastructure. The OA infrastructure should make networking and inter-operability possible in order to allow an integration of the contents into virtual research environments. From a legal perspective, it (like the Alliance) calls for an unconditional right of secondary publication for authors in the German Copyright Act (UrhG) (KII 2011: 51). In this context, KII suggests coordination with the MPG or the MPDL (KII 2011: 55).

In a position paper, the German DFG (2006: 3) states on open access:

The DFG supports a free access to all published research results (open access). The freedom of information for research and teaching should neither be restricted by copyright laws nor through technological barriers or prohibitive fees. At the same time, intellectual property needs to be appropriately protected, for example, by using Creative Common licences in electronic forms of publication.

In the context of electronic publishing, the DFG emphasises the 'necessity to pay heed to the growing importance of informal scientific communication, which provides the special opportunity to shape electronic publishing. Precisely in the context of this new form of publishing the aspect of quality assurance is of key importance' (DFG 2006: 5).

Through the Open Access Publishing programme, the DFG supports universities in the development of publication funds from which article processing charges 
(APCs) in OA journals can be paid. ${ }^{5}$ In this context, the DFG provides a grant that decreases throughout the funding period (DFG 2014a: 4):

Grant proposals can only be approved if the proposing university provides a clearly defined amount from its own budget for the financing of articles in open access journals. In the first and second year of funding, this amount is $20 \%$, in the third and fourth year $40 \%$ and in the fifth and sixth year $60 \%$ of the calculated funds needed for publication.

This line of funding is considered an initial sponsoring as the goal is to 'establish permanent and reliable structures for the financing of open access publications' (DFG 2014a: 1). The approval is subject to certain conditions. ${ }^{6}$

Moreover, the DFG demands reliable information of the proposing university on 'how it initiates the necessary redeployment of parts of its own budget for publication fees' (DFG 2014a: 6) (emphasis in original).

In the guidelines on the use of funds, the DFG urges scientists of funded projects to publish project-related works via open access: either directly at an OA publisher or by reserving the necessary rights (and if necessary after an embargo period) in an OA repository (DFG 2014b: 18).

In addition, the DFG also supported the establishment of OA journals, among others, recipients of funds were the journals Business Research, ${ }^{7}$ which publishes articles including OA data, as well as the GIGA Journal Family, ${ }^{8}$ an association of journals, which was transformed from the print-subscription model to open access. In the green open access field, the DFG funded the establishment of disciplinary-based repositories such as the Social Science Open Access Repository ${ }^{9}$ or peDOCS ${ }^{10}$ for pedagogical research.

Currently, the funding options for gold and green open access are part of the programme called Infrastructure for Electronic Publications and Digital Science Communication.

The funding of the arXiv-DH project, which is supposed to develop a model for German participation in the financing of the OA repository arXiv, was also assigned to the area of green open access. Other funded projects included:

5 Non-university institutions cannot apply for funding.

6 Costs can only be reimbursed for publications in pure OA journals (not hybrid journals) that use quality assurance in the form of peer review. Reimbursement occurs only if the publication fees do not exceed $€ 2000$.

7 See http://www.business-research.org/.

8 See http://hup.sub.uni-hamburg.de/giga/journal-family/index.

9 See http://www.ssoar.info/.

10 See http://www.pedocs.de/. 
- the Open Access Information Platform, which provides extensive information on open access; and

- Open Access Policies - What rights do German publishers grant their authors? A database through which the OA policies of academic publishing companies can be downloaded.

The Max Planck Society (MPG) operates an OA portal, ${ }^{11}$ which informs MPG employees about OA activities and provides practical tips on OA publishing and relevant copyright guidelines. The position of the MPG manifests itself in an OA policy that encourages scientists to publish that way. The portal moreover provides information on the MPG's gold open access offers ${ }^{12}$ as well as their own repository, ${ }^{13}$ OA projects ${ }^{14}$ and the OA network of internal OA experts. ${ }^{15}$ At the end of 2015, the MPG entered into an agreement with Springer according to which scientists of Max Planck institutes can publish their research results in more than 1600 of Springer's subscription journals open access and at the same time receive access to all subscription content in these and 400 other Springer journals. ${ }^{16}$ The Max Planck Digital Library, ${ }^{17}$ founded in 2006, organises the majority of the MPG's OA projects.

Like the MPG, the Fraunhofer-Gesellschaft (FhG) also supports an OA policy ${ }^{18}$ for its authors. In addition, the FhG actively promotes open access. It further operates a blog, which provides information on open access, especially with reference to the FhG. Other services include the OA Repository ePrints, ${ }^{19}$ the publication database Publica, ${ }^{20}$ which is connected to the repository, a newsletter, which informs FhG employees about new developments in open access, ${ }^{21}$ as well as an OA team which provides support on questions of scientific publishing and OA. ${ }^{22}$ At the end of 2015, the FhG passed an OA strategy which includes as measurement the establishment of a central publication fund for the financing of gold open access articles, the creation of an infrastructure for

\footnotetext{
11 See http://oa.mpg.de/.

12 See http://openaccess.mpg.de/1431088/Open-Access-Publishing---Initiativen.

13 See http://openaccess.mpg.de/3635/repositorium.

14 See http://openaccess.mpg.de/201884/Projekte.

15 See http://openaccess.mpg.de/3583/MPG-Open-Access-Netzwerk.

16 See http://openaccess.mpg.de/2151888/Open-Access-Abkommen_mit_Springer-Verlag.

17 See http://www.mpdl.mpg.de/.

18 See http://www.openaccess.fraunhofer.de/wp-content/uploads/2015/12/Fraunhofer_Open_Access_ Policy_2008_dt.pdf.

19 See http://publica.fraunhofer.de/starweb/ep09/index.htm.

20 See http://publica.fraunhofer.de/starweb/pub09/index.htm.

21 See http://publica.fraunhofer.de/starweb/ep09/newsletter.htm.

22 This offer is especially aimed at librarians in the institutes, which, in turn, consult authors.
} 
OA publication of research data and the increased support of FhG researchers in keeping relevant rights for green OA publication of already published works.

In 2005, the Helmholtz-Gemeinschaft (HGF) introduced the Helmholtz Open Science Coordination Office for supporting the Helmholtz Centres and their researchers in the implementation of open access. This is understood as an open science portal. ${ }^{23}$ The office promotes open access through, for example, workshops, talks, mailing lists and a newsletter and consults the Helmholtz Centres in OA issues. The HGF, too, passed an OA policy. ${ }^{24}$ Several of the Helmholtz Centres also operate OA repositories. ${ }^{25}$ The HGF calls for the Helmholtz Centres to support the green and gold pathway of open access. Much more than the other actors, the HGF is also engaged in issues concerning open access to research data, through the Webinar offers, for example. The HGF has framework contracts with different OA publishers, such as BioMed Central, Copernicus Publications, Multidisciplinary Digital Publishing Institute, PLOS, Springer Open and Wiley as well as with the New Journal of Physics in order to be able to invoice author fees in a bundle. ${ }^{26}$ Moreover, it is engaged in the Compact for Open-Access Publishing Equity (COPE) project, with which mechanisms for measuring appropriate publication fees should be determined. It also participates in the already mentioned SCOAP project. ${ }^{3}$ Due to the structure of the HGF, there is no central fund for reimbursing OA publication fees. The Helmholtz Centres, however, have developed appropriate mechanisms for taking over publication fees. These are different for each centre, however.

The Leibniz Association (WGL) operates an open access working group, ${ }^{27}$ encourages its employees and stipend holders to make publications openly accessible, and promotes open access in its OA policy. ${ }^{28}$ This includes the establishment of an own infrastructure (Wissenschaftsgemeinschaft Gottfried Wilhelm Leibniz 2011 a: $62 \mathrm{f}$.). Another working group has the goal of advancing the establishment of a Leibniz repository and of supporting institutions in making publications available. The LeibnizOpen ${ }^{29}$ repository does not have full texts itself but only metadata on texts that are deposited in OA repositories of the Leibniz infrastructure institutions. Each of these institutions is supported by a specialised repository and can deposit its publications there. This repository then provides the metadata to LeibnizOpen. In order to support the services

23 See http://oa.helmholtz.de/open-science-in-der-helmholtz-gemeinschaft.html.

24 See http://www.helmholtz.de/wissenschaft_und_gesellschaft/helmholtz-gemeinschaft-verankertrichtlinie-1977/.

25 See http://oa.helmholtz.de/open-science-in-der-helmholtz-gemeinschaft/open-access-der-gruene-weg.html.

26 See http://oa.helmholtz.de/open-science-in-der-helmholtz-gemeinschaft/open-access-der-goldene-weg.html.

27 See http://www.leibniz-gemeinschaft.de/ueber-uns/organisation/arbeitskreise/arbeitskreis-open-access/.

28 See http://www.leibniz-gemeinschaft.de/fileadmin/user_upload/downloads/Organisation/Arbeitskreise/ AK_Open_Access/OpenAccess-Leitlinie.pdf.

29 See http://www.leibnizopen.de. 
of the distributed institutions in the form of author counselling/assistance and the acquisition of documents for the repository, special courses on the Leibniz repository and on open access are offered. The working group on open access works closely with the working group Libraries and Information Institutions (Wissenschaftsgemeinschaft Gottfried Wilhelm Leibniz 201la: 62 f.). LeibnizOpen began its official operation in the summer of 2011 (Wissenschaftsgemeinschaft Gottfried Wilhelm Leibniz 2011b). Individual Leibniz institutions operate their own OA offers. ${ }^{30}$ In green open access, these include:

- EconStor: ${ }^{31}$ OA repository of the German National Library of Economics (Deutschen Zentralbibliothek für Wirtschaftswissenschaften [ZBW]) for publications in economics;

- NEEO: $:^{32}$ Establishment of full-text collections in economics (europaweiter Aufbau von Volltextkollektionen für die Wirtschaftswissenschaften), Leibniz partner: ZBW;

- peDOCS: OA repository of the German Institute for International Educational Research for pedagogical publications, in particular in collaboration with specialised publishers; and

- SSOAR: ${ }^{33}$ Social Sciences Open Access Repository of GESIS - Leibniz Institute for Social Sciences.

Institutions of the WGL are active in the following gold OA activities:

- Economics: ${ }^{34} \mathrm{OA}$ journal of the Institute for the World Economy and the ZBW;

- German Medical Science: ${ }^{35}$ OA publication platform of the German National Library of Medicine for medical science;

- GIGA journal family: ${ }^{36}$ OA journal of GIGA - Leibniz Institute for Global and Regional Studies;

- ISI - Information Service Social Indicators: ${ }^{37}$ OA journal of GESIS Leibniz Institute for Social Sciences;

30 See http://open-access.net/de/oa_informationen_der/leibniz_gemeinschaft/.

31 See http://www.econstor.eu/.

32 See http://www.neeoproject.eu/.

33 See http://www.ssoar.info/.

34 See http://www.economics-ejournal.org/.

35 See http://www.egms.de/dynamic/en/index.htm.

36 See http://hup.sub.uni-hamburg.de/giga/journal-family/index.

37 See http://www.gesis.org/soziale-indikatoren/service/isi/. 
- Methoden, Daten, Analysen. Zeitschrift für Empirische Sozialforschung: ${ }^{38}$ OA journal of GESIS - Leibniz Institute for Social Sciences;

- PsychOpen: ${ }^{39}$ OA publication platform for European Psychology of the Leibniz Institute for Psychology;

- different gold open access offers of Schloss Dagstuhl/Leibniz Center for Informatics; ${ }^{40}$ and

- SCOAP $^{3}:^{41}$ Partner: Technische Informationsbibliothek.

Since January 2016, the WGL has a central publication fund, ${ }^{42}$ which is subject to certain conditions. ${ }^{43}$ For example, costs exceeding $€ 2000$ are only partially reimbursed.

The Scholarly Publishing and Academic Resources Coalition (SPARC) was founded by libraries in the United States in 1998. The goal is to ensure highquality and low-price opportunities for publication for scientists. To achieve this goal, SPARC also supports authors and recommends that they should not accept any transfer of exclusive rights of usage on behalf of the publishers. ${ }^{44}$ SPARC operates an OA working group, which has the objective of creating awareness of the benefits of open access among civil society stakeholder groups (for example, patient organisations), funders of research, politicians, research institutions as well as support of academic institutions in the implementation of open access and OA-friendly employment interviews. ${ }^{45}$ In order to advance $\mathrm{OA}$ and cost-efficient scientific publishing, SPARC provides a large amount of information, for example, on

- $\quad$ financing models (Crow 2009b);

- the establishment of OA funds (Tananbaum 2010);

- non-profit publication infrastructures across campuses and within disciplines (Crow 2006a; 2009a);

- $\quad$ sponsorship of academic non-profit journals (Crow 2006b);

- information on the operation of an OA repository and a checklist on the operation of an OA journal; ${ }^{46}$

38 See http://www.gesis.org/publikationen/zeitschriften/mda/.

39 See http://www.psychopen.eu.

40 See http://www.dagstuhl.de/de/publikationen/.

41 See http://www.scoap3.org/.

42 See http://www.leibniz-gemeinschaft.de/infrastrukturen/open-access/open-access-publikationsfonds/.

43 See http://www.leibniz-gemeinschaft.de/infrastrukturen/open-access/open-access-publikationsfonds/ foerderbedingungen/.

44 See http://www.arl.org/sparc/publications/opendoors_vl.shtml as http://www.arl.org/sparc/author/ addendum.shtml.

45 See http://www.arl.org/sparc/advocacy/oawg.shtml.

46 See http://www.arl.org/sparc/partnering/planning/index.shtml. 
- $\quad$ information on the pricing structure in the journal subscription model; ${ }^{47}$

- an OA information portal; ${ }^{48}$

- information on OA; and

- innovative publication models and sponsorship for cost-efficient subscription journals or development of publication services at libraries (Crow et al. 2012).

SPARC also offers consultation ${ }^{49}$ on developing and operating scientific communication infrastructures in order to make these financially effective and innovative with respect to technology. SPARC cooperates with academic publishers in order to test new publication models. The three programmes for this purpose are: ${ }^{50}$

- SPARC Alternative: supports cost-efficient subscription journals that can be a direct alternative in disciplines in which the provision of information depends on high-priced journals.

- SPARC Leading Edge: supports projects that test OA or other innovative business models. Partnerships among others with BioMedCentral and PLOS.

- SPARC Scientific Communities: supports the establishment of nonprofit services that provide the academic discipline with peer-reviewed literature and other scientific content. These communities consciously take innovative electronic information into account and go beyond classic forms of publication such as journals.

The Soros Foundation/Open Society Foundations has supported open access since 2002. Their main argument refers to the advantages of maximising public accessibility to information, making societal communication easier, protecting civil societies and the freedom of communication in digital environments. The perspective is therefore characterised by civil society aspects rather than the science internal argument of research institutions or research funders. The hope is that open access and open science will accelerate scientific progress, especially in the neglected border areas of science. Emphasis is also put on citizen science, which involves non-scientists in research activities.

Central guidelines for research funding by the National Institutes of Health (NIH) are listed in their Grants Policy Statement under the section 'Availability

\footnotetext{
47 http://www.sparc.arl.org/resources/journals.

48 See http://www.sparc.arl.org/theme/open-access.

49 See http://www.sparc.arl.org/resources/publishers/consulting.

50 See http://www.arl.org/sparc/partner/benefits.shtml.
} 
of research results: Publications, intellectual property rights, and sharing research resources'.$^{51}$ Here, it calls for making results of NIH-funded research accessible. It also concerns the accessibility of data:

Rights in data also extend to students, fellows, or trainees under awards whose primary purpose is educational, with the authors free to copyright works without NIH approval. In all cases, NIH must be given a royaltyfree, nonexclusive, and irrevocable licence for the Federal government to reproduce, publish, or otherwise use the material and to authorize others to do so for Federal purposes. ${ }^{52}$

According to NIH policy, text publications have to be made accessible by a publisher in the open access repository PubMed Central ${ }^{53}$ - at the latest 12 months after formal publication. In addition, NIH-funded projects of more than USD 500000 are bound to OA data sharing, ${ }^{54}$ and OA needs to follow publication of relevant results. Exceptions are possible due to legal reasons, for example, data protection. Model organisms and data from genome-wide association studies funded by the NIH should also be made publicly accessible.

Scientists receiving funds from the National Science Foundation (NSF) are also obligated to make publications in peer-reviewed journals or conference proceedings accessible via open access at the latest 12 months after formal publication. A corresponding policy was passed in 2015 and became effective in January 2016.

Researchers receiving funds from the Wellcome Trust are obligated ${ }^{55}$ to make project-related publications freely accessible on one of the two OA repositories PubMed Central ${ }^{56}$ or on UK PubMed Central ${ }^{57}$ within six months after formal publication. This not only concerns journal or conference articles but also monographs or contributions to anthologies. It is also recommended that authors do not transfer exclusive user rights to publishers, and authors are encouraged, as an alternative to making texts accessible on one of the repositories, to publish directly in OA journals. The Wellcome Trust moreover prefers the use of user licences, such as the CC-By-Licence ${ }^{58}$ of Creative Commons, which not only enable the free but also open use analogous to

51 See http://grants.nih.gov/grants/policy/nihgps_2011/nihgps_ch8.htm\#_Toc271264947.

52 See http://grants.nih.gov/grants/policy/nihgps_2011/nihgps_ch8.htm\#_Toc271264947.

53 See https://www.ncbi.nlm.nih.gov/pmc/.

54 See https://grants.nih.gov/grants/guide/notice-files/NOT-OD-03-032.html.

55 See http://www.wellcome.ac.uk/About-us/Policy/Policy-and-position-statements/WTD002766.htm.

56 See http://www.ncbi.nlm.nih.gov/pmc/.

57 See http://europepmc.org/.

58 See https://creativecommons.org/licenses/by/3.0/de/. 
the criteria of open source licences. Publication fees can be reimbursed by the Wellcome Trust. Authors can inform themselves about the implementation of the policy by means of FAQs regarding access. ${ }^{59}$ To cover APCs, the Wellcome Trust either makes individual agreements with the researchers receiving funds or it supports OA funds of universities for the administration of APCs. ${ }^{60}$ The Wellcome Trust has funded several studies on the sustainability of open access or its financial issues (Wellcome Trust 2003; 2004). In 2011, a report was published in collaboration with the Research Information Network (RIN), the Publishing Research Consortium, the Research Libraries UK and JISC (Research Information Network 2011). The report assesses the cost-benefit effect of different OA variations, for example:

- green open access (without embargo period);

- gold open access; and

- delayed open access (green open access with embargo period, differentiated according to discipline).

The authors conclude that gold open access is the financially most sustainable option and provides the most attractive cost-benefit relationship. The assessment is subject to the condition that publication fees in gold open access do not exceed an average of GBP 1 995. The RIN study additionally recommends that green OA services (that is, repositories) should be used more frequently. Regarding the shortening of embargo periods, it is stated that too narrow time windows could harm the business models of academic publishers.

Both the Wellcome Trust and NIH sanction non-compliance to their OA guidelines. They put a halt to approving new grant proposals if researchers do not publish works on previously funded research open access, and funding for ongoing projects is also occasionally terminated.

Knowledge Exchange (KE) considers the advancement of open access in KE partner countries a key issue: 'We are working on solutions to support the growth of OA and ensure it is sustainable in the long term. ${ }^{\prime 61}$ Recommendations are provided, the exchange in expert networks is supported and studies are funded. The issuing of policies by which scientists are encouraged to use OA publishing, monitoring the development of open access, the evaluation of financing options for OA monographs as well as the development of finance models for gold open access are considered appropriate measures.

59 See http://www.wellcome.ac.uk/About-us/Policy/Spotlight-issues/Open-access/Guides/WTD018855.htm.

60 See http://www.wellcome.ac.uk/About-us/Policy/Spotlight-issues/Open-access/Guides/WTX036803.htm.

61 See http://www.knowledge-exchange.info/projects/project/open-access. 
Already in 2009, KE funded studies that were supposed to assess the economic effects of open access for Great Britain, Denmark and the Netherlands (Houghton 2009). The economist John Houghton concludes that open access is a more efficient publishing model than the subscription model (toll access or closed access). If there were a broad transition from toll access to open access, however, there would be a transitional phase in which the benefits of open access would not yet come into effect since the economic returns do not occur simultaneously to the publication.

This reflects the fact that a shift to open access publishing or self-archiving would be prospective and not retrospective, and that the economic value of impacts of enhanced accessibility and efficiency would not be reflected in returns to R\&D until those returns were realised. This has the effect that over a transitional period of twenty years one is comparing twenty years of costs with ten years of benefits (Houghton 2011).

Houghton assesses that, after the transition phase, the savings for a broad implementation of green open access or self-archiving (without cancellation of journal subscriptions) will be as follows: 'Open access self-archiving without subscription cancellations (i.e. 'Green $\mathrm{OA}^{\prime}$ ) would save around $€ 30$ million per annum nationally for Denmark, $€ 50$ million in the Netherlands and $€ 125$ million in the UK' (Houghton 2009: 9). Gold open access would, according to Houghton, have an even greater savings potential:

'Gold OA' open access publishing for journal articles using author-pays might bring net system savings of around $€ 70$ million per annum nationally in Denmark, $€ 133$ million in the Netherlands and $€ 480$ million in the UK (at 2007 prices and levels of publishing activity). (Houghton 2009: 9 f.)

$\mathrm{KE}$ also focuses on the provision of research data (data sharing).$^{62} \mathrm{KE}$ considers the creation of incentives to make data available, for example, through the application of metrics, which inform about impact and further use of provided data in science, of utmost importance. Furthermore, KE considers opportunities to promote infrastructure for the publication of research data and deals with the question of how the habitualisation of data sharing among scientists could be promoted. Some reports on this issue have been published (Costas et al. 2013; Van den Eynden \& Bishop 2014).

All funding options of the European Research Council (ERC) (2013) and the framework programme Horizon 2020 (European Commission 2014; 2015)

62 See http://www.knowledge-exchange.info/projects/project/research-data. 
contain obligatory OA guidelines. Publications funded by respective ERC grants have to be published in gold open access immediately or be made accessible in the post-print or publisher's version as soon as possible, but at the latest within six months on an OA repository. There are longer periods for publication in the humanities and social sciences; up to 12 months are accepted. OA publication on a repository is also obligatory if the article has already appeared in gold open access. In contrast to the ERC, Horizon 2020 only has a maximum embargo period of 12 months for publications from all disciplines. The ERC recommends the use of the servers Europe PubMed Central or arXiv, if thematically fitting. The guidelines of both the ERC and Horizon 2020 not only aim at journal articles but also at monographs. Regarding research data, the ERC recommends availability in open access. Horizon 2020 additionally demands detailed data management plans from researchers receiving funds. The expected publication costs in gold open access can be applied for at the funders.

Moreover, the European Ccommission (EC) has funded projects ${ }^{63}$ on OA research as well as the development of OA infrastructures, such as:

- DRIVER II (Digital Repository Infrastructure Vision for European Research): Networking of repositories;

- LiquidPub (Liquid Publications: Scientific Publications meet the Web - changing the way scientific knowledge is produced, disseminated, evaluated and consumed): Testing of dynamic publication models;

- OAPEN (Open Access Publishing in European Networks): Analysis of OA publication models for monographs;

- PARSE.Insight (Permanent Access to the Records of Science in Europe): Long-term archiving of digital research data;

- PEER (Publishing and the Ecology of European Research; and

- SOAP (Study of Open Access Publishing by Key Stakeholders).

The project OpenAIRE, ${ }^{64}$ also initiated by the EC, bundles access to OA publications and data from EC-funded projects. OpenAIRE first formed the technological and organisational implementation of the OA pilot project in the $7^{\text {th }}$ EU Research Framework Programme. Within this pilot, researchers receiving funds from selected disciplines (health, energy, environment, information and communication technology, research infrastructure, social sciences, economics, humanities as well as science in society) were assigned to make project-related publications available in green open access. Scientists can either deposit their

\footnotetext{
63 The funding period of the projects has ended, but they are mentioned since they are of special importance as model projects.

64 See http://www.openaire.eu/.
} 
publications in a repository of their institution or discipline or in the so-called OpenAIRE Orphan Repository. If an institutional or disciplinary repository is used, documents that stem from ERC-funded projects can be automatically added to the OpenAIRE database.$^{65}$ OpenAIRE is supposed to be the basis of an integrated European OA infrastructure. It already contains services such as Helpdesk and bidirectional links of publications and project information. Moreover, documents and other scientific objects, which do not stem from EC funding, are meanwhile also being indexed in OpenAIRE.

The German Publishers and Booksellers Association is against open access and promotes the strengthening of author rights. It especially takes contrary positions with regard to the issues in the copyright law described by the Alliance (Börsenverein des Deutschen Buchhandels 2011a: 9-13), private copies and secondary usage rights for copyright holders of scientific contributions in open access. The argumentation of the Association is mainly of a legal nature. Open access is understood as a reaction to financial shortage, which endangers the freedom of science. The Association is against secondary usage rights of scientific works. It considers the financing of OA business models as insecure and views open access as 'publisher activity of the public sector', which 'due to structural reasons already has to be more expensive, inefficient and less pluralistic than using the services of competing publishers and library services' (Börsenverein des Deutschen Buchhandels 201 lb: 3). This especially refers to green open access and the operation of repositories through public institutions (Börsenverein des Deutschen Buchhandels 2011b: 9). The consequence of implementing gold open access would result in a shortage of scientific information due to the cross-subsidisation of subscriptions through the private sector. If they disappear this would lead to increased OA fees. Moreover, the Association emphasises financial burdens for research and publication-intensive institutions following the model of APCs (Börsenverein des Deutschen Buchhandels 2011b: 9 f.). Gold OA models are viewed as rarely financially feasible. It underscores its position with the protection of publishers' business models whose investments in infrastructure and services enable scientific work and scientific provision of information. From the perspective of the Association, reform proposals such as that of the Alliance endanger 'appropriate compensation of authors' and publishers' work and thus the growing and functioning markets in the provision of scientific information' (Börsenverein des Deutschen Buchhandels 2006).

65 This, however, requires the existence of a special interface as well as changes in the database scheme of the repository software. 


\subsection{Licensing}

In the framework of its Cross-Regional Licensing programme, ${ }^{66}$ the DFG also supports the free accessibility of scientific information. This information ${ }^{67}$ (text publications or databases) can be freely accessed by members and users of scientific institutions throughout Germany. Analogous to the national licence model of the DFG, the partner organisations of the Alliance of German Research Organisations have negotiated licences with academic publishers since 2011. This allows academic users to use scientific documents free of charge. According to each licensed product, usage by a private individual outside of higher education institutions may be possible. Since this rule pertaining to private individuals only grants users from Germany access, it does not concern all products and a registration is just as necessary as the acceptance of special user agreements. However, these licences do not create real OA offers. The Alliance licences pursue the consortia principle and assume a cost sharing of participating libraries, which need to bring in $75 \%$ of the financing. The rest is provided by the DFG. In addition, further user rights are acquired. These include, among other things, usage (DFG 2010: 7 f.) for

- the development of value-added services that, for example, are allowed to use data mining;

- aggregation or integration services in virtual research environments; and

- delivering full texts for the purpose of hosting.

The Alliance licences also have an OA clause which, according to the DFG in its basic guidelines for the acquisition of DFG-funded cross-regional licences (DFG 2010: 8), allows authors to deposit their articles soon after they have appeared in licensed journals in an institutional or discipline-specific repository of their choice, usually in the form in which it had been published, and to make it OA at no extra costs. The affiliated institutions have the same right. It can also be agreed that the publisher itself deposits articles of authors in authorised institutions in a repository and to make such licensed content available open access.

With respect to the licensing of scientific information, the KII sees the need to develop models of acquisition for different levels of demand (consortial/ national, local, end user/document delivery/pay-per-view). This requires

\footnotetext{
66 See http://www.dfg.de/foerderung/programme/infrastruktur/lis/lis_foerderangebote/ueberregionale_ lizenzierung/index.html.

67 A list can be found at: http://www.nationallizenzen.de/angebote.
} 
flexible business models that have to display the following characteristics (KII 2011:31):

- $\quad$ nation-wide consortia have to be allowed by the providers (publishers);

- the individual need of an institution is influential in the decision to buy a product;

- negotiations with providers about individually designed packages need to be possible;

- $\quad$ staggered business models that take into account the degree of use and which allow gradual transitions at interfaces should be developed; and

- the transformation process of subscription models to OA models is welcome and has to be taken into account.

In technological terms, non-proprietary, independent platforms are welcome, as well as restrictions due to digital rights management (DRM), and the use of open, standardised interfaces that allow the simple implementation of metasearches.

Moreover, the further development of cross-regional and national licensing models is welcome (KII 2011 : 32). This should include a guided and transparent needs assessment, quality assurance (this way experts could approve funding for licensing) and organisation, or administration of consortia through the libraries (which head the negotiations). Financing should be ensured through a combination of local and central funds (KII 2011: 47). KII considers an increase of the acquisition budget necessary in order to continue the task of providing literature. The goal is a connection to the development of research expenditures (KII 2011: 32). In addition, according to the KII, more funds are needed in order to acquire cross-regional and national licences ${ }^{68}$ and to cover the costs for organisation and administration. These project-based structures should be transferred to sustainable financing models and regularly evaluated. In this area, KII suggests coordination by the DFG (KII 2011: 55).

The German Publishers and Booksellers Association has doubts with respect to the cost savings, in particular in the area of libraries, which, in the future, will have to do without the services (consultation, design of custom-made programmes, negotiations with providers, payment processing, invoicing, etc. $\left.{ }^{69}\right)$ of the providers. Moreover, national licences endanger the efficiency of the publisher landscape (Börsenverein des Deutschen Buchhandels $201 \mathrm{lb}$ : 1 f.). In the Association's view, national and Alliance licences lead publishers

68 KII suggests to at least triple the funds from $€ 12$ million to $€ 36$ million in order to be able to acquire programmes of larger publishers as national or cross-regional consortiums (KII 2011: 33).

69 See Börsenverein des Deutschen Buchhandels (2011b: 5) - in part services are mentioned that do not exist in consortia access. 
into an economic dependency on the DFG and the Alliance organisations (Börsenverein des Deutschen Buchhandels 2011b: 6). They are seen as instruments of state control that 'blur the most important signal of competition, the price, and may intervene in a fragile market' (Börsenverein des Deutschen Buchhandels 2011b: 4).

\subsection{Intellectual property and copyright}

According to the Alliance, there are several legal obstacles with respect to the intended, integrated and open information structure that need to be dealt with at political level, such as the current copyright law as well as different value-added tax (VAT) rates for digital and printed publications. The partner organisations advocate an author right to publish contributions in the sense of a free accessibility of science to information (Allianz der deutschen Wissenschaftsorganisationen 2008a: 8). Furthermore, VAT rates for e-publications should be adapted to the lower level of print publications. In particular, however, they demand 'that scientists are granted an unconditional right of secondary publication for their articles and dependently published works in the same format after an appropriate embargo period' (Allianz der deutschen Wissenschaftsorganisationen 2010: 4). An obligation to exercise this right should not be established. Rather, the scientists' position in negotiations with publishers should be strengthened and should provide them with control over the degree of visibility of their results (Allianz der deutschen Wissenschaftsorganisationen 2010: $4 \mathrm{f}$.). The Alliance considers an embargo period of six months as sufficient in order to guarantee economic efficiency for publishers (Allianz der deutschen Wissenschaftsorganisationen 2010: 4 f.).

On 1 January 2014, changes in the copyright law became effective, which were actually aimed at strengthening the rights of the copyright owners. They especially concerned section 38(4) of the UrhG, which says that the rights to publications return to the authors twelve months after formal publication. Authors may then re-publish the work at another location, for example, on an OA server. The following restrictions have to be taken into account, however:

- The work has to be published in collections that appear at least twice a year. In general, this rule only applies to journal articles but not to monographs, contributions in anthologies or conference proceedings as well as most other types of publications.

- The authors only regain the rights to accepted manuscript versions, not versions of the publisher. The accepted manuscript version is the final revised version of the authors and in general identical to the publisher's 
version with regard to content, but different with regard to formatting and missing pagination.

- Should the authors make this version publicly accessible, then this publication shall not serve any monetary purposes.

- This rule concerns only publications of German publishers.

- The drastic restriction concerns persons who benefit. The restriction to contributions that have emerged in the framework of research that has at least been half-funded by public funds decreases the intended promotion of open access. It only refers to publications that are mainly financed by third-party funds - for example, activities in the framework of DFG projects, the Federal Ministry of Education and Research (Bundesministeriums für Bildung und Forschung) or of foundations. Researchers from non-university research institutions also benefit from this regulation.

\section{Conclusion: Open access, research data and integrated infrastructures}

The activities and statements of the research institutions, science organisations and science policy actors aim at smooth, ideally cost-free access to scientific information. This especially concerns open access and the free access to scientific texts. The demand for and promotion of open access is mainly underscored by the acceleration of scientific communication and the increased efficiency of academic publishing. Moreover, the taxpayer argument is mentioned according to which scientific publications that are funded by the public sector also need to be publicly accessible. In addition, open access is associated with a strengthening of author rights. The demand for the right of secondary publication of scientific works was, however, not sufficiently taken into account in the 2014 change of copyright laws in the view of OA advocates. Representatives of academic publishing companies (especially the German Publishers and Booksellers Association) take opposing positions. They argue against governmental intervention in the market of scientific publications and the lacking efficiency of OA publication programmes. In addition, they consider the promotion of open access as undermining the internal logistical structures of academic publishing, including the essential services provided by the publishers, such as quality assurance and selection. Legal measures in the form of establishing a documented right of secondary usage are considered as harmful to copyrights by the German Publishers and Booksellers Association.

The institutions represented here apply a diversity of measures in support of open access: these include the further development and networking 
of repositories to strengthen green open access as well as the creation of publication funds and own publication infrastructures to strengthen gold open access. On the part of third-party funders, the approval of funds is partly bound to the condition to make project-related publications available open access (for example, NIH, NSF, Wellcome Trust, EC). In general, incentives for using open access as an option in publishing should be created. For this purpose, the testing of alternative metrics or the special consideration of such publications in evaluations is suggested..$^{70}$ Open access is also the object of several studies that have been financed by the analysed institutions. These studies focus especially on the economic efficiency of open access by putting the dissemination of scientific information in different scenarios of publishing (OA variations, national licensing, closed access/subscription model) in relation with their costs and economic as well as scientific processing. These studies are subject to several restrictions (for example, unpredictability of the quantitative development of the publication output, effects of feedback in the implementation of different OA strategies) but mostly conclude a much stronger efficiency of open access in comparison to closed access (Houghton 2011; Houghton et al. 2012; Houghton et al. 2010; Research Information Network 2011; Wellcome Trust 2004). With respect to the perspectives of the two OA strategies - green versus gold - there is currently no indication that one of them will be replaced in the mid-term. While green open access was more strongly propagated at the beginning of the discussion, this can probably be explained by the fact that there was a lack of gold OA programmes at the time. In the international OA discussion, there is currently a tendency towards a dominance of gold open access. The Finch Report (Finch et al. 2013) published in 2013, which formulated recommendations for funders of research from Great Britain, received special attention. The report summarises considerations of a working group led by Dame Janet Finch, and clearly advocates a promotion and preference of gold open access in the OA guidelines of funders of research. The guidelines of the Finch Report have already been taken over by funding institutions such as the Research Councils UK and it is expected that others will follow.

Research organisations such as the MPG (Schimmer et al. 2015) show a certain preference for a new form of gold open access, the so-called 'journal flipping', that is, the transformation of subscription journals to OA journals. Following this model, in the Netherlands, corresponding consortia agreements were made with Springer at the end of 2014. The so-called 'Springer deal' not only included the subscription or licensing of 1500 Springer journals but also

70 Here, especially metrics that take into account OA publications, which have so far been excluded from impact measurements, are addressed (for example, due to the scope of the databases used). This would, among others, concern new journals or document types that are not evaluated in Journal Citation Reports, such as proceedings, monographs, anthologies, contributions in anthologies, etc. 
the right of Dutch academics to publish open access in those journals without having to pay any article fees (Vereniging van Universiteiten 2014). On 10 December 2015, the universities announced a similar agreement with Elsevier (Vereniging van Universiteiten 2015). The existing subscriptions for Elsevier journals remain, and, in return, Dutch scientists are able publish open access in selected Elsevier journals without additional costs.

Via licensing procedures (through national or Alliance licences), scientific publications should be added to the lower cost level and free accessibility as well. Since these licences, first of all, grant users at scientific institutions (not everybody) free access, they are not a true OA variation. The licences do, however, provide scientists at licence-giving institutions the possibility to deposit their documents in repositories open access. To ensure smooth and uncomplicated access to scientific objects, the establishment of a national hosting infrastructure is also welcomed..$^{71}$ Aside from texts (licensed in open or closed access), research data as well as other types of media are also possibilities for hosting. Independence from the publisher is also strongly considered.

In the area of research data, it is required that server infrastructures be developed in order to ensure the permanent availability, archiving and provision of primary research data for third parties. This offer should be developed in close collaboration with the disciplines. In parallel, funding programmes for the development of model-like solutions were established. The scientific recognition of the provision of data should create incentives for data sharing. As a consequence, these should be subject to quality assurance and peer review and be available consistently and for citation purposes. Funders of research (for example, NIH, Wellcome Trust) require that recipients of funds follow the guidelines on data sharing and data management. The granting of funds partly depends on the presentation of records of measures taken. Moreover, special emphasis is placed on the connection of data to other data storage or information items, such as virtual research environment, full texts, databases, academic CVs and other information storage (such as research information systems).

The open access approach to research data goes one step further and demands free availability of data. In this context, there is still a need for the creation of appropriate licensing models for the provision of information. More so than in open access to text publications, in the area of research data, not only free usage but also open usage of the data is required. In such scenarios, research data should be used and processed according to open source principles. These considerations are elaborated in the Panton Principles ${ }^{72}$ and

71 First of all by the Alliance and KII. 
the Open Definition. ${ }^{73}$ According to the Open Definition, knowledge is open if it can be freely

- $\quad$ used (for example, read, analysed);

- $\quad$ processed (for example, newly evaluated, modified, and combined with other data); and

- disseminated and copied, offered for use through others.

There should be only two conditions for the use of data and information: on the one hand, naming the copyright holders and, on the other, using a Share Alike clause. When following this clause, the dissemination of edited or derived work can only happen under the same conditions as those under which the data and information had been accessible originally. Next to the condition of cost-free online use, accessibility in a technically easy-to-handle and changeable form is also to be emphasised. The objective is the use of open data formats (Herb 2012: 33 f.).

While publishers in part strive for new business models that are based on gold open access, academic libraries find new fields of activity, especially in the area of information provision (operators of repositories for publications and data with tasks such as author consultation) and as service providers for publications (for example, if they themselves administrate OA publication environments of green or gold open access or publication funds).

On the level of infrastructures, there are scenarios in which scientific communication can take place and information (texts, data, other media) can be used cooperatively where possible, depending on location and time. Virtual research environments bundle access to research and information infrastructures, publications, data, protocols - all information items that are involved in the work process. As integrative channels, virtual research environments are dependent on the number of items that can be used permanently and persistently within them. Here, open (not only cost-free) availability of contents as well as a smooth usability of research and information infrastructures is ideal.

Measures, which the analysed institutions suggest, plan or implement, aim at the most uncomplicated and ubiquitous access to scientific information. Key elements in these scenarios are open access to texts and data, establishment of data sharing and management, licensing, hosting, strengthening of author rights, (further) development of research and information infrastructures. The conceptual proximity of these considerations to Open Science Workflows (for example, Förstner et al. 2011), whose approach takes the requirements

73 See http://opendefinition.org/. 
of open definition more into account than the model of virtual research environments and itself advocates open interfaces and open dissemination of information, is striking.

\section{References}

Allianz der deutschen Wissenschaftsorganisationen. 2008a. Presseinformation: Wissenschaftsorganisationen starten Schwerpunktinitiative zur 'Digitalen Information'. München: Max-Planck-Gesellschaft. Retrieved from http://www.dfg.de/ download/pdf/presse/das_neueste/das_neueste_2008/pm_allianz_digitale_ information_080612.pdf [Accessed 15 April 2016].

Allianz der deutschen Wissenschaftsorganisationen. 2008b. Schwerpunktinitiative 'Digitale Information' der Allianz-Partnerorganisationen. Berlin. Retrieved from http://www.dfg.de/download/pdf/presse/das_neueste/das_neueste_2008/pm_ allianz_digitale_information_details_080612.pdf [Accessed 15 April 2016].

Allianz der deutschen Wissenschaftsorganisationen. 2010. Neuregelung des Urheberrechts: Anliegen und Desiderate für einen Dritten Korb. Berlin. Retrieved from https://www.mpg.de/225737/Neuregelung_des_Urheberrechts_Anliegen_ Dokument_im_Volltext_.pdf [Accessed 15 April 2016].

Börsenverein des Deutschen Buchhandels. 2006. Geplantes Urheberrecht gefährdet Bildung und Wissenschaft. Berlin. Retrieved from http://www.boersenverein.de/ sixcms/media.php/976/22-05-JPK-Resolution.pdf [Accessed 15 April 2016].

Börsenverein des Deutschen Buchhandels. 201 la. Jahresbericht 2010/2011. Berlin. Retrieved from http://www.boersenverein.de/sixcms/media.php/976/ Jahresbericht_2010-2011.pdf [Accessed 15 April 2016].

Börsenverein des Deutschen Buchhandels. 201 lb. Stellungnahme zum Gesamtkonzept für die Informationsinfrastruktur in Deutschland (KII-Papier). Berlin. Retrieved from http://www.boersenverein.de/sixcms/media.php/976/Stellungnahme KII 20111008.pdf [Accessed 15 April 2016].

Costas, R., Meijer, I., Zahedi, Z. \& Wouters, P. 2013. The value of research data. Metrics for datasets from a cultural and technical point of view. Knowledge Exchange. Retrieved from http://repository.jisc.ac.uk/6205/1/Value_of_Research_ Data.pdf [Accessed 15 April 2016].

Crow, R. 2006a. Publishing Cooperatives: An alternative for society publishers. SPARC discussion paper. Washington, DC: Scholarly Publishing and Academic Resources Coalition. Retrieved from http://www.sparc.arl.org/resources/papersguides/publishing-cooperatives [Accessed 15 April 2016].

Crow, R. 2006b. Sponsorships for Nonprofit Scholarly and Scientific Journals: A guide to defining and negotiating successful sponsorships. Washington, DC: Scholarly Publishing and Academic Resources Coalition. Retrieved from http://sparc.arl. 
org/resources/papers-guides/sponsorships-for-nonprofit-scholarly-and-scientificjournals [Accessed 15 April 2016].

Crow, R. 2009a. Campus-based Publishing Partnerships: A guide to critical issues. Washington, DC: Scholarly Publishing and Academic Resources Coalition. Retrieved from http://sparc.arl.org/resources/papers-guides/campuspartnerships [Accessed 15 April 2016].

Crow, R. 2009b. Income Models for Open Access: An overview of current practice. Washington, DC: Scholarly Publishing and Academic Resources Coalition. Retrieved from http://www.sparc.arl.org/resources/papers-guides/oa-incomemodels [Accessed 15 April 2016].

Crow, R., Ivins, O., Mower, A., Nesdill, D., Newton, M., Speer, J., Mullins, J.L., Murray-Rust, C., Watkinson, C. \& Ogburn, J.L. 2012. Library Publishing Services: Strategies for success. West Lafayette: Purdue University Press. Retrieved from http://docs.lib.purdue.edu/purduepress_ebooks/24/ [Accessed 15 April 2016].

DFG (Deutsche Forschungsgemeinschaft). 2006. Wissenschaftliche Literaturversorgungs- und Informationssysteme. Schwerpunkte der Förderung bis 2015. Bonn. Retrieved from http://www.dfg.de/download/pdf/foerderung/ programme/lis/positionspapier.pdf [Accessed 15 April 2016].

DFG (Deutsche Forschungsgemeinschaft). 2010. Grundsätze für den Erwerb DFGgeförderter überregionaler Lizenzen. Bonn.

DFG (Deutsche Forschungsgemeinschaft). 2014a. Open Access Publizieren. Bonn. Retrieved from http://www.dfg.de/formulare/12_20/12_20_de.pdf [Accessed 15 April 2016].

DFG (Deutsche Forschungsgemeinschaft). 2014b. Verwendungsrichtlinien. Sachbeihilfen mit Leitfaden für Abschlussberichte und Regeln guter wissenschaftlicher Praxis. Bonn. Retrieved from http://www.dfg.de/formulare/2_02/2_02_de.pdf [Accessed 15 April 2016].

EC (European Commission). 2014. Horizon 2020: Annotated model grant agreements. Retrieved from http://ec.europa.eu/research/participants/data/ref/h2020/grants_ manual/amga/h2020-amga_en.pdf [Accessed 15 April 2016].

EC (European Commission). 2015. Guidelines on Open Access to Scientific Publications and research data in Horizon 2020. Retrieved from https://ec.europa.eu/research/ participants/data/ref/h2020/grants_manual/hi/oa_pilot/h2020-hi-oa-pilotguide_en.pdf [Accessed 15 April 2016].

ERC (European Research Council). 2013. Open Access Guidelines for Researchers Funded by the ERC. European Research Council. Retrieved from https://erc. europa.eu/sites/default/files/document/file/ERC_Open_Access_Guidelinesrevised_2013.pdf [Accessed 15 April 2016].

Finch, J., Bell, S., Bellingan, L., Campbell, R., Donnelly, P., Gardner, R. \& Jubb, M. 2013. Accessibility, sustainability, excellence: How to expand access to research 
publications. Executive summary. International Microbiology: The Official Journal of the Spanish Society for Microbiology, 16(2):125-132.

Förstner, K., Hagedorn, G., Koltzenburg, C., Kubke, M.F. \& Mietchen, D. 2011. Collaborative platforms for streamlining workflows in Open Science. In Proceedings of the 6th Open Knowledge Conference, 30 June \& 31 July, Berlin. G8+ Science Academies. 2011. Joint G8+ Science Academies' statement on education for a science-based global development.

Herb, U. 2012. Offenheit und wissenschaftliche Werke: Open Access, Open Review, Open Metrics, Open Science \& Open Knowledge. In U. Herb (ed.). Open Initiatives: Offenheit in der digitalen Welt und Wissenschaft. Saarbrücken: universaar, 11-44. Retrieved from http://eprints.rclis.org/17183/ [Accessed 15 April 2016].

Houghton, J.W. 2009. Open Access: What are the economic benefits? Melbourne: Victoria University.

Houghton, J.W. 2011. The costs and potential benefits of alternative scholarly publishing models. Informationresearch, 16(1). Retrieved from http:// informationr.net/ir/16-1/paper469.html [Accessed 15 April 2016].

Houghton, J.W., Dugall, B., Bernius, S., Krönung, J. \& König, W. 2012. General Cost Analysis for Scholarly Communication in Germany: Results of the 'Houghton Report' for Germany. Frankfurt am Main. Retrieved from http://nbn-resolving.de/urn/ resolver.pl?urn:nbn:de:hebis:30:3-275309 [Accessed 15 April 2016].

Houghton, J.W., Rasmussen, B. \& Sheehan, P. 2010. Economic and Social Returns on Investment in Open Archiving Publicly Funded Research Outputs. Melbourne. Retrieved from http://www.arl.org/sparc/publications/papers/vuFRPAA/index. shtml [Accessed 15 April 2016].

Kommission Zukunft der Informationsinfrastruktur. 2011. Gesamtkonzept für die Informationsinfrastruktur in Deutschland. Retrieved from http://www.gwk-bonn. de/fileadmin/Papers/KII_Gesamtkonzept.pdf [Accessed 15 April 2016].

Lipp, A. 2010. Schwerpunktinitiative 'Digitale Information'. Eine Einführung. In 4. Leipziger Kongress für Information und Bibliothek. Retrieved from http://www. opus-bayern.de/bib-info/volltexte/2010/871/ [Accessed 15 April 2016].

Max-Planck-Gesellschaft. 2003. Berlin Declaration on Open Access to Knowledge in the Sciences and Humanities. Retrieved from http://openaccess.mpg.de/3515/Berliner_ Erklaerung [Accessed 12 February 2014].

Research Information Network. 2011. Heading for the open road: Costs and benefits of transitions in scholarly communications. London. Retrieved from http://www.rin. ac.uk/our-work/communicating-and-disseminating-research/heading-openroad-costs-and-benefits-transitions-s [Accessed 15 April 2016].

Schimmer, R., Geschuhn, K.K. \& Vogler, A. 2015. Disrupting the Subscription Journals' Business Model for the Necessary Large-scale Transformation to Open Access (S. 11). Max Planck Digital Library. 
Tananbaum, G. 2010. Campus-based Open-access Publishing Funds: A practical guide to design and implementation. Washington, DC: Scholarly Publishing and Academic Resources Coalition SPARC. Retrieved from http://www.arl.org/sparc/ openaccess/funds/guide.shtml [Accessed 15 April 2016].

Van den Eynden, V. \& Bishop, L. 2014. Sowing the seed: Incentives and motivations for sharing research data, a researcher's perspective (S. 45). Knowledge Exchange. Retrieved from https://repository.jisc.ac.uk/5662/1/KE_ report-incentives-for-sharing-researchdata.pdf [Accessed 15 April 2016].

Vereniging van Universiteiten. 2014. Open Access Newsletter, (1). Retrieved from http://vsnu.nl/files/documenten/Domeinen/Onderzoek/Open access/Open access newsletter 121614.pdf [Accessed 15 April 2016].

Vereniging van Universiteiten. 2015. QeA's for the agreement with Elsevier. Retrieved from http://vsnu.nl/files/documenten/Domeinen/Onderzoek/Open access/QA OpenAccess_Akkoord_Elsevier_ENG.pdf [Accessed 15 April 2016].

Wellcome Trust. 2003. Economic Analysis of Scientific Research Publishing. Report commissioned by the Wellcome Trust. London. Retrieved from http://www. wellcome.ac.uk/stellent/groups/corporatesite/@policy_communications/ documents/web_document/wtd003182.pdf [Accessed 15 April 2016].

Wellcome Trust. 2004. Costs and Business Models in Scientific Research Publishing. Report commissioned by the Wellcome Trust. London. Retrieved from http:// www.wellcome.ac.uk/stellent/groups/corporatesite/@policy_communications/ documents/web_document/wtd003184.pdf [Accessed 15 April 2016].

Wissenschaftsgemeinschaft Gottfried Wilhelm Leibniz e.V. 2009. Rahmenkonzept für die Fachinformationsinfrastruktur in Deutschland. Bonn: Arbeitsgruppe Fachinformationsinfrastruktur der Wissenschaftsgemeinschaft Gottfried Wilhelm Leibniz. Retrieved from http://www.gwk-bonn.de/fileadmin/Papers/ Rahmenkonzept-WGL.pdf [Accessed 15 April 2016].

Wissenschaftsgemeinschaft Gottfried Wilhelm Leibniz e.V. 2011 a. Jahresbericht 2010. Bonn. Retrieved from http://www.leibniz-gemeinschaft. $\mathrm{de} /$ ?nid=jber\&nidap=Sprint $=0$ [Accessed 15 April 2016] .

Wissenschaftsgemeinschaft Gottfried Wilhelm Leibniz e.V. 2011 b. LeibnizOpen: Wissenschaftliche Texte frei verfügbar. Bonn. Retrieved from http://www.leibnizgemeinschaft.de/?nid=pmakt\&nidap $=\delta$ print $=0$ [Accessed 15 April 2016]. 


\section{Open Access}

\section{Effects on Publishing Behaviour of Scientists, Peer Review and Interrelations with Performance Measures}

David Ball

\section{Introduction}

History testifies to two information and communications technology (ICT) revolutions; we are now in the grip of a third. The first ICT revolution was the development of writing. Beforehand, the only vehicle for storing information was the human memory. Transmission relied on speech and signs; if content was not to perish with the individual, replication needed time and personal contact. After the invention of writing, portable storage media reduced the restrictions imposed by time and space. Knowledge became much less vulnerable, more could be stored and passed from generation to generation or carried across long distances, and critical thinking was enhanced.

While writing represented a huge advance, scholars in the time of manuscripts knew severe limitations. They tended to travel to manuscripts, which were often in jeopardy, such as the destruction at Alexandria. It was very difficult to determine provenance and authority, and to compare texts. Dissemination by copying tended to corrupt texts.

It is almost impossible for us now to appreciate the scale and effect of the second ICT revolution - printing with movable type - we have spent our lives during its maturity. Scholars in the late $15^{\text {th }}$ and early $16^{\text {th }}$ centuries were, however, under no illusions. We hear of the printer Johann Fust having to 
flee Paris. The inhabitants of Paris believed that only someone in league with the devil could produce so many perfect copies of the Bible. Later Fust was conflated with Georg (subsequently known as Johann) Faust, who was, of course, reputed to have sold his soul to the devil in return for knowledge (Eisenstein 1993: 19-20). Particularly telling is the association of a technology so marvellous that it could only be achieved through necromancy, with the pursuit of that most dangerous commodity - knowledge.

For the scholar, the advances represented by printing were marked. The possibilities of obtaining texts were hugely enhanced. By 1503, 8 million books had been printed, more, it is estimated, than the number of manuscripts produced between $330 \mathrm{CE}$, the founding of Constantinople, and 1453, when it was captured by the Turks. At the time, the cost of copying one manuscript equated to the cost of producing over 300 printed books (Eisenstein 1993: 13-14). Provenance and authority were enhanced by the use of title pages, and texts became more organised and exploitable through indexes, tables of contents, etc. Later editions improved texts through corrections; they did not corrupt them as manual copying had corrupted manuscript texts.

The speed of production and distribution, the beauty and reliability of the texts, and the low cost must have been as impressive then as the Internet is today.

Looking forward 200 years to 1665, we see one of printing's major outcomes: Oldenburg laying the foundations of scholarly communication with the publication of the Philosophical Transactions of the Royal Society of London, a form of communication that has lasted for 350 years.

In today's third (electronic) ICT revolution, we are witnessing the birth of new forms of scholarly communication out of the restrictive chrysalis of print. Just like Johann Fust and others witnessing the birth of printing, we do not know yet what the new patterns will be, but we do know that scholarly communication will be very different in the future, and, as with all disruptive technologies, that the change will be sudden and unpredictable.

\section{Open access: description and definitions}

Since its inception, the scholarly journal has become recognised as having four functions: registration (providing a timestamp to establish paternity), certification or validation (peer review to provide a stamp of quality assurance), awareness (distribution), and archiving (preservation) (Suber 2012: 62).

In the print world, a large part of the cost of a scholarly journal of any size arises from its distribution: its physical creation, production and delivery. These and other costs (for example, marketing, collecting subscriptions, contribution 
to overheads, and surplus or profit for commercial publishers) have generally been met by subscriptions: selling physical copies to individuals and libraries.

In the electronic world, the costs of distribution, given the infrastructure of the Internet, are virtually non-existent. This has enabled the rise of the open access (OA) movement, which has spawned its own set of definitions and acronyms.

\subsection{Open access}

Suber (2012: 4) defines OA literature as 'digital, online, free of charge, and free of most copyright and licensing restrictions'. This definition condenses, with somewhat different emphasis, the three main public statements on OA, the Budapest Open Access Initiative (BOAI) of February 2002, the Bethesda Statement on Open Access Publishing of June 2003, and the Berlin Declaration on Open Access to Knowledge of October 2003. The BOAI statement, for instance, says:

By 'open access' to this literature, we mean its free availability on the public internet, permitting any users to read, download, copy, distribute, print, search, or link to the full texts of these articles, crawl them for indexing, pass them as data to software, or use them for any other lawful purpose, without financial, legal, or technical barriers other than those inseparable from gaining access to the internet itself. The only constraint on reproduction and distribution, and the only role for copyright in this domain, should be to give authors control over the integrity of their work and the right to be properly acknowledged and cited.

Suber relaxes the second part of this definition to 'free of most copyright and licensing restrictions', a recognition of the fact that authors, as well as asserting control over integrity and attribution of their work, may wish to restrict reuse to, for instance, educational or non-commercial purposes (see section 11 below on copyright).

Literature that is not OA, such as that published in the subscription journals, is generally referred to as 'toll access' (TA), i.e. there is some charge to be met either by the reader or, more generally, by a library.

Two types of OA are generally recognised: green and gold. Gold OA is delivered through journals. These may be completely OA or hybrid, as some articles are OA and others TA. Green OA is delivered through self-archiving authors deposit manuscripts in repositories, which may be institutional (aiming to capture all the articles produced by a particular institution) or disciplinary (aiming to capture all the articles in a particular discipline). 


\subsection{Green versus gold OA}

The major differences between green and gold OA are as follows. Articles in OA journals, and, of course, OA articles in hybrid journals (gold), are peer reviewed for publication. Self-archived articles (green) are generally not peer reviewed for deposit in a repository; however, they may be, and most often have been, peer reviewed for publication in TA journals. Gold OA articles therefore incur the same costs for the editorial and peer-review process as toll articles. Green OA articles do not incur these costs; they only incur a portion, very small in monetary terms, of the overhead costs of setting up and running the repository.

OA journals generally obtain rights and permissions directly from the rights holder (usually the author). For self-archiving in a green repository, the author must generally obtain the rights from the TA publisher. Many TA publishers offer blanket permission for publication in a green repository, generally after an embargo period of 6 or 12 months. The policies of individual journals and publishers can be found on the SHERPA/RoMEO website. Both green and gold OA have their respective strengths as summarised below.

Green OA is:

- $\quad$ Easy and cheap: it does not engender the overheads of a peer-reviewed journal, nor does it entail the disruption of switching payments from subscription journals to OA articles. There is also concern about the administrative burden arising from the granularity of payment at article level to OA journals, as opposed to TA subscription, which is at the title, collection or big deal level.

- Compatible with TA publishing. Scholars are therefore able to publish in TA journals, for instance, where these are of particularly high repute, and, through self-archiving, still make their articles OA, albeit after an embargo period.

- Hospitable to many other types of document, notably pre-prints (which provide the time-stamp noted at the start of this chapter), theses, and research datasets; gold OA by its nature is confined to post-print copies.

Gold OA:

- Is always immediate, while green OA is often subject to time embargoes imposed by TA publishers.

- Provides access to the published version of an article, while green OA generally provides access only to the author's final peer-reviewed manuscript, without the formatting or pagination of the published version. 


\subsection{Gratis and libre OA}

A further distinction is between gratis and libre OA.

To set the context, in many countries, such as the United Kingdom and the United States, intellectual property (IP) law offers partial 'fair dealing' or 'fair use' exemptions, typically, to use some of the UK wording, for the purposes of research or private study, or criticism and review; German law recognises Zitatrecht. These exemptions are very limited; furthermore, licences from commercial publishers may be more restrictive than the prevailing IP law.

Gratis $O A$ can be accessed free of charge. However, anyone wishing to exceed the limits of fair dealing must obtain permission from the copyright holder(s). Gratis OA removes toll barriers but not permission barriers.

Libre $O A$, on the other hand, is both free of charge and free of at least some legal and licensing restrictions. Users may exceed the legal limits of fair dealing in at least some respects. Libre OA removes toll barriers and at least some permission barriers.

Both green and gold OA are gratis. Green OA may be libre, but generally is only gratis: publishers will impose not only embargo periods on selfarchived materials, but also the sort of restrictions on use that apply to their TA publications (for example, 'all rights reserved'). Gold OA is not necessarily libre: an author is perfectly entitled to retain all intellectual property rights. However, it is common for gold OA authors to lift some of the restrictions of IP law by granting a licence (for further discussion, see section 11 below).

It is important to note that the gratis-libre distinction, which is about rights and permissions, is not the same as the green-gold distinction, which is about delivery.

\section{Economics $^{1}$}

\subsection{Costs of green OA}

In one sense, green OA (self-archiving in institutional or subject repositories) can be seen as riding on the back of TA publishing. The editorial costs of the peer review are borne by the TA journal, or rather its subscribers, leaving institutions to pay only the costs of their repositories.

The costs to Association of Research Libraries of setting up and maintaining institutional repositories were surveyed by Bailey et al. (2006). Respondents reported a range of start-up costs from USD 8000 (€ 6000$)$ to USD 1800000

1 Currency conversions are at rates prevailing in January 2013. 
( $€ 1350000$ ), with a median of USD 45000 (€33 700). The range for recurrent maintenance budgets was USD 8600 ( $€ 6$ 440) to USD 500000 ( $€ 374$ 500), with a median of USD 41750 ( $€ 31$ 300). The majority of the recurrent budgets went to staffing. Some may be an underestimate: for instance, where academic rather than repository staff archive materials. The cost of their time may well not be measured; nevertheless, it is a real cost.

The median cost for start-up and recurrent budgets over three years (startup costs plus three times annual costs) is USD 140250 (€105 100), on average USD 46750 (€ 35 000) per annum.

It is difficult to arrive at a cost per article for green OA. The following calculation is very rough and ready, but gives some sort of estimate. The Ranking Web of Repositories lists 1438 institutional repositories (IRs) and 82 other (subject) repositories. The midpoint IR in terms of size (Document Server@UHasselt) has 12916 records. Assuming it has been in operation for six years, the average number of submissions per annum is 2153 . At the average annual cost of USD 46750 ( $€ 35000$ ), the cost per submission is USD 21.71 $(€ 16.26)$ in 2006 prices. Note that this may be exaggerated if there has been an element of retrospective uploading into the repository.

Swan's (2010a) study of costs and benefits for the Joint Information Systems Committee (JISC) in 2010 is based on a survey of four UK higher education institutions (HEIs) of varying sizes and research intensity. The thoroughness and rigour of the collection and analysis of the underlying data should compensate for the small size of the sample. Swan found (2010a: iv) that

[a]nnual operating costs for the institutional repository [writing down startup costs over three years, as per Bailey], including the cost of depositing items, range from around $26000 \mathrm{GBP}$ [€ 31 100] to almost $210000 \mathrm{GBP}$ [€ 251 300]. The cost of depositing a single article varies from around 6.5 GBP [€ 7.8] to 15.4 GBP [€ 18.4], with the annual cost of depositing into the repository all articles produced by each university ranging from just over 4000 GBP [€ 4 800] to over 75000 GBP [€ 89 700].

From these calculations, it seems that a high-end cost per article of $€ 18$ for green $\mathrm{OA}$ is not unreasonable, while the average cost may be something under $€ 15$.

\subsection{Costs of gold OA}

Prima facie gold OA incurs fewer costs than TA, as there is no need for administering and collecting subscriptions (although this is offset by the need 
to collect other contributions, such as article processing charges) or for digital rights management systems or legal costs associated with licensing and policing.

Some evidence to support this supposition is provided by Edgar and Willinsky (2010) in their 2009 survey of OA journals using Open Journal Systems, an open source online journal management and publishing platform. The survey found that

- $208(20 \%)$ of OA journals recorded no cost;

- the mean annual cost of the remaining 503 journals was USD 16951 (€ 12 665);

- $\quad 798$ journals (83\%) operated under the auspices of academic departments or scholarly societies; and

- only $211(22 \%)$ belonged to non-profit (153 or $16 \%$ ) or commercial (58 or $6 \%$ ) publishers (multiple answers to this question were allowed).

Edgar and Willinsky (2010) unfortunately provide no analysis by type of publisher. This survey should perhaps be treated with some caution. First, it is restricted to the users of an open source platform. Take-up of this platform may tend to be by small and non-commercial publishers. Second, the majority of these publishers are supported by academic departments or other bodies; therefore, reported costs will be lower than actual costs, and the long-term viability of such subsidies is questionable.

OA publishing is funded by what Suber (2012: 138) calls 'author-side' contributions. By contrast, TA publishing is funded mainly from reader-side contributions.

The most obvious, though not the only, contribution to meeting gold OA costs is the article processing charge (APC). Estimates of APC costs vary widely. Solomon and Björk (2012) studied the APCs and article volumes of journals that were listed in the Directory of Open Access Journals as charging APCs. The average APC was USD 906 ( $€$ 680). The price range varied from USD 8 ( $€ 6)$ to USD 3900 ( $€ 2$ 930), with the highest charged by journals with high impact factors from major international publishers. Swan and Houghton (2012: 6) note, however, that the large commercial publishers' charges were relatively high - in the order of USD 1 000-3 000 (€ 751-€ 2250 ). As these larger publishers shift their business model to gold OA, a higher average APC is likely.

Other contributions may come from subsidies (for example, from a university, foundation or scholarly society - this is borne out by Edgar and Willinsky's [2010] study quoted above), advertising, print editions or addedvalue services. 
Some OA publishers, such as BioMed Central, Hindawi and PLOS, offer membership schemes, which typically collect an up-front annual fee from institutions and offer a discount on APCs. The UK's Royal Society of Chemistry (RSC) is now offering a new model called 'Gold for Gold'. Institutions subscribing to a package that offers all the RSC's online content, receive a number of vouchers, each enabling free OA publication of one article. The number of vouchers is calculated by dividing the subscription the RSC receives from an institution by its APC for making a full paper OA. Once all vouchers have been used, the institution may buy additional vouchers at a discount. It is not clear how this model is sustainable. The RSC itself guaranteed it for only one subscription year, 2013. It is, however, an interesting experiment in encouraging the growth of gold OA in a hybrid environment. The RSC has also committed itself to reducing subscription costs in line with the growth of OA articles in its publications. Articles placed under its Gold for Gold scheme are not counted as OA.

\subsection{Toll access costs}

Taking the reader side first, the most obvious contribution to meeting TA costs is subscriptions. According to the Society of College, National and University Libraries (SCONUL 2012), in 2010/11, UK HEIs spent a total of GBP 160m (€ $190 \mathrm{~m}$ ) on print and electronic journal subscriptions. A hidden contribution in kind is the provision, chiefly by HEIs, of the expertise of the mainly unpaid editors and peer reviewers. Other sources of revenue to meet costs are advertising and electronic or hard-copy sales of individual articles.

It is often overlooked that there are author-side contributions to TA costs too. Many journals levy page and plate charges. In addition, authors and/or their institutions donate the IP in their articles.

\subsection{Economic benefits of OA}

In their major study of 2009, Economic implications of alternative scholarly publishing models: Exploring the costs and benefits, Houghton et al. (2009) aimed to compare all the costs and benefits associated with alternative publishing and dissemination models, using UK higher education as an example. The study not only compared the cost of publishing UK article output under alternative models, including subscription, but also explored the wider benefits of open access to research in the form of increased returns to research and development (RED) expenditure. Houghton et al. (2009: xxii) concluded: 
It seems likely that more open access would have substantial net benefits in the longer term and, while net benefits may be lower during a transitional period they are likely to be positive for both OA publishing and self-archiving alternatives (i.e. Gold OA) and for parallel subscription publishing and selfarchiving (i.e. Green OA). This suggests that there are gains to be realised from moving towards more open access publishing models and that, despite the lag between the costs and the realisation of benefits, the transition would probably be affordable within current system-wide budgetary allocations.

This is, of course, a very theoretical approach - calculating likely but currently intangible benefits to UK RED over 10 or 20 years. More practically relevant is the subsequent study Going for gold? by Swan and Houghton (2012), and their explanatory comments in Houghton and Swan (2013). Economic implications of alternative scholarly publishing models (Houghton et al. 2009) addresses the question 'which is the most cost-effective model for scholarly publishing and dissemination (the activity)?' Going for gold? asks, 'what are cost implications of the alternative models for key stakeholders, primarily for UK universities and the UK higher education sector as a whole (the actors)?' It is, of course, generally HEIs that will bear any costs, and reap any benefits, from gold OA.

The main findings of Houghton and Swan (2013) are:

[t]hat disseminating research results via OA would be more cost-effective than subscription publishing. If OA were adopted worldwide, the net benefits of Gold OA would exceed those of Green OA. However, we are not in an OA world, nor are we likely to be in such a world in the foreseeable future.

Indeed, unilateral adoption of gold OA would see many HEIs, particularly the research-intensive ones, incurring significant additional costs. Unilateral adoption of green $\mathrm{OA}$, on the other hand, incurs additional but very small costs.

\section{Developing policies of funders}

Since 2006, funders commonly have been expecting, or mandating, researchers in receipt of their grants, to make the articles resulting from their research green OA by self-archiving in institutional or subject repositories. In January 2013, the Registry of Open Access Repository Mandates and Policies (ROARMAP) identified 54 funders worldwide with mandates; 43 were added in the four years between 2006 and 2009. In a recent development, European funders are starting, in varying degrees, to expect publication of results to be gold OA. 


\subsection{United Kingdom}

In some ways, the United Kingdom took the lead in terms of gold OA in June 2012 with the publication of the Finch Report (Working Group on Expanding Access to Published Research Findings 2012), comprising publishers as well as funders, academics and librarians. The report foreshadows a step change in moving, albeit unilaterally, to gold OA for all UK research publications. Interestingly, major publishers were well represented in the working group, and did not dissent. The main recommendations (Working Group on Expanding Access to Published Research Findings 2012: 7) are:

- A clear policy direction should be set towards support for publication in OA or hybrid journals, funded by APCs, as the main vehicle for the publication of research, especially when it is publicly funded.

- The research councils and other public sector bodies funding research in the United Kingdom should ... establish more effective and flexible arrangements to meet the costs of publishing in OA and hybrid journals.

- During the period of transition to OA publishing worldwide - in order to maximise access in the higher education and health sectors to journals and articles produced by authors in the United Kingdom and from across the world and which are not accessible on OA terms - funds should be found to extend and rationalise current licences to cover all the institutions in those sectors.

- The infrastructure of subject and institutional repositories should be developed so that they play a valuable role complementary to formal publishing, particularly in providing access to research data and to grey literature, and in digital preservation.

The Finch Report (2012) also takes the further step of suggesting in detail key actions for researchers, policymakers, funders, university managers, librarians and publishers. Actions (Working Group on Expanding Access to Published Research Findings 2012: 8-10) include:

- Make a clear commitment to support the costs of an innovative and sustainable research communications system, with a clear preference for publication in OA or hybrid journals, for example, government, research councils, funding councils and universities.

- Consider how best to fund increases in access during a transition period through all three channels - OA publications, subscriptions, and repositories - and the balance of funding to be provided through additional money from the public purse: by diversion of funds from 
support of other features of the research process, and by seeking efficiency savings and other reductions in costs from publishers and other intermediaries, such as government, research councils, funding councils and universities.

- Establish effective and flexible mechanisms to enable universities and other research institutions to meet the costs of APCs (for example, government, funders) and efficient arrangements for payment, minimising transaction costs while providing proper accountability, for example, universities, publishers.

- Establish publication funds within individual universities to meet the costs of APCs, making use of dedicated moneys provided by funders for that purpose, as well as other available resources, for example, universities.

- Continue to develop

- the infrastructure of repositories and enhance their interoperability so that they provide effective routes to access for research publications, including reports, working papers and other grey literature, as well as theses and dissertations;

- a mechanism for enhancing the links between publications and associated research data; and

- $\quad$ an effective preservation service, for example, funders, universities, JISC and publishers.

Taken together, the recommendations and actions provide a blueprint for moving to full-scale gold OA, with green still supported, but seemingly playing a lesser role.

Significantly, the Finch Report (Working Group on Expanding Access to Published Research Findings 2012) received not only a ringing endorsement from the UK government but, in September 2012, also a fund of GBP 10m (€ $12 \mathrm{~m}$ ) to be spent by April 2013 by 30 HEIs to support APCs for gold OA publications. This was followed in November by an announcement by Research Councils UK (RCUK) of the new block grant that it would be making to HEIs over the coming five years to fund APCs at $80 \%$ of full economic cost. ${ }^{2}$ As can be seen from the following table, RCUK expects that $75 \%$ of peer-reviewed articles that it funds (currently about 26000 per annum in total) will be made available by gold OA by 2017-18; the remaining 25\% will be made available by green OA. Financial numbers are not attached to Years 3-5; however, RCUK expects to make over GBP 100m available during the 5-year period.

2 See http://www.rcuk.ac.uk/media/news/121108/. 


\begin{tabular}{l|l|l|l|l|l}
\hline & Year 1 & Year 2 & Year 3 & Year 4 & Year 5 \\
\hline $\begin{array}{l}\text { RCUK } \\
\text { APC fund }\end{array}$ & $\begin{array}{l}\text { GBP 17m } \\
(€ 20 \mathrm{~m})\end{array}$ & $\begin{array}{l}\text { GBP 20m } \\
(€ 24 \mathrm{~m})\end{array}$ & $\begin{array}{l}\text { To be } \\
\text { determined }\end{array}$ & $\begin{array}{l}\text { To be } \\
\text { determined }\end{array}$ & $\begin{array}{l}\text { To be } \\
\text { determined }\end{array}$ \\
\hline $\begin{array}{l}\text { Expected \% of papers } \\
\text { in Gold OA (number) }\end{array}$ & $\begin{array}{l}45 \% \\
(10.5 \mathrm{k})\end{array}$ & $\begin{array}{l}53 \% \\
(12.3 \mathrm{k})\end{array}$ & $\begin{array}{l}60 \% \\
(14.0 \mathrm{k})\end{array}$ & $\begin{array}{l}67 \% \\
(15.6 \mathrm{k})\end{array}$ & $\begin{array}{l}75 \% \\
(17.5 \mathrm{k})\end{array}$ \\
\hline
\end{tabular}

In short, UK HEIs will be spending upwards of GBP 120m ( $€ 143 \mathrm{~m}$ ) on APCs over a six-year period, which equates to about $20 \%$ of their current expenditure on subscriptions.

In addition to this monetary encouragement, it is widely expected that the next research assessment exercise in the United Kingdom (which has a major financial impact on HEIs for a period of at least five years), expected in 2020, will require submissions to be OA.

\subsection{Germany}

The Deutsche Forschungsgemeinschaft (DFG) has pursued a strategy of supporting OA since 2007, initially with the emphasis on green OA. The subsequent Taking Digital Transformation to the Next Level (DFG, Committee on Scientific Library Services and Information Systems 2012: 11) takes the same overall line as the Finch Report (2012): 'Preference should be given to the 'gold road' to open access, i.e. the quality-controlled initial publication of scientific articles in an electronic medium that uses an open-access business model.' This differs from the Finch Report (2012) in foreseeing and encouraging the general conversion of subscription journals to gold OA, rather than finding funding for APCs generally. 'Funding will not primarily encourage the inception of new open-access journals but rather provide targeted incentives for converting prestigious journals that are currently subscription-based into open-access publications.' These will generally be journals sponsored by scholarly societies.

However, it should be noted that the DFG (2010) had already set up a fund to support OA publication by scholars, with the proviso that their institutions contribute $25 \%$ or more of the costs.

\subsection{European Union}

The European Commission (EC) has stated that all research publications arising from Horizon 2020, the EU's Research and Innovation programme for 2014-2020 with funding of $€ 80$ billion, will have to be open access. Both 
gold and green routes to OA are supported. The green route permits 6- or 12-month embargos. There is not, however, the emphasis on the primacy of and commitment to gold OA evident in the Finch Report (2012).

The EC has, however, also recommended that member states take a similar approach to the results of research funded under their own domestic programmes. The goal was for $60 \%$ of European publicly funded research articles to be available under open access by 2016. The size of the EU budget for Horizon 2020, and the nudge to national funders in member states, suggest that this policy will have a significant impact. Moreover, the European Research Council reaffirmed its commitment to OA in June 2012 and has joined Europe PubMed Central.

\subsection{Funders}

A further indication of the trend towards gold $\mathrm{OA}$ is given by the stance of research funders. According to SHERPA, in December 2012, 16 funders (15\% of the total) worldwide required (gold) OA publication; a further $30 \%$ encouraged it. The geographic breakdown, with the percentage for each country, is as follows:

- Austria

- Canada

- Germany

- Hungary

- Netherlands

- Sweden

- UK
$1(100 \%)$

$4(31 \%)$

$1(50 \%)$

$2(100 \%)$

$1(100 \%)$

$5(100 \%)$

$2(4 \%)$

\subsection{United States of America}

The strong and gathering impetus towards gold OA in Europe, and to an extent Canada, has not yet found formal expression in the United States. However, the European funders and their governments are bent on transforming publishing from subscription to OA. The number of funders, the size of budgets and the involvement of governments will surely have a major effect on publishers' OA policies. Even if there is no formal movement by US funders towards gold OA, the changes in the publishing industry will encourage moves in this direction. 


\section{Effects of OA publishing on the volume of publications}

According to Ware and Mabe (2009: 18-21), there were about 25400 active scholarly peer-reviewed journals in early 2009, collectively publishing about 1.5 million articles a year. The number of scholarly journals published annually has been growing at the remarkably steady rate of about 3.5\% per annum since their inception in the $17^{\text {th }}$ century, with an acceleration in the 30 years following World War II. The number of articles had been growing at a slightly lower but constant rate of $3 \%$ per annum. These rates map closely to the increase in the number of scientific researchers in the United States and the rest of the Organisation for Economic Co-operation and Development (OECD). However, growth has not been uniform across all regions (Ware $\delta$ Mabe 2009: 21):

[T]he EU's output [grew] faster than the US and [overtook] it in the late 1990s [...] The most dramatic growth, however, is in the output from the East Asia region (China, Singapore, South Korea and Taiwan); between 1995 and 2005, China's output grew at 17\% and Taiwan's at 16\% per year, compared to $0.6 \%$ for the USA and $1.8 \%$ for the EU, while the UK's output was flat.

Turning to the growth of OA publishing, the rigorous study by Laakso et al. (2011: 8-9) distinguished three periods: the 'Pioneering Years' (1993 to 1999), the 'Innovation Years' (2000 to 2004), and the 'Consolidation Years' (2005 to 2009).

The Pioneering Years were characterised by innovation by individuals or small groups of scholars, using simple technologies. There was rapid growth from, obviously, a small base: in 1993, it was estimated that 20 OA journals published 247 articles; by 2000, it was estimated that 741 journals had published 35519 articles. Many of these early journals did not survive.

The Innovation Years coincided with the general movement of journal content to electronic delivery. In terms of OA, they were characterised by burgeoning advocacy of $\mathrm{OA}$ and the development of economic models for gold OA, notably APCs. BioMed Central and PLOS demonstrated the viability and high quality of gold OA. There was significant growth of both titles and articles: by 2005, 2837 journals published 90720 articles, an increase of 155\% on 2000.

The Consolidation Years saw the growth of infrastructure to support OA, such as open source publishing software, the Directory of Open Access Journals (DOAJ) and Creative Commons licences. Discovery was enhanced and enabled by Google and Google Scholar. Growth was not as spectacular, but 
still very strong: in 2009, 4767 journals published 191851 articles, an increase of $111 \%$ on 2005.

It is clear that OA publishing is, unsurprisingly, growing at a much faster rate than publishing as a whole (for example, $111 \%$ as opposed to 3\% for articles), but from a very low base. A natural question is the proportion of OA articles to TA articles. Laakso et al. (2011) note that this question cannot be answered with any certainty. However, from incomplete data, they suggest that the percentage of OA articles in 2009 ranged from $5.9 \%$ to $7.7 \%$.

Turning to the future, Lewis (2012: 496-497), building on the work of Laakso et al. (2011), takes this $7.7 \%$ figure and makes straight-line extrapolations to predict the increase in the portion of articles that will be gold OA. Extrapolating the rate of growth in the period from 2000 to 2009, he suggests that by 2025 , the portion of gold articles would be $19.6 \%$. Based on data from 2005 to 2009 , where the rate of change increased, the portion of articles in gold OA journals would be $20.9 \%$ in 2020 and $26.8 \%$ in 2025 . Thus, these extrapolations predict that over the next 12 years, between $20 \%$ and $27 \%$ of articles will be gold OA.

However, Lewis (2012) believes that the picture is more complex. He sees gold OA as having all the characteristics of a disruptive technology, as defined by Christensen:

[D]isruptive innovations generally have two distinct characteristics. First, they bring a new value proposition to the market. This new value proposition is almost always the application of a new technology using a new business model. Second, disruptive innovations usually make it possible for customers who had not been able to access a service or product to acquire it. The fact that the disruptive innovation is inferior does not matter to these new customers, as it is better than what they had before, which was nothing.

Over time, the disruptive product improves, and from being a niche offering it comes to dominate the market. Examples can be seen in the hard disk market, and in the car and motorcycle market in the United States, where market share has been won by Japanese and Korean firms. A technologically influenced example is Kodak, whose business model was to sell analogue cameras cheaply and to make money from consumables. In spite of carrying out extensive research into digital cameras, Kodak never developed these, mainly because of middle-management inertia, and from being the dominant supplier of cameras and film, the company shrank to become a supplier solely of printers for personal computers, interestingly following the same business model of profiting from sales of consumables. The case of Kodak is discussed by Ball and Spencer (2011) in the context of the wider effect of disruptive technologies on libraries generally. 
According to Christensen (2011), the growth in market share of a disruptive technology is not linear, but follows an S-curve. Lewis (2012: 500-501) observes:

The problem is to predict when the curve will flip and the pace of adoption of the disruptive innovation will accelerate rapidly ... To take one of Christensen's examples, digital photography spent a decade incubating on the flat part of the S-curve and then in a few short years replaced nearly all film-based photography. But because there was so little market penetration early on, it was hard to see the change coming.

Assuming that the figures produced by Laakso et al. (2011) are a good estimate and that the methodology established by Christensen (2011) is sound, Lewis (2012) provides two estimates of non-linear growth:

[B]ased on the first estimate, using the 2000 to 2009 data, it is likely that Gold OA journals will publish half of all scholarly articles by 2017 and will publish $90 \%$ of the articles by 2020. The second estimate, based on 2005 to 2009 , shows that $50 \%$ of scholarly articles would be Gold OA by 2021 and over $90 \%$ by 2025 .

These predictions are startling, but Lewis's argument is based on sound figures and methodology. It is not based on intangible factors, such as the likely attitudes of scholars, perceived citation advantage, the growing reputation of OA journals or commitment to the principle of OA. These factors will no doubt play their part in the future growth of OA. A more important, immediate and concrete factor is the switch to direct funding of gold OA outlined above. This may be the pebble that starts the avalanche.

One area of marked growth is developing countries. As Ware and Mabe (2009) pointed out above, 'between 1995 and 2005, China's output [of articles] grew at $17 \%$ and Taiwan's at $16 \%$ per year, compared to $0.6 \%$ for the USA and $1.8 \%$ for the EU, while the UK's output was flat'. It is not surprising that developing countries should seek the most cost-effective ways of publishing and disseminating this output. At the start of 2013, the DOAJ included the following developing countries (as listed by the International Statistical Institute for 2013) in the top 20 by number of journals: 


\begin{tabular}{l|l|c|c}
\hline Rank & Country & No. of OA Journals & No. added 2010/12 \\
\hline 2 & Brazil & 806 & 407 \\
\hline 4 & India & 472 & 315 \\
\hline 6 & Egypt & 351 & 223 \\
\hline 9 & Romania & 253 & 184 \\
\hline 11 & Turkey & 212 & 110 \\
\hline 12 & Colombia & 208 & 111 \\
\hline 14 & Iran & 170 & 123 \\
\hline 16 & Chile & 142 & 34 \\
\hline 17 & Argentina & 136 & 78 \\
\hline 19 & Mexico & 126 & 48 \\
\hline
\end{tabular}

It will be interesting to see whether this trend continues, and whether the implied increase in academic output mirrors the economic development of countries such as Brazil and India.

\section{Research on (possible) citation advantages of OA publications}

Since its inception, there has been an assumption by its advocates, and indeed others, that OA would increase citation impact. It seems an obvious conclusion to draw from the very nature of OA, which removes the pay barrier to reading, and hence possibly citing of journal articles. It is important to point out that the assumption was never that OA would increase the citation of all articles whatever their quality or relevance to their fields but rather that the citation impact of works of appropriate relevance and quality would increase by virtue of their being OA.

Swan's synoptic report (2010b: 1-3) summarises the assumptions as follows:

- that a proportion (whose size varies according to discipline or field) of researchers do not have access through subscription journals to all the published papers that are relevant to, and might influence, their own work;

- that these people would avail themselves of the opportunity to access and read these otherwise unavailable documents if they were made freely available online;

- that some of those documents would be found to be relevant and applicable to the researchers' work and hence citable; and

- that others would be found to be irrelevant or inapplicable and would not be cited for the usual reasons that work is not cited. 
Swan (2010b: 2-3) distinguishes four possible citation advantages of OA:

1. General OA Advantage - OA articles are available to readers who otherwise have no access;

2. Early Advantage - OA articles are available before similar toll access articles, thus generating more citations over a period of time;

3. Selection Bias - authors are more inclined to make their better articles open access; and

4. Quality Advantage - better articles gain more from the General OA Advantage because they are by definition more citable than poorer articles.

We might add another factor: multiple authorship increases the possibility of selfarchiving. According to Wagner (2010), '[p]ublication in an open access journal (Gold OA) apparently is not required to get a significant OA citation advantage'.

Even from this short exposition, it is clear that disentangling and determining any citation advantage for OA articles is fraught with difficulties. What is an appropriate time after publication to measure citations? This differs from discipline to discipline. Furthermore, it is generally difficult to determine the exact date of an article becoming OA. How reliable, comprehensive and comparable are the sources of citations? Is there a bias, for instance, against developing countries, which may rely more heavily on OA literature? Is like compared with like, and is allowance made for the many variables?

Swan (2010b: 17) summarises her exhaustive analysis of 31 studies published between 2001 and 2010 as follows:

\begin{tabular}{l|l|l}
\hline \multicolumn{2}{l}{ Measure } & Result \\
\hline \begin{tabular}{l} 
Studies finding a positive OA citation advantage \\
\hline Studies finding no OA citation advantage (or an OA citation disadvantage)
\end{tabular} & 27 \\
\hline $\begin{array}{l}\text { Size of OA citation advantage when found } \\
\text { (and where explicitly stated by discipline) }\end{array}$ & $\begin{array}{l}\% \text { increase } \\
\text { in citations with OA }\end{array}$ \\
\hline Physics/astronomy & 170 to 580 \\
\hline Mathematics & 35 to 91 \\
\hline Biology & -5 to 36 \\
\hline Electrical engineering & 51 \\
\hline Computer science & 157 \\
\hline Political science & 86 \\
\hline Philosophy & 45 \\
\hline Medicine & 300 to 450 \\
\hline Communications studies (IT) & 200 \\
\hline Agricultural sciences & 200 to 600 \\
\hline
\end{tabular}


Even allowing for the difference in methodologies, in sample size, in disciplines, in types of publication, there is a clear indication that there is some citation advantage in OA, although one might conjecture that any advantage will not be at the upper limits suggested by some of the above figures. However, it is not clear whether OA is a factor of causation or a positive correlation.

It should also be noted that a study by Piwowar et al. (2007, quoted by Swan 2010b) established that 'publicly-available datasets (open data) are significantly associated with a $69 \%$ increase in citations to articles that the data accompany. This correlation is independent of Journal Impact Factor, country of authors and time since publication.' The trend towards open repositories of research data may therefore also be a significant factor in citations and impact.

\section{Effects of OA publishing (especially gold) on the reputation pyramid of scholarly journals}

The main research reflecting the reputation of OA journals was undertaken as part of the Study of Open Access Publishing (SOAP) project (Dallmeier-Tiessen et al. 2011 : 2-3). About 1.5 million individuals, obtained from the mailing lists of major publishers, were exposed to a survey, which ran for most of 2010. While a respectable total of 54000 responded to the survey, the analysis was restricted to the 38358 who had published at least one peer-reviewed research article in the previous five years. Respondents were from 162 countries, with a large representation from the research-intensive nations. Respondents were drawn from a wide range of disciplines, with biological and medicinerelated subjects making up about $37 \%$. This was therefore a large-scale survey of research-active, published scholars from a wide range of countries and disciplines, and it can be taken as representative of scholarly opinion towards the end of 2010 .

Tellingly, $89 \%$ of respondents believed that journals publishing OA were beneficial to their research field. Of the respondents, $20 \%$ cited financial benefits, $18 \%$ the public good, and $10 \%$ benefits to the individual, for instance, enhanced recognition. About 50\% felt that OA was more cost-effective than TA, with about $10 \%$ holding the opposite view. Turning to some commonly held negative opinions of OA, just fewer than 30\% believed that OA penalised research-intensive institutions, with 25\% disagreeing. Fewer than $20 \%$ felt that OA published poor-quality research, with 50\% disagreeing. About 15\% felt that OA undermines peer review, with $60 \%$ disagreeing.

Barriers to publishing OA were seen as financial (39\%) and an absence of quality OA journals (30\%). Only $2 \%$ intended to publish their next article OA. This somewhat contradicts the views just outlined, and shows considerable 
reluctance among scholars to publish OA themselves, despite the perceived benefits to the research field in the abstract. However, the picture is different in the fields of biological and medicine-related sciences, where there are established OA journals: $50-60 \%$ of researchers in these fields cite funding as the main barrier, and only 20-23\% journal quality. By contrast, in business studies, 37\% cite journal quality and only $12 \%$ funding.

A more detailed view of funding was given by $52 \%$ of respondents who had published at least one article OA. Of these, 50\% had paid no fee; over $75 \%$ of those active in the humanities and social sciences had paid nothing. One could postulate a number of factors for these disciplines: lower costs for copy production, relative newness of foundation, and subsidy by academic departments or institutions.

It seems clear from this survey that:

- OA journals are well established and well regarded in some disciplines;

- there remains a reluctance to publish OA;

- funding is a major issue; and

- only a minority perceived OA to be per se poor quality and to undermine peer review.

A later study by Björk and Solomon (2012) followed a bibliometric approach, using impact as a proxy for quality of a journal. Taking a two-year average of citations (impact factors) from the Journal Citation Reports (JCR) and Scopus, Björk and Solomon (2012: 5-6) found that 'OA journals had impact factors that were approximately $76 \%$ and $67 \%$ as high as subscription journals in JCR and Scopus respectively when analyzed by journal and $73 \%$ and $62 \%$ when weighted for articles published'. When categorising by time of launch, they found that newer journals, both TA and OA, tended to have higher impact factors than earlier journals, and that the gap between TA and OA journals narrowed over time, with later TA journals having an impact factor of about 3.8 and $\mathrm{OA}$ an impact factor of about 3.6. When analysing by discipline, they found that there was essentially no difference in impact factor between TA and OA journals launched from 2002 onwards in the fields of medicine and health.

Further analysis by method of funding shows that, for journals launched since 2002, OA journals not charging APCs had an impact factor of about 1.25, OA journals charging APCs an impact factor of about 3.2 and TA journals an impact factor of about 3.3. Björk and Solomon (2012: 9) conclude:

[F]or the newer journals, particularly in medicine and health, our results show that OA journals are performing at about the same level as subscription journals, in fact getting more citations in some subcategories [...] There are 
large numbers of both subscription and OA journals that are high quality and widely cited [...]. [N]ewly founded full OA journals compete on almost equal terms with subscription journals founded in the same period. OA articles published [in] medicine and health by publishers in the four largest publishing countries attract equal numbers of citations compared to subscription journals in these fields.

It seems fair to conclude from these two studies that:

- $\quad$ APC-funded OA and TA journals launched since 2002 are of similar impact and quality; and

- $\quad$ there are major differences between disciplines, with medicine, health and biological sciences OA journals equalling TA journals and in some subcategories out-performing them, while journals in the humanities and social sciences lag behind.

While OA journals in some areas equal the quality of TA journals, it must be remembered that OA publishing is open to abuse. There are some unscrupulous 'publishers' who will accept almost any submissions on payment of a fee, and who are hence giving OA a bad name. Their existence has prompted Jeffrey Beall to maintain a list of what he terms 'predatory publishers'. As Poynder (2013) and others observe, this binary approach (good or bad) has its faults, but as yet 'no one has come up with an adequate way of delineating the good from the bad'. Poynder also notes the number of journals in Beall's list from developing countries. This may be evidence of (unintended) bias; it may simply reflect the large number of new OA journals being produced in these countries (see section 5 above).

\section{Effects of the different models of OA on peer review practices}

Peer review is essentially a product of the print era, developed as a means of rationing the (relatively) rare resource of space in printed journals in favour of high-quality articles. Wikipedia defines scholarly peer review as:

[T] he process of subjecting an author's scholarly work, research, or ideas to the scrutiny of others who are experts in the same field, before a paper describing this work is published in a journal. The work may be accepted, considered acceptable with revisions, or rejected. Peer review requires a community of experts in a given (and often narrowly defined) field, who are qualified and able to perform impartial review. Impartial review, especially 
of work in less narrowly defined or inter-disciplinary fields, may be difficult to accomplish; and the significance (good or bad) of an idea may never be widely appreciated among its contemporaries.

It is widely regarded as the gold standard of research and scholarly communication, yet, as the definition hints, there are associated problems.

The UK Office of Science and Technology (quoted by Poynder 2013) was a little more blunt, noting that many regard peer review as 'an inherently conservative process ... [that] ... encourages the emergence of self-serving cliques of reviewers, who are more likely to review each other's grant proposals and publications favourably than those submitted by researchers from outside the group'.

Even publishers are known to comment unfavourably. In 1997, the then editor of the British Medical Journal, Richard Smith (again quoted by Poynder 2013), described peer review as 'expensive, slow, prone to bias, open to abuse, possibly anti-innovatory, and unable to detect fraud'. He added: 'We also know that the published papers that emerge from the process are often grossly deficient.'

Some hold that OA is a means of avoiding peer review to publish inferior material. This is not the case: OA per se is concerned only with access; in this sense, it is agnostic as far as peer review is concerned.

The problem arises perhaps from the conflation in TA publishing (printed or electronic) of three of the four functions of the scholarly journal defined at the start of section 2 above: TA publication provides a timestamp, access, and the stamp of quality. Both green and gold OA support the functions of the scholarly journal. Green OA provides the means of gaining the earliest timestamp, through self-archiving of pre-print copies. It also provides evidence of quality approval through self-archiving, with the publisher's permission and after an embargo period, of post-print copies, or simply the digital object identifier (DOI) on the publisher's website. To put it another way, OA provides free access to peer-reviewed research (sometimes before peer review), not access to articles free of peer review. Incidentally, it also aids preservation through duplication. Gold OA obviously supports all functions of the scholarly journal.

As noted in section 3 above, in one sense one could say that green OA rides on the back of TA, in that it provides access to peer-reviewed articles without paying the cost of peer review - a significant plank in the argument of those, such as Harnad, championing green OA over gold. Otherwise, green OA does not influence peer-review practices. It might be seen as threatening the economic viability of peer-reviewed TA journals, but it is the economic model that it threatens, not peer review. 
What OA, however, does do is that it decouples publication, or access, from the stamp of quality. Moving out of the straitjacket of print, it enables new approaches to establishing quality.

Much OA literature starts life as a pre-print version (i.e. a version of an article before peer review, as opposed to a post-print version, which follows peer review). While pre-print versions predate the Internet, they have become more established with the possibility of online pre-print servers. Perhaps the best known is arXiv, which defines itself as follows:

arXiv is proud to be able to offer such a large collection of scholarly work in a single location, without any fees and with support for users around the world. arXiv supplements the traditional publication system by providing immediate dissemination and open access to scholarly articles (which often later appear in conventional journals). It is important to note, however, that arXiv is not a repository for otherwise unpublishable material, nor is it a refereed publication venue. The moderation process is essential to ensuring that submissions are of value to the arXiv communities.

Notably, articles must be of a certain academic standard but they are not peer reviewed; what arXiv offers is early and immediate dissemination.

There have been numerous experiments with new approaches to peer review, enabled by technology.

PLOS ONE, for instance, uses rigorous peer review, but leaves it to the scientific community to decide on importance:

Too often a journal's decision to publish a paper is dominated by what the Editor/s think is interesting and will gain greater readership - both of which are subjective judgments and lead to decisions which are frustrating and delay the publication of your work. PLOS ONE will rigorously peer-review your submissions and publish all papers that are judged to be technically sound. Judgments about the importance of any particular paper are then made after publication by the readership (who are the most qualified to determine what is of interest to them).

A more radical approach was taken by Philica. There are no editors or reviewers, and submission and access are free of charge. Submissions may be on any subject, and review takes place after publication by the scholarly community at large. Its peer review process 'is both transparent and dynamic. It is transparent as reviews can be seen publicly; it is dynamic because opinions can change over time, and this is reflected in the review process.' It has not, however, been particularly successful. By February 2013, only 313 articles 
and shorter observations had been submitted since 2006. Only six articles have been reviewed in the past year, while many have never or seldom been reviewed. This hardly represents the wisdom of the crowd.

Frontiers offers traditional gold OA based on APCs with what it bills as a new approach to peer review:

Frontiers full reviews are made up of two consecutive steps, an independent and an interactive review. In the independent review phase, review editors evaluate independently from each other whether the research is academically sound following a standardized review questionnaire. Then, Frontiers implemented for the first time the real-time Frontiers Interactive Review Forum, in which authors and review editors collaborate online via a discussion forum until convergence of the review is reached.

Frontiers emphasises the open involvement of both reviewers (who are named in the published articles) and authors and the involvement of the scholarly community in the assessment phase, which analyses views and downloads and produces metrics. The importance of the approach is characterised as follows:

At Frontiers, it is not the opinion of only 2-3 reviewers, however qualified, that determines the importance of a research work, but the entire academic community. Likewise, it is not the ranking of the journal in which an article is published to determine its impact, but the article itself.

One can see in these examples that peer review is easing out of the chrysalis of print in response to the new technologies: blogs, wikis and social media as well as OA journals will play a part in scholarly communication. It is no longer space that is scarce, as in the print world; in the Internet age, the scarcity is of time and attention.

\section{Effects of OA publishing on publication, search and reception practices of scientific literature}

\subsection{Publication}

As we have seen in earlier sections:

- conservative extrapolations predict that between $20 \%$ and $27 \%$ of articles will be gold OA by 2025; more radical estimates are that $50 \%$ of scholarly articles will be gold OA by 2021 and over $90 \%$ by 2025 ; 
- $\quad$ there are clear indications that there is some citation advantage in OA;

- APC-funded OA and TA journals launched since 2002 are of similar impact and quality, although there are major differences between disciplines, with the humanities and social sciences lagging behind medicine and biological sciences; and

- there is a major expansion of OA journal publishing in developing countries, which, one can assume, will drive up the number and proportion of OA articles.

There is therefore considerable growth in the volume and quality of OA publishing, with $89 \%$ of respondents to the SOAP survey believing that journals publishing OA were beneficial to their research field, although only $2 \%$ intended to publish their next article OA. These effects may be ascribed to the nature and existence of OA publishing.

There has also been considerable advocacy of OA over recent years, notably by people such as Swan, Harnad and Suber. This seems to be having an effect: the SOAP survey found that there was little 'agreement of respondents [12$18 \%$ ] with a series of 'myths' about open access publishing', such as that OA undermines peer review or leads to the publication of poor-quality research (Dallmeier-Tiessen et al. 2011: 7-8). A further, extraneous, impetus is being given by funders in Europe starting to insist on, or at least favour, gold OA.

As noted by Dallmeier-Tiessen et al. (2011:7-8), the main perceived barrier to publishing $\mathrm{OA}$ is financial, although there are major differences between the disciplines, with the humanities, social sciences and business studies finding funding much less of a barrier. This may be due to the number of OA journals in these fields charging low or no APCs, which may, of course, change over time as OA journals in these disciplines become more established and expensive to run, losing subsidies from institutions.

This highlights a major, if not the major, obstacle to the development of OA publishing. TA publishing is embedded in the structures of universities, especially in the research-intensive institutions. A large portion of the library budget is devoted to subscriptions and their management. How can the transition from reader-side payment to author-side payment be made? In the United Kingdom, there is some funding available from RCUK, but that is tied to specific research grants. Unless there is a major disruption, as predicted by Lewis (2012), it will take several years for gold OA to expand to the point where it can bring about a decrease in TA subscriptions. During this period, universities will be faced with the prospect of funding TA subscriptions at or close to the current level and at the same time finding additional funds to pay APCs. On the part of universities, one option may, of course, be simply to divert money from subscription budgets to APC budgets, which, given the ubiquity 
of big deals, would cause a great deal of angst (for the impact of big deals on library budgets, see Ball [2004]). On the part of publishers, an option would be simply to switch from TA to OA. Obviously, changing economic models like this is very high-risk.

As author-side payment becomes more established, we may well see the development of a competitive market. In the TA market, there is some competition amongst publishers and journals for authors. However, generally one can assume there to be an over-supply of articles for publication. Generally, once an article has been accepted, the publisher is assigned the copyright, and hence has the monopoly on that content and can charge subscriptions at will. With author-side payment, OA publishers will have to compete, essentially on the cost-benefit of APCs and impact factors. Unlike the print world, there is no scarcity in terms of space for publication. Similarly, there should be no scarcity of capacity of reviewers, since the author will pay this cost. There is therefore, in theory at least, no limit to the number of articles that an OA publisher could put out.

Turning to green OA, it was noted in 2005 that some scholars are reluctant to self-archive in repositories: 'the provision of freely available pre-prints on the Internet is, according to the sample, not very common. Contributions already published elsewhere were made available for free on the Internet somewhat more often' (DFG 2005: 9, transl.). This is contradicted somewhat, at least for the social sciences, by Antelman (2006: 92), who says, 'This study finds that social scientists are self-archiving at a significant rate.' Since these surveys, we have also seen mandates becoming more common. ROARMAP shows the number of institutional, funder and other mandates rising from a handful in 2005 to 255 in 2013, with a further 26 proposed. The Open Access Directory in 2013 gives various numbers of green OA records: 25000000 as being harvested by OAIster in February 2013 and 38354066 as being harvested by Scientific Commons in 2012, although a portion of them will be 'dark deposits', with only the metadata exposed to public view.

\subsection{Search and reception practices}

It may be argued that OA has not had a great effect on the availability of articles to scholars in the large research-intensive institutions. These institutions have typically subscribed to a large portion of the literature of interest to their scholars, enhanced over recent years by subscription to big deals. Traditional provision has also included subscription to the major abstracting and indexing services, such as Scopus and Web of Knowledge, enabling discovery and supply of material not held by inter-library loan or document delivery. 
However, now there is a major search engine freely available: Google Scholar; although many researchers, particularly in the humanities, use plain Google and Google Books at least as a starting point (see Rutner \& Schonfeld 2012: 17). Google Scholar not only indexes full-text journal articles, technical reports, pre-print versions, theses, books and other documents, including selected Web pages that are deemed to be scholarly; it also provides access to abstracts of articles that have cited the article being viewed. Although different in coverage, Google Scholar has been shown to match Scopus and exceed Web of Science in the number of citations returned in at least one subject field and, 'within a year of its introduction, Google Scholar was apparently responsible for bringing far more visitors to the BMJ Web site than PubMed' (Kulkarni et al. 2009).

A major advantage is that Google Scholar also indexes the content of institutional and subject repositories. It therefore discovers not only TA and gold OA articles but also self-archived green OA materials, even 'dark deposits'. These materials are freely available when beyond any embargo periods imposed by publishers. Many repositories also provide an email button, enabling scholars without subscriptions to request a copy of an article from the author before the embargo expires.

Many academic libraries now also provide sophisticated search engines, such as the EBSCO Discovery Service. These have the capability to search across a very wide range of resources, tailored to the requirements of individual institutions. They will typically be configured to cover not only TA resources to which the university subscribes, but also OA resources, such as OAIster.

In short, there is a considerable volume of green OA materials (25-38 million) in repositories, indexed by a major free search engine, and hence discoverable by and available to anyone with an Internet connection.

\section{Interaction of OA with performance measures and other incentives in universities and research institutions}

As we have seen in section 6 above, there does seem to be at least some citation advantage for OA articles. This is due in part to toll-free availability (more researchers have access; hence, there will be more citations), and in part to early appearance, for instance, as pre-print versions in repositories, leading to earlier high numbers of citations. Insofar as additional citations represent increased impact, an OA article can therefore be expected prima facie to outperform a TA article of similar citability.

This outperformance should be an incentive to publish gold OA, or at least to self-archive. However, as we saw from the SOAP survey above, only $2 \%$ 
of those surveyed intended to publish their next article OA, despite viewing OA favourably. This reluctance may be ascribed to two factors suggested by SOAP: a lack of funding (cited by 39\%) and a lack of high-quality journals in some disciplines (cited by 30\%) (Dallmeier-Tiessen et al. 2011: 7-8). There is also an element of conservatism: given a perceived choice between publishing gold OA and publishing in a high-impact-factor TA journal, most academics will choose the latter because of perceived benefits to a career. In addition, the citation advantage has by no means been proved satisfactorily. However, authors can have the best of both worlds by publishing in high-impact TA journals and by self-archiving in the institutional repository.

The performance measures so important to scholars in terms of career, and to universities in terms of research assessment exercises and reputation with funding bodies, may therefore be seen to have acted as a brake on the development of gold OA. This, of course, as noted in section 4 above, is now being eased by the policies of a number of funders, particularly in Europe, which, while not explicitly favouring it, allow and indeed fund gold OA.

An excellent example of a policy linking deposit of articles to research evaluation is provided by the Higher Education Funding Council for England (HEFCE 2015). The policy insists that 'to be eligible for submission to the post2014 REF [Research Excellence Framework] [the next research assessment exercise], authors' outputs must have been deposited in an institutional or subject repository' (HEFCE 2015: 1). Deposit must also take place on acceptance by a publisher (HEFCE 2015: 5). There is evidence from individual institutions that this policy is already having the effect of increasing the number and proportion of OA deposits. At University College London, for instance, the repository contained 10000 OA outputs in 2011 and 14000 OA papers in 2013, after which OA content sharply increased to 22500 papers by September 2015 (Ball 2015: 5).

Policies - of both funders and institutions - are therefore contributing to growth in the deposit of OA resources. Important work on policies has been done by the European project PASTEUR4OA, which 'aims to support the European Commission's Recommendation to Member States of July 2012 that they develop and implement policies to ensure Open Access to all outputs from publicly-funded research'. As part of the work of PASTEUR4OA, the database of OA policies, ROARMAP, was extended and elaborated. It now records, and links to, the conditions of every known policy under an exhaustive set of categories, and is fully searchable. This database as a whole provides a rich source of data to analyse when studying policy effectiveness.

The project also considered the mandatory policies in place at over 120 universities around the world and assessed the effectiveness of each policy. This was measured in terms of the percentage of OA material available from 
each institution compared to the total number of articles published from those institutions each year. Using regression analysis, the project determined that the critical elements of a policy, whether of a funder or an institution, are as follows (Swan 2015: 9):

The policy requires that research articles be deposited in an Open Access repository. In addition, the policy must state that this deposit step cannot be waived. The policy links deposit with research assessment (performance evaluation). These are important results for the continuing development of Open Access.

\section{Copyright}

As noted in section 2, the original OA statements of 2002-2003 aimed at freedom from virtually all copyright restrictions. However, OA is agnostic as regards copyright: permissions may be as restricted as with TA publishing, or the author may reserve some rights, for instance, of commercial use, or there may be no restrictions at all.

The Creative Commons initiative provides a range of common licences that allow various degrees of permission. There are six gradations in the generally used licences:

- from the freest, CC-BY, which 'lets others distribute, remix, tweak, and build upon your work, even commercially, as long as they credit you for the original creation';

- to CC-BY-NC, which 'lets others remix, tweak, and build upon your work non-commercially, ... although their new works must also acknowledge you and be non-commercial'; and

- to the most restrictive, CC-BY-NC-ND, 'only allowing others to download your works and share them with others as long as they credit you, but they can't change them in any way or use them commercially'.

There is also the ultimate OA licence (CC-Zero or CCO) for copyright holders who wish to place their work entirely in the public domain.

The self-archived versions of articles published in TA journals will carry the same restrictions imposed by the publishers as the published articles themselves. However, over time, the existence and awareness of the Creative Commons licences should enhance the usability as well as the availability of gold OA articles. 
It should also be remembered that authors, or their institutions, are the first holders of the copyright of articles, whether green, gold or TA. As such, they are at liberty to assign or reserve rights in their work. The position of individual authors vis-à-vis publishers can be strengthened by institutional mandates or policies insisting on the reservation of rights.

\section{Conclusion}

It is clear from the foregoing that OA is only about toll-free access. Of itself, it does not affect any other aspect of scholarly communication, except perhaps in increasing or bringing about earlier citations. However, it does open the door to changing, developing or at least experimenting with many aspects of scholarly communication.

We have just seen that copyright in OA materials can be as restrictive as the TA norm of 'all rights reserved'; however, through the new infrastructure of Creative Commons licences, it enables materials to be as free as CC-BY or even CC-Zero.

Turning to quality assurance, many OA journals operate peer review in just the same way as the traditional TA journals. In some disciplines, they are matching or even exceeding the quality and impact of concurrent TA journals. In the TA world, publication amalgamates access, a timestamp and the stamp of quality. Gold OA enables their separation and opens the possibility of different forms of peer review. Author-side payments also make a theoretically unlimited increase in content published possible.

\subsection{The future}

Like the protagonists of the last ICT revolution, we cannot predict how scholarly communication will develop under OA. There are some pointers, however.

We have seen the new possibilities of changing peer review from the closed and somewhat discredited system operating under TA. One emerging model is for a short initial review and collaborative enhancement of the technical quality of articles to be undertaken. This is followed by publication, with the expectation that the scholarly community at large will engage with the content, and assess and develop the importance of the ideas.

This process will be fostered and enhanced by the current move towards open access to the datasets of publicly funded research. The article and associated data form the nucleus of an organic corpus of scholarly debate, which is open to any scholar with access to the Internet. While the science, technology and 
medicine community has led the way in the move to OA, this form of debate may foster a rebirth of the humanities monograph, which has always suffered under the economics of TA print.

Another development is the overlay journal. In its purest form, the overlay journal selects green pre-print versions from OA repositories, reviews their quality and has the journal title (i.e. the quality stamp) added to the metadata of approved articles (for an early exposition of this idea, see Ball and Spice [1996]). In other manifestations, the overlay journal will provide links to (generally OA) articles published in other journals. It therefore acts as a kind of alerting service, drawing together articles on a particular topic and hence saving the reader time.

\subsection{Challenges}

It seems from the evidence cited here that OA is becoming embedded in the research process, initially as green but increasingly as gold OA, the latter given impetus by the actions of research funders. There are three main challenges:

- Given that OA is neutral regarding most elements of the scholarly communication process, but has the potential to enable radical change, the onus is on the research community to develop, test and implement new models for scholarly communication.

- Despite the advocacy around OA, there is still a need to inform scholars, funders and administrators of its possibilities and implications.

- At a practical level, the transition from TA to gold OA seems problematic and, according to Houghton et al. (2009), costly, for both universities and TA publishers. Means need to be developed to ease the transition without large additional costs and without destroying the richness of existing provision. Some concrete steps are recommended in the Finch Report (2012) (see section 4 above).

\section{References}

Antelman, K. 2006. Self-archiving practice and the influence of publisher policies in the social sciences. Learned Publishing, 19:85-95. Retrieved from http://eprints. rclis.org/7420/1/antelman_self-archiving.pdf [Accessed February 2013].

Bailey, C.W. et al. 2006. Institutional Repositories. Washington, DC: Association of Research Libraries. ARL SPEC Kit 292. Retrieved from http://www.arl.org/ bm doc/spec292web.pdf [Accessed February 2013]. 
Ball, D. 2004. What's the 'big deal', and why is it bad deal for universities? Interlending and Document Supply, 32(2):117-125. Retrieved from http://eprints. bournemouth.ac.uk/1487/ [Accessed February 2013].

Ball, D. 2015. Institutional Policy Implementation at University College London (UCL). PASTEUR4OA case study, PASTEUR4OA. Retrieved from http://www. pasteur4oa.eu/sites/pasteur4oa/files/resource/Case\%20Study_University\%20 College\%20London_UK_Final.pdf [Accessed February 2016].

Ball, D. \& Spencer, C. 2011 . Goodbye to all that: Disintermediation, disruption and the diminishing library. In C. Turner (ed.). Online Information 2011: Proceedings. London: Incisive Media, 125-130. Retrieved from http://eprints.bournemouth. ac.uk/18935/ [Accessed February 2013].

Ball, D. \& Spice, C. 1996. The Big Flame: A model for a universal full-text electronic library of research. In Libraries and Associations in the Transient World: New technologies and new forms of co-operation: Conference proceedings: Third International Conference 'Crimea 96'. Foros: The Organizing Committee, Vol. 2, 112-115. Retrieved from http://eprints.bournemouth.ac.uk/1/ [Accessed February 2013].

Björk, B.-C. \& Solomon, D.J. 2012. Open access versus subscription journals: A comparison of scientific impact. BMC Medicine, 10(73). Retrieved from http:// www.biomedcentral.com/1741-7015/10/73 [Accessed February 2013].

Budapest Open Access Initiative. 2002. Read the Budapest Open Access Initiative. Retrieved from http://www.budapestopenaccessinitiative.org/read [Accessed day February 2013].

Dallmeier-Tiessen, S. et al. 2011. Highlights from the SOAP project survey: What scientists think about open access publishing. arXiv. Retrieved from http://arxiv. org/abs/1101.5260v2 2011 [Accessed February 2013].

DFG (Deutsche Forschungsgemeinschaft). 2005. Publikationsstrategien im Wandel? Ergebnisse einer Umfrage zum Publikations- und Rezeptionsverhalten unter besonderer Berücksichtigung von Open Access. Bonn: Deutsche Forschungsgemeinschaft. Retrieved from http://www.dfg.de/download/pdf/dfg_im_profil/evaluation_ statistik/programm_evaluation/studie_publikationsstrategien_bericht_dt.pdf [Accessed February 2013].

DFG (Deutsche Forschungsgemeinschaft). 2010. Merkblatt: Open Access Publizieren. Bonn: Deutsche Forschungsgemeinschaft. Retrieved from http://www.dfg.de/ formulare/12_20/12_20.pdf [Accessed February 2013].

DFG (Deutsche Forschungsgemeinschaft) \& Committee on Scientific Library Services and Information Systems. 2012. Taking Digital Transformation to the Next Level: The contribution of the DFG to an innovative information infrastructure for research. Strategy paper. Bonn: Deutsche Forschungsgemeinschaft. Retrieved from http://www.dfg.de/download/pdf/foerderung/programme/lis/strategy_ paper_digital_transformation.pdf [Accessed February 2013]. 
Edgar, B.D. \& Willinsky, J. 2010. A survey of scholarly journals using open journal systems. Scholarly and Research Communication, 1(2). Retrieved from http://srconline.ca/index.php/src/article/view/24/41 [Accessed February 2013].

Eisenstein, E.L. 1993. The Printing Revolution in Early Modern Europe. Canto edition. Cambridge: Cambridge University Press.

HEFCE (Higher Education Funding Council for England). 2015. Policy for Open Access in the Post-2014 Research Excellence Framework. Retrieved from http://www. hefce.ac.uk/pubs/Year/2014/201407/ [Accessed February 2016].

Houghton, J. et al. 2009. Economic Implications of Alternative Scholarly Publishing Models: Exploring the costs and benefits: A report to the Joint Information Systems Committee (JISC). Retrieved from http://www.jisc.ac.uk/media/documents/ publications/rpteconomicoapublishing.pdf [Accessed February 2013].

Houghton, J. \& Swan, A. 2013. Planting the green seeds for a golden harvest: Comments and clarifications on Going for Gold. D-Lib Magazine 19(1/2). Retrieved from http://www.dlib.org/dlib/january13/houghton/01houghton.html [Accessed February 2013].

Kulkarni, A.V. et al. 2009. Comparisons of citations in Web of Science, Scopus, and Google Scholar for articles published in general medical journals. JAMA, 302(10):1092-1096. Retrieved from http://jama.jamanetwork.com/article. aspx?articleid=184519 [Accessed February 2013].

Laakso, M. et al. 2011. The development of open access journal publishing from 1993 to 2009. PLOS ONE, 6(6). Retrieved from http://www.plosone.org/article/ info \%3Adoi\%2F10.1371\%2Fjournal.pone.0020961 [Accessed February 2013].

Lewis, D.W. 2012. The inevitability of open access. College and Research Libraries, 73(5):493-506. Retrieved from http://crl.acrl.org/content/73/5/493.full. pdf+html [Accessed February 2013].

Piwowar, H.A., Day, R.S. \& Fridsma, D.B. 2007. Sharing detailed research data is associated with increased citation rate. PLOS ONE, 2(3). Retrieved from http:// www.plosone.org/article/fetchArticle.action?articleURI=info:doi/10.1371/ journal.pone.0000308 [Accessed February 2013].

Poynder, R. 2013. The OA interviews: Ashry Aly of Ashdin Publishing. Retrieved from http://poynder.blogspot.co.uk/2013/01/the-oa-interviews-ashry-aly-of-ashdin. html\#more [Accessed February 2013].

Rutner, J. \& Schonfeld, R.C. 2012. Supporting the Changing Research Practices of Historians: Final report from ITHAKA S+R. Retrieved from http://www.sr.ithaka. org/research-publications/supporting-changing-research-practices-historians [Accessed February 2013].

SCONUL. 2012. Annual library statistics 2010-2011. London.

Solomon, D.J. \& Björk, B.-C. 2012. A study of open access journals using article processing charges. (Pre-print; accepted for publication in the Journal of the 
American Society for Information Science and Technology). Retrieved from http:// www.openaccesspublishing.org/apc2/ [Accessed February 2013].

Suber, P. 2012. Open Access. Cambridge, MA: MIT Press.

Swan, A. 2010a. Modelling scholarly communication options: Costs and benefits for universities: Report to the JISC. London: JISC. Retrieved from http://repository.jisc. ac.uk/442/ [Accessed February 2013].

Swan, A. 2010b. The Open Access Citation Advantage: Studies and results to date. Technical report. School of Electronics \& Computer Science, University of Southampton. Retrieved from http://eprints.ecs.soton.ac.uk/18516/ [Accessed February 2013].

Swan, A. \& Houghton, J. 2012. Going for Gold? The costs and benefits of Gold Open Access for UK research institutions: Further economic modelling. Report to the UK Open Access Implementation Group. London: UK Open Access Implementation Group. Retrieved from http://repository.jisc.ac.uk/610/2/Modelling_Gold_Open_ Access_for_institutions_-_final_draft3.pdf [Accessed February 2013].

Swan, A. et al. 2015. Open Access Policy: Numbers, analysis, effectiveness. Retrieved from http://pasteur4oa.eu/sites/pasteur4oa/files/deliverables/PASTEUR4OA\%20 Work\%20Package\%203\%20Report\%20final\%2010\%20March\%202015.pdf [Accessed February 2016].

Wagner, A.B. 2010. Open access citation advantage: An annotated bibliography. Issues in Science and Technology Librarianship, 60(2010). Retrieved from http:// www.istl.org/10-winter/article2.html [accessed February 2013].

Ware, M. \& Mabe, M. 2009. The STM Report: An overview of scientific and scholarly journals publishing. Oxford: International Association of Scientific, Technical and Medical Publishers. Retrieved from http://www.stm-assoc.org/2009_10_13_ MWC_STM_Report.pdf [Accessed February 2013].

Working Group on Expanding Access to Published Research Findings. 2012. Accessibility, Sustainability, Excellence: How to expand access to research publications. Report of the Working Group on Expanding Access to Published Research Findings (Finch Report). London: Research Information Network. Retrieved from http://www.researchinfonet.org/wp-content/uploads/2012/06/FinchGroup-report-FINAL-VERSION.pdf [Accessed February 2013]. 


\title{
Copyright and Changing Systems of Scientific Communication
}

\author{
Alexander Peukert \& Marcus Sonnenberg
}

This article presents an overview of the role of copyright in the context of changing systems of scientific communication. The analyses are based on German and European copyright law. The primarily descriptive sections 1 and 2 on substantive copyright law in scientific works and copyright contract law are oriented towards the 'prevailing opinion' informed by highest-instance case law. Section 3 reports on the criticism of currently prevailing copyright in scientific works and alternatives currently under discussion.

\section{Scientific communication as an object of copyright protection}

In order to determine the significance of copyright with respect to systems of scientific communication, the extent to which scientific expression and findings are objects of protection under copyright must be clarified.

\subsection{Scientific works}

Scientific works have always been included among the objects of protection covered by copyright. In the $19^{\text {th }}$ century, they were still listed as works of 'literature'. ${ }^{1}$ It was only with the current Act on Copyright and Related Rights (hereinafter 'Copyright Act') of 9 September 1965 that scientific works were

1 See Article 2(1) of the Berne Convention for the Protection of Literary and Artistic Works 1886/1971 ("The expression "literary and artistic works" shall include every production in the literary, scientific and artistic domain'). 
placed explicitly and prominently in Articles 1 and 2(1) alongside works of literature and art.

\subsubsection{Scientific literary works}

According to Article 2(1)(1), Copyright Act, included among scientific works are scientific literary works, such as fixed written compositions and oral speech. ${ }^{2}$ However, in this respect, only the concrete 'form' of the thought process is capable of protection under copyright, rather than the scientific content as such.

The concrete embodiment of speech, shaped by the process of thought, is understood as the form capable of protection. ${ }^{3}$ The concrete text is the scientific literary work to the extent that it refers to an 'author's own intellectual creation'. As a rule, the qualitative prerequisites for protection are fulfilled in the cases of whole monographs, articles, book chapters or longer text passages. ${ }^{4}$

The capability of protection of a concrete representation reaches its end only where this is necessary due to scientific concerns or where there exists a general rule within the area under consideration. ${ }^{5}$ Brief text passages, such as a single sentence or sentence portion, are only accorded protection according to case law when these are as such particularly significant or originally formulated and thereby exemplify a creative characteristic. ${ }^{6}$

Scientific teaching and scientific results (the 'content'), on the other hand, are public domain and not protected by copyright. ${ }^{7}$ Hence, a scholar who, for example, is the first to discover or explain historical facts, relationships or theories in the natural sciences has no copyright on his or her intellectual

2 See, for example, Federal Supreme Court, case no. I ZR 15/58, 25.11.1958, GRUR 1959, pp. 251, 251 Einheitsfahrschein; Federal Supreme Court, case no. I ZR 106/78, 21.11.1980, GRUR 1981, pp. 352, 353 - Staatsexamensarbeit.

3 Rehbinder \& Peukert, Urheberrecht, 17 $7^{\text {th }}$ edn, 2015, marginal note 214 ff.; European Court of Justice, case no. C-5/08, 16.07.2009, GRUR 2009, pp. 1041, marginal note 35 ff. - Infopaq I; Federal Supreme Court, case no. I ZR 9/95, 16.01.1997, ZUM-RD 1997, pp. 329, 331 ff. - CB-Infobank I; Federal Supreme Court, case no. I ZR 12/08, 01.12.2010, ZUM 2011, pp. 151, 155 -Perlentaucher.

4 Frankfurt Court of Appeal, case no. 11 U 66/11, 27.03.2012, ZUM 2012, pp. 574, 577 ff.; Federal Supreme Court, case no. I ZR 106/78, 21.11.1980, GRUR 1981, pp. 352, 355 - Staatsexamensarbeit.

5 Federal Supreme Court, case no. I ZR 106/78, 21.11.1980, GRUR 1981, pp. 352, 355 Staatsexamensarbeit; Federal Supreme Court, case no. I ZR 16/89, 12.07.1990, GRUR 1991, pp. 130, 132 ff. - Themenkatalog.

6 CJEU, case no. C-5/08, 16.07.2009, GRUR 2009, p. 1041, marginal notes 44-48 - Infopaq I (considered possible for the formulation 'a forthcoming sale of the telecommunications group TDC which is expected to be bought'); Federal Supreme Court, case no. I ZR 12/08, 01.12.2010, ZUM 2011, pp. 151, 152 marginal notes 37, 39 - Perlentaucher; answers in the affirmative for the formulation 'A cancer in the morale of the German nation' from the Frankfurt Court of Appeal, case no. 11 U 66/11, 27.03.2012, ZUM 2012, pp. 574, 578.

7 Federal Supreme Court, case no. I ZR 106/78, 21.11.1980, GRUR 1981, pp. 352, 353 Staatsexamensarbeit; Federal Supreme Court, case no. I ZR 16/89, 12.07.1990, GRUR 1991, pp. 130, 132 ff. - Themenkatalog; Federal Supreme Court, case no. I ZR 140/09, 01.06.2011, GRUR 2011, p. 803, marginal note 49 ff. - Lernspiele. 
efforts - anyone may make use of this from a copyright perspective - without naming the scientific pioneer. ${ }^{8}$

However, the distinction between 'form' and 'content' presents difficulties. The transition between both categories is, in certain cases, fluid. Thus, the collection, selection, allocation and arrangement of material in a specific outline of a text is considered capable of protection to the extent that it is not exhausted in a factually obvious table of contents - such as the chronological construction of a historical work. ${ }^{9}$ After all, the prevailing opinion also accords authors of scientific material protection for 'concrete original connections, conclusions and evaluations', 'when these extend beyond the public domain core of scientific teachings and theories'.$^{10}$ An example of this is the recognition in a postdoctoral thesis that Germany is the leader in earthquake research, even though the country is not among the particularly endangered areas. ${ }^{11}$

\subsubsection{Illustrations of a scientific nature}

According to Article 2(1)(7), Copyright Act, included among protected scientific works are: 'Illustrations of a scientific or technical nature, such as drawings, plans, maps, sketches, tables and three-dimensional representations'. A scientific illustration is characterised by the fact that it serves to impart educational or instructional information about the represented object through the means of expression of graphic or plastic description. The purpose of conveying information distinguishes these works from works of art, which primarily appeal to aesthetic sensibilities. The means of expression through graphic or plastic description differentiates them from literary works, whose means of expression is language. ${ }^{12}$

A typical example of a scientific illustration would be a model that represents a protein in a graphic form. ${ }^{13}$ Yet, the group of potentially protected illustrations of a 'scientific nature' is not limited to such clear-cut examples. Even the illustration of the most basic scientific discoveries - such as learning games for children consisting of control units and exercise books (for example, miniLUK)

8 Entirely the prevailing opinion, see Rehbinder \& Peukert (supra note 3), marginal note 219; Frankfurt Court of Appeal, case no. 11 U 66/11, 27.03.2012, ZUM 2012, pp. 574, 577; to the contrary, Haberstumpf, 'Das Urheberrecht - Feind des Wissenschaftlers und des wissenschaftlichen Fortschritts?', ZUM 2012, pp. 529, 536. The rules of internal scientific communication demand such a specification.

9 Federal Supreme Court, case no. I ZR 157/77, 07.12.1979, GRUR 1980, pp. 227, 231 - Monumenta Germaniae Historica; Federal Supreme Court, case no. I ZR 29/79, 27.02.1981, GRUR 1981, pp. 520, 521 ff. - Fragensammlung; Federal Supreme Court, case no. I ZR 16/89, 12.07.1990, GRUR 1991, 130, 132 ff. - Themenkatalog.

10 Frankfurt Court of Appeal, case no. 11 U 66/1 1, 27.03.2012, ZUM 2012, pp. 574, 579.

11 Frankfurt Court of Appeal, case no. 11 U 66/11, 27.03.2012, ZUM 2012, pp. 574, 579.

12 Federal Supreme Court, case no. I ZR 140/09, 01.06.2011, GRUR 2011, 803, marginal note 39 m.w.N. Lernspiele.

13 Frankfurt Court of Appeal, case no. 6 W 31/89, 04.04.1989, GRUR 1989, p. 589 - Eiweißkörper. 
- are subsumed hereunder. ${ }^{14}$ At the same time, as with literary works, the requirements on an 'author's own intellectual creation' of a scientific representation are low. A specific manner of representation that transcends everyday production in the relevant area is sufficient. ${ }^{15}$ On the other hand, one must recognise the principle that only the concrete 'form' is capable of protection not, however, the abstract game or representational concept (the 'content'). ${ }^{16}$

On the whole, it appears that copyright operates with a different understanding of the term 'science' than do the sciences in their self-description or constitution with respect to academic freedom. While 'science' is there defined as the serious and systematic attempt, according to content and form, to determine the truth in research and teaching, ${ }^{17}$ copyright-related case law takes the concept of a scientific work much further to include common, yet economically valuable, crossword puzzles and word games. ${ }^{18}$

\subsubsection{Content of legal protection}

The creators of scientific literary works and representations and likewise the producers of scientific editions - the 'author' (Article 7, Copyright Act) - enjoy the same comprehensive legal protection as do all other authors. Authors' moral rights include the right of first publication, the recognition of authorship and the integrity of the work (Articles 12-14, Copyright Act). ${ }^{19}$ The commercial exploitation rights extend to all existing and as of yet unknown forms of material and non-material exploitation of scientific works. Included are, in particular, the right to produce copies whether on a temporary or on a lasting basis, and this regardless of by which means of procedure or in which quantity they are made (Article 16(1), Copyright Act). Also included is the right to make a work available on the Internet (Article 19a, Copyright Act). Furthermore, adaptations or other transformations of a work may only be published or exploited with the consent of the author of the adapted or

14 Federal Supreme Court, case no. I ZR 140/09, 01.06.2011, GRUR 2011, p. 803, marginal note 43 with further references - Lernspiele.

15 Federal Supreme Court, case no. I ZR 140/09, 01.06.2011, GRUR 2011, p. 803, marginal note 50 Lernspiele.

16 Cologne Court of Appeal, case no. 6 U 225/08, 13.07.2012, ZUM 2012, pp. 975, 979 - Lernspiele.

17 Constitutional Court, case no. 1 BvR 424/71, 29.5.1973, BVerfGE pp. 35, 79, 112 ff.; Constitutional Court, case no. 1 BvR 174, 178, 191/71 among others, 1.3.1978, BVerfGE pp. 47, 327, 367.

18 See Peukert, Das Verhältnis zwischen Urheberrecht und Wissenschaft: Auf die Perspektive kommt es an!, 4 JIPITEC 2012, p. 142 ff.; Federal Supreme Court, case no. I ZR 16/89, 12.07.1990, GRUR 1991, pp. 130, $132 \mathrm{ff}$ - - Themenkatalog ('The area of science is not only limited to research and teaching in a narrow constitutional sense.'); on prize competitions as scientific representation, see Munich Court of Appeal, case no. 6 U 2093/88, 19.09.1991, GRUR 1992, pp. 510, 510 ff.

19 The publisher is not entitled to these authorisations for the first publication of a posthumous work. See Article 71(1), third sentence, Copyright Act. 
transformed work (Article 23, Copyright Act). Copyright expires 70 years after the author's death (Article 64, Copyright Act).

\subsubsection{Limitations of protection in a scientific context}

Copyright is subject to certain restrictions ('limitations'). ${ }^{20}$ In line with the stipulations in various regulations, a work may be used without the author's permission. Several limitations pursue the purpose of easing scientific communication. ${ }^{21}$

Among these limitations is, firstly, the right to quote, which, in the interest of general cultural and scientific advancement, serves the freedom of intellectual exchange of others' ideas. ${ }^{22}$ According to Article 51, Copyright Act in particular, it is permissible to include individual works after publication in an independent scientific work for the purpose of explaining the contents if the source is clearly specified. The right to quote allows for the word-for-word reproduction of a few text passages, illustrations and images in order to document and explain one's own scientific statements. More extensive reproduction of others' text passages, etc. that lack an explanation of the content in one's own work may be permissible in artistic text collages. ${ }^{23}$ Concerning scientific works, however, such an expanded interpretation of the right to quote is not recognised. Rather, the scientific work containing the quotation must constitute the main idea, while the reproduced text passages, representations, etc. remain secondary, and an inner connection must exist between the works or work portions used and the ideas of the one using the quotation. ${ }^{24}$

While quotation free of remuneration is permissible, other limitations on copyright in the context of the sciences are coupled with lump-sum remuneration obligations, which are handled by collecting societies (for example, VG Wort). This concept is valid in particular for the production of single copies of a work for private scientific use, which is permissible if and insofar as such copying is necessary for this purpose, that it serves no commercial purpose, and if the

20 The same is true for related rights in scientific editions and posthumous works. See Articles 70(1), 71(1), third sentence, Copyright Act.

21 Rehbinder \& Peukert (supra note 3), marginal note 645 ff.; De la Durantaye, Allgemeine Bildungs - und Wissenschaftsschranke, 2014, pp. $73 \mathrm{ff}$.

22 Federal Supreme Court, case no. I ZR 32/92, 30.06.1994, GRUR 1994, pp. 800, 803 - Museumskatalog.

23 See Constitutional Court, case no. 1 BvR 825/98, 29.06.2000, GRUR 2001, pp. 149, 151 - Germania 3; Federal Supreme Court, case no. I ZR 212/10, 30.11.2011, GRUR 2012, p. 819 marginal note 14 ff. Blühende Landschaften.

24 Federal Supreme Court, case no. I ZR 83/66, 03.04.1968, NJW 1968, pp. 1875, 1877 ff. - Kandinsky (denied for 69 reproductions of works by Kandinsky in a book on the artists' group 'Der blaue Reiter'). Federal Supreme Court, case no. I ZR 32/92, 30.06.1994, GRUR 1994, pp. 800, 803 - Museumskatalog; Federal Supreme Court, case no. I ZR 69/08, 29.04.2010, NJW 2010, p. 2731 marginal note 26 Vorschaubilder $I$. 
copies are neither distributed nor communicated to the public. ${ }^{25}$ Accordingly, scholars themselves, or through contracting others, may produce reprographic and digital copies of scientific works.

In this regard, public libraries are permitted to transmit copies upon request (Article 53a, Copyright Act). Here, a distinction must be drawn between analogue paper copies and electronic copies. In response to an individual order, public libraries are permitted to reproduce and transmit by post or facsimile, individual articles published in newspapers and periodicals and also small parts of published works insofar as the exploitation by the person placing the order is permissible pursuant to Article 53, Copyright Act. Reproduction and transmission in other electronic forms are permissible solely as a graphic data file and for the purpose of scientific research, to the extent justified by a non-commercial purpose. Such transmission of copies in electronic form is, however, prohibited when access to contributions or small portions of a work is clearly available to members of the public at locations and times of their choosing through a contractual agreement under equitable conditions. In this regard, concerning transmission in digital form, the online offerings from the publisher have priority. Where such online offers exist under 'equitable conditions', public libraries must refrain from transmitting copies thereof in electronic form.

The latter reservation is not found explicitly among the legal regulations concerning the making available of works to the public for instructional and research purposes (Article 52a, Copyright Act). According to this provision, it is permissible to make available to the public already published, small, limited parts of a work, small-scale works, as well as individual articles from newspapers or periodicals for a specifically limited circle of persons for their personal scientific research, and for this purpose, to produce copies to the extent that this is necessary for the respective purpose and is justified for the pursuit of non-commercial aims. The intention here is to privilege small research teams who, in particular, store journal articles in a common online folder, which is protected by technical access mechanisms from the general access of all Internet users. This provision, however, does not permit works to be stored on a university's intranet server in a way that access would be available to all researchers working there. ${ }^{26}$ The German Federal Supreme Court, however, views making available to the public as unnecessary for the specific purpose and thereby as prohibited if the rightholder offers the works or portions thereof in a digital form for use on the network of the individual

\footnotetext{
25 See Article 53(2)(1) and (6), Copyright Act and Koblenz Court of Appeal, case no. 6 U 606/83, 07.08.1986, NJW-RR 1987, p. 699.

26 See BT-Drucks. 15/837, p. 34.
} 
institution under equitable conditions. The required licensing fee must be equitable and the licensed offer easily accessible. ${ }^{27}$ It is left to the scientific publishers themselves to decide whether to market their works online directly or whether to be satisfied with a share of a lump-sum remuneration payment according to Article 52a IV, Copyright Act.

It has been correctly pointed out that this priority of an equitable licensing offer must consequently also pertain to the permissibility of digital copies for personal scientific research purposes. ${ }^{28}$ According to this reading, in the digital age, only the right to quote remains without restriction and free of charge. Incidentally, German copyright law plainly assumes that scientific communication takes place primarily via digital, access-controlled publishers' databases. Contractual licences replace legal usage authorisations. These licences determine what an individual researcher may undertake with the contents of scientific publishers' databases.

Finally, the provisions, which enable the authorisation-free, massdigitalisation of orphan and out-of-print works intended to strengthen the knowledge and information society, are mentioned. A work is orphaned when the rightholder cannot be determined or located; out-of-print means simply that a work is no longer supplied by the publisher. Orphan books, academic journals and other writings, works on film and sound storage media may be digitised and made available to the public for cultural and educational purposes by institutions that are publicly accessible and which serve the public interest, such as libraries, archives, museums and public broadcasting organisations. However, these privileged institutions must determine in advance through a diligent search that the specific work is genuinely orphaned. As the relevant provisions of Articles 61-61c, Copyright Act only permit the commercialisation of orphan holdings by publicly financed institutions within narrow limits, it seems questionable if and when a comprehensive indexing can be expected of orphan library holdings in the Deutsche Digitale Bibliothek and EUROPEANA under these strict constraints. ${ }^{29}$ Against this background, the provisions on out-of-print works (Articles 13d and e, Copyright Administration Act) appear more feasible. These provisions have placed the collecting societies Wort and Bild-Kunst in the position to license all books, academic journals, newspapers, magazines or other written works published prior to 1 January 1966 and which

27 Federal Supreme Court, case no. I ZR 84/11, 20.3.2013, GRUR 2013, p. 1220 marginal note 39 ff. Gesamtvertrag Hochschul-Intranet; Federal Supreme Court, case no. I ZR 76/12, 28.11.2013, GRUR 2014, p. 549 marginal note 58 ff. - Meilensteine der Psychologie.

28 See Berger, Die öffentliche Zugänglichmachung urheberrechtlicher Werke für Zwecke der akademischen Lehre - Zur Reichweite des § 52a I Nr. 1 UhrG, GRUR 2010, pp. 1058, 1064.

29 See Rehbinder \& Peukert (supra note 3), marginal notes 667-670. 
are currently out of print, and located in the holdings of publicly accessible libraries, museums, archives, etc. for non-commercial digitising purposes. ${ }^{30}$

\subsection{Computer programs}

Included among the works protected under section 2(1)(1), Copyright Act are computer programs, which are important both as a means of communication as well as being an object and result of research. Because software is subject to a special European Union (EU) Directive, ${ }^{31}$ its legal protection deviates from that of other work and must be examined separately.

As with other types of works, a distinction must be drawn at the outset between the 'expressions' of a computer program, which are eligible for protection, and the ideas and principles not protected under copyright which, as an element, form the basis for a computer program. Included among the expressions eligible for protection are the source and object codes but not, however, the user interface, the functionality of a computer program, the programming language or the file format. ${ }^{32}$

From a qualitative perspective, the source and object codes are protected if they represent individual works in the sense that they are the result of an author's own intellectual creation. No other criteria, in particular qualitative or aesthetic criteria, shall be applied in determining their eligibility for protection. ${ }^{33}$ Thus, all computer programs enjoy protection to the extent that they transcend an utterly banal programming effort. ${ }^{34}$ An assumption exists in this regard: ${ }^{35}$ ultimately, all computer programs that find an application in a relevant fashion in systems of scientific communication are protected under copyright.

The exploitation rights in computer programs are essentially the same as those for other works. In particular, the source and object codes may not be reproduced, made available to the public or adapted (Article 69c, Copyright Act). There are, however, significant differences with respect to the limitations of the legal protection of software as compared with the remainder of copyright. The special provisions regarding computer programs permit usage without

30 More specifically Rehbinder \& Peukert (supra note 3), marginal notes 671-674.

31 Directive 2009/24/EC of the European Parliament and of the Council of 23 April 2009 on the legal protection of computer programs (codified version), OJ no. L 111 from 5.5.2009, p. 16.

32 See Article 69a(1) and (2), Copyright Act; likewise CJEU, case no. C-393/09, 22.12.2010, GRUR 2011, p. 220 marginal notes 44-46 - BSA/Kulturministerium; CJEU, case no. C-406/10, 02.05.2012, EuZW 2012, p. 584 marginal notes 39, 45 - SAS/World Programming.

33 Article 69a(3), Copyright Act.

34 BGHZ pp. 123, 208 - Buchhaltungsprogramm.

35 Federal Supreme Court, case no. I ZR 90/09, 20.9.2012, ZUM-RD 2013, p. 371 marginal note 23 ff. UniBasic-IDOS. 
authorisation and remuneration only where this is necessary for the intended purpose including error correction, the making of a backup copy, observation, study or testing of a program, as well as for decompilation (Articles $69 \mathrm{~d}$ and e, Copyright Act). According to the prevailing opinion, these special provisions supersede the general limitations on copyright and in particular the limitations in the interest of science, be it reproduction for personal scientific use, the dispatch of copies or usage within a smaller network of researchers. ${ }^{36} \mathrm{~A}$ controversial point of view holds that the right to quote remains applicable. ${ }^{37}$

\subsection{Databases}

The third protected subject matter important in scientific communication concerns databases. These too are subject to an individual EU Directive, governing protection requirements, the area of protection and limitations differing from other categories of works. ${ }^{38}$ In this regard, one must further differentiate between copyright protection for collections of works (collections) and database works, and the suigeneris protection of other investment-intensive databases.

\subsubsection{Copyright in collections and database works}

Collections and database works are characterised according to Article 4, Copyright Act in that the selection or arrangement of the works, the data or other individual elements must constitute the author's own intellectual creation. With such collections or databases, the primary purpose is not completeness; the purpose is rather the creative and individual selection or arrangement as seen in scientific volumes and encyclopaedias. The copyright owner of the collection/database is typically the publisher. Due to its selection work as the editor, it enjoys independent and extensive legal protection in addition to the authors' copyrights in their individual contributions. Database works may be reproduced for one's own scientific use, as long as this does not serve a commercial purpose. ${ }^{39}$

\footnotetext{
36 Dreier, in: Dreier \& Schulze (eds), Urheberrechtsgesetz, $4^{\text {th }}$ edn, 2013, Article 69a, Copyright Act, marginal notes 3, 33; Grützmacher, in: Wandtke 8 Bullinger (eds), Praxiskommentar zum Urheberrecht, $4^{\text {th }}$ edn, 2014, Article 69a Copyright Act marginal note 75.

37 Dreier, in: Dreier \& Schulze (eds), (supra note 36), Article 69a Copyright Act, marginal note 34; to the contrary, Grützmacher, in: Wandtke \& Bullinger (eds), (supra note 36), Article 69a, Copyright Act, marginal note 75 ('Article 51, in its spirit and purpose, is still unsuitable for computer programs').

38 Directive 96/9/EC of the European Parliament and of the Council of 11 March 1996 on the legal protection of databases, OJ no. L 77 from 27.3.1996, p. 20.

39 Section 53(5), sentence 2, Copyright Act.
} 


\subsubsection{Sui generis protection of database makers}

European copyright protects not only the selection and arrangement efforts of scientific publishers, but also those businesses that invest in a database. Whoever provides an 'essential investment' in the acquisition, examination or representation ${ }^{40}$ of works, data or other independent elements, receives an exclusive sui generis proprietary right for a period of 15 years following publication of the database. Thereby, an incentive for investment in electronic databases is established. The database maker (investor) disposes over an exclusive right to reproduce, distribute and make available to the public the database either in its entirety or, with respect to the total investment, a quantitatively or qualitatively essential portion. ${ }^{41}$ Even non-essential (individual) portions of a database may not be used to the extent that this occurs repeatedly and systematically and where a 'normal' analysis of the database would be affected.

Both the publisher's copyright in a database and the database maker's rights are independent of the type of information arranged or collected. In particular, the database does not have to be comprised of copyrighted material. Instead, any type of dataset is sufficient - for example, raw scientific data. ${ }^{42}$ Academic publishers are hereby accorded legal ownership, placing them in the position to control access to scientific information as such (the 'content').

Nevertheless, non-essential portions of a database - for example, an individual dataset - may be used without infringing the rights of the database maker. Furthermore, Article 87c(1)(2) states that the reproduction of essential portions of a database, according to the nature or extent, is permissible for personal scientific use if and insofar as the reproduction is justified for that purpose and the scientific use does not serve commercial purposes and where the source is clearly cited. Repeated and systematic retrievals, however, are always prohibited so that, for example, scientific analyses of publishers' databases ('data mining') require the agreement of the database investor. ${ }^{43}$

40 Not, however, in the original production of the data, etc. See CJEU, case no. C-203/02, 09.11.2004, EuZW 2004, p. 757, marginal note 28 ff. - The British Horseracing Board Ltd and Ors. v. William Hill Organization Ltd.

41 Thereby, the value of the individual dataset is not meant, rather the relevance of the extracted portion with respect to the protected investment. See CJEU, case no. C-203/02, 09.11.2004, EuZW 2004, p. 757, marginal note 28 ff. - The British Horseracing Board Ltd and Ors. v. William Hill Organization Ltd.

42 CJEU, case no. C-545/07, 05.03.2009, GRUR 2009, p. 572, marginal note 73 - Apis/Lakorda.

43 Reichman \& Okediji, When copyright law and science collide: Empowering digitally integrated research methods on a global scale, Minnesota Law Review 96 (2012), pp. 1362, 1423. 


\subsection{Protection of scientific editions and posthumous works and press publishers' related rights}

Finally, three 'related rights' to copyright need to be pointed out which have a certain relationship to scientific communication but which possess only slight practical significance. Article 70, Copyright Act accords the 'author' of a scientific edition of a non- or no-longer copyright-protected work or text a 25 -year right in such an edition if it represents the result of scientifically organised activity and differs substantially from previously known editions of the work or text. According to Article 71, Copyright Act, one who publishes a non- or no-longer copyright-protected work for the first time (for example, a scientific manuscript which was thought to be lost) likewise enjoys a 25-year exclusive right to exploit the posthumous work. The related right for press publishers (Articles 87f-h, Copyright Act) should indeed ultimately find application with respect to academic journals. ${ }^{44}$ However, this only extends to the making available to the public of such 'press products' or portions thereof through commercial search engines and news aggregators.

\subsection{Legal protection of technical protection measures}

Irrespective of all these copyright authorisations, a rightholder is able to prevent all unauthorised usage of its protected subject matter, specifically a scientific database, through the employment of technical protection measures (digital rights management or DRM) and to sanction this in its licensing terms and conditions. Thus, even the access to an individual dataset, and thereby specific scientific information, can be made dependent on the acquisition of a licence. This model of access-controlled databases, already established in practice, is legalised and promoted by European copyright law in that the technical and actual control is placed under additional legal protection. Concerning the legal protection of technical protection measures, a distinction must be made between computer programs on the one hand, and protected scientific subject matter on the other.

\subsubsection{Legal protection of technical protection measures in computer programs}

To the extent that computer programs are supplied with DRM measures, only the directive on the legal protection of computer programs from 1991 has relevance. ${ }^{45}$ Insofar Article 69f(2), Copyright Act determines that a rightholder

\footnotetext{
44 Jani, in: Wandtke \& Bullinger (eds), (supra note 36), Article 87f, Copyright Act, marginal note 4.

45 On the specialty of the computer program directive, CJEU, case no. C-128/11, 03.07.2012, GRUR 2012, p. 904 - UsedSoft.
} 
may demand the destruction of such means solely intended to simplify the unauthorised removal or circumvention of any technical protection measures, such instruments are declared illegal per se. While usage of these instruments in the circumvention of DRM systems is not explicitly prohibited, case law nevertheless grants rightholders such defence entitlements, and this on the basis of general private law (intentional damage contrary to public policy, section 826 of the German Civil Code) and the right against unfair competition. ${ }^{46}$

\subsubsection{Legal protection of technical protection measures in other works and databases}

Directive 2001/29/EC, ${ }^{47}$ implemented in Articles 95a ff., Copyright Act, governs DRM systems which control the usage of individual scientific works and in particular scientific databases. According to this, circumvention of effective technological measures is prohibited, as well as rendering this possible by producing and offering of circumvention tools. A DRM system is considered 'effective' and thereby protected when an access or reproduction control has been put in place. It is sufficient that the average user may be hindered in deactivating the measure. It must be assumed that in practice, DRM systems put in place by scientific publishers enjoy legal protection, even though they may be continually circumvented.

With the aid of DRM systems, scientific publishers and database producers are able to override all science-relevant limitations. Articles 95b(1)(5) and (6) (b) determine that a rightholder who implements technical protection measures must subsequently make available to scholars all necessary means so that they may make use of the limitations of Article 52a (intranet usage) and Article 53(2) first sentence and (2)(1) (reproduction for scientific use). This regulation remains, however, practically irrelevant. Still more important is that, according to explicit rules, this does not apply to online databases. ${ }^{48}$ This means when a DRM system is utilised, seminal exploitation of scientific works and databases over the Internet may take place with complete disregard for the limitations of copyright law.

\subsection{Conclusion}

On the whole, copyright protects and promotes the business model undertaken by most scientific publishers: an exclusive, access-controlled online database,

\footnotetext{
46 On Article 1 of the Act against Unfair Competition (former version), Federal Supreme Court, case no. I ZR 220/95, 09.11.1995, GRUR 1996, p. 78 -Umgehungsprogramm.

47 Directive 2001/29/EC of the European Parliament and of the Council of 22 May 2001 on the harmonisation of certain aspects of copyright and related rights in the information society, OJ no. L 167 from 22.6.2001, p. 10.

48 Article 95b(3), Copyright Act.
} 
the usage of which is subject to a flat rate ('big deal') or an individual ('pay-perclick') licensing fee. In this business model, the traditional distinction between the copyright-protected 'form' and freely accessible scientific 'content' is null and void. The interested user is only able to access even raw scientific data, theories and expressions when he or she has procured licensed access to the online database. European copyright provides publishers and database producers with total control over scientific information on the Internet. ${ }^{49}$

\section{Scientific works and databases as contract subject matter}

The conclusion above implies that the powers of copyright lie completely with the publisher. Apart from the database maker's right, which originally derives from the investor, for this purpose, a contractual acquisition of rights from the authors, i.e. scholars, is necessary. ${ }^{50}$ They are free to decide when and with whom they assign their rights, and to what extent.

\subsection{The original rightholder in scientific works}

The original copyright owner in a work is its 'creator' - the 'author' (Article 7, Copyright Act). With respect to scientific works, the creator is the person who formulates the scientific literature or who realises a concrete scientific representation (for example, a model). However, a scientific discovery, the establishment of a theory or the production of raw data does not result in copyright. Scientists who confine themselves to this are not 'authors' as defined by copyright; copyright is tied rather to the concrete expression in language or representation of this information alone. ${ }^{11}$ According to this definition, the original rightholder is also a scientist who is either employed or tenured at a research institution and who has created a scientific work in fulfilment of obligations deriving from the employment or service relationship. ${ }^{52}$ In consideration of academic freedom, such works are fundamentally considered free and the personal achievement of the individual scientist. The employer acquires neither a tacit exploitation right upon conclusion of an employment

49 Hilty, Das Urheberrecht und der Wissenschaftler, GRUR Int. 2006, pp. 179, 181.

50 Different from the producers of sound recording media or film material, publishers do not receive an original right related to copyright in published literary works. The business model in the publishing industry is based thus far on derived copyrights. On the rights related to copyright for press publishers, see section 1.4 above.

51 On this point, friction results from the right to claim identification in copyright, to which only the person who formulated the contribution or representation is entitled, and the scientific practice of claiming identification, according to which those who supply 'only' raw data are also identified as 'authors'.

52 See Article 43, Copyright Act. 
contract, nor are employed or tenured scientists required to submit an offer granting their employer an exploitation right in the works. ${ }^{53}$

Case law, however, has recognised exceptions to this so-called 'university professor's privilege'. Thus, a professor's heirs were required to offer to the university where he/she was active, possible copyrightable exploitation rights in extensive archaeological excavation materials, which could be of use for further research purposes. ${ }^{54}$ In a collection, specifically concerning a journal edited over many years at a university institute, the financing university tacitly acquired exploitation rights because it could not be assumed that numerous university employees should have worked in practice for the individual publisher. ${ }^{55}$ Finally, universities retain the exploitation rights in multiplechoice exams drafted by research assistants who are under their direction. ${ }^{56}$ Regarding traditional articles or monographs produced in individual or joint authorship, it remains the case that individual scholars alone may dispose of and freely decide to whom exploitation rights are granted.

\subsection{Copyright contract law and scientific publishers}

In German copyright contract law, this power of disposition is secured in numerous ways. The regulations are based on the idea that individual authors are in a weaker position structurally as opposed to commercial middlemen, such as publishers, and therefore require legal protection. ${ }^{57}$

Copyright is not transferable among those still living (Article 29, Copyright Act). And where in doubt, the author also grants exploitation rights according to the so-called 'transfer purpose principle' only insofar as the purpose envisaged by both parties to the contract makes this necessary. ${ }^{58}$ Where the holder of an exclusive exploitation right does not exercise the right or does so insufficiently or where the author no longer stands behind the work, he or she may revoke the exploitation right. ${ }^{59}$ Payment of equitable remuneration is compulsory for the granting of exploitation rights. ${ }^{60}$ However, exceptions are recognised specifically with respect to works for academic qualification

\footnotetext{
53 Dreier, in: Dreier \& Schulze (eds), (supra note 36), Article 43, Copyright Act, marginal note 12 with further references.

54 Federal Supreme Court, case no. I ZR 244/88, 27.09.1990, NJW 1991, pp. 1480, 1483 Grabungsmaterialien.

55 Berlin Superior Court, case no. 5 U 2189/93, 06.09.1994, NJW-RR 1996, p. 1066 - Poldok.

56 Cologne District Court, case o. 28 O 161/99, 01.09.1999, NJW-RR 2000, pp. 1294, 1295.

57 Rehbinder \& Peukert (supra note 3), marginal note $932 \mathrm{ff}$.

58 See Article 31 (5), Copyright Act and Rehbinder \& Peukert (supra note 3), marginal note $980 \mathrm{ff}$.

59 See Articles 41, 42, Copyright Act. See further the provisions of the Publishers' Act (Verlagsgesetz) which, however, only affect traditional print publishing and not online rights.

60 Articles 32, 32a, 32b, 36 and 36a, Copyright Act.
} 
and other scientific contributions because the respective works can only be published economically when the publisher is not liable for remuneration (rather, only receives a subsidy for printing costs) ${ }^{61}$

Of further interest to scientific journals and collections is the regulation whereby the publisher or editor may, in cases of doubt, acquire an exclusive right of reproduction, distribution and making available to the public. The author may however otherwise reproduce, distribute and make available to the public the work upon expiry of one year, unless otherwise agreed. ${ }^{62}$ This provision serves the purpose of making a second publication possible. Admittedly, this non-mandatory rule of doubt only takes effect once the publisher has explicitly ensured a grant of comprehensive, exclusive exploitation rights. This shortcoming should be avoidable through the compulsory second publication right for scientific authors according to Article 38 IV, Copyright Act, valid since 2014, which is dealt with in detail in the context of the relationship between copyright and open access. ${ }^{63}$

Between 1966 and 2008 it was still the case that exploitation rights could not be granted effectively for yet unknown types of exploitation. The purpose of this provision was to ensure that the publisher, upon development of a new technology, would subsequently be forced to acquire authorisation from the author at a separate price. Accordingly, up until the early 1990s, scientific publishers were unable to obtain the rights for the online exploitation of scientific works. ${ }^{64}$ As the intended subsequent acquisition of rights proved unfeasible in practice (cf. orphan works), in 2008, the prohibition against granting exploitation rights concerning unknown types of exploitation was lifted and replaced by an agreement-in-writing requirement, a right of refusal and a special right to remuneration. ${ }^{65}$ For publishing contracts concluded between 1966 and the beginning of the 1990s, it would have remained the case that publishers were not authorised for exploitation on the Internet. In order to place them in the position of being able to import their archives into online databases, a legal fiction was codified whereby the online rights were deemed as granted to the publisher when the author exclusively granted all other exploitation rights, unlimited by location and in perpetuity. ${ }^{66}$ Whether this provision actually results in scientific publishers being authorised to include an entire publishing portfolio in their online databases depends on the content of

\footnotetext{
61 Schulze, in: Dreier \& Schulze (eds), (supra note 36), Article 32, Copyright Act, marginal note 61.

62 Article 38(1) and (2), Copyright Act.

63 See section 3.2 .2 below.

64 Ehmann \& Fischer, Zweitverwertung rechtswissenschaftlicher Texte im Internet, GRUR Int. 2008, pp. 284, 286.

65 Articles $31 \mathrm{a}$ and 32c, Copyright Act.

66 Article 137l, Copyright Act.
} 
the legacy contracts on a case-by-case basis. The subsequent, fictive acquisition of rights is generally denied to newspaper publishers, in particular. ${ }^{67}$ However, this segment is heavily impacted by the notion: 'where there is no accuser, there is no judge'.

One can conclude from the provisions sketched above that applicable copyright contract law is completely tailored according to the traditional marketing model of (print) publishers. As opposed to many other copyright regimes, namely that of the Anglo-American copyright system, the provisions prevent an author's complete loss of rights. At the same time, however, as a practical result, a similar acquisition of exclusive exploitation rights by publishers is possible and even fabricated with respect to online rights in the interest of the digital database business model.

\subsection{Open content model}

Alternatively, exploitation forms based on openness and access such as free/ open source software and Creative Commons have, on the other hand, only had an impact on current copyright contract law in so-called 'Linux clauses'. Accordingly, an author may grant a basic exploitation right to everyone, free of charge and without regard for a written agreement for unknown types of use. ${ }^{6}$ With these provision, the legislator recognises that open content models 'represent effective communication and cooperation structures', which create a new interest and protection arrangement between authors, exploiters and end users, to which the statutory compensation and written agreement requirements do not fit. ${ }^{69}$

Open content contracts are indeed based on the copyright of the author/ licensor, who offers utilisation of a work to all interested users in either a comprehensive or specific respect. As opposed to other traditional publishing agreements, the granting of exploitation rights/licensing contracts does not serve the purpose of procuring an exclusive legal position for an individual acquirer. Rather, the fundamental idea goes in another direction where everyone may use the work free of charge - or where required, under certain conditions, such as a prohibition against commercial exploitation and identification of the

67 The argument for this is based on Article 38(1) and (2), Copyright Act, whereby the author may otherwise reproduce and distribute his journal or collection contributions one year after publication, so that the publisher was never able to acquire 'all essential' exploitation rights; see Sprang $\&$ Ackermann, Der 'Zweite Korb' aus Sicht der (Wissenschafts-)Verlage, K\&R 2008, pp. 7, 10; Ehmann \& Fischer (supra note 64$)$, p. 289.

68 Articles $31 \mathrm{a}(1)$, second sentence, 32(3), third sentence, 32a(3), third sentence, $32 \mathrm{c}(3)$, second sentence, Copyright Act.

69 See BT-Drucks. 14/6433, 15; BT-Drucks. 14/8058, 19; BT-Drucks. 16/1828, 37; BT-Drucks. 16/5939, 44. 
name of the author. ${ }^{70}$ Copyright is thus transformed, through the power of private and autonomous decision, from being an instrument for the limitation of access into being an instrument enabling, and in the case of open source software, even forcing openness. ${ }^{71}$ In systems of scientific communication, these contract models have attained increasing significance in the establishment of open access. ${ }^{72}$

Yet, nowhere near all scientific works are furnished with a specific open content licence. Scholars often simply make their works available online without further explanation. Such action has been qualified by the Federal Supreme Court as simple consent excluding specific illegal uses. An authorised party, or another with his or her agreement, ${ }^{73}$ who makes texts or images freely available on the Internet without restriction, declares him- or herself as being in implied agreement with the 'general acts of exploitation according to the circumstances'. The interpretation of implied consent must be oriented on objective content from the perspective of the recipient of consent. As the consent to general online exploitation is targeted at the general public, it can only be retracted through generally recognisable circumstances, such as the removal of material from one's own home page or the activation of technical protection measures. A retraction with respect to an individual user with continued availability of the content is protestatio facto contraria irrelevant. Included in (legally permissible) general online exploitation is non-commercial reproduction by a private Internet user (downloading, printing) ${ }^{74}$ and image searches of so-called 'thumbnails'. ${ }^{75}$ The legal status of simple consent has the potential to bring social (including scientific) and copyright norms closer without complicated licensing constructs. ${ }^{76}$

70 See Rehbinder \& Peukert (supra note 3), marginal notes 855-857.

71 On open source licences, see Jäger $\&$ Metzger, Open source software, $3^{\text {rd }}$ edn, 2011; on Creative Commons licences, see Berlin District Court 16 O 458/10, 08.10.2010, MMR 2011, pp. 763, 763 ff.; further Krujatz, Open Access, 2012, p. 110 ff.

72 See subsection 3.2.2 below; and Jaeger \& Metzger, Open Content-Lizenzen nach deutschem Recht, MMR 2003, p. 431 ff.; Mantz, Open Access-Lizenzen und Rechtsübertragung bei Open Access-Werken, in: Spindler (ed.), Rechtliche Rahmenbedingungen von Open Access-Publikationen, 2006, pp. 55 ff.

73 See, for example, Federal Supreme Court, case no. I ZR 140/10, 19.10.2011, NJW 2012, p. 1886, marginal note $16 \mathrm{ff}$ - Vorschaubilder II.

74 Federal Supreme Court, case no. I ZR 94/05, 6.12.2007, NJW 2008, 751, marginal note 27 - Drucker und Plotter I.

75 Federal Supreme Court, case no. I ZR 69/08, 29.4.2010, NJW 2010, 2731, marginal note 28 ff., 33 ff. Vorschaubilder I.

76 See Peukert, Der digitale Urheber, in: Bullinger et al. (eds), Festschrift für Artur-Axel Wandtke zum 70. Geburtstag, 2013, pp. 455 ff. 


\subsection{Contract law and computer programs}

The principles of copyright contract law mentioned above essentially also apply to computer programs. Here too, the programmer, as an author, is the original rightholder. Whether or not the programmer exercises his or her rights in the realisation of an exclusive exploitation or in any open source model rests with his or her private autonomous decision.

A special rule applies in the case of programmers in an employment relationship. Where a computer program is created by an employee during the execution of his or her duties or following the instructions of his or her employer, the employer is exclusively entitled to exercise all economic rights in the computer program, unless otherwise agreed. ${ }^{77}$ Out of consideration for academic freedom, this should not, however, apply to software programmed during free and individually guided research insofar as the rights remain exclusively with the employed/tenured scientist, while the universities, etc. are dependent on an explicit granting of exploitation rights. ${ }^{78}$

\subsection{Contract law and databases}

As mentioned, a distinction must be made with respect to scientific databases. The original rightsholder in a collection or database work is the one who undertakes the selection or arrangement of the elements as a personal intellectual creation - as a rule, the editor. ${ }^{79}$ His or her contractual legal relationship to the publisher follows the same principle valid for works of scientific literature and representations. Thus, the editor has the power with respect to his or her intellectual creation of whether to grant an exclusive right or to select an open access model.

The sui generis right of database makers, however, originates in the hand of the investor, for example, a scientific publisher. Consequently, no contractual protection provisions exist to the benefit of the weaker author. Rather, the database maker acquires exploitation rights from the scientific author in the individual works contained in the database. The database maker then licenses all derived exploitation rights and original rights in the database to an institutional (for example, a university) or individual licensee. As a rule, the contract only permits the reproduction (downloading and printing) of database contents for personal scientific purposes. A more extensive exploitation, in particular in the form of further making available to the public or editing of

77 Article 69b, Copyright Act.

78 Dreier, in: Dreier \& Schulze (supra note 36), Article 69b, Copyright Act, marginal note 7.

79 Rehbinder \& Peukert (supra note 3), marginal note 340. On the acquisition of exploitation rights in scientific collections through university employers, see subsection 2.1 above. 
database contents is, as a rule, not included in the licence and thus constitutes an infringement. The boundaries of permitted exploitation limitations in database licence contracts result primarily from consumer protection law and more precisely the General Terms and Conditions Act. Accordingly, the standard contract terms of scientific publishers may not be unusual and may not place the licensee unduly at a disadvantage contrary to the dictates of good faith. ${ }^{80}$ However, as copyright legalises and promotes the maximum control over database content up to and including a pay-per-click model, such restrictive contract terms are in principle valid. ${ }^{81}$

\section{Criticism of current copyright in scientific works}

\subsection{The digital dilemma in the sciences}

'Copyright increasingly falls short in its function with respect to the production of scientific works. ${ }^{\prime 82}$ This statement serves as an example of the widespread criticism of current copyright in scientific works.

This criticism begins with the argument that the logic of copyright deviates fundamentally from the communication conditions and norms within the scientific community. ${ }^{83}$ Generally, scholars do not publish because of the prospect of earning royalties; rather, they publish because of intrinsic motives and the acquisition of reputation, which is monetised indirectly. Copyright turns scientific communication to a large extent into an exclusive, marketable commodity, which as a single, isolated element ('work') is individually assigned to one specific person ('author') and is only available according to the stipulation of the potential buyer's ability to pay. Scientific communication, on the other hand, in principle proceeds in a non-enclosed communication context, characterised by preferably complete references to the state of research (quotation), openness, universality, comprehensiveness and collaboration. The individual results, at least in the form of raw data, findings and theories, are viewed by the scientific community as being a public good, belonging to everyone and no one.

80 Sections 305, 307, German Civil Code; and Rehbinder \& Peukert (supra note 3), marginal note $1157 \mathrm{ff}$.

81 Rehbinder \& Peukert (supra note 3), marginal note 1171. However, by virtue of a special provision, contractual agreements with which, among other things, the usage of non-essential portions of a database are prohibited (Article 87e, Copyright Act) as well as the contractual exclusion of legally permissible uses of protected computer programs for the purpose of making backup copies, for test purposes and decompilation are null and void (Article 69g(2), Copyright Act).

82 Hilty (supra note 49), p. 179.

83 In detail Peukert, Das Verhältnis zwischen Urheberrecht und Wissenschaft: Auf die Perspektive kommt es an!, 4 JIPITEC p. 142 ff. (2012), with further references. 
These differences have always existed. But in the age of book printing, it was necessary to accept them if the transfer of knowledge was to be organised as a decentralised market. Publishers assumed the technologically and organisationally formidable task of spreading scientific findings. Since the first Copyright Act of 1710, the publishers' business model has been based on the exclusive rights that were transferred or granted to them by scholars. This legal exclusivity promised profits and created an incentive to enter the scientific publishing market, which was in turn conducive to the degree of distribution of science and its communication conditions within the bounds of technical possibility. The 'content' of scientific work thereby remained copyright-free.

Digitalisation and the Internet have fundamentally changed the original conditions of traditional scientific publishing systems. Henceforth, scientists are able to undertake the representation and global distribution of their findings themselves; a traditional knowledge broker is, in principle, no longer necessary. Nevertheless, in the 1990s, copyright and with it the exclusive marketing model, were extended to digital networks. The business model of access-controlled databases made possible by copyright, which as mentioned conveys total control over scientific information, persists here. This creates the digital dilemma in copyright of scientific works: digitalisation allows maximum access and at the same time maximum control. ${ }^{84}$

This general conflict manifested itself around the turn of the century in the so-called 'journal (price) crisis' ${ }^{85}$ An ever-decreasing number of publishers active specifically in the science, technology and medicine (STM) segment demanded ever-expanding database packages, consistently with ever-higher prices, which forced libraries to cancel subscriptions to other journals and monographs. The Internet's promise of guaranteeing comprehensive, global access, turned virtually into the opposite. A growing digital gap emerged between those who were able to benefit from a campus or national licence and those situated outside of academic organisations and located generally in the southern hemisphere who had to do without access.

The behaviour on the part of publishers in this respect, however, unequivocally pursued the logic of the database model made possible by copyright: the more content that is made available, the more dependent researchers are on access, and the higher the prices become to offer still more content, and so forth. The more this price screw was turned, the clearer an atypical value chain became from a copyright perspective: the public sector finances the production and for the most part, the representation and quality

84 See in general Peukert, Das Urheberrecht und die zwei Kulturen der Online-Kommunikation, GRURBeil. 2014, pp. 77-93.

85 See with further references, for example, Hilty (supra note 49), p. 183 ff.; Brintzinger, Piraterie oder Allmende der Wissenschaften?, 38 Leviathan pp. 331, 332 ff. (2010). 
control (peer reviewing) of scientific findings, which are subsequently assigned from scientists to publishers, who then license back the content to publicly financed libraries.

\subsection{Suggested solutions}

As a reaction to this situation, which is increasingly seen as untenable even among academics, essentially two approaches are under consideration. These envision either changing scientific substantive law or they advocate in different forms that publicly financed research findings be made available to the public through the principles of open access.

\subsubsection{Changing substantive copyright law}

The most radical copyright-related approach is found in US draft legislation from 2003 in which the US Copyright Act would have been changed to the extent that 'copyright protection [...] is not available for any work produced pursuant to scientific research substantially funded by the Federal Government' ${ }^{86}$ Meanwhile, this 'Public Access to Science Act' failed to pass the initial hurdles of the US legislative process and has not been taken up again since. One likely reason is that abolition of copyright in scientific works is incompatible with international law conventions on copyright. ${ }^{87}$

A discussion of copyright in scientific works is therefore concentrated on an expansion of scientifically related limitations to copyright - in other words, on additional legal usage permissions. Discussions along these lines are taking place at the World Intellectual Property Organisation (WIPO) on an international law agreement in the interest of education and the sciences, so far without even coming close to an international consensus. ${ }^{88}$ At national level in Germany, committees of the Federal Parliament and Federal Assembly have called for the introduction of a 'broader and more general education and science limitation' ${ }^{89}$ In the literature it has been suggested that written works

produced within the framework of teaching and research activities financed primarily by public funds and published in periodicals should be available

86 H.R.2613 Public Access to Science Act, 108th Congress (2003-2004), http://thomas.loc.gov/cgi-bin/ query/z?cl08:H.R.2613.

87 See supra note 1 .

88 See http://www.wipo.int/copyright/en/limitations/index.html.

89 See BR-Drucks. 737/1/12 from 5.12.2012, p. 2; further the recommended decision and report of the Judiciary Committee of the German Lower House from 4.7.2007, BT-Drucks. 16/5939, p. 26 ff.; the Third Preliminary Report of the Investigative Commission, Internet und digitale Gesellschaft [Internet and the Digital Society] - Copyright, 23.11.2011, BT-Drucks. 17/7899, 21; De la Durantaye (supra note 21), p. $191 \mathrm{ff}$. 
to the public for purposes of access to information for the first six months following their initial publication, [...] to the extent that this is necessary for the pursuit of non-commercial purposes. ${ }^{90}$

According to another draft,

the use of a published work through public intuitions, who have been assigned tasks in the areas of education, sciences and culture [...] is permissible insofar as this is justifiable within the scope of their duties and in the pursuit of noncommercial aims [...] within the framework of 1. teaching and research, 2. advanced training and further education, and 3. documentation, conservation and preservation. ${ }^{91}$

Proposals for a general education and scientific limitation follow a similar direction, permitting, among others, uses 'for purposes of scientific research' being specified through legal examples. ${ }^{92}$ The permitted use should, in each case, trigger a right for remuneration, which is to be asserted by a collecting society.

The reservation in favour of non-commercial scientific use in all of these proposals takes the requirements of the EU InfoSoc Directive into consideration. ${ }^{93}$ This restriction is considered problematic to a certain extent because commercial research in businesses is also dependent on comprehensive access. A corresponding change to European copyright is therefore also necessary with respect to a reorganisation of legal protection for technical protection measures, which should no longer enjoy a preference over limitations to copyright. ${ }^{94}$ The European Commission would also like to improve the copyright-related conditions for commercial and non-commercial research, in particular concerning text and data mining. ${ }^{95}$

The proposals on the expansion of copyright-related limitations have in common that the exclusive right in scientific works with respect to certain uses is reduced to the author's remuneration right. Public research that is not commercially oriented and educational institutions would be authorised, and

\footnotetext{
90 Hansen, Zugang zu wissenschaftlicher Information - alternative urheberrechtliche Ansätze, GRUR Int. 2005, pp. 378, 383 ff.

91 Pflüger, Positionen der Kultusministerkonferenz zum Dritten Gesetz zur Regelung des Urheberrechts in der Informationsgesellschaft - 'Dritter Korb', ZUM 2010, pp. 938, 944.

92 De la Durantaye (supra note 21), p. $213 \mathrm{ff}$.

93 See Article 5(3) lit. a InfoSoc Directive 2001/29/EC (supra note 44).

94 Reichman \& Okediji (supra note 43), pp. 1432 ff. and 1440 ff. (also for scientific exploitation for subsequent commercial use).

95 European Commission, Strategy for a Digital Single Market for Europe, COM (2015) 192 final, 6.5.2015, p. 8.
} 
at the same time liable, to pay. Their offerings would nevertheless compete with publishers' access-controlled databases.

Another approach pursues models of compulsory licences ${ }^{96}$ or an obligation to contract. ${ }^{97}$ Through these instruments, publishers would be compelled to open up their databases to competitors, who may then offer this scientific information in a differently edited form, so that a price competition between numerous commercial database providers, who essentially offer substitutable products, would arise. The desired effect would be, on the one hand, lowering of prices for scientific databases, and on the other, an increased incentive for publishers to edit and network scientific content optimally.

Both the proposals favouring broad scientific limitations and the approaches just discussed ultimately result in a situation where scientific works would no longer exist exclusively in access-restricted publishers' databases. Instead, an additional source of information would be available. Both conceptions, however, differ with respect to the question of whether this additional source is a freely available server of public education and research institutions (a limitations solution) or a DRM-protected database of one or more commercial 'information brokers' (a compulsory licence model). While the advocates of a broad scientific limitation above all seek to guarantee unhindered access to scientific information, the advocates of a compulsory licence or an obligation to contract worry no less about the structuring and processing of an otherwise overwhelming flood of data.

All of the abovementioned proposals, however, encounter very considerable political, in addition to legal reservations. Publishers in particular argue that the instruments of the critics impair the 'normal exploitation' of protected scientific subject matter in the form of an exclusive database model. Such a legislative intrusion into the (derived) copyright-related exclusivity in the digital environment is incompatible with relevant international and European guidelines. ${ }^{98}$ These objections are, at any rate, justified insofar as digital copyright serves precisely the purpose of providing authors and their publishing partners with full exclusivity, up to and including a pay-per-click

96 Hilty, Renaissance der Zwangslizenzen im Urheberrecht? - Gedanken zu Ungereimtheiten auf der urheberrechtlichen Wertschöpfungskette, GRUR 2009, pp. 633, 641 ff. With reference to access rights according to media law, see also Peifer, Wissenschaftsmarkt und Urheberrecht: Schranken, Vertragsrecht, Wettbewerbsrecht, GRUR 2009, pp. 22, 28.

97 Krujatz (supra note 71), pp. 279 ff. and 280 (authors and publishers as the owners of an exclusive exploitation right in a scientific literary work are obligated 'to grant a right of reproduction, making available to the public and distribution for the purpose of further publication in another manner than the first publication to every other intermediary on equitable conditions,' as long as the source of the first publication is given).

98 See Articles 9(2), Bern Convention, 13 TRIPS, 10 WCT, 16(2) WPPT, 5(5) InfoSoc Directive 2001/29; and for interpretation, see Senftleben, Copyright, limitations and the three-step test, 2004. To the contrary, however, see Hansen (supra note 90), p. 384 ff.; De la Durantaye (supra note 21), p. 204 ff. 
structure. Proposals which hollow out the centre of this business model are indeed therefore incompatible with prevailing international and European copyright law. ${ }^{99}$

Ultimately, the structural weakness of all the proposals addressing copyright needs to be pointed out. As with copyright itself, the limitations, compulsory licences and obligations to contract only apply in the territory of those legislatures that have enacted these regulations. ${ }^{100}$ A regulation in the interest of digital science limited to and therefore only implemented within the territory of Germany or the EU would miss the inherent global character of scientific communication from the outset. Specifically, the gap between north and south would remain. ${ }^{101}$

\subsubsection{Open access}

The open access (OA) movement seeks to avoid precisely these deficits in a genuine copyright-related solution. It pursues worldwide technically and legally unrestricted access to scientific information, without the necessity of modifying substantive copyright law. ${ }^{102}$

Relationship to copyright. The copyright-related starting point of the OA movement is the recognition that it is left to the individual rightsholder whether and how his or her right is exercised. Copyright in no way forces scholars, as the original rightsholders, into an exclusive form of exploitation.

Rather, scholars may decide to release their work either completely or with certain caveats. The vast majority of copyright laws in the world permit a complete waiver of rights so that the work enters the public domain. In this respect, even the restrictive German copyright law explicitly stipulates that an author may grant an unremunerated, non-exclusive exploitation right for every person. In addition, there is the option to agree to the act of exploitation in an informal and implied manner. The author may reserve certain rights, in particular with respect to direct commercial exploitation and the author's moral rights. ${ }^{103}$ Consequently, copyright does not stand in the way of an immediate, complete and worldwide shift in scientific communication to an OA first publication - if the authors concerned so desire.

99 Correct in this respect, Peifer (supra note 96), p. 25; in detail on international law, Peukert, A bipolar copyright system for the digital network environment, 28 Hastings Communications e Entertainment Law Journal (Comm/Ent), pp. 1-80 (2005).

100 In detail, Peukert, Territoriality and extraterritoriality in intellectual property law, in: Handl, Zekoll \& Zumbansen (eds), Beyond Territoriality: Transnational legal authority in an age of globalization, 2012, pp. 189-228.

101 To the contrary, Hilty (supra note 96), p. 638 (open access is only a territorial solution).

102 See in addition the contributions by Herb and by Ball in this volume. Further, German UNESCO Commission, Open Access - Chancen und Herausforderungen, 2007.

103 See section 2.2 above. 
And not least, copyright may be exercised in such a flexible way that a publisher may, if necessary, be granted an exclusive exploitation right for a specific period of time, but the author reserves the right to make the work available to the public for non-commercial purposes, either himself or herself or through others at the same time, time-delayed, and in the same or a differing format. ${ }^{104}$ In other words, copyright also permits a co-existence of the publisher and OA models. From this perspective, copyright guarantees above all decision-making power on the part of the scientist/author for one or the other form of scientific publication.

However, should there be an unlimited granting of exclusive online and reproduction rights in favour of a publisher, the author, in the exercise of his or her personal autonomy, has waived the right to opt for open access. Should the work then nevertheless and without the publisher's authorisation be made available on the Internet, the author would violate both the publishing contract and the publisher's exclusive exploitation right. ${ }^{105}$ In this case, the author personally commits an act of copyright infringement. This scenario is considered a relevant obstacle to the broader expansion of so-called 'green $\mathrm{OA}^{\mathrm{A}}$, as by no means do all publishing contracts permit a parallel OA publication of the manuscript from the outset. Many scholars lose out on this option in that they sign publishing contracts unmindfully or, if need be, perceive the negotiation of an exception in favour of a delayed open access as pointless or shy away from the effort altogether.

This lock-in effect should be breached through the mandatory secondary publication right according to Article 38(4) Copyright Act. According to this, the author of a scientific contribution - which is the result of a research project publicly funded by at least $50 \%$ and which has appeared in a collection which is published periodically at least twice per year - has the right, even if he or she has granted the publisher or editor an exclusive right of use, to make the contribution available to the public in the accepted manuscript version upon expiry of 12 months after first publication, unless this serves a commercial purpose, and where the source of the first publication is indicated. The purpose of this regulation is to place scholars who received public financing in the position to make their contributions available to the public without remuneration in the manner of downstream green open access. Falling within the ambit of the provision are not only contributions produced in publicly sponsored, third-

\footnotetext{
104 Article 32(3), sentence 2, Copyright Act. Ultimately, the author retains a non-exclusive exploitation right in the work. So that the reservation becomes contractual subject matter, the author must declare the reservation upon submission of the manuscript or change a differently worded publishing contract either through deletion or amendment. Agreement on the part of the publisher to the changed terms may also be implied should the publisher publish the work as agreed without addressing the reservation again (see section 151, first sentence, no. 2., Alt. German Civil Code).

105 See Schulze, in: Dreier \& Schulze (eds) (supra note 36), section 31, Copyright Act, marginal note 56.
} 
party-funded projects or at extra-university research institutions, but the entire research output of state universities. ${ }^{106}$ The regulation has mandatory character insofar as the right of secondary publication, as far as the publisher is concerned, may not be waived. And still it remains a personal autonomous exercisable right of the publicly financed scientific author, who is not obligated to undertake a downstream OA publication. The voluntary principle of open access is not contested by the mandatory right of secondary publication; rather, it is safeguarded with respect to stronger negotiating partners, such as publishers. ${ }^{107}$ The author's disposition authority is restricted; however, not the scope of protection of copyright. The proposal is therefore correctly seen as unproblematic in terms of international, union and constitutional law. ${ }^{108}$

The obligation for open access for publicly financed research findings. The mandatory right of secondary publication has the effect that exclusive publishing rights, as an obstacle for green OA, expire after certain embargo periods. Especially in the humanities, significant reservations exist with respect to OA, which, according to the comments so far, have their roots in scientific systems themselves rather than in copyright. ${ }^{109}$ Even if all publicly financed scholars were to make their contributions available in downstream green OA, this would lead to a co-existence of $\mathrm{OA}$ and publishing systems. As this condition is viewed as unsatisfactory, there are increasing calls for the establishment of mandatory OA requirements across the board as the primary form of publication. Its implementation would result in a situation where in addition to the production and representation, the propagation of scientific findings would be transferred into the publicly financed academic system, while publishers would withdraw from the value chain for scientific publications. ${ }^{110}$

At the height of the journal price crisis more than 10 years ago, a proposal was put forward to change Article 43, Copyright Act to the effect that authors employed by a university would be obligated to offer their work, produced within the framework of their teaching and research activities, for publication to the university - where necessary non-exclusively. Only when a work was not claimed by the institution within a period of two months would the scholar be entitled without restriction to the exploitation right according to copyright. ${ }^{111}$

\footnotetext{
106 In detail, Peukert, in: Schricker \& Loewenheim, $5^{\text {th }}$ edn, 2016, section 38, marginal note 45 ff. with further references.

107 Hansen (supra note 90), p. 382.

108 Hansen (supra note 90), p. 382.

109 See Taubert \& Weingart, 'Open Access' - Wandel des wissenschaftlichen Publikationssystems, in: Sutter \& Mehler (eds), Medienwandel als Wandel von Interaktionsformen, 2010, pp. 159, $170 \mathrm{ff}$.

110 On this ultimately decisive question, Brintzinger (supra note 85), p. 344; Finch Group Report, Accessibility, Sustainability, Excellence: How to expand access to research publications, 2012, http://apo.org.au/ sites/default/files/Finch-Group-report-FINAL-VERSION.pdf, p. 11.

111 Pflüger \& Ertmann, E-Publishing und Open Access - Konsequenzen für das Urheberrecht im Hochschulbereich, ZUM 2004, pp. 436, 441 ff.
} 
This solution, based on the German Act on Employees' Inventions, ${ }^{112}$ would have the effect that the decision regarding OA publication would no longer lie with the scholar but rather with the public employer. Current reservations with respect to OA would be overturned by shifting the authority of consent to the academic organisation. Even if a university were to claim only a nonexclusive exploitation right in the relevant work, it would be entitled to the decision of whether and how this right is exercised. The scientific author would have to push for an adequate exercise of the exploitation right by appealing to the fiduciary duty from the employment contract. This proposal was met with unanimous rejection on the part of OA proponents. ${ }^{113}$ The two-month reservation period with regard to the assertion of exploitation rights by itself would present an unconstitutional intrusion in the heart of personal academic freedom in the form of a free decision on first publication. ${ }^{114}$

An alternative model does not begin with the individual scholar and his or her copyright, but rather with the general institutional and academic law conditions of the publication industry. ${ }^{115}$ The starting point would be a regulation in university law in which articles and monographs produced in the context of teaching and research activity funded by at least 50\% public financing would be published first according to OA principles. ${ }^{116}$ This legal framework would have to be rendered more precisely in the internal statutes and charters of universities extending into work and project-financing contracts in terms of an obligation in principle for an OA first publication. ${ }^{117}$ These obligations would be sanctioned in the qualification, appointment and evaluation statutes, which from a certain cut-off date would only recognise contributions first published

112 See Article 42, Act on Employees' Inventions.

113 Hansen (supra note 90), p. 379 ff.; Steinhauer, Das Recht auf Sichtbarkeit, 2010, p. 31, but then considering id., 72.

114 See Constitutional Court, case no. 1 BvR 174, 178, 191/71 among others, 1.3.1978, BVerfGE 47, 327, 381 ff.; Schmidt-Assmann, Wissenschaft - Öffentlichkeit - Recht, in: Dreier (ed.), Rechts und staatstheoretische Schlüsselbegriffe: Legitimität-Repräsentation-Freiheit, 2005, pp. 67, 77.

115 See in detail, Peukert, Ein wissenschaftliches Kommunikationssystem ohne Verlage - zur rechtlichen Implementierung von Open Access als Goldstandard wissenschaftlichen Publizierens, in: Grünberger $\delta$ Leible (eds), Die Kollision von Urheberrecht und Nutzerverhalten im Informationszeitalter, 2014, pp. 145 ff.

116 On the whole, this corresponds with the so-called golden road to OA, which favours the first publication of a scientific contribution in an OA journal, and likewise the first publication of other scientific writings such as monographs, collections, etc. in an OA form.

117 Tendencies in this direction are found in particular in the UK in reaction to the Finch Group Report (supra note 109). However, the intended obligatory OA principles are conceived to enable a coexistence between OA and publishers, where either a first publication is reserved for hybrid OA journals financed by publishers or secondary publication after observation of an embargo period; see Higher Education Funding Council for England, HEFCE statement on implementing open access, http://www.hefce. ac.uk/news/newsarchive/2012/statementonimplementingopenaccess/; RCUK announces new Open Access policy, http://www.rcuk.ac.uk/media/news/2012news/Pages/120716.aspx. Similar requirements also apply to research support by federal agencies in the United States; see Executive Office of the President, Office of Science and Technology Policy, Expanding Public Access to the Results of Federally Funded Research, http://www.whitehouse.gov/sites/default/files/microsites/ostp/ostp_public_access_ memo_2013.pdf. 
in open access as capable of consideration. Exceptions would be granted only in consideration of special academic interests - such as participation in an international collection released by a publisher or for international students.

From an infrastructural and institutional perspective, such a realignment of systems of scientific communication would be very long on requirements. ${ }^{118}$ Moreover, the question concerning constitutionality presents itself again. Scientific publishers would be massively affected, because they would be practically taken out of action as the primary intermediaries of publicly financed science. However, a fundamental right to the preservation of a customer base and business model does not exist; ${ }^{119}$ occupational freedom may be restricted in the interest of an overriding public interest - in this case, the access to publicly financed research findings. ${ }^{120}$

The decisive issue, on the other hand, would be the question of whether a fundamental and far-reaching sanctioning of an OA obligation is compatible with scientific freedom. To some extent, such an obligation has been categorised as an unconstitutional intrusion into the heart of scientific freedom, which protects not only the if and when, but also the how and where of a publication. ${ }^{121}$ According to another view, Article 5(3) of the German Constitution does not present an obstacle for a realignment of the basic conditions of scientific communication to open access, should this be desired by the legislator and academic institutions. ${ }^{122}$

Regarding the latter view, it should be mentioned that the individual decision of when and in what media a contribution is published, remains unchanged exclusively with the scholar. The restriction of personal choice to OA media could be justified by the goal of the preservation and support of the functional capacity of universities and the protection of other subjects of fundamental rights, in particular students ${ }^{123}$ - for their part protected by

118 Worthy of particular note are the requirements to replace the journal impact factor with author- or article-based evaluation criteria; to adapt the citation rules in OA publications; to establish additional OA journals and subject-specific repositories, such as for German-language jurisprudence; to ensure sufficient peer reviewing in an OA system; to change the academic conventions to the effect that making available to the public a contribution in a repository is equivalent to the final 'printing proof'; and certainly not least to bid farewell to the notion that academic articles must be published in a 'journal' - and not for example in an institutional series of a faculty. See in more detail, Peukert (supra note 115), p. $163 \mathrm{ff}$.

119 Constitutional Court, case no. 2 BvO 1/65, 18.3.1970, BVerfGE 28, 119, 142; Constitutional Court, case no. 1 BvR 35/82, 31.10.1984, BVerfGE 68, 193, 222 ff.; BGH MMR 2007, pp. 704, 705 (a competitor has no right to the preservation of his customer base).

120 See for example, Constitutional Court, case no. l BvR 459 u. 477/72, 2.10.1972, BVerfGE 36, 47, 59.

121 Rieble, Autorenfreiheit und Publikationszwang, in: Reuß \& Rieble (eds), Autorschaft als Werkherrschaft in digitaler Zeit, 2009, pp. 29 ff.

122 Bäuerle, Open Access zu hochschulischen Forschungsergebnissen? Wissenschaftsfreiheit in der Informationsgesellschaft, in: Britz (ed.), Forschung in Freiheit und Risiko, 2012, pp. 1, 11 ff., 14.

123 See Constitutional Court, case no. 1 BvR 1289/78, 7.10.1980, BVerfGE 55, 37, 68 ff.; Constitutional Court, case no. 1 BvR 1864/94, 26.2.1997, BVerfGE 95, 193, 212; Constitutional Court, case no. 1 BvR 
Article 5(3), first sentence of German Constitution. For this, free scientific activity must continue to be possible and safely practised under the application of the new framework for the publishing industry; ${ }^{124}$ an obligation under academic law for open access would, however, be unconstitutional if this would structurally endanger free academic activity and accomplishment. ${ }^{125}$ In this respect, the Constitutional Court grants the legislator the competence to assess and freedom to predict. ${ }^{126}$ But before these indicated and far-reaching changes to the internal norms of scientific communication come into effect, in particular concerning the selection of texts and the distribution of reputation in an OA system, an obligation to first publish in open access with the exclusion of publishers must be seen as being scientifically inadequate and for this reason unconstitutional. ${ }^{127}$ Finally therefore, this model only confirms that a fundamental change in systems of scientific communication can only be carried out step-by-step ${ }^{128}$ within the sciences themselves rather than being imposed from the outside through the law.

911/00 among others, 26.10.2004, BVerfGE 111, 333, 353 ff.; Constitutional Court, case no. 1 BvR 462/06, 28.10.2008, BVerfGE 122, 89, 114.

124 Constitutional Court, case no. 1 BvR 424/71, 29.5.1973, BVerfGE 35, 79, 116 ff.; Constitutional Court, case no. 1 BvR 748/06, 20.7.2010, BVerfGE 127, 87, 115 ff.; Constitutional Court, case no. 1 BvR 911/00 among others, 26.10.2004, BVerfGE 111, 333, 355; Constitutional Court, case no. 2 BvL 4/10, 14.2.2012, BVerfGE 130, 263 marginal note $159 \mathrm{ff}$.

125 Constitutional Court, case no. 1 BvR 911/00 among others, 26.10.2004, BVerfGE 111, 333, 355; Constitutional Court, case no. 1 BvR 748/06, 20.7.2010, BVerfGE 127, 87, 116; Constitutional Court, case no. 2 BvL 4/10, 14.2.2012, BVerfGE 130, 263 marginal note 160; Schmidt-Assmann, Die Wissenschaftsfreiheit nach Art. 5(3 GG als Organisationsgrundrecht, FS Thieme 1993, pp. 697, 701.

126 See Constitutional Court, case no. 1 BvR 424/71, 29.05.1973, BVerfGE 35, 79, 117; Constitutional Court, case no. 1 BvR 911/00 among others, 26.10.2004, BVerfGE 111, 333, 356; Constitutional Court, case no. 1 BvR 748/06, 20.7.2010, BVerfGE 127, 87, 116; Constitutional Court, case no. 1 BvR 911/00 u. a., 26.10.2004, BVerfGE 111, 333, 355 ff.; Constitutional Court, case no. 2 BvL 4/10, 14.2.2012, BVerfGE 130, 263 marginal note 160.

127 Peukert (supra note 115), p. 171.

128 Regarding the time frame see Luhmann, Die Wissenschaft der Gesellschaft, 1990, p. 600 (it has taken respectively 200 or more years until society became accustomed to the alphabet and printing - an 'incredibly' rapid change). 



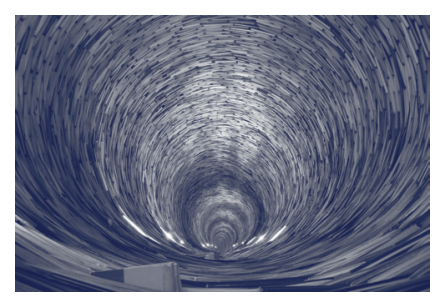

PART 3

Visions 



\section{Visions Concerning the Future of Publishing in Science}

In academic publishing, the interests of several actors are involved. On the one hand, there are the publishing companies, which are oriented towards economic efficiency while also acting as service providers for the scientific community. On the other hand, there are the libraries whose main task of providing literature is subject to rapid change due to the increased significance of digital publication. Moreover, there are the scientists who strive to disseminate their research results to the internal and external public in an efficient manner and consequently, to gain reputation. In the course of the work by the IWG, it frequently became clear that academic publishing is diverse and that perspectives about ideal conditions in the mid to long term differ strongly. These recommendations for the future of scholarly publishing take this into account and represent a carefully balanced compromise between what some consider the minimum requirements and what others are barely willing to accept. This compromise character has led us editors to conclude this volume with visions about the future of the communication system. The authors were able to write down their hopes, ideal conditions and future perspectives freely. The results are very different texts with heterogeneous goals, disciplinary references and time horizons. In summary, there are some points on which there is consensus, for example, with regard to the dynamics of change and their causes. There is controversy, however, about the evaluation of the development and about what should be maintained from the current system and which goals we should pursue with respect to the communication system. The visions therefore represent preliminary results of a science-internal discussion about issues concerning publishing. This discussion will need to be continued due to the constant development of technological opportunities at many locations and at different levels of science.

The visions begin with the contribution by Martin Grötschel who describes his dream of a digital world of information within publicly funded science with the term 'open science'. His hope for public accessibility of all research results 
- from the surveying of data to the final publication - is expressed in a list of measures that could help to realise this dream eventually.

Reinhold Kliegl's contribution also takes up the notion of 'open science' with the following considerations: dynamic progress in the development of knowledge is always the result of an interaction between competition and cooperation, which in the past has lost its balance. A new balance and a new culture of dealing with mistakes could be found in science if all research results - such as research data or software - would be freely accessible prior to publication.

The recommendations for the future of scholarly publishing are the point of reference for the critical chapter by Volker Gerhardt. Reflecting on - in his opinion - the 'techno-pragmatic optimism of the recommendations' and their preference for electronic formats, he weighs the pros and cons of digital and printed publication and determines the role the printed book can also have in the future.

The contribution by Peter Weingart deals with a pathological development in the area of gold open access - the so-called 'predatory journals', whose emergence has a lot to do with methods of the new public management. Starting from the analysis of the status quo and the currently visible growth tendencies, he develops a dystopian and a utopian future scenario of academic publishing.

The visions conclude with a contribution by Niels Taubert who focuses on the future of the often criticised anthology, the most widespread format for the publication of research articles in German-speaking sociology. Taubert deals with the questions of why the anthology should be maintained and how it can be translated into a digital and freely accessible format in future. 


\section{Electronic Publishing, Open Access, Open Science and Other Dreams}

Martin Grötschel

It may seem a bit egomaniacal when I describe how I envision not only scholarly publishing in the future, but also outline further considerations on open access and open science, which go beyond the actual intention of this anthology (Taubert \& Weingart 2016). In this article, one should expect extensive data analyses of the publication behaviour in the sciences (which in this article also include the humanities and social sciences) and prognoses derived from them. However, this has already been done in a detailed manner in other contributions to this volume. I therefore take the liberty to state my opinion, which is based on many years of dealing with this issue, subjectively. I will point out basic characteristics and make general considerations, but I will not focus on the precise roles of the players in this field, the concrete design of the involved information technology, or details concerning the legal framework.

Previous history: For 25 years, I have dealt with questions on academic publishing, the documentation of research and the representation of knowledge. I have done so not because of scientific interest, but because around 1990, several other scientists and myself, in particular scientists who dealt with information technology (IT) issues, became aware that there was about to be a period of change within publishing in general. Obviously, the development of this area was not to be left to the traditional actors - as failed policies/developments were already apparent then. Costs for journals and books exploded, and at the same time, IT made it possible to shift ever more editorial work to the authors and editors. Moreover, the visible opportunities of the rapidly developing information technologies for the improvement of supply of literature and knowledge representation were only hesitantly taken 
up by the 'players of the game' (for example, publishing companies, libraries, database providers). This made it necessary for scientists to speak out.

Thus, among other things, I headed a special information project of the German Mathematician's Association (DMV), supported by the Federal Ministry of Education and Research (BMBF) from 1992 on, and was cofounder and first chair of the IuK-Initiative of German scientific societies. This initiative started with mathematics and physics, then chemistry, computer sciences, electronic engineering, biology, psychology, pedagogy and social sciences joined. The successes were, however, infrequent because the inertia of the system was stronger than expected. During that time, I predicted the demise of many small and medium-sized academic publishing companies and the concentration of the market into a few publishing houses. Through funding measures, the BMBF tried to 'make the small publishers electronically fit'. This delayed the change but was useless in the end. In many disciplines, the concentration into few highly profitable publishing companies became reality. The process, however, has taken twice as long as I had thought at the time. The shift of publishing in general to libraries, universities and scientific societies, contrary to our hopes, did not take place.

My dream: The TELOTA Initiative (TELOTA is an acronym for The Electronic Life Of The Academy) of the Berlin-Brandenburg Academy of Sciences and Humanities (BBAW), which I initiated and led for ten years, began its work in 2001. Its goal was the development of tools with which research results of the Academy (primarily from the humanities) could be digitally documented and presented. At the time, there was still a lot of scepticism within the Academy. Back then, I presented my perspective on further developments in the article 'My digital dream'. The article begins as follows:

'You deal intensively with electronic information and communication', said one of the editorial staffers of the journal Gegenworte. 'Couldn't you provide us with your dream vision of the digital information world?' - 'That's very simple', I said. 'I want everything, immediately, anytime, anywhere available for free.' 'Isn't that a bit over the top?' - 'Maybe', I replied, 'but you asked me about my dream!' (Grötschel 2001: 10).

Through my own activities in publication, communication and information, I am actively involved in the realisation of my dream. For example, more than 20 years ago I began to make all of my scientific articles and books freely accessible via my website ${ }^{1}$ and other servers.

1 See http://www.zib.de/groetschel/publications/publications.html. 
I rediscovered the text of the speech I gave at the workshop on the strategic design of the TELOTA Initiative in the year 2000 and notice today that the present article repeats many of the claims I made back then. Some of it was utopia; some of it has by now been implemented by BBAW in general or specifically through particular BBAW projects. There is, however, still enough left to do for the future.

Fifteen years since the publication of 'My digital dream' is a long time, and the dream has not yet become a reality. It should be noted though, I called my brief statement 'dream' and not 'prognosis', and I intentionally did not mention a time frame. I knew, of course, that the dream would never come true in this radical form, and meanwhile I have also learned that, even for realising parts of it, many high obstacles have to be overcome.

Is it worth holding onto it? I continue to have this dream, and I will not abandon it because I am strongly convinced that this is the right goal of the scholarly publication system, and that everybody who intensively thinks about the function of science has to come to this conclusion as well. My dream has meanwhile extended significantly. The publication system in general has to offer more and has to be developed into a system of comprehensive documentation of research and knowledge. Open science is the true goal - more on this later.

Publicly funded science: Please note here, my remarks concern publicly funded science. I am far from suggesting behaviour or marketing guidelines to authors, journalists, musicians, filmmakers, and others who live off the publication of their works. Persons and institutions that finance research from their own resources and in their own interest can, of course, use their results in any way they want to. But government-funded research and research that is funded by non-governmental third parties and which is aimed at gaining general scientific insight should - in my opinion - be published in a way that I describe in this article.

Objectives of research and science: I cannot give an overview of the historical development of science and research here. Today, in almost every country, research (mostly connected to university teaching) is mainly financed by the state. The expectations and positions are diverse. Some scientists believe that the freedom of research enshrined in the Constitution (in Germany called Grundgesetz) gives them the right to do what they please. Others, in turn, feel obligated to put their area of expertise explicitly into the service of industry, economy or society. Some taxpayers are happy about basic new insights 'about the world' (such as the recent direct proof of the existence of gravitational waves), while the majority, on the other hand, expects the development of something useful and thus that all of our lives are in some way improved. There is no doubt that we scientists have always 'delivered' and contributed to the improvement of the quality of life, even if one considers that research 
results could also have and have had negative effects. Science always operates in a field of tension: academic freedom and ethical responsibility have to be balanced honestly. This also implies that the public needs to be informed about research results and their consequences.

Briefly put, this means: science serves to increase and improve information!

Eventually the goal is, of course, the creation of 'knowledge' in the sense of valid information. To elaborate this in detail would go beyond the scope of this chapter, though. If and how new or improved information can be employed or applied can be analysed scientifically; decisions about the use, however, are made in complicated political, social and economic processes.

Efficiency: An important goal (at least for me, since my scientific field of expertise is mathematical optimisation) is the improvement of the efficiency of research. I do not want to analyse questions that have already been solved. Rather, I want to have quick and cross-disciplinary access to existing and quality-assured literature and data that are relevant for my projects. I want to work temporally independent from the restrictions of others (for example, opening hours of libraries and archives). And I want to analyse material that seems relevant with IT tools in order to be able to decide quickly whether it is pertinent to my topic.

Basic convictions: At this stage, publishing in general comes into play. Do I keep new information a secret, do I delay its publication, in what form do I publish it, will I provide it to only a small, specialised or nationally limited circle of people, do I ask for money for my publication, do I claim property rights or will I make it freely accessible? Here the views diverge. Many factors emerge simultaneously in complex ways and they mutually interact. These range from a political position on altruism, fear of being cheated, vanity of persons and institutions, reputation and career advancement to profit maximisation. Everything that plays a role in 'normal life' does so here as well.

My basic position is very simple: as a scientist, I myself am paid by public funds and thus consider the results of my research a public good that needs to be made freely accessible to the public without any restrictions. For the first time in the history of humankind, this is now possible and I therefore advocate that it should be done.

There is a second reason. Like all scientists, I, too, would like my research results to be taken notice of by as many colleagues as possible. Contemporary information technologies extend reachability in ways that used to be inconceivable. Free access via the Internet enables quick access to literature and data for students and scientists throughout the world. Interested laypeople can inform themselves without obstacles (for example, difficult to obtain access to libraries or prohibitive sale prices), and scientists in economically disadvantaged countries are able to participate in the development. For me, 
it is hard to imagine that this is not enticing and that it does not dominate every discussion against this development. The open access (OA) movement has emphatically formulated these core issues in different declarations ${ }^{2}$ that have been signed by a large number of scientifically renowned institutions. All colleagues in my own scientific environment support this idea.

Search: Every active scientist is well versed in their own discipline. But even in related areas it has, in the current publication system, so far been difficult to inform oneself and to access relevant literature. I have experienced this in many practical projects in different fields of application of mathematics (for example, in the engineering sciences and economics). Due to my recent appointment to the presidency of the BBAW, my field of action has significantly broadened and I now have to become informed about many areas of research with which I previously had nothing to do. Personally, I now profit enormously from all that is immediately available via the Internet, anytime, anywhere and free of charge. However, the material could be organised in a better and more userfriendly way.

Open access: Declarations on open access have existed for more than 15 years, but many of the institutions that have signed them still have difficulties with their implementation. The situation is changing now. The European Union is a forerunner, ${ }^{3}$ and some German federal states (currently Baden-Württemberg, Berlin $^{4}$ and Schleswig-Holstein) have passed OA strategies and demand their implementation in concrete measures by their scientific institutions. This leads to discussions and planning activities, and ever more third-party funders demand the OA publication of results of research projects they funded. Whether green or gold is the right way or whether other OA forms of publication should be chosen, is discussed in detail in other parts of this volume.

Open data, open source and open science: Making data (open data) and algorithms (open source) publicly and freely available also increasingly becomes a focus of attention - not least due to the fact that the verifiability of published results is of increasing relevance. One simply no longer trusts each diagram in a publication and seeks security by testing it on one's own. Recently, for example, media reported that most results from 100 psychological studies that were published in well-reputed journals could not be replicated. Such findings, too, slowly open the way to what is called 'open science'. A working definition of this concept is as follows:

\footnotetext{
2 See for example, http://openaccess.mpg.de/Berliner-Erklaerung.

3 See http://ec.europa.eu/research/participants/data/ref/h2020/grants_manual/hi/oa_pilot/h2020-hi-oapilot-guide_en.pdf.

4 See http://www.parlament-berlin.de/ados/17/IIIPlen/vorgang/d17-2512.pdf.
} 
Open science is about disclosing all components of the scientific process and to present it in a transparent way through the Internet. More precisely: In open science, the entire process of scientific insight from the survey of data, the use of software, the kind of algorithmic processing and discovery, up to the interpretation should be documented comprehensively and made publicly available.

For me, open science is the actual goal! If one wants to make consistent use of the opportunities that digitisation provides, then science must be presented that way in the (hopefully not too distant) future.

There will not be a brief, precise and operable definition of this concept for all areas of research since the working methodologies and approaches in the different fields are too different from each other. In the open disclosure of the knowledge acquisition process and the associated information, for each discipline, different challenges and discipline-specific issues need to be taken into account. These include, among others:

- $\quad$ securing reproducibility and reusability;

- making publications, data sources, algorithms, software tools and interfaces technologically and legally available via the establishment of open discipline-specific information infrastructures;

- networking;

- financing of disclosure; and

- $\quad$ sustainable availability - taking data protection into account.

Compared to my digital dream, this open science dream is much more unrealistic, but to anyone engaged in the service of science, it is clear that it is worth taking every possible step with the goal of partially realising this dream.

Many initiatives demonstrate that open science is not just a lunatic idea. In the framework of the Open Knowledge Foundation Germany, a Germanspeaking open science working group was formed in Berlin in 2014, which presents the goals of open science in a mission statement. This is also done by the 'Digital Information' initiative of the Alliance of German Research Organisations in several position papers that appear under the objective ${ }^{5}$ of 'providing researchers with the best possible information infrastructure that they need for their research'.

In 2014, the Joint Science Conference (GWK) established the Council for Information Infrastructure (RfII), which in its first recommendations ${ }^{6}$ deals with

5 See http://www.allianzinitiative.de/start.html.

6 See http://www.rfii.de/de/index/. 
the structures, processes and the funding of the management of research data in Germany. The RfII commits itself in principle to the open science paradigm. The Global Young Academy presents information material and reports on open science on one of its websites. ${ }^{7}$ The European Commission is committed to open science, and presents its vision on a website. ${ }^{8}$ A working group implemented by the International Council for Science (ICSU), the InterAcademy Partnership (IAP), the International Social Science Council (ISSC), and The World Academy of Sciences (TWAS) has recently produced a document ${ }^{9}$ that deals with this issue. Explanations of diverse aspects of open science, open source, open knowledge and similar keywords can be found in Herb (2012). The Open Research Glossary ${ }^{10}$ is an extensive collection of terms and concepts and their explanation that are common in connection with this field.

Effects of open science: A description of all consequences of open science would go beyond the scope of this article. For the purpose of orientation, I will merely mention some important keywords.

Open science will produce massive data volumes (big data) like ubiquitous communication activities and production processes do. Big data can no longer be handled manually, but need to be processed, understood and used algorithmically. Data should not lie around unutilised but should be seen as raw or reusable material for innovation. Big data is not the end of theory but the beginning of new possibilities of insight. I mention only gene sequencing and combinatorial chemistry. And there are many unexplored domains to be investigated still.

One extremely important topic will therefore be machine learning, which is based on the tools of computer science and mathematics, but which - without special knowledge about the investigated datasets - will only provide insights with little significance. An important goal here is to derive causality from statistically observed correlation and to explain it theoretically. In addition, questions of technological and legal security, protection against forgery, data protection in general, etc. need to be taken into account. Here, significant scientific challenges lie before us.

Progress in this area has direct consequences on developments in the economy. This has been summarised under the keyword Industry 4.0, and will supposedly lead to entirely new supply chains and production processes. The same is true for e-government, an area in which Germany has a lot of catching up to do.

\footnotetext{
7 See http://globalyoungacademy.net/activities/open-science/.

8 See http://ec.europa.eu/research/openscience/index.cfm.

9 See http://www.icsu.org/science-international/accord/open-data-in-a-big-data-world-short.

10 See https://figshare.com/articles/Open_Research_Glossary/1482094.
} 
The free access to data can promote the involvement of scientifically interested citizens who, for example, may come to new insights due to a different perception of the given data (citizen science). This will not be desirable or advisable everywhere (nuclear research, gene technology) but, for example, hobby astronomers discovered extra-solar planets due to the free availability of data from the Kepler mission. ${ }^{11}$

Obstacles: After this excursion to the 'huge issues', let us now return to the small 'digital dream'. Why does not all that I hope for take place? Unfortunately, it is difficult to change traditions. In all the promises I mentioned, there are also always persons and groups of people who have something to lose. In the scholarly publication system, there are several groups that will suffer different losses: power, influence, jobs, business areas, and profits are at stake. Moreover, many of those who will be concerned by the changes are strong players in the publication system. Within this, a number of oligopolistic or monopolistic areas have been established which will be particularly hard to break up. Much has been written about this. I do not want to report again about the delaying tendencies that, first of all, come from the publishers. However, some libraries, editors of journals, authors, scientific societies or individuals also play a role in the delay of the transformation. In spite of this, I still see the sun rising because currently more and more traditionalists change their minds.

Strong OA mandates: The transition could be sped up through governmental measures. One possibility would be to make it an obligation for every researcher receiving public funds to publish their results open access (strong OA mandate). In this volume, Peukert and Sonnenberg argue that this would in principle not violate the freedom of research guaranteed by constitutional law, but the technological prerequisites for such a strong intervention in the existing system are not yet given. This could be solved, but it will take time and will most likely meet a lot of opposition.

E-print-archives and e-journals: From my perspective, the most important task is to conduct efforts of persuasion. What happens in physics, mathematics, computer science and related disciplines via the e-print service $\operatorname{arXiv}^{12}$ is surely a role model. Preprint versions can (after an initial check) be deposited on the arXiv server to become generally accessible, and they may undergo the usual process of review afterwards. After a positive evaluation, they can be found in independent journals or overlay journals as evaluated publications. This entire process is transparent and can be cited. Similar procedures could be established in all disciplines or at institutional, regional or national level. This

11 See http://kepler.nasa.gov/.

12 See http://arxiv.org/. 
would provide an important basis for the electronic publication system of the future, and indeed, such a development is already taking place.

So much has been written about the development and dissemination of electronic journals (e-journals) that I do not wish to repeat it. I would, however, like to point out a welcome development. Open Journal Systems (OJS) is open source software for the administration and publication of academic journals, which is continuously being developed further by different institutions and individual persons. The code is freely accessible and the program can be used free of charge. In Germany, OJS is used in the German Research Council project 'Sustainable OJS infrastructure for the electronic publication of academic journals, ${ }^{13}$ in order to make the publication of electronic journals at universities easier and more permanent in the long term. This is an important step to advance the so far missing coordination.

Books: Books are a chapter in themselves and play very different roles in the different disciplines. They are of special significance in the humanities. Currently, the first electronic platforms for book publications in the humanities are being established. One example is the Berlin excellence cluster Topoi, which has developed a convincing new model with the Edition Topoi. Many areas of the humanities have been sceptical about digitisation, but change is in sight. This is particularly advanced by a younger generation to which dealing with IT is part of their daily academic work. Whether the model of electronic book platforms will be successful also depends on how strongly it is used by top researchers who - especially in the humanities - often seem to be of the opinion that the quality of a book corresponds to the quality of its publisher. It would be interesting to evaluate in this respect the experiences of the over 20 university publishers that have joined the university publishers common working group.

Data repositories: The data repositories necessary for open science will surely be established in reference to the needs of the different disciplines. This already happens globally in areas such as high-energy physics, astronomy and the geosciences, where enormous amounts of data are cooperatively stored and processed. Already in 1966, the Committee on Data for Science and Technology (CODATA) was formed in the framework of ICSU. CODATA is responsible for data management, making data accessible and securing reliable numerical data. This mainly takes place in the area of 'big science'. The activities, however, can also be used as examples for good practice in the establishment of 'data collecting locations'.

The coordinated establishment of disciplinary or regional repositories is necessary. 'Digital humanities data centres', which not only host publications

13 See http://www.ojs-de.net/index.html. 
but also provide and care for useful programs as well as maintain databases and other data collections that require independent graphical user interfaces, would be especially important for the fragmented humanities. In this way, enormously useful value-added services (search tools, statistical and quantification tools, edition environments, automatic translations, alert systems, etc.) could also be offered that simplify the overall work effort. The Council for Information Infrastructure (RfII) has recently made excellent proposals for moving in this direction and establishing permanently funded centres for research data. ${ }^{14}$

Abuse and unintended side-effects cannot be avoided in networking, utilisation and provision of large data collections. The scientific repositories do not differ in this respect from other such data collections. Attention is necessary, but this is not a specificity of research data repositories. Continuous improvement of software tools helps to reduce potential dangers.

Dispersal and fragmentation: There is surely the danger of dispersal and fragmentation during the transition to the electronic world. One must not try to reinvent the wheel at every turn. Institutional vanity needs to be overcome, and more standardisation and collaboration should be advocated. The electronic collections have to cooperate in order to enable easy and efficient accessibility across the world.

Legal questions: Legal problems are of high importance. On this, the chapter by Peukert and Sonnenberg provides extensive detail. The digitisation of documents, of which the origin lies outside of the copyright protection period is, of course, possible - whether it is appropriate, however, depends on the discipline. For the future, publication agreements need to be made in such a manner that the described access to publications and the further processing of data are appropriately organised for OA use. Many are currently working on this issue. I am convinced that there will be a convergence to international standards in the near future. One problem, though, will be the establishment of OA access to the publications and data of the past years.

Strengths and weaknesses: The promises described above sound like a brave new world in which everything seems to work without flaws. Experience, however, shows that details are harder to control than the statements above may suggest. I am, nevertheless, optimistic that this new electronic open science publication system will prove its superiority over the traditional system in almost all disciplines and almost all relevant aspects.

Some challenges and problems should be pointed out, though.

Growth: The possibility of electronic publishing surely leads to growth in size that will not necessarily lead to an increase in quality. It may then become more difficult to find willing and competent reviewers. By applying diverse

14 RfII Empfehlungen 2016: Leistung aus Vielfalt, see http://www.rfii.de/de/category/dokumente/. 
technological and algorithmic tools for the support of editors and reviewers, electronic publication systems can undoubtedly deal better with this growth than traditional ones.

Long-term archiving: For long-term archiving of digital research results, generally accepted standards and processes are still lacking even though this is being worked on intensively across the globe. In the debate about this challenge, however, one should not pretend that printed formats could survive in the long run. In this context, I should not need to mention library fires or the deterioration of paper due to acid or inappropriate storage. Costs (for example, for providing sufficient storage capacities for a growing number of paper documents as well as their air conditioning) start to burden the budgets of many institutions strongly. They lead to considerations about abandoning the traditional document inventories, even more so since the use of existing print documents continues to decrease. Being responsible for the budget of the BBAW with a library of 670000 volumes and an archive with 6000 running metres of documents with approximately 100 million manuscript pages, I know what I am talking about. Will anybody ever look at that? Digitised versions may be useful, but the digitisation of these many fragile documents is very expensive. The long-term archiving of electronic documents will make an active archive management necessary. I do not believe, however, that, once standards are agreed upon, the costs will be higher than maintaining traditional libraries and archives.

Costs: What about the costs of 'electronification'? Anybody who is familiar with this issue is convinced that the costs of an electronic open science publication system will be lower than the costs of the current system. Here, several synergy effects need to be lifted to balance the additional costs of electronic provision (networking, advice and support mechanisms, maintenance, etc.). Inferring from my experience, the existing library budgets are sufficient to finance the system in the long run. The transition period will be expensive since two systems need to be operated in parallel during this time and important organisational decisions have to be made. There will be 'allocation battles' and it needs to be clarified who pays for what in the long run. Libraries will, of course, not be abolished, but their role will have to be redefined.

Plagiarism: It is occasionally claimed that electronic availability will lead to plagiarism. Unauthorised copying has always existed, but the probability of being discovered has also increased since software is now able to prove plagiarism more easily than ever before.

Monopolisation: One danger is the monopolisation of knowledge by those who own the repositories. This problem can be solved by establishing a decentralised, international repository system in the public domain as well as 
by respective contracts between the repository operators and their scientific partners and by mirroring of repositories (globally distributed copies of the databases). I am certain that there will be consensus at international level. Some critics say that such a publication system should only be accepted if it is verified through a system of binding multi-lateral contracts on the basis of international resolutions secured by supra-national criminal justice. One can, of course, put obstacles as high as one wants to. If I wanted to polemicise, I could add that also the abrogation of neutron bombs, espionage and IT terrorism needs to be called for since storage systems could be disturbed by them.

Print publications: Electronic publishing does not exclude printed publication at all. I read most articles in printed form and books almost always on paper. High-quality print on demand is nowadays cheap and of similar quality as traditional printing. Libraries can put the printed versions of books and journals on their shelves if they think it is feasible. If I, however, had to write this article without access to the Internet, I would not even have started because the search effort would simply have been too big.

$B B A W$ and open access: Some words on the Academy. It is without question that many of the long-term projects of the BBAW collect, compile, transcribe and edit important material that, for a large number of historians, philologists, political scientists, literary scientists and others, is of enormous significance for their basic research. In the past, anthologies were produced in a costly manner (for example, in half-leather bindings). This may correspond to their significance but leads to high book prices and small circulation figures. Hardly anyone still buys such volumes. Admittedly, there are some bestsellers, but a detailed analysis of the sales, conducted in parallel by the excellence cluster Topoi, has revealed book sale numbers in the low three-digit area. One cannot speak of dissemination here. The electronic provision of this material of the BBAW in open access, wherever that was possible based on the contracts made long ago, has given access to a whole new set of readers and boosted research on these issues. When the entire Marx-Engels edition is completed in 10 years, hardly anyone will put the 114 volumes of the edited literary heritage of Karl Marx and Friedrich Engels on their bookshelf and read them all. Only the electronic availability and searchability of this incredibly extensive material makes it a user-friendly and useful collection of documents of high political significance.

Digital humanities: The mentioned OA efforts on behalf of the BBAW are part of the Academy's overall strategy to engage intensively in the field of digital humanities (see Grötschel 2015). Digital humanities (DH) is a brief description for the application of information technology in the humanities. In this context, the cultural and social sciences as well as some aspects of digital 
art and media are often involved too because they, at least with reference to the use of information technology, analyse similar issues and work with similar methods. In DH, it is not about the simple use of computers but about the use of diverse tools of mathematics and computer sciences for the study of issues in the humanities. The globally diverse DH activities contribute significantly to the realisation of my digital dream. A wonderful overview of what currently happens in the digital humanities is provided by the $01 / 2016$ edition of the journal Akademie Aktuell of the Bavarian Academy of Sciences with its focus on 'Digital Humanities: More than humanities with other means'.

Final remarks: Philosophers did not always have the correct vision, even if they were of outstanding significance. This, for example, is also true of Socrates who did not write, as we all know. Oral tradition would not have carried his thoughts into our current age. Fortunately, he had people who 'recorded' some of his ideas. In an unfinished manuscript on the Democritus tradition, Friedrich Nietzsche wrote: ${ }^{15}$

We do not know why Socrates did not write and thus deprived the world of a clear image of his spirit: his reasons must have been of strange nature

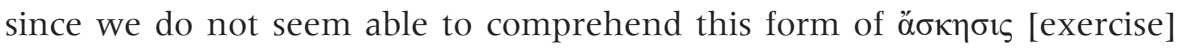
through which he betrayed himself of a large pleasure as well as evaded the obligation, which is at the same time the right of outstanding thinkers, to influence the most distant mankind and to work not only for the current and limited but for all time.

I hope the great philosophers of our time will not only leave their thoughts on paper because I am convinced that they are even more useful if they are stored electronically. Essential, however, are the better possibilities of dissemination provided by the electronic open science publication system that have the potential to have a global effect and contribute to the passage of ideas in a vivid communication and thus to their endurance. It would be fine if, in a couple of hundred years, all the 'great philosophical ideas' could be found and accessed immediately, anytime, anyplace and free of charge.

15 See https://archive.org/details/gesammeltewerke02nietuoft. 


\section{References}

Grötschel, M. 2001. Mein digitaler Traum. Gegenworte, 8:10-16. Retrieved from https://edoc.bbaw.de/frontdoor/index/index/docId/1091 [Accessed 15 April 2016].

Grötschel, M. 2015. Konsequent vernetzt: Digital Humanities und die BerlinBrandenburgische Akademie der Wissenschaften. In M. Grötschel (ed.). Die Akademie am Gendarmenmarkt 2015/16. Berlin: Berlin-Brandenburgische Akademie der Wissenschaften, 14-23. Retrieved from http://www.bbaw.de/ publikationen/jahresmagazin/jahresmagazin-2015-16 [Accessed 15 April 2016]. Herb, U. 2012. Offenheit und wissenschaftliche Werke: Open Access, Open Review, Open Metrics, Open Science \& Open Knowledge. In U. Herb (ed.). Open Initiatives: Offenheit in der digitalen Welt und Wissenschaft. Saarbrücken: universaar, 11-44. Retrieved from http://eprints.rclis.org/17183/ [Accessed 15 April 2016].

Hoffmann, K.-H. 2016. Schwerpunkt: 'Digital Humanities: Mehr als Geisteswissenschaften mit anderen Mitteln'. Akademie Aktuell: Zeitschrift der Bayerischen Akademie der Wissenschaften, 01/2016

Peukert, A. \& Sonnenberg, M. 2016. Das Urheberrecht und der Wandel des wissenschaftlichen Kommunikationssystems. In N. Taubert \& P. Weingart (eds). Zukunft des wissenschaftlichen Kommunikationssystems. Berlin: De Gruyter.

Taubert, N. \& Weingart, P. (eds). 2016. Zukunft des wissenschaftlichen Kommunikationssystems. Berlin: De Gruyter. 


\title{
A Vision of Scientific Communication
}

\author{
Reinhold Kliegl
}

The Berlin-Brandenburg Academy of Sciences and Humanities (BBAW) has published Recommendations on the Future of Scholarly Publishing. These recommendations represent a core set of policies upon which the BBAW as a whole has officially agreed, albeit not without heavy and lingering dissent among its members. At the outset, I was sceptical that the interdisciplinary research group drafting these recommendations would find any common ground - for the diversity of the publication formats and models and the heterogeneity of the disciplines and their representatives was immense. I was also wondering whether it is even desirable or necessary. Why not let every discipline find its own way? Fortunately, as it stands, this initiative and many similar ones prove an important point. The common goal of all sciences and humanities to achieve a better understanding of the world and to share this knowledge universally with as little cost as possible to the individual is still strong enough to motivate joint action on how we want to document and facilitate growth in scientific knowledge in the future. Scientific knowledge must be reliable, open to scrutiny and criticism. It is the result of global cooperation, extending also across earlier generations. Its growth is facilitated by competitive claim to fame, based on the desire to be the first to report an important advance of knowledge (for example, Merton 1973).

Publications are the primary format to document the corpus of scientific knowledge in almost all disciplines. Given their central role, it is not surprising that side-effects have evolved that to some degree undermine the common goal. For example, the number of publications and the number of citations of these publications serve as convenient indicators of scholarly reputation. These indicators are instrumental in allocating positions, obtaining awards, raising research funds and, yes, writing even more publications. Thus, in a way, publications have achieved the status of a 'common currency' in the scholarly 
system. In principle, there is nothing wrong with this development. Indeed, I suspect, for example, that the development of objective indicators has been an effective strategy to counteract nepotism in old-boy networks. Obviously, we need to improve, not abandon, objective indicators. In particular, we need to address the problem of their reactivity (i.e. the measure itself influences the object of measurement) (see Espeland \& Sauder 2007; see also Weingart 2015 , for a general discussion). The main and very serious problem of current indicators is that they have become an end in themselves to the extent that for some colleagues, they are taken to be more important than the substance they are supposed to indicate. These issues were elaborated in sections 5.4 and 5.5 and translated into a set of sensible specific policies in sections 6.8 to 6.11 of the Recommendations.

Building on these recommendations, but also going beyond them, I will briefly highlight two issues that derive from or at least are intertwined with current problems of the scholarly publication system. I will then argue that these problems can be addressed effectively if we support and embrace open science initiatives.

\section{Problems with journals}

The traditional journal-based publication system trades off speed of growth in knowledge against quality control. For an excellent summary of the many issues, I refer to Krumholz's (2015) editorial perspective in Circulation: Cardiovascular Quality and Outcomes. He succinctly characterises journals as too slow, too limited, too unreliable, too focused on the wrong metrics, too powerful, too parochial, too static, and too dependent on a flawed business model. These are actually the headings of the editorial paragraphs. He concludes (2015: 2):

We have arrived at the juncture where medicine and science need new vehicles for the dissemination of knowledge. [...] The question for all of us [...] is how that would best be accomplished in a new world that is flat, digital, and transparent.

Indeed, it is not long ago that our scholarly publication system began to implement the opportunities afforded by technological developments related to digital publication, storage space for data, instant and global availability of knowledge. The problems have been recognised and constructive proposals for their resolution are actively worked on (see relevant sections in Fiedler et al. 2016; The Royal Society 2015). A very promising approach are so-called 'overlay' journals where the traditional peer-review process uses submissions on the green access arXiv pre-print server for initial reviews, revisions and final publication (Ball 2015). Thus, journals such as Discrete Analysis or The Open 
Journal of Astrophysics exist only as virtual layers on arXiv.org. I will sidestep these developments to highlight below what I perceive to be a principled, even more encompassing answer.

\section{Competition dominates cooperation}

Growth in knowledge is driven, in part, by the dynamics of competition and cooperation between researchers or research groups. I suspect that the current reward system, which is strongly linked to maximising the number and citations of publications and to questionable indicators of journal impact, has led to an imbalance of the dynamics of competition and cooperation between scientists (or groups of scientists). Arguably, the increase in the number of publications and the immediate and global availability of associated statistics (such as impact factors of journals or the h-index) have reinforced competition, at the cost of cooperation and even some of the joy in science. ${ }^{1}$ I admit that this claim is based on a gut feeling about how scientific disciplines have changed over the last decades rather than on solid empirical evidence. I am ready to stand corrected, but I am not alone with this sentiment. For example,

In the last 50 years, there have been many changes to the substance, conduct, and style of research. Many of these changes have proved disastrous to the life of scientists and to science itself. As a consequence, the near-romantic spirit of adventure and exploration that inspired young scientists of my own and earlier generations has become tarnished. Now, many of us feel beleaguered by bureaucrats and by politicians: they affect our lives profoundly, apparently without an understanding of the way discoveries are made or of the nature of science itself. (Lawrence 2016: 1)

\section{Open science}

To overcome these shortcomings, we must re-evaluate the future of scholarly publications in the broader context of the future of scholarly communication to re-align our scientific goals with scientific practice. For me, the relevance of publications was put into perspective by the following quote from a paper which introduced the concept 'reproducible research':

An article about computational science in a scientific publication is not the scholarship itself, it is merely advertising of the scholarship. The actual scholarship is the complete software development environment and the

1 There is, of course, variance between scientists in whether they are primarily guided by power or achievement motives. There may be joy for those seeking power in the current situation. 
complete set of instructions which generated the figures (Buckheit \& Donoho 1995: 5, citing an internal report by Clearbout 1994).

Publications are advertisements! Nowadays this is often no longer a figurative, but a literal description of articles in high-impact journals where, with an eye towards citation statistics, hype often trumps substance and where the technical details about the research are relegated to supplements, if they are included at all. Indeed, on the basis of an analysis of journal rank, Brembs et al. (2013: 5) conclude:

(1) journal rank is a weak to moderate predictor of utility and perceived importance; (2) journal rank is a moderate to strong predictor of both intentional and unintentional scientific unreliability; (3) journal rank is expensive, delays science and frustrates researchers; and, (4) journal rank as established by [impact factor] violates even the most basic scientific standards, but predicts subjective judgments of journal quality.

Brembs et al. (2013) recommend abandoning journals in favour of setting up a new communication system in line with the above proposal for reproducible research.

Reproducible research is the precursor of what is nowadays usually referred to as 'open science'. For a state-of-the-art comprehensive review of this initiative, I refer to a recent Organisation for Economic Co-operation and Development (OECD). According to this report,

[open science] refers to efforts by researchers, governments, research funding agencies or the scientific community itself to make the primary outputs of publicly funded research results - publications and the research data - publicly accessible in digital format with no or minimal restriction as a means for accelerating research; these efforts are in the interest of enhancing transparency and collaboration, and fostering innovation. (OECD 2015: 5)

As elaborated in the next paragraph, this definition explicitly also encompasses, among others, open source software and open collaboration through tools of information communication technology (ICT). Given the heavy dependency on the web and modern software tools, it is also not surprising that the initial development occurred primarily in the domain of computer science. Thus, what has emerged as a broad and growing movement during the last years has been around for some time and has spread to other disciplines since (for example, psychology and linguistics). 
Free software development as role model

The first initiative that made output of research available to the scientific community as early and as completely as possible was the Free Software Foundation (Stallman 1985). This initiative started with the GNU General Public Licence four 'freedoms' with respect to software:

- $\quad$ freedom to run the programme;

- freedom to study the programme;

- freedom to redistribute; and

- freedom to distribute copies of modified versions.

Those of us who use Emacs, Linux, gcc, etc. are still profiting directly from the GNU project established in this context.

The second and third initiatives that had a profound effect on many natural and social sciences are the R Project for Statistical Computing (founded in 1993 as part of the Free Software Foundation's GNU project) and the Git project (a member of Software Freedom Conservancy, also a not-for-profit organisation). The R Project is now the de facto standard software for instruction in statistics in psychology, displacing commercial alternatives. Git (available since 2008) is a system for the cooperative and simultaneous development of software by an in principle unlimited number of contributors. The entire development process is recorded in detail and previous states of the software can be restored. Thus, there is maximal transparency about who contributed what and when to the project.

The basic idea for both projects is very simple. The development of new software occurs in the public domain. The source code of computer programs is already available during their development, and the community is invited to help improve the code by fixing bugs, implementing new features, writing or translating documentation, or by beta-testing the program and reporting errors. Obviously, the software is debugged much more quickly than software developed in a closed shop. ${ }^{2}$

\section{Cooperation and competition: striking a new balance}

Is this approach therefore ready to be used in non-computing disciplines? A very successful example was provided by the Open Science Foundation (OSF), which published the replication of 100 psychological experiments of which only roughly one third were judged successful (Open Science Collaboration

2 The main drawback of open source projects is a much larger variance associated with development and support of open source compared to commercial software. 
2015). Much could be and has been written about how this low rate relates to the problems with current research practices as described above. The point here, however, is that everything about these 100 experiments (correspondence with original authors, data, analysis scripts, etc.) is documented in a transparent and accessible way on the OSF platform. Moreover, the platform is available to everybody. It provides tools for cooperation, and users can also set different degrees of privacy for documents in the repository. A similar platform, DataWiz, is under development at the Leibniz Centre for Psychology Information and Documentation.

Carrying out one's research in the public domain is radically different from the past practice of science. How can we convince the scientific community to join this initiative? The answer is that the benefits for scientists' workflow must outweigh the cost of learning to handle this software. This is a big hurdle because our colleagues do not have time; they need to publish articles. We will need all the support we can get to develop user interfaces that respond to users' intuitions. Users will join if they can publish articles faster this way than via the traditional way.

We will also need a change in mind-set. This can be illustrated best by how one handles errors in research. In a highly competitive environment, errors are associated with a fear of loss of status. There will be an inclination to cover it up. Obviously, this slows down the accumulation of reliable knowledge. However, the open source community programmers welcome reports about errors in their software, for errors need to be eliminated as quickly as possible. To witness their attitude and cooperative spirit, I recommend simply following exchanges on a relevant Google group for some time. Moreover, this kind of constructive and supportive behaviour is obviously spilling over into general help groups, most notable stackexchange.com. These exchanges cut across disciplines and across countries and everybody has a good time. We need to foster such cooperative environments within the disciplines.

Finally, scientific societies, foundations and academies might want to reevaluate their awards. By far the most of them honour individual achievements. We could reverse this ratio, at least for a number of years, and recognise collaborative projects. In this context, adversarial collaboration deserves special attention (Fiedler et al. 2016). Let us also rethink how individuals earn reputation in this context. Consistently contributing problem solutions on stackexchange.com at international level should be worth a few publications when this person applies for a job. Similarly, helping to debug software that is used by many and across many disciplines is an important contribution. Such activities also serve the primary goal of science, namely the accumulation of reliable knowledge. 
Much of the debate about the scholarly publication system focuses on issues within the confines of the current system, such as costs and benefits of gold versus green open access to publications. We need to resolve these issues, but I suggest we also aim higher. If reproducible research as practiced in software development is integrated into the regular workflow of research projects in the natural and social sciences and humanities (at least a part of them, for example, digital humanities), then many of the highly controversial topics will dissipate. For example, until recently, I never felt bad about granting copyright for an article to a publisher. Possibly, I intuitively felt that this is advertising. I do not think I would ever hand over to a publisher my data or computer programs. They are the foundation of my research and I love to share them with my colleagues. Of course, one size does not fit all; reproducibility of experimental or empirical research is not important in some disciplines. The general point is that to think about how transparency and cooperation could be increased might serve as a productive starting point to tackle analogous problems in any discipline.

So, to end on a slightly (meta-)competitive note, as senior members of an academy, we owe it to the younger generation to help re-engineer the scholarly communication system in such a way that the motives that had us enter the field of science regain ground again in the future. And I think we are winning already.

\section{References}

Ball, P. 2015. The journal that publishes no papers. Nature, 526: 146.

Brembs, B., Button, K. \& Munafò, M. 2013. Deep impact: Unintended consequences of journal rank. Frontiers in Human Neuroscience, 7(291):1-12.

Buckheit, J.B. \& Donoho, D.L. 1995. Wavelab and reproducible research. In A. Antoniadis (ed.). Wavelets and statistics. New York, NY: Springer, 55-81.

Espeland, W.N. \& Sauder, M.M. 2007. Ranking and reactivity: How public measures recreate social worlds. American Journal of Sociology, 1 13:1-40.

Fiedler, K., Elbert, T., Erdfelder, E., Freund, A., Kliegl, R. \& Stahl, C. 2016. Empfehlungen der DGPs-Kommission 'Qualität der psychologischen Forschung'. Psychologische Rundschau, 67:59-74.

Krumholz, H.M. 2015. The end of journals. Circadian Cardiovascular Quality and Outcomes. doi:10.1161/CIRCOUTCOMES.115.002415

Lawrence, P.A. 2016. The last 50 years: Mismeasurement and mismanagement are impeding scientific research. Current Topics in Developmental Biology, 116:617-631. doi:10.1016/bs.ctdb.2015.12.013 
Merton, R.K. 1973. The normative structure of science. In R.K. Merton (ed.). The Sociology of Science: Theoretical and empirical investigations. Chicago, IL: The University of Chicago Press, 267-286.

OECD (Organisation for Economic Co-operation and Development). 2015. Making open science a reality. In OECD Science, Technology and Industry Policy Papers, 25. Paris: OECD Publishing. doi:10.1787/5jrs2f963zs1-en

Open Science Collaboration. 2015. Estimating the reproducibility of psychological science. Science, 349(6251).

Stallman, R. 1985. The GNU Manifesto. Retrieved from http://www.gnu.org/gnu/ manifesto.html [Accessed 1 February 2016].

The Royal Society. 2015. The future of scholarly scientific communication. Retrieved from https://royalsociety.org/events/2015/04/future-of-scholarly-scientificcommunication-part-1/ [1 February 2016].

Weingart, P. 2015. Nostalgia for the world without numbers. Soziale Welt, 66:2. 


\section{Methodological Optimism Regarding the Digital Future}

Critical Remarks on the Recommendations on the Future of the Scholarly Communication System

Volker Gerhardt

Acceleration. The digital acceleration of communication sucks everything into its wake. It does not leave any country out, and it is as inevitable on the seven seas as it is in aviation. It advances everywhere nearly simultaneously. The pace alone at which changes have taken place over the past few decades, and which include everything that people do publicly or privately in the most remote corners of the world, is a historic innovation.

The domestication of fire, after which the natural history of humankind entered its decisive phase, as well as the utilisation of images, symbols and signs, through which humankind's cultural history has become narrative, have taken millennia. It took more than ten centuries before the autonomy of law found constitutional recognition in ancient Athens and Rome.

Only with science, and its supporting, promoting and eventually overpowering technology, did the pace of innovation increase significantly. However, throughout its longest phase of development, science remained restricted to comparatively few individuals. The printed book ignited a movement which, after only a few decades, dragged an ever-increasing number of people into a rapid and unpredictable process. The history of the Reformation, which nobody expected to turn out the way it did, demonstrates what it means to be sucked in by a technological novelty.

The pace and extent of the world's digital change, however, surpasses everything that human culture has produced to date with respect to 
technological advances. Electronic information technology is developing at a speed that is only beaten by its distribution; even before a person learns how to read or write, he/she is captivated by technology's spell. Without any difficulty, information technology crosses the boundary between work and leisure that has existed for thousands of years and even tears down the barriers between private and public consciousness which have taken the utmost institutional effort to erect. And, of course, the sciences themselves are not unscathed by the revolution they initiated.

A recommendation that is long overdue. Against this background, it is not only understandable, but as necessary as it is commendable, that science deals with the consequences of those fundamental changes which concern its lifeblood publication and the dissemination of knowledge. Today, one can characterise the significance of scientific publishing in the seemingly paradoxical coupling of an older and newer term: in this central function of knowledge and science, the substance of both comes to the fore and without which neither would be possible, nor perhaps even necessary.

The aforementioned dramatic changes have been the topic of discussion for years, not only within the sciences but in every field where knowledge, education and information - thus also books, journals and newspapers - are involved. Here, experts speak about the so-called print media.

Thus, it is high time that an academy of sciences takes a position on the opportunities and risks of electronic publishing. Not only because the promotion and maintenance of the interdisciplinary solidarity of the sciences belongs to publishing's core tasks, but also because, freed from predefined performances for teaching and research, it has a duty to ensure the mutual exchange of knowledge as well as the public exposure of scientific insights.

In addition, the topic is of great importance today. This is especially true with regard to the Berlin-Brandenburg Academy of Sciences (BBAW), formerly the Prussian Academy of Sciences. The BBAW's publication department has used electronic computers for 35 years, and spent several hundred thousand euros on its long-term programme to digitise and retro-digitise its back list. Moreover, it is involved in highly complex and legal negotiations with publishing companies with respect to affordable conditions for open-access publishing. Its globally distributed editions of ancient, medieval and contemporary texts have to tackle overwhelming volumes of written work, so the transition to digital recording, surveying and dissemination in fact began some time ago.

If the present recommendations for the future of scholarly publishing lead the BBAW to take on a major part of its electronic data processing, this has to be heartily welcomed. As a scholar of the humanities, my hope was that there would at least be some acknowledgement of the history of academic publishing in general. Anyone who has been somewhat involved in the 
intense public debate about the political and legal consequences of Internet communication would have welcomed a clear academic statement on widespread fears. Moreover, reference to the fundamental significance of publishing for the internal health of science is expected from a philosophy of science which is not tied to any particular discipline. It is not the 'diversity of scientific publishing, the media and associated organisations ${ }^{\prime 1}$ that contribute to the 'differentiation' and 'productivity' of science. Rather, the public itself makes science possible. Knowledge as such, as we know from a renowned member of the Berlin Academy, is bound to be communicated and, as the member not only gathered from his reading of Kant but also from his preoccupation with Plato, science can only exist under the conditions of critical scrutiny. ${ }^{2}$

Thematic focus on one single question. The drawbacks mentioned in the recommendations can also be viewed positively: they illustrate the authors' noteworthy degree of abstraction. They refrain from historical reminiscence as well as from political or systematic corollaries and dedicate themselves entirely to the question of how publishing's digital revolution can be used for the promotion and development of the sciences.

One may regret this focus. But science feeds off abstraction and, since its Babylonian beginnings, is founded on the division of labour. As a result, one will not blame the recommendations for abstaining from discussing many things that have dominated public debate in the two years since the authors developed their text. Their aim was to contribute to clarifying the current challenges involved in the public funding of research publications. In addition, they have noted the need for action to restrict private publishers' monopolistic power.

In carrying out this task, the authors intentionally put themselves under time pressure and knowingly took the risk that their recommendations would not mirror the broad spectrum of the large academy of sciences. There is no mention of the symbolic function that is universally attributed to books, no mention of the tradition of education that books represent, not the slightest hint of nostalgia for the disappearing culture of reading. ${ }^{3}$ The text reads like the commentary of a - highly qualified - consulting agency. This underlines the specialised scope of the recommendations. However, it is questionable as to whether the underlying cost-benefit calculation corresponds to the tasks of an academy of sciences with large, not yet completed anthology projects.

1 Cf. Empfehlungen zur Zukunft des wissenschaftlichen Publizierens (BBAW 2015: 18).

2 I refer to the co-founder of the Berlin University and reformer of the Academy, Friedrich Schleiermacher: the complete edition of his works (co-edited by the BBAW) has not yet appeared.

3 During the consultations on the Recommendations Michael Hagner's Zur Sache des Buches (Hagner 2015) appeared. 
Indeed, the value of the recommendations lies in their focus on the technological, scientific, financial and administrative issues that emerge with the new media. The general knowledge that is applied here is impressive, and the effort to secure the quality standards of academic thinking, to ensure competence as well as transparency in every respect, is not only noteworthy but also highly commendable.

Trust in the success of one's own actions. One also has to show appreciation for the techno-pragmatic optimism that defines the future-oriented tenor of the recommendations. What this means can be illustrated with one example. The scientific advisory board for the preparation of the $350^{\text {th }}$ anniversary exhibition of the Peace of Westphalia in 1998 also included leading figures from the numerous German federal archives who provided a significant number of the exhibits shown on that occasion in Münster and Osnabrück. When the leaders of the archives came together, they had already discussed the cost of redigitising their already digitised inventory in 1996. And the dreaded question was when the third round of digitisation would become necessary.

Today a leader of one of Germany's most important literature archives, a renowned cultural historian who surely is not aversive to modern technology, warns against the 'digital junk room' that archives could become if they put their trust in a technology that suddenly becomes unavailable because the technological, legal or political situation has changed. The scenarios for such an always possible break in continuity are apparent with regard to the current political situation in the world.

The authors of the recommendations are also aware of these fears. They speak of technological development's 'incompleteness' that 'cannot be foreseen today' (BBAW 2015: 31). But they do not let their methodological optimism mislead them into thinking that technology will solve existing problems. Thus they emphasise the need for further development work: 'So that the principle of a permanent availability of scientific publications can be realised, ongoing efforts such as the investment in means for adapting the pathways of accessibility to the changing standards and technologies are necessary' (BBAW 2015: 31).

This is true, and it implies the cost of an unlimited amount of time that would have to be added to the already enormous costs of each phase of digitisation. Wouldn't it have been obvious, then, to add that the continuation of publishing and printing large anthologies not only fulfils a promise to existing buyers and users, but also ensures an almost 'permanent availability' from the moment of their delivery? And should the financial considerations underlying the overall comments not have included an additional statement to the effect that books, at least for the editing academy, are significantly cheaper? 
This is a pragmatic question to a pragmatism that is solely fixated on electronic media. But there is another theoretical warning: the recommendations could have approximated the public understanding of science if the objections and alternatives, of which there are many, had been mentioned and discussed with regard to their pros and cons. Surely this would have increased the depth of the recommendations. One can imagine that the authors of the recommendations had been concerned that their considerable effort would have been less convincing.

The opposite, however, would have been the case. If the authors had at least shown, by means of the only relevant case for academies of science, which long-term benefits are connected to the editions of large documentaries and volumes that appear in print, then their plea for parallel digitisation would have been much more convincing.

This can be said openly because each member of the BBAW has the conviction that the sciences naturally and increasingly have to adapt to the electronic media, which they already use intensively. And one can also say this without moving away from the principled optimism that, for better or worse, we need when dealing with new technologies. For this reason, pointing out the weakness of the recommendations because they refrain from discussing basic objections and suggesting alternative approaches relevant for the BBAW, does not put the methodological optimism related to the use of digital technology into question.

Civilisational consequences of digital innovation. The faith guiding the recommendations is necessary in everything that concerns our future, regardless of whether we do research, advise politicians or award renowned prizes. Thus, one cannot and should not object to the recommendations. They take the side of the new, and demand, one should note, 'ongoing' support for further innovations. That is, even if it causes extreme 'permanent' costs, truly in the sense of science, which, especially in view of a rather destructive public debate, should be emphasised here.

The performative self-contradiction of critics of Internet communication is obvious - they use that very same communication to voice their concerns. One could say it is tragic that no criticism of the Internet can exist without the Internet. Thus, there is no better confirmation of the indispensability of the digital media than their being supported by a contradictory cultural critique.

The reasons for this critique do not simply emerge from a vague fear of what is new; in many cases the criticisms are also valid. However, no one should expect the digital revolution's anticipated profound ethical, legal and political consequences for human life to occur all at once. Instead, it will take decades until appropriate institutional measures have been taken to do what is necessary to protect an individual's integrity and fundamental rights. 
Digitisation saves us time, digression and repetitive work. But it also requires new rules and qualitatively transformed institutions to protect and respect the rights of individuals. Enormous financial resources will be required to make receiving and processing information cheaper. Whoever brings up economic arguments in the Internet debate should take this fact into account.

We have yet to gain the experience that will show us how to maintain a humane future under the conditions of global Internet traffic. Since the knowledge necessary for this will likely never be sufficient, we can only guess how big the future challenges will be - even if seemingly satisfactory solutions have been found for current challenges.

This is to some extent also true for a scientific academy. It is wise to think about how to manage electronic media, and there are surely good reasons to first of all focus on optimal procedures for open access. The BBAW recommendations do this in an exemplary manner. My critique regarding their final draft in the spring of 2015 was due to the fact that one of the central tasks of the BBAW was only vaguely mentioned. ${ }^{4}$ Furthermore, it could not be overlooked that, in spite of all the praise for digital techniques, the contribution of the cultural sciences and humanities to the utilisation of electronic data processing was neglected.

The objections of several members from the humanities prevented the worst omissions. ${ }^{5}$ However, while this does not make the recommendations satisfactory, it no longer has to be feared that they will harm the BBAW. Thus, one can hope that the recommendations will find an audience that will lead to a crossdisciplinary discussion. The test will then be whether the recommendations with their critical position towards publishers as well as their confidence in the self-steering mechanisms of science - point in the right direction.

Moreover, it is hoped that the cultural and historical frameworks, which are not mentioned in the recommendations, will also be elaborated on. Even if the focus is only on technological and economic issues, it must not be overlooked that it is not only the long-term safeguarding of academic freedom that depends on the systemic conditions underlying the monopoly of a few enterprises controlled by one national judicial system.

We thus not only need more diversity in the sciences but also more competition in their digital environment. If an economically secure and legally protected plurality in the global village of the worldwide web cannot be created,

4 This pertains to the Academy's projects, i.e. ca. 180 research projects in the eight science academies in the Federal Republic with a total budget of $€ 60$ million. The largest share of these are the editions of inscriptions, text collections, dictionaries and critical editions from history, philosophy, theology, art, literature and music. These belong not only to Germany's, but (it must be said nowadays) also to the world's cultural heritage. The largest share by far of the BBAW budget is made up of funds appropriated separately by federal and state governments for the Academy editions.

5 I recall the critique by Horst Bredekamp and Jürgen Trabant in the spring session of the Academy's advisory board as well as my letter to the President of the BBAW on 10 March 2015. 
all BBAW recommendations are either only printed pieces of paper or soon to be forgotten traces of data on the Internet. ${ }^{6}$ This may be acceptable in the case of one statement, but, with respect to the cultural heritage, development, safeguarding and realisation of the task of the sciences, this must not happen.

What to do? ${ }^{7}$ From the perspective of the BBAW's projects, on whose behalf I speak, it is necessary that the series of the complete editions (Gesamtausgaben), which have been in the editing process for years, come to completion in a form that has been long recognised. This is my first point.

In order to illustrate its significance, two examples may suffice: for Immanuel Kant, there are more than 30 printed half-leather editions; therefore, the missing eight or nine volumes, which we should have completed in Berlin by 2024, have to be in precisely the same format. ${ }^{8}$ This holds especially true for cases in which older editions, which have been developed according to early $20^{\text {th }}$ century standards, need to be revised. This, too, should be completed by 2024 .

For the Marx-Engels edition (MEGA), more than half of the planned 120 volumes are available: The second unit of economic texts has been completed. Twenty published books of the 32 planned volumes of the first unit with writing by both authors have been completed. Half of the 32 volumes of the exchange of letters has been completed; as have half of the 32 volumes with excerpts, notes and drafts. In view of the enormous international interest in this edition, it would be a disaster for libraries and a political humiliation of the highest degree if the rest of these works were only provided in a digital version.

Thus, a binding agreement of all the sciences is necessary which states that, for all those involved and in view of the historic complete editions, a point of no return has been reached; the government, states and assigned departments are obligated to complete the book editions in the form in which they were begun.

My second point is that one does not have to be a visionary to see that open access provides science and the public with a number of benefits, but that its realisation is not cost free. Open access advocates have tried to give the impression that this was the case; they claimed that the costs presented by publishers was merely the pursuit of profit, and that it would be an easy exercise for editors to simply go onto the Internet themselves. ${ }^{9}$

\footnotetext{
6 See Gerhardt (2014).

7 After submitting this chapter, the editors of this volume, Peter Weingart and Niels Taubert, asked me to add an additional point to the previously indicated measures. I agreed to do so even if it is difficult to look into the future and that undoubtedly specialists, economists, net technologists and specialised politicians should be the first to speak out.

8 The Academy is obligated to do so through the contract with the publisher.

9 See Gerhardt (2009).
} 
Today everybody knows how cost-intensive and difficult digitisation is; the advocates have finally admitted that there are additional costs. ${ }^{10}$ With regard to numbers, experts could be a bit more precise. Regardless of whether we edit the volumes in the form of books or not, we need more personnel for processing texts and significantly more money for electronic conversion, which should not only present reading versions but also involve extensive development, broad networking and permanent availability. Additional costs should already be taken into account for ongoing projects - not only in annual budgets but also in the basic decisions of the presidency (Präsidium) and the Scientific Commission of the Union of Academies (Wissenschaftliche Kommission der Union der Akademien).

Third: In the above argument, the uncertain future of the digital world has been emphasised. The technological optimism expressed in the recommendations is without alternative; I am not aware of any reasons with regard to science or technology that would suggest not sharing such optimism. But who can guarantee the political and economic continuity underlying the hopeful expectations for the future? Surely none of the open access advocates! Thus, the future safeguarding of our scientific knowledge exclusively via a technological system should always be viewed with extreme caution. There is no protection from international law! What was self-evident for the postal service in the $19^{\text {th }}$ century has not even begun yet. But it is obvious that global Internet traffic can only operate in a global legal framework.

It is true that written laws can be lost. Today, however, it does not even take centuries, a paradigm change or epochal change, an economic crash or a clash of civilisations, but merely the market-effective replacement of some monopolists by a stronger competitor and large parts of the stored data will no longer be available to those in whose name one has posted them onto the Internet.

It would be easy to paint an even drearier picture. However, only a slight shift in technological competence suffices to prevent the emphatically proposed benefits of electronic publishing. In order to not let this risk become a danger for the science system as a whole, one is obligated, in my view, to advocate for a plurality of established and new publishing procedures. To only speak of the benefits of open access without addressing its risks may be admissible if done by lobbyists. If, however, a scientific academy becomes the advocate of a single method, it not only renounces its own scientific diversity but also neglects its responsibility for the future safeguarding of its scientific output.

10 Cf. the present decision by the Berlin Senate: Open Access Strategy for Berlin of 10 July 2015. It states: 'Some of the recommendations imply an additional effort and need the pertinent financial backing. Other measures can be reached by adapting financial flows and reorganisations in the cultural and scientific institutions.' 
Fourth: Since the BBAW considers policy advice as one of its genuine tasks, it seems appropriate that it informs itself about the opportunities and risks of modern information technology. It should at least consider how scientific reliability can be assured and increased in the area of data technology.

One essential point has already been mentioned: a global Internet can only function in the long run if there is global legal control. Since the world republic, as envisioned by Kant as the most reliable but politically unlikely solution, cannot be introduced, the goal should be a system of multi-lateral contracts, if possible, based on an internationally accepted resolution. The goal here must also be a cross-national criminal jurisdiction.

Fifth: There will not be legally binding international regulations as long as there is only one politically and economically dominant global player. Even though Europe and especially Germany have a lot to thank the United States (US) for, it is of utmost necessity that the digital-political monopoly of the US is broken. What Europe has attempted (and eventually achieved) with the development of the Airbus industry should also have been done a long time ago in the area of digital technologies. ${ }^{11}$

The European Union (EU) is limiting itself in this regard since the large number of member countries does not allow for a concentrated large-scale initiative. Large projects cannot be realized because the smallest partners, even if they are not able to pay, also want to play an influential role. This is indeed one of the structural problems of the EU. But this could be overcome by determined action on behalf of the more powerful partners (as well as by an innovative organisation that could provide smaller states with long-term benefits) - if possible, before there is only bilateral competition between the US and China. To point out new pathways is a task that would suit the BBAW better than being involved in the politics of self-interest that are already the domain of many corporations and special organisations.

Sixth: The threat to individual freedom and the restriction of personal rights as a result of the omnipresence of the Internet is one of the most dominant public debates in Germany. The BBAW does not refer to this debate at all while commenting on electronic publishing. Thus, it distances itself from such popular debate. This is, however, no longer simply an issue of style if, as a result of universal digitisation, intellectual property as well as the independence of intellectual work as a whole are put in jeopardy.

11 The last attempt to create a special UN committee on issues of digital communication took place in 2012. At that time, the USA prevented the initiative by pointing out that a central steering/monitoring of the Internet would endanger its free development. Details can be found at http://www.thenewamerican. $\mathrm{com} /$ tech/computers/item/19235-un-october-summit-reopens-grab-for-global-internet-control (14.06.2016). Moreover, activities of the non-profit organisation ICANN should be pointed out here. 
This is not just true in the plagiarism and fraud cases that ethics committees have to deal with. It is even more serious if access to research results is not given because of the one-sided security issues of individual states, or if an organised breach of secrecy occurs, or if confidential communication between researchers is no longer possible. Industrial espionage on a grand scale should not only concern industrial research organisations but also top-tier scientific research institutions.

One does not need to point out that this is something on which a scientific academy should issue a statement on. It should, however, be emphasised that it would be appropriate for an Academy to point out the legal means that already exist with respect to intellectual property as well as the protection of individual and institutional freedoms. As a result of a private Austrian citizen's complaint, the European Supreme Court made a far-reaching decision on 6 October 2015 regarding data protection. ${ }^{12}$ The so-called Safe-Harbor decision is also important to science, whose practitioners and institutions should remember the significance of the already existing legal means to take control of their own achievements.

Each new development leads to new questions about the behaviour of the people involved. I have tried to point out how fundamental the changes that come with the digital innovation are. After almost 40 years of new media not simply being used by the military, the world has been changed more powerfully than by any other technological novelty. If this technology is to remain a means of serving human goals and purposes, then one can say without exaggeration that it poses the largest challenge ever for humanity the innovations of the Internet allow humanity to experience itself for the first time as a subject that is challenged to act. In my opinion, the appropriate task of any scientific academy must be to make society aware of this.

\section{References}

BBAW (Berlin-Brandenburgische Akademie der Wissenschaften). 2015. Empfehlungen zur Zukunft des wissenschaftlichen Publizierens. Berlin: BBAW.

Gerhardt, V. 2009. Dann gehen wir eben ins Netz. Gegenwort in GEGENWORTE. Gegenworte, 21:22-25.

Gerhardt, V. 2014. Licht und Schatten der Öffentlichkeit. Über Risiken und Chancen der digitalen Innovation. Wien: Picus.

Hagner, M. 2015. Zur Sache des Buches. Göttingen: Wallstein.

12 In the case of Max Schrem's complaint, the court ruled that EU states are obligated to develop measures for data protection individually. This can be the starting point for a global protection of the freedom of science and the freedom of people involved in it. 


\title{
Trust, Quality Assurance and Open Access
}

\author{
Predatory Journals and the Future \\ of the Scholarly Publication System
}

Peter Weingart

The roots of the business model of predatory journals

By the end of the 1990s at the latest, the neo-liberal paradigm of 'new public management' (NPM) had taken hold of science policy in the leading science nations. In this context, economic incentives were introduced in a social system to which they were foreign until then, perhaps with the exception of law, chemistry, medicine and the engineering sciences, which were closer to the economy or monetary remunerations, respectively. The larger part of the academic system, however, followed the logic of self-direction by internal disciplinary acquisition of reputation. With the introduction of performance measures, policymakers hoped to gain control over a system which was inaccessible to most of them with respect to its operational logic. The advantages of simple quantitative measures seemed so convincing that the concerns expressed initially against the radical reduction of such a complex process like the assessment of contributions to the stock of knowledge by the competent peers and the attribution of reputation based on it were ignored.

More fatal than the carelessness, sometimes even arrogance, among politicians was the ease with which the scientific community could be won over as without its eager acceptance of indicator-based performance evaluations, NPM would have failed or could at least have been shaped more intelligently. As a result, science submitted to the logic of 'externalised performance measurement' and all its intended but also its unintended dysfunctional 
effects. One of the latter is that especially younger scholars are exposed to a competition in which not a wealth of new ideas and innovative thinking are criteria of success but countable products, in particular publications appearing in scholarly journals. These, in turn, are subject to indicators supposedly measuring quality, that is, journal impact factors (JIF).

The world of money, which surrounds the odd world of science and on which science ultimately depends, is not one of solid businessmen (the merchant prince for whom a handshake was a contract) but rather one which is populated by many clever characters who occupy areas that are not legally regulated with their sneaky business ideas. Where it is profitable, they may even cross the borderline of the law of the land or of morality. Earlier, before digitisation, these people issued chain letters, promotional excursions for elderly ladies and sales of oriental rugs. No one would have thought that science, of all things, would become a source of income for shady racketeers, but NPM has made it possible.

Digitisation, which has many positive but also many questionable consequences, has brought science, among other things, the option of electronic publishing open to all authors (open access). From the perspective of many scientists, particularly in the natural sciences, where the turnover of knowledge and thus the pace of publishing is rapid, this option is very attractive. The traditional journals often have high rejection rates and lengthy review processes, and they ask hefty fees. For the young scientist, the rationale is to counter the publication pressure by choosing a journal that publishes their article rapidly and cheaply.

It is exactly this group, defined as demand or a potentially lucrative market, to which both the large publishers and diverse racketeers respond. They offer open access (OA) journals that publish rapidly and without lengthy and risky review processes. The names of these journals are often vacuous, sometimes they sound similar to the names of renowned journals, and their number is growing and hard to trace. The latter refers to all those organisations, funders, university administrations and ministries that have initiated performance measures in the first place. According to Jeffrey Beall - the librarian from Boulder, Colorado, admonisher and guardian over the development of the socalled 'predatory journals' - between 2011 and 2016, the number of obscure publishers had risen from 18 to 923, and between 2013 and April 2016, the number of stand-alone journals had increased from 126 to 1220 . He has meanwhile created two additional lists: one is that of 'hijacked journals', that is, journals for which a fraudulent website with a stolen identity of a regular journal has been set up. Under this wrong identity, these journals advertise for articles in the OA format, that is, the author pays. The number of these journals has gone up from 30 in 2015 to 101 in 2016. As a result, the number 
of published articles has also gone up: from 53000 in 2010 to 420000 in 2014. In addition, these new highwaymen of the scholarly publishing system have come up with further finesse. To fake the reputation of their journals, they invent new metrics or mock organisations that compute the JIF, which has been in use for some time. Among them - this is the second list - are such flowery names as the 'Einstein Institute for Scientific Information' or the 'International Society for Research Activity'. ${ }^{1}$

Meanwhile organisations have emerged as well, so-called 'article brokers', that squeeze in between author and journal. There is, for example, an 'Association for Scientific and Engineering' whose Chinese initiators one should thank for not having a good command of the English language. Beall comments:

On its website, it claims to be 'an international non-profit organization dedicated to advancing science for the benefit of all people,' but this is a big lie. It's an unethical firm that preys on scholarly authors desperate to get their work published in indexed journals to advance their careers [...] All the parties benefit, except one. The authors get published in an indexed journal and advance their careers. The article broker charges a fee and generates revenue. The editor receives payments from the article broker for his or her help in getting the papers published. But because the editor or owner of the journal is getting under-the-table payments to facilitate the acceptance and publication of the articles, peer review suffers. There is an incentive to accept and publish as many papers as possible, regardless of their scientific soundness, to make more money.

The victims, of course, are the readers, the consumers of scholarly literature, which includes all researchers. Article brokers are constantly seeking cooperative editors, offering deals some cannot turn down. ${ }^{2}$

This describes comprehensively what holds true for the entire development, from predatory journals to article brokers. It is about the semi-legal but unethical business practices on the Internet enabled by digitisation which - via NPM - have entered science and threaten the fragile fabric of trust and quality control.

The business model taken up by the predatory publishers was originally developed by the large science publishers. They were the first to adapt to

1 All data under https://scholarlyoa.com/2016/01/05/bealls-list-of-predatory-publishers-2016/. Unfortunately, the website of Beall's list was shut down in January 2017 with no explanation given. Cf. http://retractionwatch.com/2017/01/17/bealls-list-potential-predatory-publishers-go-dark/. 
the challenge of open access and developed a new variant of the connection between quality decisions and monetary incentives. Gold open access is no threat to the publishing business if they collect so-called 'article processing charges' (APCs) from authors instead of subscription fees from libraries. These fees - the amount of which is only limited by the willingness of the authors' paying home institutions - are the basis of the business model of predatory publishing.

With the introduction of the APC-based gold open access model and its voluntary acceptance by funding organisations in the United States and the European Union, coupled with the mandate for scientists to publish in this format, science policy has manoeuvred itself into a precarious position. Not only are the costs for the public purse incalculable, but the model prepares the ground for a loss of trust in the quality assurance mechanisms that permeate the entire science system. Even if the share of articles in predatory journals of all OA articles paid by authors is still small - estimates vary from $1 \%$ (Bjornshauge) to 5-10\% (Beall) - the dynamic of the development is reason for concern (Butler 2013: 435). In the meantime, the structure of the market has already changed. Since 2012, those publishers that publish between 10 and 99 journals have the largest market share (Shen \& Bjork 2014). Now the small crooks are coming.

Anyone who believes that this is primarily a problem of developing countries and that the suspect publishers have their headquarters there, is in for a surprise. In their study, Shen and Bjork come to the conclusion that the regional distribution of both authors and publishers is very uneven: three quarters of the authors come from Asia and Africa (Shen \& Bjork 2015). John Bohannon received a lot of attention with an experiment in which he sent an article with obviously wrong findings to hundreds of OA journals and tested their quality controls - with devastating outcome (Bohannon 2013). In Bohannon's sample, one third of the journals originated from India. With this, the country has the largest share of OA publishing. Surprisingly, however, he saw the United States in second place (Bohannon 2013: 64-65). On the basis of this experiment, Bohannon (2013) concludes that the corporations that reap the profit have their headquarters in the United States or Europe, even if the editors and the bank accounts of the journals are based in developing countries. 'Journals published by Elsevier, Wolters, Kluwer, and Sage all accepted my bogus paper' (Bohannon 2013: 65). Indeed, developing and threshold countries are especially vulnerable insofar as they press their scientists more than the countries in the North to publish internationally. Thus, they are also damaged more severely.

Predatory journals and publishers build on open access and discredit it at the same time even if open access does not automatically lead to such practices 
(Berger \& Cirasella 2015). The question about what the consequences of predatory journals will be on science, invokes two possible scenarios.

\section{Dystopia of the scholarly publication system}

In principle, predatory journals abrogate the central control mechanism of science which, at the same time, constitutes trust without which knowledge production cannot grow or can grow only very slowly. When, in highly specialised research fields, it is generally no longer known who is very good and who is not so good, the internal, implicit attribution of reputation becomes impossible. In the better case, other criteria, such as profitability or political acceptability, take the place of substantive assessments of research contributions. The increasing economisation of science, which replaces intrinsic motivation by external monetary incentives, first of all leads to the neglect of economically uninteresting fields, such as the humanities (Lill 2016). A further consequence could be the erosion of research ethics or norms of good scientific practice because of 'goal displacement' (Osterloh \& Frey 2000). Even though a causal link can hardly be proved, it is conspicuous that the sensitivity about fraud in science has led to regulatory efforts worldwide that react to an increased incidence of scientific malpractice. If the operators of predatory journals can procreate unhindered, driven by the political pressure on scientists to publish plenty and fast, the disorientation that already makes it difficult to distinguish unequivocally between regular but lower-quality journals and predatory journals will increase (Berger \& Cirasella 2015). Bad research replaces good research because the reliance on and citation of the work of good researchers is no longer directed by quality control. The cost of replication will increase, a fact indicated already by the growing number of retractions (Van Noorden 2011).

If one extrapolates this development even further, grave consequences for the position of science in society can be imagined, that is, for the authority of science as the ultimate instance of the production of certified knowledge. If this position is lost, there is the concern that science will come under the influence of ideology. Both the religiously motivated radicalisation in recent years and the mobilisation of questionable beliefs via the social media (for example, the anti-vaccination campaign) are warning signs. In the end, society abdicates the very institution that it has created against the horrors of the religious wars of the $17^{\text {th }}$ century.

\section{Utopia of the scholarly publication system}

Most likely, it will not turn out to be quite so bad. At first, the system reacts by trying to protect itself through controls. The Directory of Open Access Journals (DOAJ) was established in order to guard against the 'blacklisting' of OA journals. However, in reaction to Bohannon's experiment, the DOAJ had to 
slash 114 journals from its 'white list' and sharpen its criteria of admission. A similar strategy is pursued by the Open Access Scholarly Publishers Association (OASPA). Its members have to commit to a code of conduct, but even here, mistakes happen (Berger \& Cirasella 2015: 134). Controls can lead to absurd consequences. The South African Department of Education originally paid generous financial rewards to universities and research institutions for publications under their respective addresses in order to promote the international visibility of its researchers - and to boost their productivity. Now it sees its budget threatened by the fraudulent practices of predatory journals. The universities - implementing the department's policy - ask authors to reveal the names of their reviewers, and if that should be impossible, at least those of their home organisations, supposedly to document the solidity of the peerreview process. This institution should have known that, by doing so, it asks the editors of scholarly journals to violate the rules of good scientific practice.

If this example suggests that the development will progress in the direction of an ever-increasing elaborate bureaucratisation, one can think of a utopian scenario, which leads to a more intelligent use of digitisation. A first step for science and science policy is to abandon the JIF and all other performance indicators that are based on the quantity of publications. In view of their methodological deficiencies, this step is long overdue anyhow and is demanded by international science organisations (International Medical University and the San Francisco Declaration). Such a step would effectively spoil the business model of predatory journals and their publishers.

Even more utopian is the suggestion to create a platform that contains all aspects of an open peer-review system that would be accessible to all scientists. They would, however, all need to have an account to be identifiable. 'Peer reviews, metrics and ratings would then be able to expose fraudulent behaviour by editors, who could eventually be excluded from the platform' (Wehrmeijer 2014: 79). Such a platform could be supported by a consortium of universities and would, in principle, make journals superfluous. It is also imaginable that such formats would take the place of publicly financed libraries, perhaps administered by them, as subsidiaries of science that is committed to the common weal and is itself a public good. In such a system, predatory journals and their publishers would have no place. 


\section{References}

Berger, M. \& Cirasella, J. 2015. Beyond Beall's List: Better understanding predatory publishers. CeRL News, March:132-135.

Bohannon, J. 2013. Who's afraid of peer review? A spoof paper concocted by Science reveals little or no scrutiny at many open-access journals. Science, 342, October:60-65.

Butler, D. 2013. The dark side of publishing: The explosion in open-access publishing has fuelled the rise of questionable operators. Nature, 495(28).

Enserink, M. 2012. As open access explodes, how to tell the good from the bad and the ugly. Science, 338(23):1018.

Lill, F. 2016. Angriff auf die freien Denker. Die Zeit, 15(31):61.

Osterloh, M. \& Frey, B.S. 2000. Motivation, knowledge transfer, and organizational forms. Organization Science, 11 (5):538-550.

Shen, C. \& Bjork, B.-C. 2014. 'Predatory' open access: A longitudinal study of article volumes and market characteristics. BMC Medicine, 13:230.

Van Noorden, R. 2011. The trouble with retractions. Nature, 478(6):26-28.

Wehrmeijer, M. 2014. Exposing the predators: Methods to stop predatory journals. Unpublished MA thesis. Leiden University, Leiden. 



\section{Publishing in German Sociology in the Year 2030}

Niels Taubert

Prognoses about the future that go beyond the coming days, weeks and months are always at risk of becoming ridiculed. The observer in the future looking back will see the author's hubris to assess the future development and will find it easy to identify deviations from the predicted course of events. When it comes to computers - or more generally digitisation - there should be even more caution as unfulfilled prognoses are legion. Not too long ago, it was inconceivable that there would be a need for personal computers. Soon after, the notion that the use of paper in offices would come to an end was widespread. In the recent past, the marketability of the tablet computer was met with doubt, and from the perspective of the classic media, the social media platform Facebook was considered merely an 'index' in the web. Precisely these experiences with information and communication technologies make the saying 'everything that can be invented has already been invented" ${ }^{1}$ seem meaningless. Therefore, the following shall not be a prognosis of the future but a description of what would be desirable for publishing in sociology in the year 2030. Thus, a prognosis is replaced by a utopia.

\section{Status quo}

If one looks from the perspective of other disciplines at how we, sociologists from Germany, inform each other about research results, then one would think it is highly deficient. First of all, there seems to be no unity in the communication: it cannot be described along one axis but only in terms

1 The source of this often-used quote is unclear. It is wrong, however, that it was made by Charles Duell, who from 1899-1902 was Commissioner of the United States Patent and Trademark Office. 
of several dimensions. One divide lies between theoretical sociology and quantitative empirical sociology. The former considers itself to be part of an intellectual discourse, while the latter tends towards a communication ideal of the natural sciences. One side cherishes the printed book; the other the peerreviewed journal article. A second discrepancy can be found between Germanspeaking and English-speaking sociology. One side considers the publication in English a prerequisite for excellence; the other side finds a work written in German sufficient. There are even more breaks between different schools and approaches of theoretical and methodological nature. They go hand in hand with different ratings of different journals and publishing companies. These disunities are the expression of a plural understanding of quality within the discipline.

Publication activity is distributed in a strange way: there are only a small number of peer-reviewed journals in German-speaking sociology, and the community is only weakly represented in journals published in English. This may not only be because sociologists from Germany submit few articles to foreign journals. Another reason may be that the journals consider themselves to be voices of sociology of the respective countries and that they are not entirely internationalised. Thus, nearly two thirds of articles appear in a medium of dubious reputation, an anthology whose publication logic evokes irritation or even amusement among scientists from other disciplines. The slowest contributor determines the time of publication. The period between writing and publication thus often spans across several years. The decision about worthiness of publication of submitted manuscripts is subject to individual assessment and the available time of the editors. Quality criteria are thus hard to follow, also because contributions are usually 'invited', and a reversal of that decision is not considered to be a tolerable practice of editors. The unclear reputation of some anthologies is also to the detriment of quality, so that authors do not always strive to achieve the highest level while being aware of the editors' needs - keywords here are 'risk of failure of anthologies', 'coherence of the volume' and 'length of the manuscript announced to the publisher'. All this is well known and yet we (sociologists) all participate.

My third comment on the status quo refers to the publishing landscape in general. German-speaking journals, anthologies and monographs are produced by a significant number of small publishing companies that are in part managed by their owners. This surely does not only entail disadvantages. Close collaboration and short ways of communication make it possible to correspond to the individual standards of publication and production. For the last couple of years, Springer VS, a large international publishing company, has been successfully active in the discipline. Problematic developments, such as the establishment of an oligopoly and increased prices, as is the case in the 
natural and engineering sciences as well as medicine, have so far not been apparent in sociology. Not least due to the structure of the publishers, however, digital publication in sociology is only slowly on the rise. Many publishing companies are too small to pursue individual strategies of digitisation and thus seek cooperation with other publishers and libraries in order to make electronic publication possible. Springer VS, however, did not have to take such small steps. Since it could make use of the distributing platform of its mother company, it was possible to make the entire portfolio digitally available within a short period of time.

\section{0 - Digital open access publications}

Which developments can be expected for the year 2030 against this background? One hope is that the discipline will neither adopt the forms of publication of the natural sciences nor that it will remain entirely untouched by larger, crossdisciplinary trends. Rather, it should become familiar with the opportunities of digital publication and develop a publishing culture that uses these potentials in a productive manner.

\section{Dissemination of digital publication}

In spite of some aversions and eventually unwarranted fears with respect to digital publication, it will have become standard by the year 2030. This is due to its possibilities of accessibility, reception, and connection with qualitative and quantitative research data, the utilisation of data and text mining tools and not least its automatic searchability. However, the intellectual culture of the printed book lives on, albeit to a smaller extent than is the case today. The notion has persevered that the reception of complex texts requires a format that is 'handy', and this format is the printed monograph. Within the discipline, it continues to exist parallel to the electronic version, in particular in sociological theory, where the proportion of dual published monographs has stabilised around 10\% by the year 2030 .

\section{Fate of the anthology}

In quantitative terms, the anthology has lost its significance dramatically, but it persists in coherent and carefully conceptualised volumes that are also well curated by their editors. The majority of research articles, however, appear in thematically established smaller journals whose existence goes back to a wave of foundations in the 2020s. These do not follow the natural science model of double-blind peer review. Due to the multi-paradigmatic diversity of the discipline, the model of the better anthologies was adopted, namely the model of a constructive evaluation. Here, those involved know each 
other, the reviewers work closely with the author and provide advice for the further development of a text. This procedure is applied by a large number of newly founded journals. Occasionally, authors suggest reviewers and the satisfaction with the results of the procedure is surprisingly high. There are even individual reports about research co-operations that originated from this non-blind constructive peer review. Due to lobbying by the discipline, the model is recognised and supported by the funding organisations.

\section{Publishing landscape}

Fortunately, the diversity of the publishing companies within the discipline was maintained. During the founding of the journals, attention was paid to the fact that the ownership rights to the titles remained with the Deutsche Gesellschaft für Soziologie (German Society of Sociology), or with individual research institutions. At the same time, the diverse personal contacts to the publishing companies were used to develop feasible financing models on the basis of publication fees that would give the publishers a stronger degree of security in planning than was previously the case with the decreasing sales number of printed anthologies. Moreover, this way, free accessibility in the framework of the gold OA model could be realised. The obligation to deliver standardised metadata to a specialised information service made it possible to create an index for almost all publications of the discipline, which is welcomed by the interested public as well as other sociologists because the latter no longer have to ask themselves whether they are overlooking pertinent publications.

\section{Probabilities}

The ways by which research results in sociology are announced will undoubtedly have changed by 2030. But, how strong is the probability of such a publication culture in sociology that is based on digital, freely accessible journals? This question cannot be answered fully and if it were possible, this text would turn into a prognosis. However, some factors can be pointed out that, in all likelihood, will influence the development of the publication culture in the future. It can be expected that the assessment of research performance in the framework of formal procedures of research evaluation will continue to play an important role in the course of recruitments and proposals for third-party funding. A sociology that primarily focuses on publications in anthologies will undoubtedly have considerable difficulties in this context. In view of the publication culture of other disciplines, this type of publication is not considered of high reputation. In recruitment procedures, its status is controversial, and in proposals for third-party funding, journal articles are required. Thus, the tendency is against the publication of articles in anthologies. Pressure to change, however, could also come from strategies 
in science policy that promote OA publishing. If there will indeed be a shift in libraries from purchasing to subscription budgets, which will then finance gold OA publications, the culture of anthologies within sociology will enter troubled waters. The current guidelines on the use of these funds refer to other publication types, namely reviewed articles in OA journals. If this remained the case, the discipline would be in danger of being cut off. There would then be the opportunity to advocate change in the guidelines of publication funds, to fight for the reservation of funds from the library budget for the acquisition of anthologies or to use the opportunity to reform the ways in which the circulation of research results is organised within the discipline.

Turning to my final point: the question of how we will publish in the year 2030 primarily depends on how the discipline itself reacts to opportunities and challenges of digital publishing and whether it will be able to position itself with respect to this ongoing change. Sociology has a weak degree of organisation but it has also been able to surprise more than once. Therefore, a broad discussion of a desirable future of publishing does not seem impossible. 
THE FUTURE OF SCHOLARLY PUBLISHING

Open Access and the Economics of Digitisation

Edited by Peter Weingart and Niels Taubert

The formal scientific communication system is currently undergoing significant change. This is due to four developments: the digitisation of formal science communication; the economisation of academic publishing as profit drives many academic publishers and other providers of information; an increase in the self-observation of science by means of publication, citation and utility-based indicators; and the medialisation of science as its observation by the mass media intensifies. Previously, these developments have only been dealt with individually in the literature and by science-policy actors.

The Future of Scholarly Publishing documents the materials and results of an interdisciplinary working group commissioned by the Berlin-Brandenburg Academy of Sciences and Humanities (BBAW) to analyse the future of scholarly publishing and to make recommendations on how to respond to the challenges posed by these developments.

As per the working group's intention, the focus was mainly on the sciences and humanities in Germany. However, in the course of the work it became clear that the issues discussed by the group are equally relevant for academic publishing in other countries. As such, this book will contribute to the transfer of ideas and perspectives, and allow for mutual learning about the current and future state of scientific publishing in different settings.

\section{○}

